\title{
‘The Kāpiti Distressway': A Sociological Case Study of Public Involvement in a Socio-Technical Controversy
}

BY

Morgan Jasper Hamlin

\begin{abstract}
A thesis
submitted to the Victoria University of Wellington in fulfilment of the requirements for the degree of

Doctor of Philosophy
\end{abstract}

Victoria University of Wellington

2016 


\begin{abstract}
This thesis examines public involvement in socio-technical controversies from a sociological perspective. Public engagement in science and technology is becoming increasingly important in societies where citizens are asked, and expected, to be involved with issues that have been dominated by experts. In New Zealand, a contemporary example of public participation in science and technology is the large-scale road building programme called the Roads of National Significance. The central aim of this thesis is to understand how the public engage with and create meaningful evaluations of complex issues that are associated with expertdriven politics and top-down decision-making processes. I examine the public's involvement in the Kāpiti expressway project by discussing how locally-based groups evaluated and publicised it as an object of concern. Specifically, I investigate the demonstration and visual imagery technologies that were utilised to publicise the expressway as a public matter. I then explore how opponents translated their concerns with the environmental, political, and social aspects of the project as legal and technical issues. The second aim of this thesis is to contribute to the material turn in the human sciences by engaging with object-oriented (Barry, 2013; Latour, 2005a; Marres \& Lezaun, 2011) and socio-cultural (Boltanski \& Thévenot, 2006) approaches to public involvement in socio-technical controversies. The role that technologies play in materialising public participation and re-presenting the Kāpiti expressway project as an object of concern are examined. However, to create a dialogue between object-oriented and socio-cultural approaches to public dispute, I investigate the technologies of justification and criticism, and the cultural modes of evaluation that qualify people and things within moral vocabularies. I argue that the public were obliged to re-present the Kāpiti expressway as an object of concern by demonstrating how their personal objections were relevant to the legal and technical aspects of the project. A range of technological devices enabled local groups to evaluate the project during the early planning stages of the project, but convincing decision-makers to reject the expressway involved the difficult task of critiquing the planning process, and enrolling allies. This thesis uses a qualitative, case study approach to socio-technical controversies. I use interviews, qualitative observations, and documentary methods to examine the actions of locally-based groups and the modes of evaluation used to challenge the Kāpiti expressway project.
\end{abstract}




\section{Acknowledgements}

I would like to thank my supervisors Chamsy el-Ojeili and Mike Lloyd for their guidance and feedback. I would also like to thank my participants for their insight, time, and help with this project. Finally, the wonderful support from my parents, Amy, Demita, Gradon, Ian, Olly, Maree, Robyn, and the SACS students and staff has been invaluable. 


\section{Table of Contents}

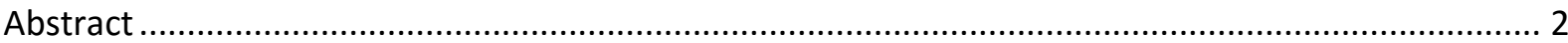

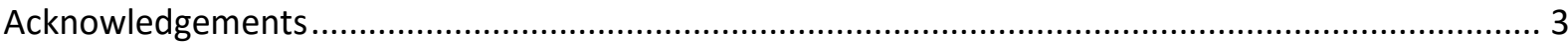

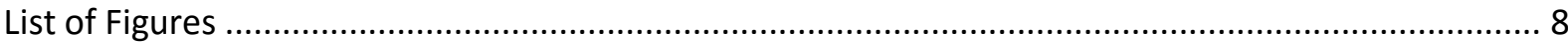

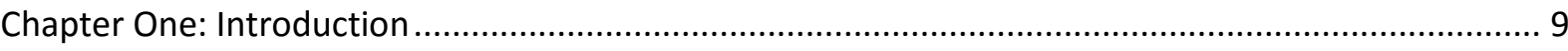

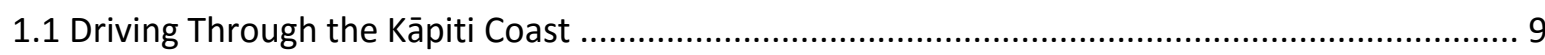

1.2 Public Involvement in Socio-Technical Controversies............................................................... 12

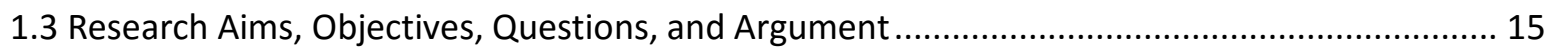

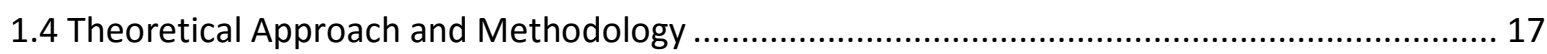

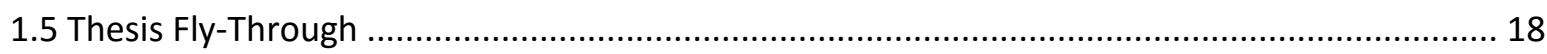

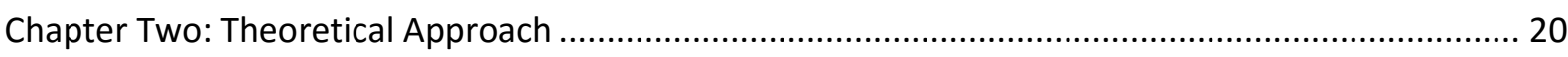

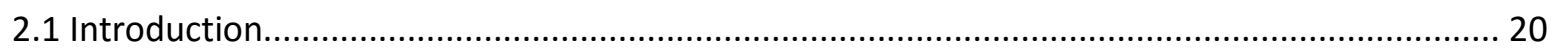

2.2 Public Participation in Science and Technology: An Overview ................................................ 20

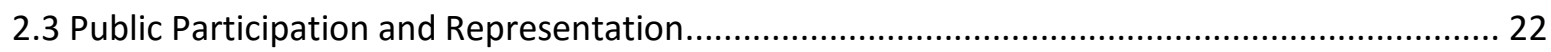

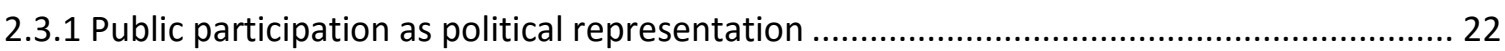

2.3.2 Public participation, representation, and objects of concern........................................... 25

2.4 The Material Turn in the Human Sciences and Sociological Theories of Dispute....................... 29

2.5 Object-Oriented Theories of Dispute and the Pragmatic Sociology of Critique ......................... 34

2.6 Overview of Theoretical Approach and Key Concepts .............................................................. 38

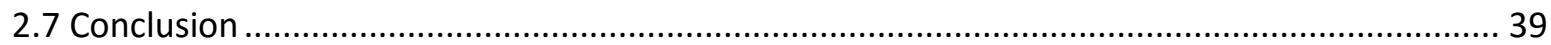

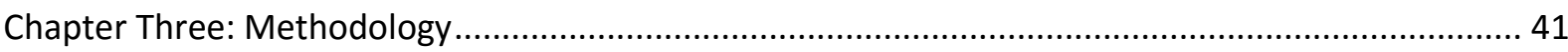

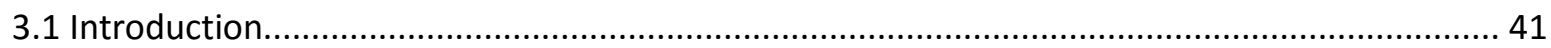

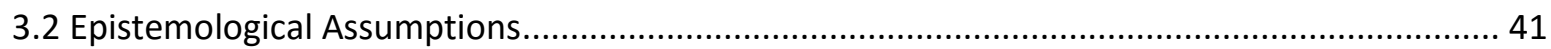

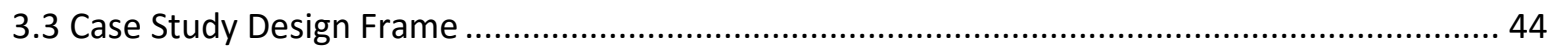

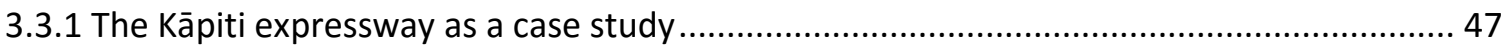

3.3.2 Public involvement in the Kāpiti expressway controversy.................................................... 49

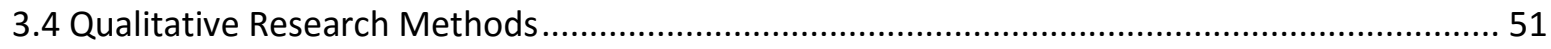

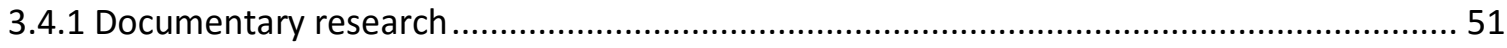

3.4.2 Semi-structured interviews and qualitative observations ............................................... 54

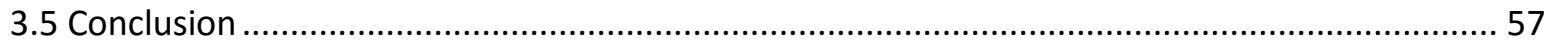

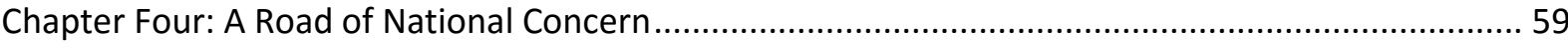

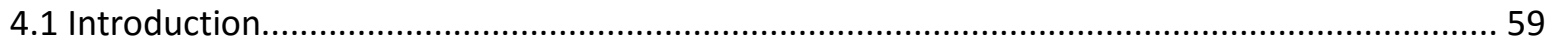

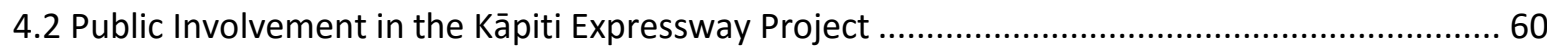

4.3 The Social and Environmental Impacts of the Kāpiti Expressway................................................ 62 


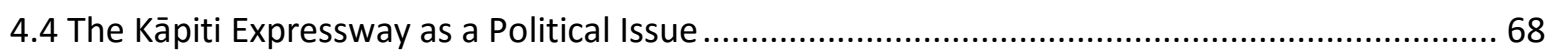

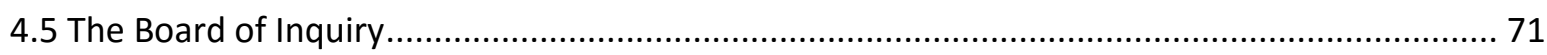

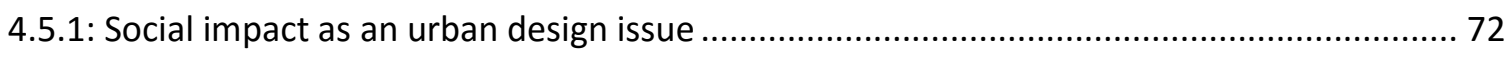

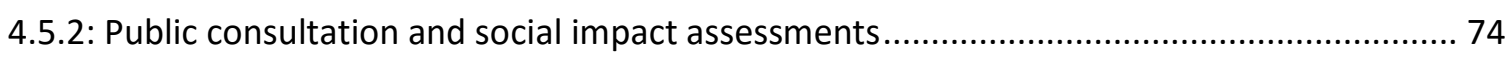

4.6 Conclusion: Public Involvement in Socio-Technical Controversies ............................................. 76

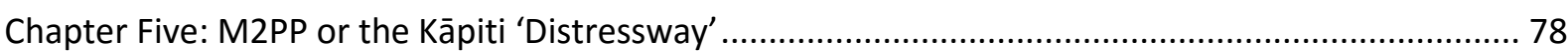

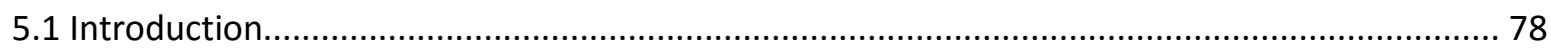

5.2 Protests and Demonstrations in Socio-Technical Controversies ............................................... 79

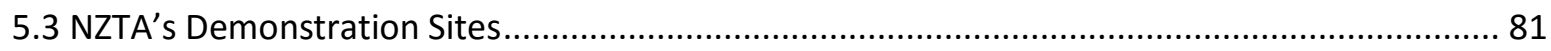

5.3.1 Demonstrating matters of fact: Public consultation 'at a distance' ................................... 82

5.3.2 Demonstrating matters of public concern: Face-to-face public consultation ...................... 84

5.4 Community Organised Demonstration Sites: Public Meetings and Protests............................. 87

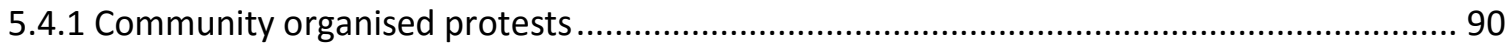

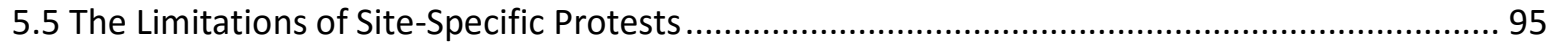

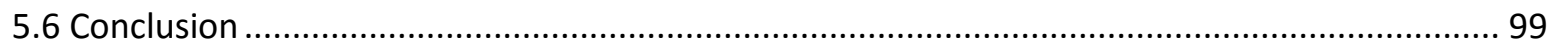

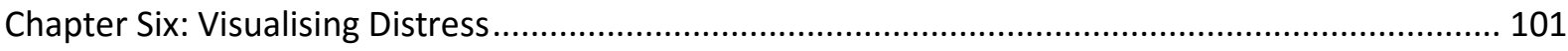

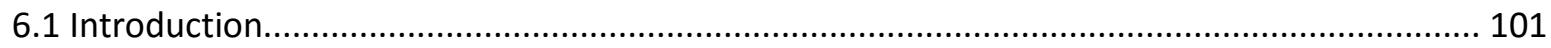

6.2 Visual Representations and Demonstrations in Public Disputes ......................................... 102

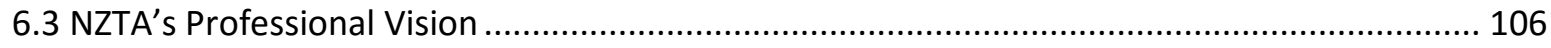

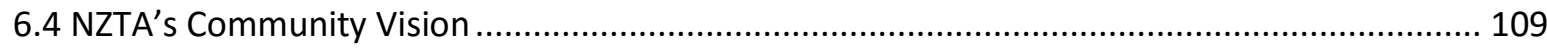

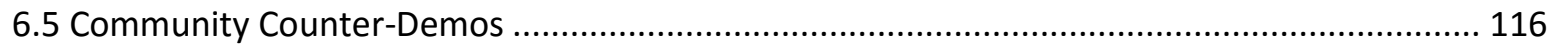

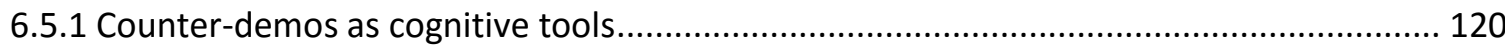

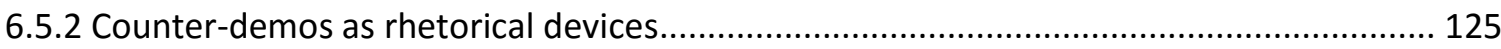

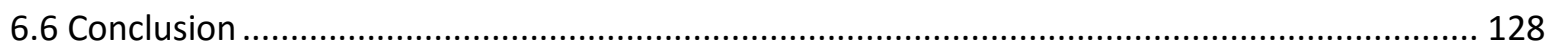

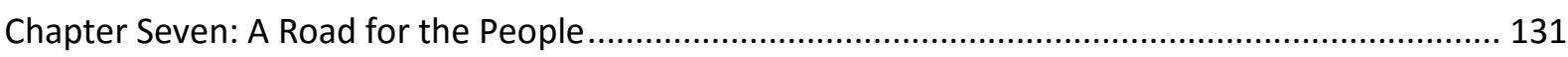

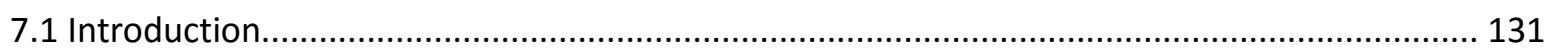

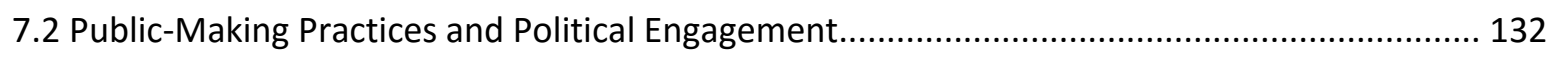

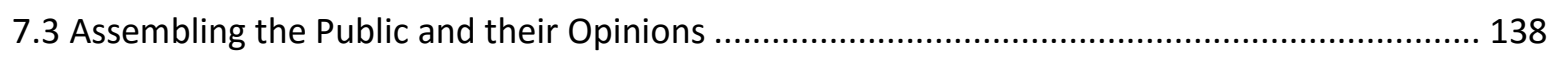

7.4 The 'Preferred Option' and the Rhetorical Construction of the Local Community .................. 141

7.4.1 The preferred option as an empty signifier ................................................................... 142

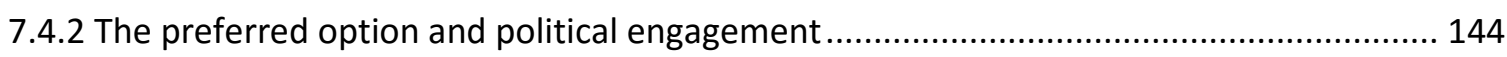

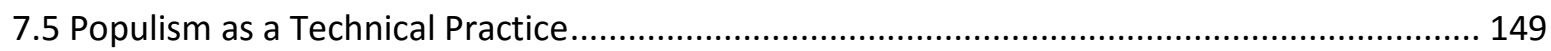

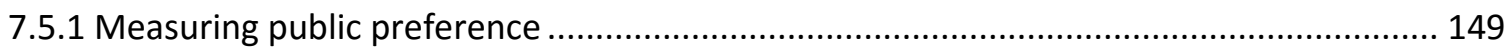

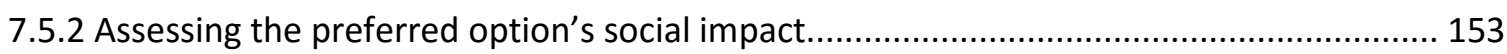

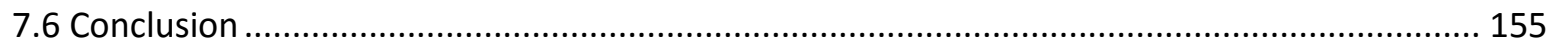

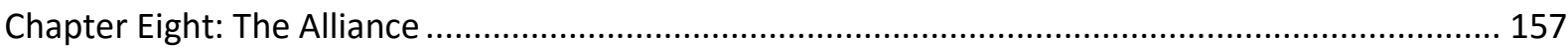




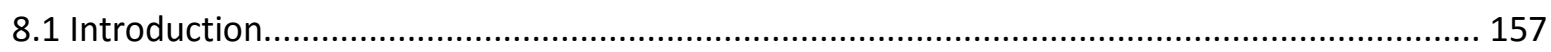

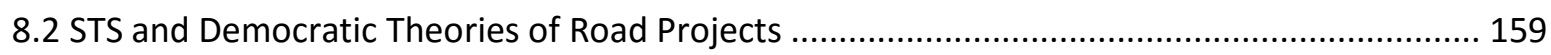

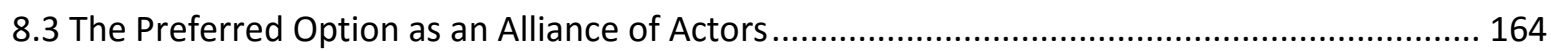

8.3.1 Forming The Alliance: Creating an alliance of human and nonhuman actors ................... 166

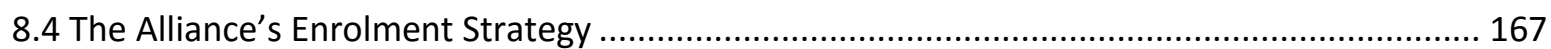

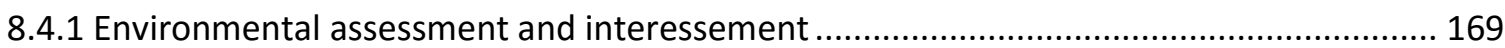

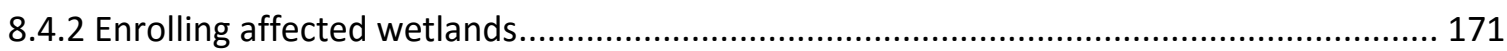

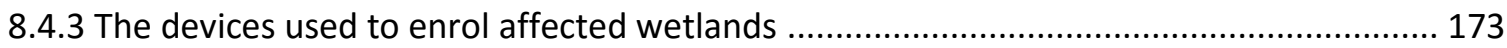

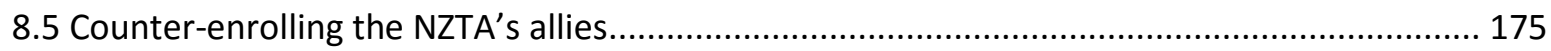

8.5.1 The challenges of counter-enrolling the NZTA's allies .................................................. 175

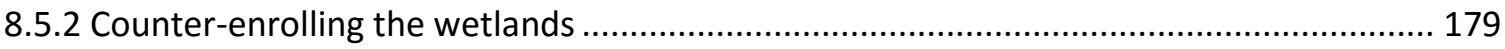

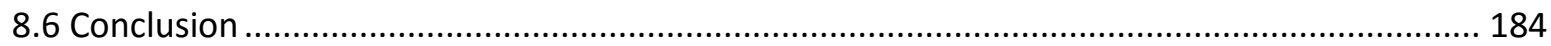

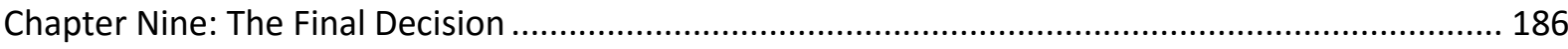

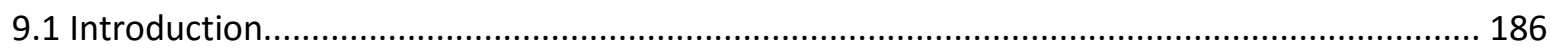

9.2 Decision-Making, Rubber Stamping, and Critique .............................................................. 187

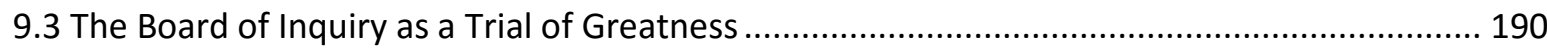

9.4 Board of Inquiry as a Rubber Stamping Exercise .............................................................. 192

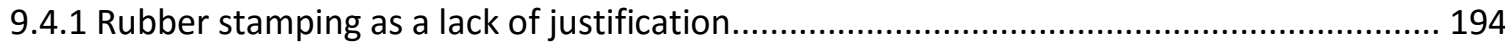

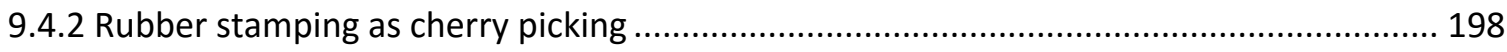

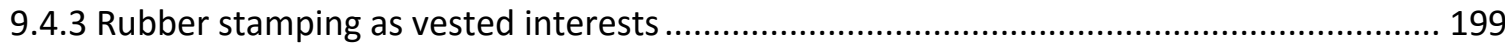

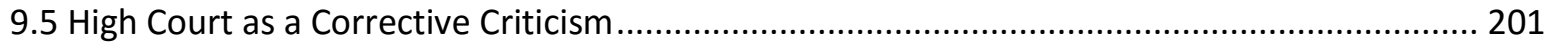

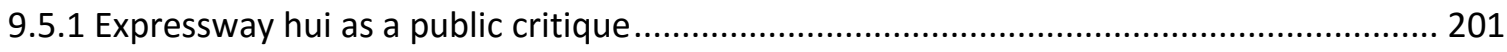

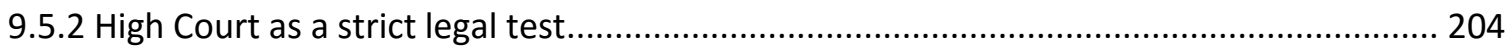

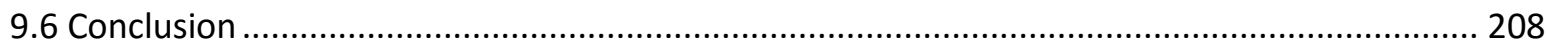

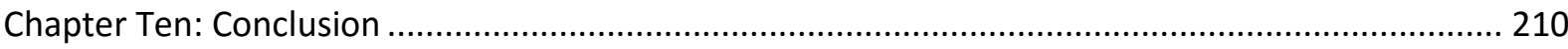

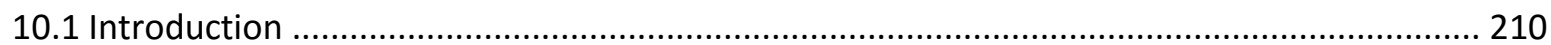

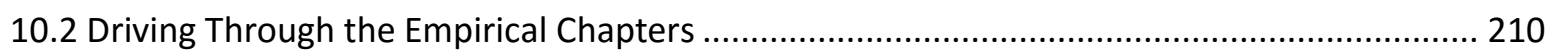

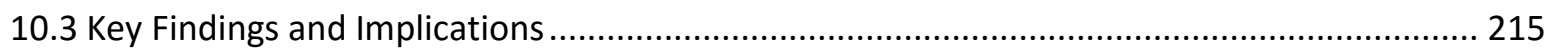

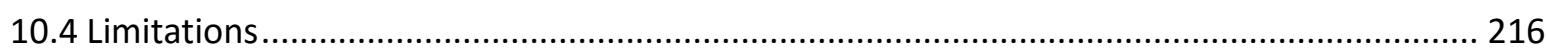

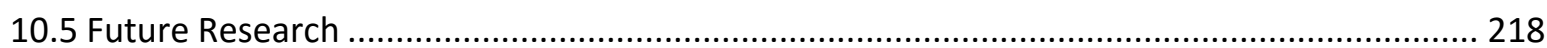

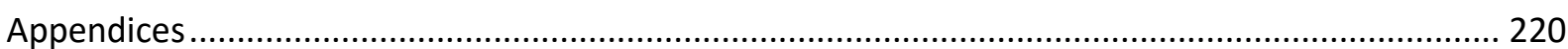

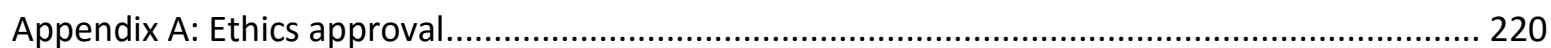

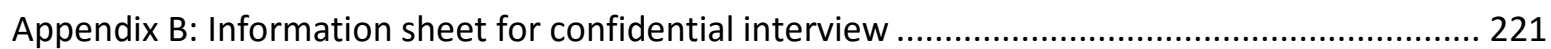

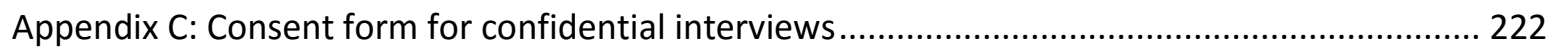

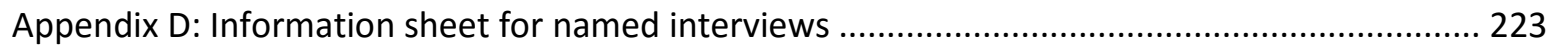

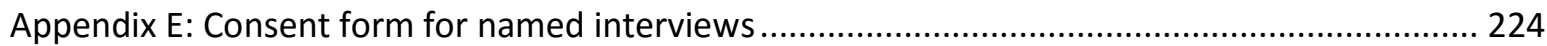


Appendix F: Interview guide

References.

226 


\section{List of Figures}

Figure 1. Personal visit to the MacKays to Peka Peka Information Centre............................ 10

Figure 2. Personal visit to the proposed Kāpiti Road interchange......................................... 10

Figure 3. Visual simulation of the Kāpiti Road interchange (Boffa Miskell, 2012)............... 11

Figure 4. Kāpiti Road interchange, April 2015................................................................... 11

Figure 5. MacKays Crossing to Peka Peka - Concept map (New Zealand Transport Agency,

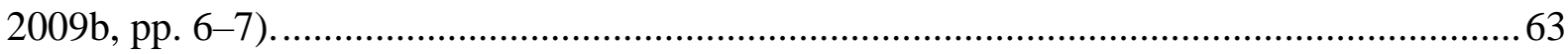

Figure 6. Connections: Kāpiti Road to Mazengarb Rd (McIndoe, 2012a).............................. 74

Figure 7. Feedback form (New Zealand Transport Agency, 2009b)................................... 83

Figure 8. MacKays to Peka Peka Information Centre......................................................... 85

Figure 9. Waikanae Railway station protest (Shipman, 2011). ........................................... 92

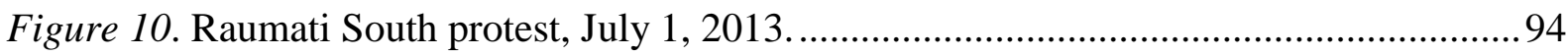

Figure 11. 'Kāpiti Expressway: Prehistoric Policy' protest..................................................98

Figure 12. "indicative road carriageway alignment" (New Zealand Transport Agency, 2010b,

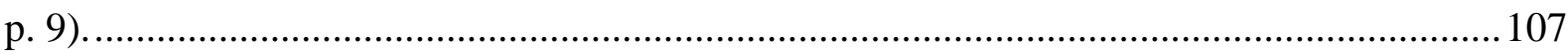

Figure 13. "MacKays to Peka Peka visual fly-through" (New Zealand Transport Agency, n.d.-b).

Figure 14. "Indicative aerial view of the Wharemauku Stream expressway bridge" (New

Zealand Transport Agency, 2011b, p. 4).

Figure 15. "Indicative view looking west on the Wharemauku Stream path - before mitigation work" (New Zealand Transport Agency, 2011b, p. 4) ....................................... 114

Figure 16. "Mitigation treatment" (New Zealand Transport Agency, 2011a)....................... 114

Figure 17. "What will the proposed expressway look like?" (The Sustainable Option, n.d.).

Figure 18. Through the Heart website (Sun Harvest Media, 2012). ...................................119

Figure 19. Through the Heart documentary (Sun Harvest Media, 2012). ............................ 121

Figure 20. 'Pointing' (Sun Harvest Media, 2012). ............................................................. 122

Figure 21. "Wharemauku Bridge: Western Link Road design” (Sun Harvest Media, 2012).

Figure 22. "Wharemauku Bridge: NZTA Expressway design" (Sun Harvest Media, 2012).123

Figure 23. Kāpiti Road interchange (Sun Harvest Media, 2012). ....................................... 123

Figure 24. Balloons (Sun Harvest Media, 2012). ........................................................... 124

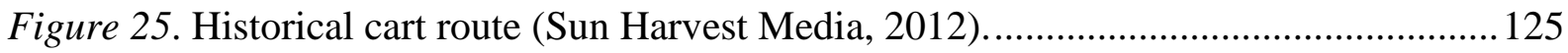

Figure 26. Wharemauku wetlands............................................................................. 172 


\section{Chapter One: Introduction}

\subsection{Driving Through the Kāpiti Coast}

February 2013. It is the height of summer in Wellington and I am driving up to the Kāpiti Coast to enjoy its semi-rural charm and to see where a proposed four-lane, 18 kilometre expressway through the centre of Paraparaumu township could be built. You know you are leaving central Wellington when State Highway 1 transitions from four lanes to two at the small township of Pukerua Bay. This transition signals that you are leaving the bustling city of Wellington and entering the quiet, seaside communities that are scattered along Kāpiti's pleasant coastline. A winding coastal road wedged between Paekakariki Hill and the Tasman Sea connects Wellington to Kāpiti while also adding to the feeling that you are no longer in an urban concrete jungle.

Having just experienced the transition from a busy city centre to an idyllic coastal community from my car, I start thinking about how a large expressway could be integrated into the semirural environment that is enjoyed by over 50,000 residents that live along the Coast. The proposed MacKays to Peka Peka Expressway (henceforth Kāpiti expressway), which is the focus of this thesis, will take the State Highway away from its current route near the railway corridor and shift it through the townships of Raumati South, Paraparaumu, Waikanae, and Peka Peka. My first stop is the MacKays to Peka Peka Information Centre at the Coastlands Mall in Paraparaumu. The Information Centre provides the public with a range of updates about the project, information panels, maps, and a visual simulation or 'fly-through' of the expressway that is displayed on a LCD screen. I look at a large, complex map of the expressway to find a suitable site that I could visit and take photos of the landscape before construction starts (See Figure 1). I find a large, proposed interchange on Kāpiti Road and decide to make this my first visit.

I leave the Coastlands Mall in search of the proposed Kāpiti Road interchange in Paraparaumu. I arrive next to a vacant corridor of land that has been earmarked for a road project since the 1950s and take a photo of the landscape (see Figure 2). I look at the before and after artwork prepared by New Zealand Transport Agency (NZTA) and I can see it will have a significant presence in the local communities (see Figure 3). My initial thought was: "what would it be like to live with a 26 metre wide state highway in the neighbourhood?" 
Fast-forward two years later to 2015, and the construction of the project reveals that it will have an imposing presence in the community when it is built. The photograph below reveals that it will be a huge concrete structure that will dominate the landscape (see Figure 4). The semi-rural feel that is depicted in Figure 2 has been replaced by a large structure that is slowly taking form. It is as if Wellington's concrete tentacles have finally reached this tranquil part of the country.

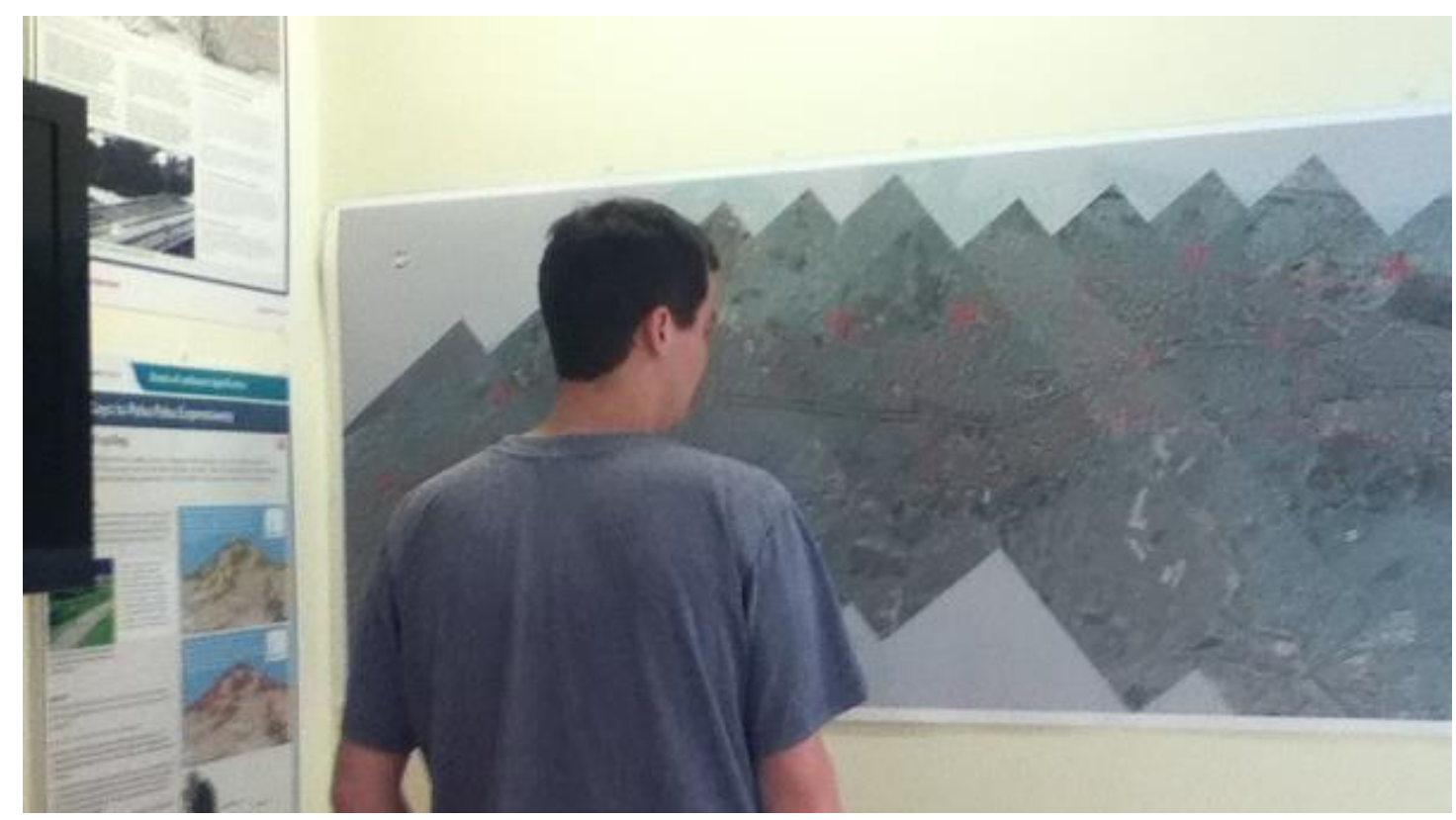

Figure 1. Personal visit to the MacKays to Peka Peka Information Centre.

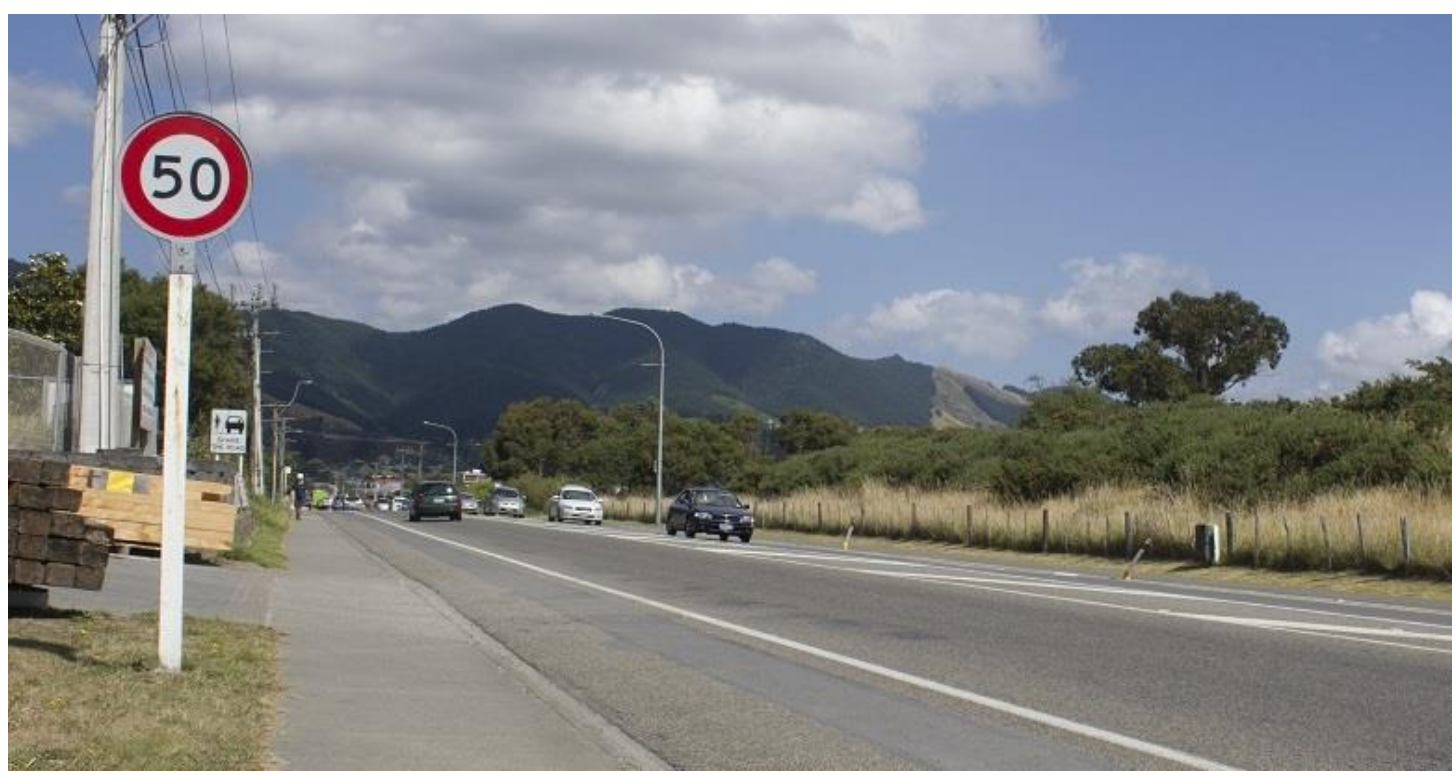

Figure 2. Personal visit to the proposed Kāpiti Road interchange. 


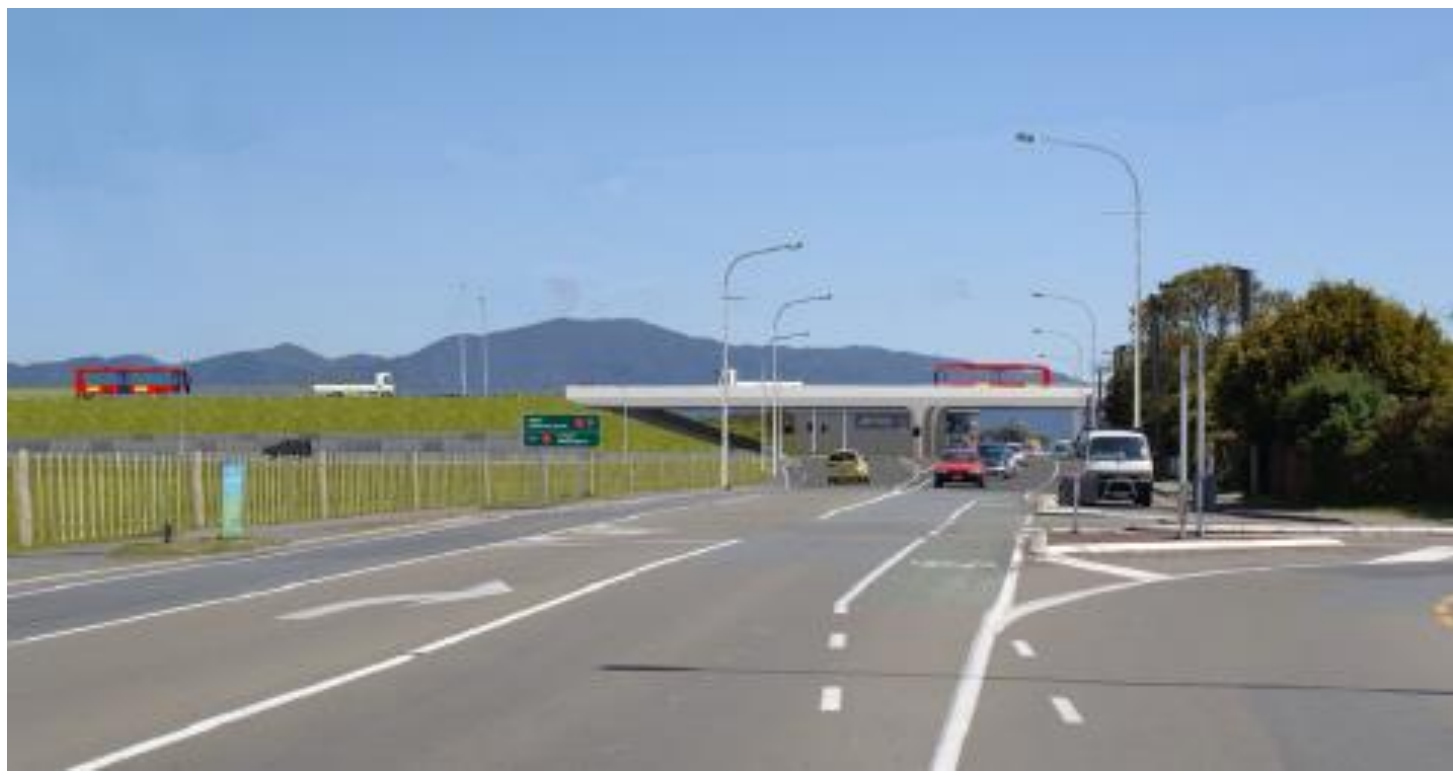

Figure 3. Visual simulation of the Kāpiti Road interchange (Boffa Miskell, 2012).

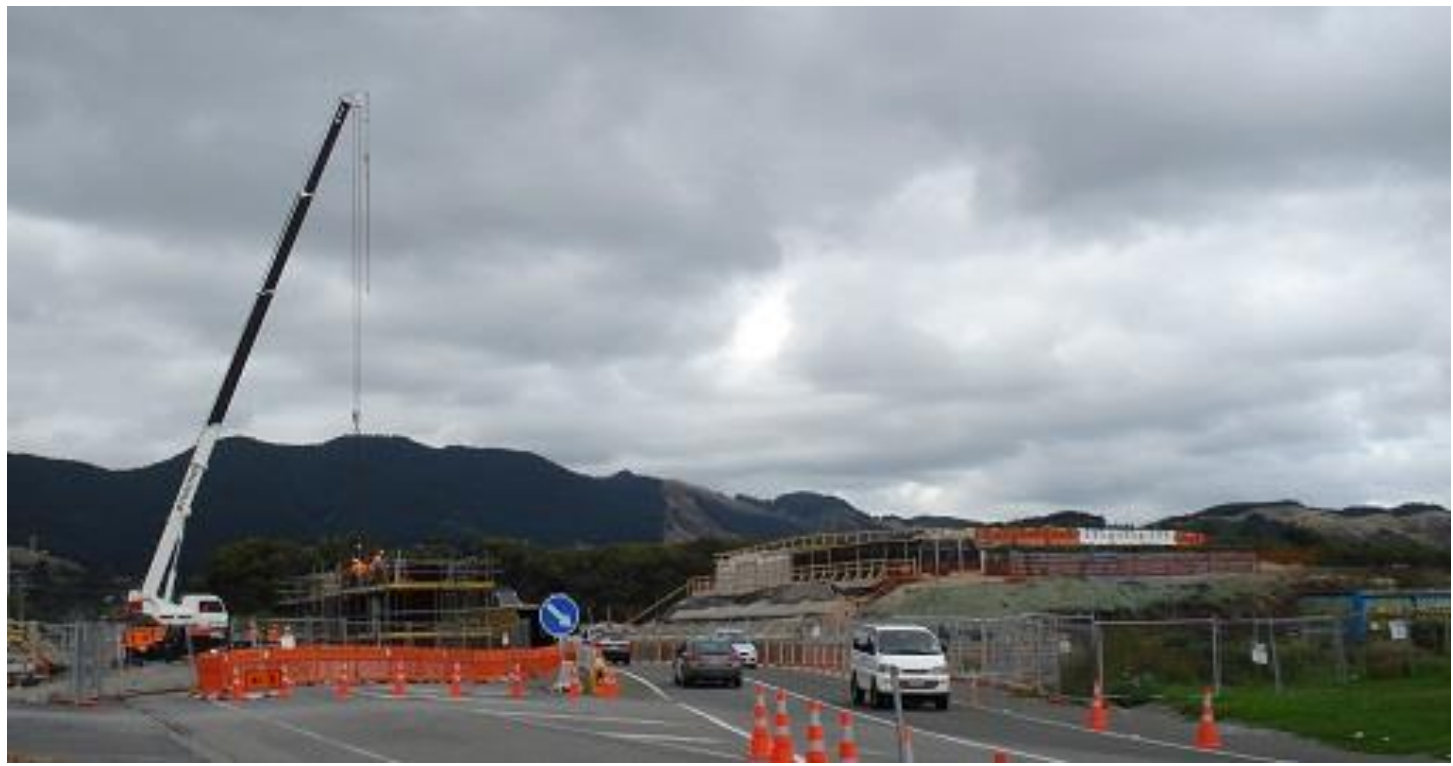

Figure 4. Kāpiti Road interchange, April 2015.

Having previously worked as an automotive technician, I have first-hand experience of the impacts that vehicles can have on the environment and health: they produce a lot of noise, dust, particulates, and they contribute to air pollution and climate change. However, for people unfamiliar with the impacts of roads and vehicles, I could only imagine what it would be like to participate in the planning of a project that could significantly alter the look and feel of the local community. As the project promises to improve travel time I imagined that some residents would welcome the new expressway. I also imagined that many residents would be very concerned by the proposal and would want to challenge it. 
However, there were lingering questions that I was unable to answer. For example, if the public wanted to oppose, or participate in, the expressway project, how would they do this? How would they engage with the various legal, scientific, and technical issues with the road project? And, how would they find allies to oppose an issue that is often associated with notin-my-backyard (NIMBY) politics? Just thinking about these questions made me tired, so I was impressed to find out that a number of local groups had been actively opposing the expressway project since 2009. I wanted to find out more about how concerned residents and local groups engaged with and evaluated this very technical issue.

\subsection{Public Involvement in Socio-Technical Controversies}

This thesis examines the issue of public involvement in socio-technical controversies from a sociological perspective. Public engagement in science and technology is becoming increasingly important in societies where citizens are asked, and expected, to be involved with public issues that revolve around matters of risk, trust, and uncertainty (Wynne, 2007), and the safety and well-being of the people that are affected (Irwin \& Michael, 2003). Rather than having a deficit or inability to understand or engage with issues involving science and technology, the public's 'local' knowledge (Wynne, 1992) is now seen to play an important role in either enriching professional expertise or in co-producing scientific knowledge (Bucchi $\&$ Neresini, 2008). Indeed, a number of social scientists have coined terms such as "scientific citizens" (Irwin, 2001), "technological citizenship" (Barry, 2001), and "technical democracy" or "hybrid forums" to examine public involvement in socio-technical controversies (Callon, Lascoumes, \& Barthe, 2011). There are numerous cases of public involvement in sociotechnical controversies and decision-making processes, but some of the more well-known examples include the debates over biotechnology, genetically modified foods and crops, the siting of energy and waste facilities, and climate change decision-making.

In New Zealand, a contemporary example of public participation in an issue that has been dominated by experts is transport infrastructure projects. In 2009 New Zealand's National-led government announced that it was planning to build seven Roads of National Significance (RoNS) at an estimated cost of 11 billion dollars. All seven road projects have received extensive media coverage on the public consultation process and opinions on the benefits and problems of building large motorways in urban environments. In particular, the MacKays to Peka Peka section of the Kāpiti Expressway has generated a high level of public interest. From 2009 to 2013 approximately seven public meetings and nine protests were publicised in 
the media. Additionally, the New Zealand Transport Agency (NZTA) received a large number $(1,617)$ of submissions during the public consultation period, and the Board of Inquiry received over 700 submissions.

While public participation in infrastructure projects is now a common occurrence, the planning and decision-making process was, and to some extent still is, a top-down process. For instance, freeway projects of the mid twentieth century used a top-down decision-making process that had little regard for the people who lived near them. Rather than consulting affected communities, the routing of freeways in the United States was made by highway engineers (Mohl, 2008). This meant that, in some states, thousands of residents were either displaced or forced from their homes (Mohl, 2008, p. 196). Rather than participating in the planning and decision-making process, concerned citizens organised grassroots opposition movements, protests, and legal action (Dyble, 2007; Mohl, 2004).

However, top-down approaches to planning began to change with the demand for public participation in the 1960s and early 1970s (Arnstein, 1969; Fiskaa, 2005). In New Zealand, transport planners are now required by law to consult the public and to develop in-depth environmental and social impact reports that consider alternative road types and designs. This means that transport planners are confronted with the difficult task of designing a road that balances technical considerations with environmental, social, and economic concerns. Consequently, decision-makers are often required to consider evidence submitted by lay people and experts. Moreover, the public are faced with the daunting task of supporting or criticising public projects that are developed by experts according to legal and technical considerations.

There have been various studies on the RoNS projects from a range of academic disciplines notably transport planning and economics - but there have been no sociological studies to date on public involvement in these projects. Therefore, I will examine the Kāpiti expressway project as a case study of public involvement in socio-technical controversies. As there have been numerous plans to construct a road on the designated route since the 1950s, I will provide insights into this important public issue, while also contributing to the sociological literature on public dispute.

Public involvement in socio-technical controversies implies that there is a need for greater representation in issues that affect culturally and socially diverse populations. Indeed, in the human sciences there is an extensive literature on the importance of representation, 
consensus, and disagreement in politics and planning. Previous research into public participation in transport planning processes and socio-technical controversies has highlighted the issue of representation by drawing on procedural and deliberative theories. For instance, a number of researchers have focused on meaningful participation in public issues (Arnstein, 1969; Fiskaa, 2005), democratic decision making, and communicative planning (Flyvbjerg, 1998; Flyvbjerg, Bruzelius, \& Rothengatter, 2003; Healey, 1993; Kemp, 1985; Mees \& Dodson, 2007; Throgmorton, 1992).

However, with the recent material turn in the human sciences, science and technology studies (STS) of public participation in socio-technical controversies have shifted away from humancentred theories of representation by foregrounding the material and technological aspects of political life (Barry, 2013; Callon et al., 2011; Latour, 2005a; Marres, 2012; Marres \& Lezaun, 2011). These studies of public participation have focused on how materials and devices do not play a secondary role in controversies, but are integral to public disputes and political life (Barry, 2013, p. 7). Object-oriented and device-centred approaches to public dispute focus on how objects of concern are accurately re-presented to the people that have gathered around them (Latour, 2005a, p. 6). An emphasis on nonhumans and technologies does not mean that humans and political representation are unimportant in public disputes: it means that political representation is examined alongside the important problem of how issues are re-presented to an audience. As Latour (2005a, p. 6) suggests, object-oriented approaches ask: "Who is to be concerned; What is to be considered?"

There are a small, but growing, number of object-oriented studies of public infrastructure disputes (Barry, 2001, 2013; Hird, Lougheed, Rowe, \& Kuyvenhoven, 2014; Latour, 1996; Sage, Dainty, \& Brookes, 2011; Suchman, 2000). This thesis contributes to object-oriented approaches to public involvement in socio-technical controversies by developing an approach that incorporates the insights from socio-cultural approaches to public dispute and criticism. Material and technological approaches to politics tend to overlook the cultural modes of evaluation that actors use to assess and criticise public issues. Similarly, socio-cultural approaches to politics can prioritise discourse and rhetoric while downplaying the material and technical aspects of political life (Barry, 2002, p. 269). For instance, actor-network theories tend to focus on how actors are enrolled into a network. However, Boltanski and Thévenot's (2006) pragmatic sociology of critique (PSC) focuses on the various ways people and things "qualify" for enrolment within various moral vocabularies or orders of worth (Thévenot, Moody, \& Lafaye, 2000, p. 265). According to Irwin, Jensen, and Jones (2013, p. 
121), Boltanski and Thévenot's approach to studying disputes is a useful addition to actornetwork theories because criticism and justification call "attention to 'something being at risk'. In that way, critical debates are crucial elements of the engagement and not diversions from it". As the connections between object-oriented and discourse-centred approaches are not often made (Magaudda, 2013), this thesis creates a dialogue between these two contrasting approaches to public dispute by examining public involvement in the Kāpiti expressway project.

\subsection{Research Aims, Objectives, Questions, and Argument}

The central aim of this thesis is to understand how the public engage with and create meaningful evaluations of complex issues that are associated with expert-driven politics and top-down decision-making processes. As important public issues, such as proposed road projects, are developed within legal and professional frameworks, the key aim of this thesis is to understand how the public connect their personal or collective concerns with the legal, scientific, or technical aspects of a public issue.

The second aim of this thesis is to contribute to the material turn in the human sciences by engaging with object-oriented and socio-cultural approaches to public involvement in sociotechnical controversies. The role that technologies play in materialising public participation and re-presenting the Kāpiti expressway project as an object of concern are examined. However, as justification and criticism take centre stage in public disputes, this thesis creates a dialogue between object-oriented and socio-cultural theories by investigating the technologies of justification and criticism, and the cultural modes of evaluation that qualify people and things within moral vocabularies.

To understand public involvement in the Kāpiti expressway controversy and to contribute to the material turn in the human sciences, I have developed three objectives. The first objective is to understand how the public engaged with the Kāpiti expressway project. By mapping the dynamics of public involvement in this controversy, I examine how locally-based groups evaluated and publicised the project over a four year period (from 2009 to 2013). Specifically, I discuss how engagement with the expressway project was enacted through a range of technologies and devices that materialised participation - the technologies of demonstration, visual imagery technology, and measurement devices. 
The second objective is to understand how the public evaluated the expressway project. I examine how residents and opposition groups evaluated it as a public issue by discussing how they translated their initial concerns with the environmental, political, and social aspects of the project as legal and technical problems. This objective highlights the challenges involved in making a persuasive evaluation or critique of the expressway project. I suggest that challenging the expressway project involved finding relevant proof, enrolling allies, and producing justifiable critiques of the planning and decision-making process.

The final objective of this thesis is to demonstrate how my analysis of the Kāpiti expressway controversy contributes to the material turn in the human sciences. Discussing how technologies and devices materialise public involvement in socio-technical controversies will demonstrate how this thesis contributes to object-oriented approaches to public engagement in science and technology. And, discussing how actors evaluate and criticise the expressway project within cultural modes of evaluation will create a dialogue between object-oriented and discourse-centred theories. Specifically, I explore the connections between the pragmatic sociology of critique, rhetorical theories of dispute, and science and technology studies.

In relation to the thesis aims and objectives, I have developed three research questions. The first and second research questions focus on the Kāpiti expressway controversy, while the third research question focuses on the relationships between object-oriented and socio-cultural approaches to dispute. First, how did the public engage with the Kāpiti expressway project? Second, how did the public create persuasive evaluations and criticisms of the project? Finally, how can object- and discourse-oriented approaches to public dispute be used to provide an alternative understanding of public involvement and representation in sociotechnical controversies?

While the public were concerned with the issue of community representation in the planning process, I argue that they were obliged to re-present the expressway as an object of concern by demonstrating how their personal objections were relevant to the legal and technical aspects of the project. A range of technological devices enabled local groups to evaluate the project during the early planning stages of the project, but convincing decision-makers to reject the expressway involved the difficult task of critiquing the planning process and enrolling allies. My argument contributes to object-oriented and socio-cultural approaches to public dispute by demonstrating how criticism, justification, and the technologies of politics 
illuminate the complex relationships between the cultural and material dimensions of public involvement in socio-technical controversies.

\subsection{Theoretical Approach and Methodology}

To respond to the research questions, I use a qualitative, case study approach to sociotechnical controversies. I utilise interviews, qualitative observations, and documentary methods to examine the actions of local Kāpiti groups and the modes of evaluation used to challenge the expressway project. Specifically, I primarily focus on the actions of Save Kāpiti and, to a lesser extent, The Alliance for a Sustainable Kāpiti (ASK) and the Raumati South Residents Association. To investigate the range of actions and evaluations used by the local groups, I analyse publicly available documents, technical reports, hearing transcripts, media items, and evidence submitted to the Board of Inquiry and High Court. Additionally, qualitative observations of events, protests, and a High Court hearing combined with in-depth, semi-structured interviews are used to examine how disputants enrolled allies, engaged with the project, and evaluated the planning process and the NZTA's evidence.

A constructionist epistemology and ontology underpins my case study approach and theoretical resources. As I will be examining how the disputants engaged with and evaluated the expressway project, a constructionist epistemology has influenced how I approached the dispute. Instead of criticising the expressway project by examining the socio-political processes and power relations that influence the planning process, I focus on how the disputants evaluated and criticised the expressway project. A constructionist ontology also informs my decision to focus on the planning and decision-making aspects of the expressway project as I examine the project as an alignment of human and non-human actors. That is, rather than employing a social constructionist ontology, which would foreground the social interests, values, and ideologies in influencing the decision to build the expressway, a constructionist ontology is used to foreground the relational and material aspects of technology and artifact construction.

As I will discuss, a constructionist epistemology and ontology aligns with the object-oriented and socio-cultural approaches that are utilised in this thesis. Specifically, I primarily utilise the object-oriented theories developed within actor-network theory (Callon, 1986; Latour, 2005a) and studies of science and technology (Barry, 2001, 2002, 2013; Marres, 2007; Marres \& Lezaun, 2011; Rosental, 2013; Suchman, 2000). In terms of the socio-cultural or discoursecentred approaches used in this thesis, I primarily draw on Boltanski and Thévenot's (1999, 
2006) pragmatic sociology of critique and, secondarily, rhetorical theories of public dispute (Griggs \& Howarth, 2008; Laclau, 2005). While object-oriented and discourse-centred approaches have different emphases, together they help provide a rich sociological account of the Kāpiti expressway controversy.

\subsection{Thesis Fly-Through}

In Chapter Two, I outline the key concepts used in the thesis in relation to the literature on public involvement in socio-technical controversies and the material turn in the human sciences. I compare object-oriented and discourse-centred theories of public dispute to the literature on the politics of artifacts, and public involvement in planning and decision-making processes. I then discuss the relationships between materialist and discursive theories of politics and public participation by situating these approaches within the material turn in the human sciences. In Chapter Three, I outline the epistemological assumptions and methodology that underpins and guides my research approach.

The first three empirical chapters (Chapters Four, Five, and Six) examine how local groups evaluated and publicised the expressway project as an object of concern. Chapter Four maps the dynamics of public involvement by examining how the public engaged with the expressway project during the four year planning phase. I discuss how concerned residents and opposition groups translated their concerns with the environmental, political, and social aspects of the expressway project as legal and technical issues with its design and planning. As the local groups had to persuade others that the expressway was an important public issue, Chapter Five discusses how they had to not only evaluate the project, but also publicise it as an object of concern. In this chapter, I argue that a number of demonstration sites and techniques helped supporters and opponents of the project publicise and represent the expressway as either an object of concern or a matter of fact. Chapter Six continues to examine the issue of publicity by examining how the potential impacts of the project were visualised, publicly displayed, and debated. It focuses on the issue of what it would be like to 'live' with an expressway in the community. I claim that the debates over the impacts of the project not only involved representing the concerns of residents, but also visualising their concerns to the wider public and decision-makers.

The final three empirical chapters (Chapters Seven, Eight, and Nine) examine how local groups translated their concerns with the project in two legal settings - the Board of Inquiry and the High Court. Chapter Seven examines how public participation in the route selection 
or 'preferred option' process was used to make persuasive appeals to a majority figure that had been treated badly within the planning process. I suggest that appealing to the public or majority figure was not simply rhetorical, but also involved challenging the devices and techniques that assembled publics and materialised participation. Chapter Eight continues to focus on the issue of route selection by investigating how the disputants enrolled allies to support or oppose the alignment of the expressway. In this chapter I argue that the local groups faced the difficult challenge of counter-enrolling the actors that were aligned with the expressway project. As the local groups were unable to successfully oppose the expressway project during the Board of Inquiry, they challenged the decision to approve the project in the High Court. In this final substantive chapter (Chapter Nine), I examine how the local groups attempted to translate their concern with rubber stamping during the inquiry as legal issues that could be persuasively argued in the High Court. Rather than being a knee-jerk reaction, I suggest that the issue of rubber stamping was used as a corrective criticism of the decisionmaking process. Finally, I conclude my research by summarising the empirical chapters, discussing the implications of my findings, reflecting on the limitations of my study, and commenting on the possibilities for future research. 


\section{Chapter Two: Theoretical Approach}

\subsection{Introduction}

The aims of this chapter are to outline my sociological approach to the Kāpiti expressway controversy and to discuss my contribution to the material turn in the human sciences and, more specifically, object-oriented theories of dispute. In the first half of this chapter, I discuss the ontological assumptions and theoretical underpinnings of my research by comparing object-oriented and socio-cultural theories of dispute. I start by outlining the societal relevance of public participation in science and technology and how it relates to academic theories of representation in socio-technical controversies that are associated with top-down styles of decision-making. Specifically, I compare theories of political representation that focus on the procedures and performances of public participation with object-oriented theories that focus on how issues are re-presented to an audience. I then locate object-oriented theories within constructionist approaches to political life and the material turn in the human sciences. In the second half of this chapter, I discuss my contribution to the material turn in the human sciences by creating a dialogue between object-oriented and socio-cultural theories of dispute. I examine their contrasting approaches to the role of culture and nonhumans in controversies as examples of the "broken boundaries", or convergences and differences (Magaudda, 2013), between STS and sociological theories of culture. I then discuss how Boltanski and Thévenot's pragmatic sociology bridges socio-cultural and object-oriented theories of dispute. Finally, I outline my object-oriented and socio-cultural approach to the Kāpiti expressway controversy by identifying the key concepts that I will utilise in this thesis.

\subsection{Public Participation in Science and Technology: An Overview}

In Chapter One I highlighted that my decision to study public participation in large-scale road projects relates to my interest and experience in the automotive industry and my observation that the public were being asked to engage with specialist or technical issues that are not often talked, or thought, about. Public participation in transport projects, planning processes, and other issues that involve science and technology have become significant issues in New Zealand. The rise of environmentalism in the 1960s, the push for sustainable development in the 1980s, and the enactment of the Resource Management Act (RMA) in 1991 helped create a "new era in which it was expected that the public would have a far greater say in decisions affecting the environment" (Parliamentary Commissioner for the Environment, 1996, p. iii). 
This new era of public participation continued with the reforms to the Local Government Act 2002 that emphasised public involvement in local government decision-making processes (Bond \& Thompson-Fawcett, 2007) and the strengthening of accountability and democratic governance (Cheyne, 2015). Moreover, the various amendments and reforms to the RMA and new controversies involving science and technology (such as genetic modification) meant that public participation in issues involving science, technology, and the environment have become increasingly important in New Zealand (Hindmarsh \& Du Plessis, 2008). The significance assigned to public participation in science and technology can be seen with the recent (2013) initiatives from the New Zealand government to encourage greater public engagement in issues involving science, technology, and the environment (Salmon \& Priestley, 2015).

Internationally, the salience of public participation in issues involving science, technology, and the environment is, among other things, linked to environmentalism, modernity's risks, science and society movements, and a more general push to democratise decision-making processes (Marres, 2012, p. 16). In response to these broad trends, public participation in issues that have traditionally been dominated by experts is now a common practice (Jasanoff, 2003; Marres \& Lezaun, 2011). For example, Britain's bovine spongiform encephalopathy (BSE) crisis and concerns surrounding biotechnology prompted the House of Lords (2000) Select Committee on Science and Technology to issue a report on the importance of improving public understanding of science (Jasanoff, 2003). Around the same time (2001), the European Union produced a White Paper on governance that recommended increasing public participation in policy making and restoring public trust in expert advice as a result of the controversies surrounding bio-technologies and food safety (Commission of the European Communities, 2001). And, in Japan, Mikami (2015, p. 87) notes that the repeated nuclear incidents in the 1990s led to signs of democratisation in nuclear policy with the establishment of the Round-Table Conference on Nuclear Power Policy.

In particular, the growing number of socio-technical and environmental accidents and controversies in the twentieth century seems to have encouraged a heightened sense of awareness and concern with issues involving science and technology (Beck, 1992; Callon et al., 2011; Wynne, 2007). Rather than the public simply misunderstanding, or being ignorant of, scientific and technological issues, which is often called the "deficit model" of public understanding of science, many academics, governments, and other authorities are now focusing on how science-public interactions can be improved (Irwin \& Michael, 2003, p. 38). 
This shift from deficit to understanding is often seen as being crucial for permitting, rather than impeding, the development of science, innovation, and new technologies (Irwin, 2001). More radically, the public and other non-experts are now seen as essential in the coproduction of scientific knowledge (Bucchi \& Neresini, 2008; Callon et al., 2011). In this context, STS researchers have argued that citizenship and democracy are being reconfigured in contemporary societies (Barry, 2001; Callon et al., 2011; Irwin, 2001). For example, Barry (2001, pp. 127-128) suggests that with the increasing importance of science and technology in education, economic development, and society more generally, "the individual citizen is increasingly expected, and increasingly expects, to make his or her own judgements about scientific and technological matters".

\subsection{Public Participation and Representation}

Public participation in projects that are dominated by legal, technical, and scientific considerations is often framed as an issue of representation. The academic literature on political representation in transport and socio-technical controversies can be divided into two areas: the formal, procedural aspects of public disputes and the informal, public performances that surface when citizens are directly affected by an issue. These theories highlight the importance of political representation in top-down decision making processes. However, as I will discuss, focusing on political representation tends to provide a narrow approach to the issue of public involvement in socio-technical controversies. Object-oriented and material approaches to public dispute recognise the significance of political representation, but also highlight the importance of representing objects of concern and the technologies and devices that materialise public participation.

\subsubsection{Public participation as political representation}

The idea that the public should be involved with issues that affect them and their communities brings into focus the problem of political representation. One aspect of political representation is the role that planning processes play in fostering or restricting public deliberation and participation. Proceduralist theories of public dispute argue that opening an issue to public debate can help ensure that decision-making processes are fair and democratic. This means that citizens are not simply present in the planning process, but also actively scrutinise issues in a space that is "open", rather than "exclusive" (Habermas, 1989, p. 1). As Bohman (1996, p. 25) explains, the public refers to not only the body of citizens, but also "the way citizens 
deliberate" and "the type of reasons they give in deliberating". According to Fraser (1990, pp. 58-59), deliberation within what Habermas calls the "public sphere" can be understood as a mechanism for "holding the state accountable to "society' via 'publicity" and also an ideal type of discursive interaction that is based on "unrestricted rational discussion of public matters". More generally, Bohman (1996, p. 27) defines public deliberation as "a dialogical process of exchanging reasons for the purpose of resolving problematic situations that cannot be settled without interpersonal coordination and cooperation".

Proceduralist theories have been applied to the issue of public participation in transport and urban planning processes. Planning theories of public participation tend to focus on how opening the planning process to the public can help resolve their concerns and can produce more democratic outcomes. Public participation in a project usually means that citizens can express their concerns to planners and decision makers through the planning process rather than through other means, such as demonstrations or protest. According to some public participation theories, whether participation is an effective method for resolving public concerns depends on the level of engagement. Connor (1988) suggests that public participation can help prevent and resolve objections to a project through education, information feedback, and consultation. Similarly, Arnstein's (1969, p. 217) classic study of citizen involvement in planning processes argued that effective public participation, that is, being able to affect the final outcome of a project or process, involves creating partnerships, delegating power, and citizen control. She claimed that other types of public participation, such as consultation and information feedback, tend to be either 'tokenism' or "nonparticipation" (Arnstein, 1969, p. 217). In relation to transport infrastructure projects, Flyvbjerg, Bruzelius and Rothengatter (2003, p. 111) suggest that transparency and representative participation can help ensure that public interests are protected.

Another aspect of political representation is the important role that informal, public demonstrations play in representing public voices that have been excluded within formal planning processes. Expressing disagreement through established legal and political procedures, such as public meetings or in a court, are just some of the ways that citizens can support or oppose a motorway project. I focus here on how citizens can express their concerns through informal public performances, such as demonstrations and campaigns, because this has been a popular and, to some degree, successful way of making claims on the actors and agencies involved in motorway projects. 
It is important to note that road and motorway protests can be used not only to oppose a project, but to support it. For instance, in Peru, Harvey and Knox (2012, p. 522) suggest that some communities eagerly awaited the new motorways by staging marches, demonstrations, and road blocks. They suggest that, in some countries, roads can "enchant" because they hold the promise of social transformation and economic improvement (Harvey \& Knox, 2012, p. 522).

Expressing disagreement through informal public performances has been one of the most common ways that people have challenged proposed road projects. In the early and midtwentieth century, many Western countries, such as the USA, did not have legislation that gave citizens the ability to contest motorway projects through legal action (Mohl, 2004). According to Mohl (2004, p. 678), this meant that, while citizen movements attempted to oppose the freeways, most highway officials built the "expressways quickly before opposition coalesced and politicians caved in to an outraged public".

Like other forms of activism, motorway protests are forms of action that demonstrate a claim publicly. The public performances that were used to support or oppose proposed motorway projects in the 1950s and 1960s, for instance, ranged from campaigns, public hearings, petitions, and publicity (Issel, 1999), to direct action, group formation (Mohl, 2004). To use Tilly and Tarrow's (2007, p. 13) idea of "modular performances", motorway protestors in the 1950s and 1960s drew on a range of existing or "generic" claim-making performances, but adapted them to the local conditions of the time to make them publicly compelling.

Contemporary motorway protests and campaigns still rely on extant contentious repertories, but appear to have become more diverse and sophisticated. As Sheller and Urry (2000, p. 751) claim, while motorway protesters now use direct actions such as stopping traffic, 'reclaiming the streets', mass trespass, living in trees that are threatened by the project, and squatting in buildings, they also use digital technologies, such as the internet, mobile phones, and digital cameras to communicate their actions to the public. Moreover, motorway protesters are usually not only local residents, but also environmental activists who not only oppose particular road projects, but are also interested in highlighting other environmental issues and the "fundamental failings of modern society" (Doherty, 1999, p. 277).

Social movement theories of motorway protests, therefore, are useful for highlighting how activists have framed road projects as meaningful public issues. Protestors often draw on a range of meaningful "frames" (North, 1998; Snow \& Benford, 1988), "popular demands" 
(Griggs \& Howarth, 2007), “orders of worth” (Thévenot et al., 2000), and cultural codes/themes (Alexander, 2006; Gamson, 1992; Jasper, 1992) to engage with public issues and to mobilise allies. As della Porta and Diani (2006) suggest, the attribution of meaning to an event, project, individual, or group underpins all conflicts and helps mobilise actors and social groups into action.

Motorway protestors have helped voice public concern with controversial road projects, but it is important to note that protests have had limited success with stopping large motorways from being built. Like other forms of activism, the success of motorway protests depends on, what Tilly and Tarrow (2007, pp. 49-50) call, the "political opportunity structure", which is "the framework within which people decide whether to mobilize, make decisions about optimal combinations of performances to use, and are likely to succeed or fail in their efforts". For example, Mohl (2004, p. 676) suggests that the freeway revolts in the USA had different histories due to particular social, geographical, and political conditions. In particular, he suggests that extensive alliances; strong support from local politicians and from influential media sources; a strong historic planning tradition; and legal action were important factors that helped stop some freeways from being built (Mohl, 2004, p. 676). It is important to note, however, that not all motorway protests are dependent on the political environment or draw their support from political actors. Doherty (1999, p. 283) argues that a number of British road protesters in the 1990s relied on "small scale resources" from environmental groups and did not form alliances with political parties.

\subsubsection{Public participation, representation, and objects of concern}

Procedural and social movement theories have illuminated the importance of public involvement in socio-technical controversies by highlighting the issue of political representation, but I suggest that an important aspect of representation that tends to be overlooked in these theories is the re-presentation of issues as objects of concern. Theorists of science and technology have shifted away from human-centred theories of representation by focusing on how an issue is represented to the people who gather around it (Latour, 2005a). Object-oriented theories focus on how materials and artifacts play an important part in disputes. The objects of a dispute, as Latour (2005a, p. 5) argues, helps “"[trigger] new occasions to passionately differ and dispute". As Barry (2013, p. 7) suggests, objects and their properties and behaviour "should not be thought of as incidental to politics, but as integral to the disagreements and disputes that lie at the heart of political life". For example, in a review 
of Barry's research into the Newbury bypass protests, Callon (2004, p. 124) highlights how the protesters did not represent "already constituted groups", but "[pointed] to the object or thing about which she wants to speak to (with) others".

One implication of this approach is that objects, technologies, and devices take centre stage when examining public participation and representation. As Barry (2013, p. 8) explains, controversies involving science and technology "revolve around disagreements not just about the rights and interests of human actors . . ., but also about the causes of climate change, the safety of genetically modified organisms, the origins of diseases, the risks of floods and the consequences of nuclear accidents". In relation to public involvement in road projects, an important problem that confronts opponents is how the road in question can be re-presented as a wider environmental, political, or social issue. As I will discuss, foregrounding the objects of politics brings into focus the literature in science and technology studies on the "politics of artifacts".

The idea that artifacts are political is relevant to the issue of public involvement in sociotechnical controversies as it foregrounds how technological design can be beneficial for some actors and problematic for others. That is, to challenge a road project, or other artifact, the public are obliged to highlight the detrimental impacts of the road. This means that the public are not simply represented in socio-technical controversies, but also participate by representing the central issues as objects of concern. Here I focus on three theoretical approaches to the politics of artifacts: critical (or sub-political), social constructionist, and object-oriented approaches. I suggest that, in contrast to critical and social constructionist theories, object-oriented approaches to the politics of artifacts provide useful tools for examining public involvement in the Kāpiti expressway controversy.

Critical or sub-political theories of artifacts tend to focus on, what Matthewman (2011, p. 5), calls the "external" politics of artifacts; that is, how they shape human conduct. Winner's (1980, p. 123) early research into the politics of artifacts focused on the compatibility of certain artifacts with "particular kinds of political relationships" and how the design of an artifact can be "a way of settling an issue in a particular community". He focused on how a bridge was deliberately designed to keep buses off the overpasses and, therefore, "to limit access of racial minorities and low-income groups to Jones Beach, Moses's widely acclaimed public park" (Winner, 1980, pp. 123-124). 
While Winner did not focus on public participation, critical theories of artifacts have highlighted the difficulty of challenging infrastructure projects that sustain the system of automobility. Critical theories of automobility have examined how automobile systems can remain unchallenged by the public due to their dominance as a mode of transportation. For instance, Urry (2007, p. 119) argues that "social life has been irreversibly locked in to the mode of mobility that automobility both generates and which can so far only be dealt with through its further expansion and restructurings of time and space”. Böhm, Jones, Land, and Paterson (2006, p. 6) argue that automobility is sustained as it intersects with issues of truth, power, and subjectivity. They suggest that "the attribution of deviance to alternatives to the car means that those advocating such alternatives have trouble articulating successfully their own regime of truth regarding cars" (Böhm et al., 2006, p. 8).

Social constructionist and object-oriented theories eschew critical theories that assume artifacts have stable meanings and uses, and focus on how artifacts participate in the social world as non-human actors or mediators. While object-oriented theorists, such as Latour (1992), agree that artifacts can discriminate against certain people by being designed in certain ways, they tend to argue that people can find alternative ways of using an artifact. Matthewman (2011, p. 80) suggests that "what a technology is cannot be determined by design. Instead, technological meaning is always to be found in use". For instance, Winner's claim that Moses' bridges were designed to exclude buses from accessing Jones Beach, has been challenged by Woolgar and Cooper (1999). They suggest that, while Moses might have designed the bridges to have social effects, buses have been traveling on the bridges since at least 1992, which could be due to changes to the bridges structure or smaller buses being used (Woolgar \& Cooper, 1999). Woolgar and Cooper (1999, p. 443) argue that artifacts have ambivalent qualities (they can be enabling and oppressive, they can be good and bad) and so "a quest for a definitive account of the actual character of a technology" can overlook everyday experiences of technology.

Social constructionist and object-oriented theories of artifacts highlight how public involvement in an infrastructure project involves representing it as an object of concern. They suggest that technology is not simply designed for political reasons, but is shaped by a range of factors. Social Construction of Technology (SCOT) theories claim that technology is not independent of the meanings that social groups impose on it (Jarzabkowski \& Pinch, 2013; Pinch, 2010; Pinch \& Bijker, 1989). SCOT theorists highlight the idea that the meaning of an artifact is not stable, but is related to shifting social contexts and social groups who use it. 
When one interpretation establishes dominance it can stabilise the meaning of the artifact and people's ideas about its design and use (Kirkpatrick, 2008, p. 26). In relation to road projects, SCOT theorists emphasise how interest groups socially construct a road by debating what they are for (Hommels, 2010; Norton, 2008).

In contrast to social constructionist approaches, object-oriented theories of technology (in particular, actor-network theories) argue that 'the social' is only one factor in stabilising the meaning of artifacts (Law, 1987, p. 113). Because social interests are variable, it can be problematic to claim that artifacts reflect the interests of the social groups that participate in the debate. Actor-network theorists argue that a controversy is settled by successfully enrolling human and nonhuman actors into a network. For example, from an ANT perspective, a completed road can be viewed, as Suchman (2000, p. 316) suggests, "as an arrangement of more and less effectively stabilized material and social relations". There are often a number of competing ways of designing and constructing roads and the final design is often the outcome of a range of social, material, environmental, economic, and technical factors. As Law (1987, p. 113) argues, "the stability and form of artifacts should be seen as a function of the interaction of heterogeneous elements as these are shaped and assimilated into a network [emphasis in original]".

In terms of public involvement in road projects, ANT's focus on artifacts as an issue of stabilisation suggests that re-presenting a road as an object of concern involves counterenroling the human and nonhuman actors that have been aligned with the project. Debating the social impacts of a road and what it will be used for can be a persuasive method of representing roads as objects of concern. However, as road projects are interconnected with a range of other technical, environmental, and economic considerations, a persuasive representation of a road would take these considerations into account.

The idea that representation involves gathering people around an issue and representing it to the people that have been assembled is underpinned by a constructionist ${ }^{1}$ ontology that provides an object-centred or materialist understanding of politics and publics. A number of STS theorists have developed their own distinctive understanding of politics and publics, but they tend to agree that publics are not social groups per se, but collectives that are assembled and made real in relation to issues and through a range of practices and technologies (Barry, 2001, 2013; Latour \& Weibel, 2005; Lezaun \& Soneryd, 2007; Marres, 2012; Osborne \&

\footnotetext{
${ }^{1}$ I discuss the meaning of constructionism in Chapter Three.
} 
Rose, 1999; Whatmore \& Landström, 2011). The idea that publics are made real is consistent with a common theme within STS that realities are performed into being (Matthewman, 2011, p. 166). For example, in relation to public involvement in infrastructure projects, Barry (2013, p. 102) argues that the communities affected by the Baku-Tbilisi-Ceyhan (BTC) pipeline project did not pre-date the project, but were performed "into being in order that they could be informed and consulted, and the impacts on them assessed".

I examine the theoretical approaches to public participation in the empirical chapters, but here it is worth briefly outlining Marres' idea of "material publics" as it underpins my analysis of public involvement in the Kāpiti expressway project. In contrast to procedural theories that emphasise public deliberation and political representation, Marres (2005, p. 208) argues that "issues spark a public into being". She links the idea of the public with the problems that confront particular members of a society; that is, without an issue, there is no public (Marres, 2005). This means that publics are not simply represented in issues, but are "problematically entangled" in them (Marres, 2012, p. 56).

Marres' understanding of the public is informed by the American pragmatists John Dewey and Walter Lippman. According to Marres (2005, p. 212), both Dewey and Lippman argued that the public deal with problems that are not addressed adequately by other social groupings or institutions. According to Lippman (as cited in Marres, 2005, p. 211), “where the facts are most obscure, where precedents are lacking, where novelty and confusion pervade everything, the public in all its unfitness is compelled to make its most important decisions". What Lippman is suggesting here, according Marres (2005, p. 212), is that simple problems can be easily managed by existing authorities and institutions, but complex, unfamiliar problems require a public that "may adopt problems that no one else is taking care of". In contrast to Lippmann, Dewey argues that a public not only emerges when existing social groupings fail to deal with an issue, but emerges when people "are affected by the indirect consequences of transactions, to such an extent that it is deemed necessary to have those consequences systematically cared for" (as cited in Marres, 2005, p. 213). Despite their differences, Lippman and Dewey both agree that the public are not a social community, but are a political community formed by people who are affected by a particular issue (Marres, 2005, p. 214).

\subsection{The Material Turn in the Human Sciences and Sociological Theories of Dispute}

Materials and nonhumans have always been at the heart of ANT and STS theories of science and technology, but they have only recently been placed centre stage in theories of politics 
and public involvement in socio-technical controversies. The emergence (in the last ten to fifteen years) of what is often called "new materialism" (Coole \& Frost, 2010), the "material turn" (T. Bennett \& Joyce, 2010; Mukerji, 2015), or the "turn to ontology" (Woolgar \& Lezaun, 2013) signifies a renewed interest in materialism across the human sciences in general and, in particular, materialist approaches to politics and dispute (Barry, 2013; Braun \& Whatmore, 2010; de Vries, 2007; Latour \& Weibel, 2005; Marres \& Lezaun, 2011). Lemke (2015, p. 4) notes that, while the literature on new materialism has been developed from within a variety of theoretical and disciplinary perspectives, it is underpinned by the concern that the dominance of discourse and culture in the social sciences has led to conceptual flaws and problematic understandings of nonhumans and contemporary politics. As I have discussed, ANT and STS researchers have pointed out that focusing on human representation provides a one-sided understanding of politics that prioritises discourse, citizen representation, and human agency at the expense of the objects of politics and the importance of nonhumans and objects in political life.

It is important to note that new materialism is not only a reaction to the problems associated with discourse- and cultural-centred theories, but is also a redefining of 'older' theories of materialism. New materialism is 'new' in the sense that it departs from theories that associate materiality with social and economic structures (for instance, historical materialism) and anthropological theories that examine the cultural meanings embedded in objects (J. Bennett, 2010, p. xvi). New materialism problematizes older theories by claiming that they reproduce a divide between active human subjects and inactive matter (Coole \& Frost, 2010, p. 8). That is, new materialist approaches suggest "that matter itself is to be conceived as active, forceful and plural rather than passive, inactive and unitary" (Lemke, 2015, p. 4).

I contribute to the material turn in the human sciences by creating a dialogue between objectoriented and socio-cultural approaches to public dispute. First, I focus on the differences between object-oriented and socio-cultural theories by examining their approaches to culture and nonhumans. I suggest that object-oriented theories tend to prioritise action over wider cultural contexts that constrain action, while socio-cultural approaches tend to reduce nonhumans and material artifacts to discourse or sign systems. Second, I discuss how, in contrast to other socio-cultural approaches to public dispute, Boltanski and Thévenot's pragmatic sociology balances action and culture without reducing the importance of nonhumans and material artifacts to discourse. Finally, I suggest that focusing the diverse 
cultural modes of evaluation that influence public debates can be a useful addition to objectoriented studies of socio-technical controversies.

STS theorists have helped broaden the issue of political representation by foregrounding the objects of concern that animate controversies and assemble publics, but object-oriented theories tend to downplay the diverse cultural modes of evaluation that underpin the public's engagement with, and evaluation of, objects of concern. This is somewhat surprising because the idea of culture has been central to the development of the social construction of technology theories (Bijker, Hughes, \& Pinch, 1987), the sociology of scientific knowledge (SSK), and STS ethnographies that study the practice of science in relation to scientific culture (Knorr-Cetina, 1999; Latour \& Woolgar, 1986; Pickering, 1992b). Moreover, because of the theoretical diversity within STS some researchers have applied STS concepts to other areas of life outside of the laboratory (see Magaudda, 2013, p. 5). However, as I will discuss, focusing on culture as a resource tends to reinforce the divide between STS and cultural sociology by downplaying the idea that culture can enable and constrain action.

By focusing on the resources that actors mobilise during a controversy, object-oriented theories of public dispute tend to adopt an instrumental and strategic understanding of culture. For example, in ANT there is a tendency to study culture as a resource that enables action rather than a wider context or set of norms that influences scientific practice (see Asdal, 2012). This is because the idea of culture as a wider context that constrains action can create a problematic separation of science from society and can also overlook the nuances of scientific practice by prioritising all-encompassing cultural, historical, or social explanations (Latour \& Woolgar, 1986, p. 32). Focusing on culture as a resource allows STS researchers to examine how actors construct knowledge claims and support their findings. For example, in relation to scientific practice in laboratories, Pickering (1992a, p. 3) suggests that culture "denotes the field of resources that scientists draw upon in their work".

The idea of culture as a wider context can be problematic, but an exclusive focus on culture as a resource can overlook how it constrains action. I agree with Latour and Woolgar's (1986) suggestion that culture and society tend to be used as off-the-shelf explanations for action, but focusing on culture in relation to resources and strategy can imply that it is simply a set of cognitive tools that are selected by individuals during the course of a dispute (Thévenot, 2007, p. 410). Also, an exclusive focus on cultural resources suggests that it does not motivate actions that are driven by ideals and values, but is simply used for situational purposes ( $\mathrm{P}$. Smith, 2001, p. 64). Since the "cultural turn" in sociology, which began in the 1970s, cultural 
sociologists have emphasised the importance of sign systems and social classifications in shaping social action and influencing how people interpret and engage with public issues (Nash, 2010, p. 30). Rather than simply being one aspect of social life, many sociologists of culture now examine how it is constitutive of social reality and political life (Nash, 2010, p. 31). For example, Moody and Thévenot (2000, p. 274) suggest that focusing on culture as a resource that is used strategically tends to reduce it to "the instrumental manipulation of language and arguments to mobilize support, without examining the practical constraints on this manipulation or its context". Similarly, Alexander (2003, p. 12) agrees that culture is a type of resource, but suggests that tying culture to instrumental strategies can mean that it becomes a dependent variable rather than "an 'independent variable' that possess a relative autonomy in shaping actions and institutions, providing inputs every bit as vital as more material or instrumental forces". Therefore, the different emphases placed on culture as a resource or a context/classification system in sociological studies of controversies appears to have reinforced the boundaries between object-oriented and socio-cultural approaches to public dispute.

In addition to the issue of culture, I suggest that divergent understandings of the role of nonhumans and material artifacts in controversies has reinforced the divide between objectoriented and socio-cultural theories of dispute. As the name suggests, object-oriented theorists emphasise the important role that objects, things, and nonhumans play in controversies. This decision to focus on the human and nonhuman aspects of dispute has been inspired by David Bloor's (1976, p. 7) principle of symmetry, which states that the researcher should explain true and false beliefs using the same type of explanation or cause. Bloor's principle of symmetry has been expanded within object-oriented theories of dispute to examine not only conflicting viewpoints, but also the study of associations. Callon's (1986) notion of generalised symmetry extends Bloor's principle to the study of networks or associations. This means that the researcher should not prioritise social and cultural elements over nonhumans, materials, and devices when studying controversies and the making of actor-networks (Law, 1987, p. 130). While the idea of symmetry has many implications for sociological research, one implication that is relevant to the study of disputes is that material artifacts should not simply be treated as things that need to be (socially) explained. Depending on the controversy or study, material artifacts can be treated as actors that do not simply prop up more meaningful human activity, but also permit, encourage or block a course of action (Latour, 2005b, p. 72). 
In contrast, socio-cultural approaches to public dispute tend to prioritise discourse and human action in controversies. By focusing on the idea that culture underpins and constrains meaningful human action, cultural and discursive theories of dispute tend to overlook the complex associations between humans, nonhumans, and objects. This oversight appears to be influenced, as Bennett (2005, p. 135) suggests, by "an implicit onto-story, wherein humans are radically distinguished from other entities, upon a scenography of subjects and objects, of active Mind and inert Matter". For example, Laclau and Mouffe's (2001) concept of articulation can help understand how diverse social groups, such as workers and environmentalists, are able to create alliances by linking or articulating their struggles. Laclau and Mouffe's theoretical approach is explained in more detail in Chapter Seven, but in very general terms, the concept of articulation highlights how demands from human actors are made equivalent through the production of empty signifiers that actors can identify with and attach their demands to (Griggs \& Howarth, 2008). However, the process of articulation, as Braun and Disch (2002, p. 509) highlight, is a 'modern' form of politics that assumes "humans and their words are the only actors".

Another example of an asymmetrical socio-cultural theory of dispute is Alexander's American cultural sociology. In public discourse, Alexander and Smith (1993) suggest that people, social relationships, and institutions are rarely evaluated in isolation, but are linked when actors make public evaluations. Although non-human actors, devices, and materials play significant roles in assembling the social (Latour, 2005b), they suggest that society is underpinned by a set of binary codes that interrelate civil society actors, their relationships, and institutions "in a patterned and coherent way" (Alexander \& Smith, 1993, p. 161). For example, prominent civil society actors, such as Presidents, are not only evaluated in terms of whether they are 'rational', 'calm, and 'realistic', but also in terms of a discursive structure of civil relationships and institutions they are seen as responsible for (Alexander \& Smith, 1993, pp. 162-163). So it follows that a President who is democratically minded will be associated with 'open', 'trusting', and 'truthful' relationships and will 'create' institutions that are inclusive, rule governed, and impersonal (Alexander \& Smith, 1993, p. 163).

Beyond the problems associated with analyses that focus on binary themes (Lynch \& Bogen, 1996; McLennan, 2005), Alexander and Smith's (1993) approach to controversies does not refer to any nonhuman actors or artifacts. The purpose of their study was to illustrate their distinctive approach to the study of culture, but in doing so they reinforce the divide between STS and cultural sociology by adopting an asymmetrical sociology that divides human society 
and culture from the nonhuman world of 'nature' (Latour, 1993b). Alexander (2003, 2010) and other American cultural sociologists (Debs, 2012; P. Smith, 2003) have examined the relationship between culture and materiality, but their focus on how meanings are embedded in material forms continues to rest on, what Bennett (2005) calls, human-centred onto-stories. For example, Alexander (2003, p. 185) suggests that "we must learn to see technology as a discourse, as a sign system that is subject to semiotic constraints even as it is responsive to social and emotional demands". And Smith's (2003, p. 27) study of the guillotine as a punishment technology examines it as "a pivotal icon in the complex and overlapping, richly charged semiotic universes of both the Enlightenment and the Gothic". To clarify, I am not suggesting that American cultural sociology should adopt the notion of generalised symmetry. Rather, I suggest that a number of cultural sociological theories appear to reinforce the boundary between object-oriented and socio-cultural theories of dispute.

Of course, there are some similarities between socio-cultural and object-oriented theories of dispute. Both theoretical approaches highlight the importance of agency and the culturally specific resources that are mobilised in a dispute. And they also share anti-essentialist and constructionist approaches to the study of human and nonhuman worlds. However, their different understandings of culture and the nonhuman world highlights the differences between STS and cultural sociology (Magaudda, 2013).

\subsection{Object-Oriented Theories of Dispute and the Pragmatic Sociology of Critique}

Beyond the broad divergences between STS and cultural sociology, Boltanski and Thévenot's pragmatic sociology of critique (PSC) stands out in its attempt to bridge socio-cultural and object-oriented theories of dispute. Unlike discourse- and cultural-centric theories of dispute, Boltanski and Thévenot's pragmatic sociology provides a symmetrical study of disputes that focuses on wider cultural contexts without losing sight of how it is used strategically. Other researchers have also identified similar convergences between STS, ANT and Boltanski and Thévenot's pragmatic sociology (Bénatouïl, 1999; Blok, 2013; Guggenheim \& Potthast, 2012; Silber, 2003). Indeed, both Latour (1993, 2005) and Boltanski and Thévenot (2006) have commented on their similar understandings of the social world. I explore the epistemological points of convergence between these two theoretical approaches in Chapter Three, but in this section I outline Boltanski and Thévenot's pragmatic sociology of critique in relation to culture and the nonhuman world. 
The distinguishing feature of the pragmatic sociology of critique is its emphasis on justification and, of course, critique. These two concepts play a central role in their sociological theory because of their interest in examining situations of disagreement; that is, disputes. Indeed, Boltanski and Thévenot see the social world as if it were a scene of a trial (Boltanski, 2011, p. 25). In situations where people disagree, justifiable criticisms and common definitions of a situation are used to help coordinate action, avoid violent confrontations, and assess the worth or value of a person or thing (Boltanski \& Thévenot, 1999).

A justification, in Boltanski and Thévenot's theory, is not simply an argument or the framing of an issue, but is an appeal to a common good and principle of equivalence (or common definition) that is regarded as legitimate in a particular situation (Thévenot, 2007, p. 410). However, to develop a persuasive argument, disputants cannot simply mobilise broad appeals to a common good or principles of equivalence: they must also offer relevant proof and qualify people and things as being relevant to the type of common good being referred to. That is, disputants are subject to "reality tests" that examine the reality of the claims put forward (Boltanski, 2011, p. 105). Therefore, in Boltanski and Thévenot's sociology of critique, a justification refers to the process of making a particular viewpoint "generalizable and relevant for a common good, showing why or how this general claim is legitimate" (Thévenot et al., 2000, p. 236).

To examine how actors produce justifications that appeal to a common good while also offering relevant proof, Boltanski and Thévenot (2006) developed a theoretical model that identifies six "orders of worth" or modes of justification that operate in public disputes and various situations of disagreement. The six orders of worth refer to industrial, market, civic, opinion, domestic, and inspired modes of evaluation (Boltanski \& Thévenot, 1999, p. 368). Briefly, "market worth" justifications are based on price, cost, and market competitiveness; "industrial worth" justifications are based on technical efficiency, reliability, and planning; "civic worth" justifications are based on equality and solidarity; "domestic worth" is based on locality and tradition; "inspired worth" is based on emotion and inspiration or creativeness; and opinion or "renown worth" is based on public opinion and fame (Thévenot et al., 2000, pp. 240-252). Thévenot et al. (2000, p. 256) also suggest that there is an emerging "green worth" that is based on environmentalism or "green-ness". To clarify, the orders of worth are not simply different types of common good, but are "common worlds" that were identified in Boltanski and Thévenot's (1999, pp. 367-369) study of classical political philosophy texts 
and contemporary "handbooks or 'how to' guides to correct behaviour in modern companies". The common worlds have "diverse underlying principles of order ... [and] beings (persons and things) which inhabit these worlds" (Boltanski \& Thévenot, 1999, p. 369). For example, technical efficiency underpins the "industrial world" and the "worthy" beings that occupy this space are experts who are technically competent and objects that "are efficient, productive, operational” (Boltanski \& Thévenot, 1999, p. 373).

In contrast to a justification that appeals to a common good or principle of equivalence, a critique is a challenge to the legitimacy of a test. Critique is a creative process that involves actors' actively engaging in and evaluating a situation. A critique can be a "corrective" criticism of an existing trial system that aims to make it fairer or it can be a "radical" criticism that seeks to replace an existing testing system with a different type of test (Boltanski \& Chiapello, 2005a, p. 33). A corrective critique is internal to an order of worth or common world in the sense that it aims to increase the strictness of the test by revealing forces that are not relevant to the order of worth it is located in (Boltanski \& Thévenot, 1999). For example, a road project that is being assessed by an impartial judge can be critiqued if the judge is friends with the sponsor of the project or has connections to a lobby group. A radical critique, in contrast, is external to the testing system's common world. Because people and things exist in more than one common world it is possible to criticise a test from an alternative order of worth. Rather than trying to improve the fairness of the test, a radical critique questions the relevance of the test by highlighting that the people and objects intersect with multiple orders of worth (Boltanski \& Thévenot, 1999, p. 374). For instance, the testing system used for a road project might prioritise a test of transportation efficiency, but a disputant could denounce this test by arguing that a test of environmental sustainability is more appropriate. Due to the intersecting of the common worlds, a key issue for disputants is to reach an agreement by establishing a "compromise" between the different orders of worth. A compromise refers to "an attempt to make compatible two (or more) orders of worth within the process of justification" (Thévenot, 2002, p. 64). For instance, a road project can be qualified within industrial and environmental orders of worth if it improves transportation efficiency while also avoiding ecologically sensitive areas.

Modelling the process of how personal viewpoints are made general and relevant in a dispute helps to connect object-oriented and socio-cultural approaches to controversies by examining how the resources available to a disputant are influenced by the underlying orders of worth. Instead of an exclusive focus on culture as a resource that can help an actor gain an advantage 
in a dispute or "trial of strength" (Latour, 1987), the pragmatic sociology of critique examines how disputes are often organised as legitimate tests that are "subject to justificatory constraints" (Boltanski \& Chiapello, 2005a, p. 31). Boltanski and Chiapello (2005a) suggest that their understanding of dispute incorporates Latour's idea that every dispute is a test of strength that reveals how disputants attempt to gain an advantage. However, it also incorporates the idea that tests are also legitimate arrangements that make "it possible to compare particular individuals [and objects] using equivalence conventions that take into account only a single aspect of their existence" (Boltanski \& Chiapello, 2005b, p. 258). For example, in a transport planning dispute, competing road projects could be made equivalent in terms of a market test of economic investment and not a civic test of the health and welfare of local residents. By examining disputes as tests of strength and legitimacy, the researcher can bridge object-oriented theories that focus on the resources mobilised to secure an advantage in a dispute with socio-cultural theories that examine how culture underpins and constrains human action.

Boltanski and Thévenot's pragmatic sociology also helps bridge object-oriented and sociocultural approaches to dispute by providing a symmetrical theory that foregrounds the importance of human and nonhuman actors in a controversy. Unlike cultural sociological theories that socially explain material artifacts by examining their meanings, Boltanski and Thévenot investigate how people and things are aligned in ways that allow arguments to be supported and tested. Their approach to public dispute is symmetrical in the sense that objects and nonhumans are not simply empty signifiers that have meanings arbitrarily attached to them by human actors. For example, Thévenot (2002, p. 63) suggests that a road that is "qualified for the market is not simply a matter of labelling or rhetoric: it has significant consequences for the reality of the road - in terms of its width, its gradients, and its potential traffic load". The material relevance of objects aligns with ANT's central idea that nonhumans can encourage or block human action (Latour, 2005b, p. 72). However, Boltanski and Thévenot's sociology departs from ANT in the sense that they focus on the underlying orders of worth that influence how humans and nonhumans are aligned. For example, a road that is qualified for a market evaluation aligns humans as customers and nonhumans as marketable goods. The pragmatic sociology of critique, therefore, helps bridge object-oriented and socio-cultural theories of disputes by examining how humans and nonhumans are aligned and how they are qualified within competing criteria of evaluation (Lamont \& Thévenot, 2000, p. 7). 
Overall, I suggest that Boltanski and Thévenot's pragmatic sociology is a useful addition to the material turn in sociological studies of controversies. Their sociological approach helps provide a symmetrical theory of dispute that also foregrounds the importance of justification and the orders of worth that underpin socio-technical controversies. Specifically, the pragmatic sociology of critique can reveal the important role that evaluation and criticism play in debates that involve re-presenting objects of concern. Focusing on justification and actors' critical capacities helps bridge object-oriented and socio-cultural theories of dispute by striking a balance between (1) culture as a resource and culture as a constraint on action, and (2) nonhuman agency and the process of qualifying nonhumans within culturally diverse modes of evaluation.

\subsection{Overview of Theoretical Approach and Key Concepts}

In this thesis I will be drawing on a range of concepts from object-oriented and socio-cultural approaches to dispute. I primarily draw on ANT, STS, and the pragmatic sociology of critique, but I have remained open to alternative theoretical approaches that are able to illuminate issues that have not been adequately addressed by these theories. Specifically, I also draw on rhetorical theories of dispute to examine the populist appeals mobilised in the Kāpiti expressway controversy (Griggs \& Howarth, 2008; Laclau, 2005). Rather than examining the key concepts in this chapter, I outline and discuss my theoretical approach in the empirical chapters. However, to provide an overview of my theoretical approach I briefly outline the key concepts that I will use in each chapter.

In Chapter Four, I use Latour's (2005a) idea of “objects of concern"' and Boltanski and Thévenot's (2006) orders of worth framework to examine how residents and local groups engaged with the Kāpiti expressway project by qualifying it as an object of concern. In Chapter Five, I examine how the expressway project was publicised as an important issue by drawing on Barry's (2001) understanding of demonstration as a practice of making things publicly visible to others.

Chapter Six continues to focus on the importance of demonstration by discussing how the expressway project was visualised as a public issue. A number of concepts from the literature on visual representations in science and technology inform this discussion: Stark and Paravel's (2008) “tools of representation”, Rosental's (2013) “demo-models”, and Goodwin's

\footnotetext{
${ }^{2}$ Also known as "matters of concern" (Latour, 2004a).
} 
(1994) “professional vision”. However, I primarily draw on Boltanski and Thévenot's (1999) concept of "regimes of engagement" to understand how residents and local groups engaged with and evaluated the expressway project.

In Chapter Seven, I use Barry's (2013) idea of “public-making” and Marres’s (2012) concept of "material participation" to examine how public consultation techniques assemble publics and make them 'real'. This chapter also draws on Laclau's (2005) concept of populism and Barry's (2001) idea of technologies of politics to examine the modes of political engagement that underpinned the preferred option controversy.

Chapter Eight continues to drill down into the preferred option issue by examining how disputants enrolled allies to support or oppose the NZTA's preferred expressway alignment. This chapter primarily draws on Callon's (1986) sociology of translation and the associated concepts of problematisation, interessement, and enrolment. More generally, I discuss how Latour's (2005a) idea of objects of concern and re-presentation relates to human-centric theories of democratic representation. Finally, in Chapter Nine, I utilise Boltanski, Chiapello, and Thévenot's concepts of "criticism" and "trial" to examine the High Court appeal and the public critiques of the planning process.

\subsection{Conclusion}

In this chapter I have outlined a theoretical approach to socio-technical controversies that seeks to bridge object-oriented and socio-cultural theories of dispute. This theoretical approach informs my analysis of the Kāpiti expressway controversy and is used to create a constructive dialogue between STS and cultural sociological approaches to dispute. I started this chapter by outlining the increasing importance of public participation in issues involving science and technology. I connected my observation that the public are being asked to engage with specialist or technical problems with the current trend of involving the public in issues that have traditionally been dominated by experts. To examine the increasing importance of

public participation in science and technology, I compared proceduralist and social movement theories of political representation to, my preferred, object-oriented approach to representation, which is underpinned by a constructionist ontology and materialist understanding of public participation. I then outlined my contribution to the material turn in the human sciences by examining two points of tension between STS and cultural sociology: their conflicting views on the importance of culture as a resource for enabling action or a context that constrains action, and the importance assigned to nonhumans and material 
artifacts. In contrast to discourse-centred approaches to cultural sociology, I suggested that Boltanski and Thévenot's pragmatic sociology provides a symmetrical theory of dispute that overcomes the limitations of actor-centred understandings of culture without reducing the importance of nonhumans and material artifacts to discourse.

My study of the Kāpiti expressway, therefore, is underpinned by object-oriented theories that have been developed within STS and ANT, and Boltanski and Thévenot's sociology of dispute. I have also drawn on Laclau's rhetorical approach to public dispute as it illuminates an issue (populist modes of political engagement) that is not adequately addressed in Boltanski and Thévenot's theoretical framework. As this chapter has only provided an overview of the key concepts that will be used, each empirical chapter contains a section that explains the theories and concepts that I use to examine the Kāpiti expressway controversy. 


\section{Chapter Three: Methodology}

\subsection{Introduction}

In Chapter Two I discussed my theoretical approach to public involvement in socio-technical controversies by situating it within the material turn in the human sciences and outlining how object-oriented and socio-cultural theories of dispute understand the social world. This chapter continues to discuss the implications of utilising a materialist and actor-centred approach to socio-technical controversies by foregrounding the epistemological assumptions that inform my analysis. I then discuss the methodology that underpins my actor-centred approach to public involvement in the Kāpiti expressway project. Specifically, I outline my case study approach to public involvement in socio-technical controversies and the three methods that I will utilise: documentary research, interviews, and qualitative observations.

\subsection{Epistemological Assumptions}

My theoretical approach to public involvement in the Kāpiti expressway project is underpinned by a constructionist epistemology. Here, I identity two points of convergence within object-oriented theories of dispute (STS and ANT) and Boltanski and Thévenot's pragmatic sociology of critique (PSC): an understanding of controversies that foregrounds the role of objects and nonhumans in constructing publics and objects of concern; and a descriptive approach to controversies that highlights the critical capacities of the disputants. My discussion focuses on how these convergences underpin my analysis of public involvement in the Kāpiti expressway controversy.

As constructionism is a broad theory of knowledge that is defined in relation to the researcher's theoretical perspective, it is useful to understand the general meaning of this term. To use Crotty's (1998, p. 42) definition, constructionism can be described as "the view that all knowledge, and therefore all meaningful reality as such, is contingent upon human practices, being constructed in and out of interaction between human beings and their world, and developed and transmitted within an essentially social context". This means that, in contrast to realist or objectivist ${ }^{3}$ theories of knowledge, meaningful reality is "not discovered,

\footnotetext{
${ }^{3}$ Objectivism is closely aligned with positivism, which claims that reality exists independently from human consciousness and thought. Crotty (1998, pp. 5-6) defines objectivism as "the epistemological view that things exist as meaningful entities independently of consciousness and experience, that they have truth and meaning residing in them as objects ('objective' truth and meaning, therefore), and that careful (scientific?) research can attain that objective truth and meaning".
} 
but constructed ... through an interplay between subject and object" (Crotty, 1998, p. 9). In other words, "the world and objects in the world . . . are our partners in the generation of meaning" (Crotty, 1998, p. 44). Constructionism is closely aligned with qualitative research, but it differs from subjectivist, or post-modern, epistemologies that view meaningful reality as being created entirely within language and not from the complex relationship between subject and object (Crotty, 1998, p. 43).

Object-oriented and socio-cultural approaches to public dispute are both underpinned by a constructionist epistemology. Both of these theoretical approaches emphasise the important role that objects and non-humans play in constructing meaningful reality. Despite their theoretical differences regarding the primacy of social, cultural, historical, and material factors in constructing knowledge of the world (see Pickering, 1992), both ANT and STS agree that truth and knowledge are not simply 'discovered' through 'objective', scientific methods, but are constructed within negotiations between humans, actor-networks, and cultural and historical contexts. Similarly, Boltanski and Thévenot's socio-cultural approach to controversies is informed by a constructionist epistemology. Their pragmatic sociology highlights the importance of language and culture in creating meaningful reality, but it also highlights the connection between cognition and the material environment (Thévenot, 2001) and the role of objects in supporting arguments, providing relevant proof, and reaching agreement (Boltanski, 2011, p. 28).

This thesis is underpinned by a constructionist epistemology that foregrounds the relational and material construction of publics and objects of concern. In line with the constructionist approach to controversies outlined above, I assume that reality is not simply a 'social construction', but is an outcome of the heterogeneous associations that construct it. There is no common definition of constructionism within STS or ANT literatures, but Law's (2009) idea of a "material-semiotic sensibility" underpins my relational understanding of the Kāpiti expressway controversy. Like the semiotic study of signs, a material-semiotic understanding of reality suggests that everything, including people, are outcomes of their relationships and interactions with other things. This means that there is no 'essential' nature to reality because humans, non-humans, and things are constructed or made in a web of relations. For example, Law and Mol (1995, p. 277) claim that "objects, entities, actors, processes - all are semiotic effects ... [that] are interactively constituted; outside their interactions they have no existence, no reality". They use Callon's study of Électricité de France's electric vehicle to highlight the idea that it is "a set of relations between electrons, accumulators, fuel cells, 
laboratories, industrial companies, municipalities, and consumers; it is nothing more" (Law \& Mol, 1995, p. 277). In relation to the Kāpiti expressway, I will examine how it was not simply a material artifact designed by engineers, but also an alignment of human and nonhuman actors. Similarly, a range of devices and technologies made it possible for actors to publicise and qualify the expressway as an object of concern.

The idea that publics and society more generally are materially constructed is underpinned by the assumption that nonhumans play an important role in making and stabilising society. While the idea of nonhuman agency is controversial, the relationships between humans and nonhumans can be illustrated with Callon and Latour's (1981) observation that it is difficult for an actor to maintain power without material resources. Callon and Latour (1981) argue that social hierarchies in baboon societies (and other animal societies) are held together through face-to-face social interaction. This means that the power of the 'dominant' baboon is always under threat as they only have 'soft' resources, such as their physical strength or social skills. In contrast, human societies are held together with additional material and symbolic resources. A range of resources make it possible to organise people on a global scale (Law, 1987); enforce social divisions and rules (Latour, 1992; Winner, 1980); and stabilise institutions, such as multinational corporations (Callon \& Latour, 1981). In relation to this thesis, I discus how a range of devices and technologies materialise public participation in the Kāpiti expressway project. As I will examine, the NZTA's public consultation exercises did not simply inform the public, but also made them real by assembling them and measuring their opinions.

As I have discussed, object-oriented and socio-cultural approaches to public dispute are underpinned by a constructionist epistemology, but they also share an actor-centred understanding of how knowledge of the (constructed) world can be generated. It can be useful to highlight the distinctiveness of these two approaches to public dispute by comparing them to context-dependent social theories. Because there are many diverse theoretical perspectives that are informed by a constructionist epistemology, there is no agreed upon approach for generating knowledge of the social world. For instance, many sociological theories generate knowledge of the social by developing concepts and frameworks that reveal the social forces that structure society and shape people's beliefs, behaviours, and actions. That is, there is a tendency within sociological research to see the analyst as possessing a meta-language or social theory that actors do not possess (Latour, 2005b, p. 49). By developing a metalanguage, sociologists adopt a context-dependent approach to social research that explains or 
interprets social action by relating it to deeper economic, social, or cultural structures and contexts. Similarly, another type of context-dependent sociology, as Latour (2005b, p. 3) suggests, explains what other domains of knowledge (for instance, law, science, and biology) cannot account for by adding a 'social dimension' or explaining "the 'social aspects' of nonsocial phenomena".

In contrast, actor-centred approaches within STS, ANT, and PSC focus on how actors explain and interpret the social world. The starting point for these actor-centred theories is to focus on how the social is assembled or constructed. This means that ready-made concepts and social forces, such as capitalism, power, and patriarchy, should not simply be used to explain social action and the structure of society, but should be examined as phenomena to be explained. For example, both Boltanski (2011, p. 23) and Latour (2005b, p. 12) agree that focusing on powerful social forces that structure social life implies that sociologists already know in advance what they will find. As Latour (1986, p. 269) explains, sociologists can argue that "Reagan, Napoleon, the City of London, or capitalism 'have got power"', but this claim does not reveal how actors become powerful, macro-actors. By following the actors and tracing associations, sociologists can examine, for example, why large numbers of people obey, or do not obey, orders or how multinational corporations grow, or do not grow, in size (Latour, 1986, p. 269). Similarly, Boltanski (2011, p. 22) suggests that a focus on powerful structures can make it appear as if "everything seems decided in advance, [which means that] the very concept of action tends to become void of meaning".

\subsection{Case Study Design Frame}

To discuss why my thesis is underpinned by an actor-centred understanding of constructionism, I outline my case study approach to socio-technical controversies. A case study approach to public involvement in planning and socio-technical controversies is used to examine how residents and local groups engaged with and evaluated the Kāpiti expressway project. A case study is used as it can provide a detailed account of the public's involvement in controversies and because it is a widely used approach in studies of public participation in infrastructure projects, and science and technology. I briefly compare context-dependent and actor-centred case studies and then justify my decision to utilise an actor-centred approach in this thesis.

Case studies, as the name suggests, provide detailed accounts of an event, phenomenon, situation, or other subject. Providing a more precise definition of the case study can be 
problematic as it is not a method per se, but a design frame that can incorporate a wide variety of epistemological positions, methods and research techniques, such as interviews, surveys, and participant observation (Thomas, 2011, p. 512). In relation to sociological case studies, Burawoy (1991) suggests that a case study can be defined in relation to the level of analysis and the generalisability of a situation. On one end of the spectrum are context-dependent case studies that relate particular examples to a macro-social context. This means that the subject of a case study (for example, the Kāpiti expressway) could be examined as an instance of an analytical or theoretical frame (for example, public involvement in socio-technical controversies), which would be the object of the study (Thomas, 2011, p. 512). For example, Burawoy's (1998, p. 5) extended case method examines single case studies or situations "in order to extract the general from the unique". The implication of this approach is that a case only exists if it is interpreted or located in a wider context; that is, it should be a case of something (Thomas, 2011, p. 513).

In relation to case studies of infrastructure and transport projects, a number of studies have interpreted single infrastructure projects within the wider frame of democratic decisionmaking in planning processes. For instance, Flyvbjerg's (1998) urban planning and megaproject case studies tend to focus on how transparency and representative participation can help ensure that the public interest is protected (Flyvbjerg et al., 2002). Similarly, Figueroa's (2005) case study of a motorway project in Denmark focused on how protests against the motorway not only challenged the decision to construct the motorway, but also provided a prompt to improve democratic practices in the transport sector.

On the other end of the micro/macro and particular/general spectrum are actor-centred case studies that stay at the level of singularity. Actor-centred approaches, such as ethnomethodology, actor-network theory, and Boltanski and Thévenot's pragmatic sociology, examine particular cases in relation to an analytical frame, but they do not 'explain' their cases by referring to wider social forces (Latour, 2005b, p. 137). Focusing on the details of a particular case can reveal the unexpected and situated aspects of a phenomenon, which can be subordinated if the case is explained in relation to a wider context or deeper structure (Lynch \& Bogen, 1996, p. 270). In terms of responding to Thomas's (2011) idea that a case only exists if it is interpreted within a theoretical frame, action-centred approaches would argue that interpretation, context, and structures remain crucial in any case study. However, in action-centred case studies, these wider concerns are re-specified by examining how the actors themselves interpret events, and use theories and concepts (such as 'power' and 
'society') in a range of situations (Lynch \& Bogen, 1996). Moreover, interpretation can still play an important role in the research, but it is carried out without being crushed by a "powerful explanatory system" (Boltanski, 2011, p. 23). For instance, the Kāpiti expressway controversy could be located within the general context of public involvement in sociotechnical controversies. However, rather than explaining the public's involvement by referring to a wider political context, I will examine how the actors engaged with and evaluated the project by mobilising terms like 'democracy', and 'rubber stamping'.

As this thesis is focusing on how the actors engaged with and evaluated the Kāpiti expressway project, an actor-centred case study approach is utilised. There are several reasons why context-dependent approaches can be problematic when examining the dynamics of a public dispute. First, while context-dependent case studies provide insights into the politics of infrastructure projects, the complex alliances between human and nonhuman actors that are implicated in infrastructure disputes are often overlooked. In contrast, ANT and STS case studies tend to give equal attention to human and nonhuman actors (Latour, 1996; Sage et al., 2011). One problem with focusing on the human actors involved in a controversy is that it can suggest that there are clearly identifiable actors that 'determine' the outcome of the dispute. For example, case studies of road projects often foreground the conflicts between residents, lobby groups, and politicians. However, focusing on human actors does not capture the complex ways transportation projects align humans and nonhumans into a network. Suchman (2000), for example, uses an ethnographic approach to understand bridge-building as a persuasive performance, which, if successful, aligns humans and nonhumans.

Finally, focusing on a wider context can downplay the diverse range of arguments and strategies that are mobilised in socio-technical controversies. For example, Habermasian planning theories argue that transport planning decisions are dominated by a technical or instrumental rationality that reinforces unequal power relations and prioritises certain forms of knowledge (Mees \& Dodson, 2007). While it is important to highlight unequal power relations within disputes, it is also important to examine the other modes of evaluation that are mobilised in socio-technical controversies. For instance, Thévenot et al.'s (2000) case studies of the Somport road tunnel and Clavey River dam project revealed that disputants critiqued the projects from a range of environmental and cultural modes of evaluation. They argued that their action-centred case studies "involve[d] a great variety of modes and themes of argumentation, a wide range of innovative tactical interventions, and complicated arrangements of people and organizations" (Thévenot et al., 2000, p. 230). 


\subsubsection{The Kāpiti expressway as a case study}

Selecting a case or specific road project for this thesis was informed by Flyvbjerg's (2006) case selection strategy, which compares random selection strategies with information-oriented selection strategies. As I will be examining public evaluations of a road project it was important that information on the project, disputes, and decision-making process was publicly available. This meant that selecting a representative case from a random sample would not have been the best strategy. This is because typical cases, such as small-scale road projects, do not often face fierce public opposition or have a large collection of publicly available documents (Flyvbjerg, 2006, p. 229). Therefore, my strategy was to select a road project based on its information content and accessibility - in terms of publicly available information, being able to observe the controversies, and accessing participants.

Selecting a road project based on its information content narrowed the list to the Roads of National Significance (RoNS) programme. The RoNS programme has been selected because many of the projects have generated a high level of public interest and criticism. Moreover, when I started my research most of the projects were in the planning stages, which allowed me to follow the controversies as they happened. In 2009, New Zealand's National-led government announced that it was planning to build seven large highway projects at an estimated cost of 11 billion dollars. According to the New Zealand Transport Agency (NZTA, 2013), the Roads of National Significance programme is “one of New Zealand's biggest ever infrastructure projects". The seven projects, which will be built in New Zealand's largest cities, will either upgrade the existing roads or will construct new expressways. Each of the seven projects have been divided into sections or smaller projects. There are approximately twenty nine smaller projects or sections currently being built or planned. For instance, the Wellington Northern Corridor consists of eight sections: Wellington airport to Mt Victoria Tunnel, the Tunnel to Tunnel project, Terrace Tunnel Duplication, Aotea Quay to Ngauranga, Linden to MacKays (Transmission Gully), Kāpiti Expressway (MacKays to Peka Peka and Peka Peka to Otaki), and Otaki to Levin.

To ensure that the selected case could be accessed and observed an "extreme", conflict filled case has been selected (Flyvbjerg, 2006). Flyvbjerg (2006, p. 230) argues that when researchers need to obtain a large amount of information, extreme cases can be an appropriate research strategy as "they activate more actors and more basic mechanisms in the situation studied". An extreme case allows me to examine the dynamics of a dispute and the range of actions and evaluations that were utilised by the disputants. 
Of course, other types of cases could have been selected. In addition to extreme cases, Flyvbjerg (2006) suggests that there are also maximum variation cases, critical cases, and paradigmatic cases. Maximum variation cases can be used to compare and contrast cases based on one dimension (for example, comparing the social impacts of the RoNS projects). Because of my focus on an in-depth analysis of the public's involvement in a socio-technical controversy, comparing and contrasting different examples would shift the aims and objectives of my research. Moreover, because of the size and complexity of large road projects, in-depth analyses of multiple projects would not be feasible in a two to three year time frame and with limited resources. For example, the NZTA's application for the resource consents for the Kāpiti expressway was approximately 7000 pages. Additionally, there were over 700 submissions to the Board of Inquiry, and over 300 media items on the expressway were published between 2009 and 2013.

A critical case could also be used to examine public involvement in socio-technical controversies. Flyvbjerg (2006, p. 229) defines a critical case "as having strategic importance in relation to the general problem". Critical cases enable the researcher to make logical deductions and generalisations. For example, I could make the following generalisation about the Kāpiti expressway project: "if public engagement in the Kāpiti expressway is high, then it must also be high in the other RoNS projects". As I am not comparing the RoNS projects or making general statements, a critical case is not being used. Moreover, as Flyvbjerg (2006) notes, it can be problematic comparing cases because of the different variables and dynamics within each case. For example, Flyvbjerg's (2006, p. 231) study of urban planning in Aalborg found that the "Chamber of Industry and Commerce, was substantially stronger than their equivalents elsewhere".

Finally, a paradigmatic case could be used to "develop a metaphor or establish a school for the domain that the case concerns" (Flyvbjerg, 2006, p. 230). As this thesis will not be examining the Kāpiti expressway as a metaphor or as a foundation for a new theory, a paradigmatic case selection strategy has not been used. Moreover, determining the metaphorical or prototypical value of a case can be problematic as no standard or rule-based criteria exist for doing so (Flyvbjerg, 2006, p. 232).

The Kāpiti expressway project has been selected as an extreme case because of its close proximity to Wellington and the high level of public involvement in the planning process. First, while almost all of the RoNS projects are controversial, the Kāpiti expressway project generated substantial controversy in the media and a high number (approximately 725) of 
submissions to the Board of Inquiry. Also, the Kāpiti expressway is located on a route that was 'earmarked' for the smaller Western Link Road or 'WLR' (a two-lane road). When the WLR project was put on hold in response to the government's RoNS programme in 2009, many residents and local groups became active opponents of the expressway project. This is because they were anticipating a smaller two-lane road, rather than a high-speed, four-lane expressway. In the 1990s, there were debates over whether State Highway 1 should be relocated to the urban, 'Sandhills route'. Based on their discussions and publications, Transit New Zealand and the Kāpiti Coast District Council (KCDC) decided to plan a local arterial road on this urban route (James, 2012). In 2006 the Western Link Road designation was confirmed by the Environment Court and based on further design work the road type was limited to two lanes (James, 2012, p. 13). By 2009, the Western Link Road (WLR) project had gained regional consents for its construction and was in its final design stages.

Second, the urban location of the Kāpiti expressway has been controversial because of the scale of the project. When built, the expressway will have a very visible presence in the communities along the Kāpiti Coast. The urban, Sandhills corridor had been included in the district plans as a motorway designation since 1956. Initially, it was part of the proposed Wellington to Foxton Motorway, but it remained vacant as the state highway was built on the edge of the district - on a route that follows the railway corridor and the Tararua range. For many concerned residents, building a four-lane expressway on this urban route would literally divide their communities.

Finally, the Kāpiti expressway was the only project in the Wellington region at the time (early 2013) that was receiving a high level of scrutiny from residents and local groups. The Board of Inquiry were considering the evidence for and against the project and local groups were organising protests and various publicity campaigns. Moreover, the local groups and residents had been actively opposing the project since it was first announced in 2009 and the project was receiving weekly coverage in local media outlets. At the time, the Kāpiti expressway appeared to be an extreme case that could illuminate the issue of public involvement in sociotechnical controversies.

\subsubsection{Public involvement in the Kāpiti expressway controversy}

Although there were a variety of actors, organisations, and groups involved in the project, I focus on the local groups that had been actively opposing the expressway since 2009. The meaning of the term 'public' is discussed in other chapters, but in terms of the selection of 
participants, I have used it to refer to the residents of Kāpiti, local opposition groups, and community groups that were involved in the project. This meant that I excluded political actors (such as politicians and councillors), lobby groups (for example, the Automobile Association), institutions, and local businesses. I focus on the actions of local groups as the aim of the thesis is to examine the public's involvement in the controversy. Local groups, rather than individual residents, were selected because of their public visibility in the dispute. The local groups organised public meetings, protests, and made legal appeals, which meant that I was able to observe their actions and collect a large archive of public documents on them. While not all residents and groups were publicly involved in the project, I identified approximately thirty community and opposition groups that publicly opposed the project.

Specifically, I will focus on Save Kāpiti and, to a lesser extent, The Alliance for a Sustainable Kāpiti (ASK) and the Raumati South Residents Association. I examine the actions of these groups as they appeared to be the most well-resourced and vocal opponents of the expressway project. I have also interviewed residents and people who have been involved with the opposition groups and who have also made submissions to the Board of Inquiry. The purpose of these interviews was to provide context for the discussion and to find out how the public engaged with the project, enrolled allies, and evaluated the expert evidence, and planning process.

Iwi groups also played a very active role as participants and opponents of the project, but focusing on Māori participation in planning controversies and RMA processes would take me beyond the aims of my research. As tangata whenua (the people of the land), Māori play a key role in all government policies and plans. The Treaty of Waitangi is a key document in the Resource Management Act as "all persons exercising functions and powers under it, in relation to managing the use, development, and protection of natural and physical resources, shall take into account the principles of the Treaty of Waitangi (Te Tiriti o Waitangi)" (Resource Management Act, No. 69, 1991, p. 60). The important issue of Māori consultation and participation in planning processes and the management of resources was a very significant issue, but, as a central research theme, it is beyond the scope of this thesis. Instead, I discuss the involvement of Māori and iwi groups in relation to the actions of the local oppositions groups. This approach will help illuminate the importance of Māori in land-use and planning controversies while keeping my research focused on the aims and questions of the thesis. 


\subsection{Qualitative Research Methods}

The following research methods have been used to examine the public's involvement in the Kāpiti expressway controversy: documentary research, qualitative observations, and in-depth interviews. In this section I outline the three research methods that are being utilised in relation to sampling, the recruitment of participants, and ethical considerations. I then discuss how documentary research and interviews relate to object-oriented and socio-cultural approaches to public dispute.

\subsubsection{Documentary research}

Documentary research is used in this research to examine the content of the disputes and the resources that were mobilised by disputants. Specifically, I identify and examine the controversies that surfaced during the planning process. I also analyse how documents and audio-visual material were an integral part of the disputes and public engagement with the project.

My approach to documentary research focuses on what Prior (2008) calls documents as "resource". Prior suggests that two influential approaches to document analysis in the social sciences are documents as resource and documents as "topic". To analyse documents as a topic, social researchers can examine how the content of documents are produced. For example, Foucaultian approaches to discourse focus on how the content of a text is produced within discursive formations or historical forms of knowledge and technologies that influence what can be said on a certain topic. Alternatively, according to Prior (2008, p. 825), researchers can also examine "how documents function in, and impact on, schemes of social interaction and social organisation". That is, rather than examining the content of a document, researchers can examine documents as actors that play an active role in organising activities, interactions, and the development and maintenance of networks (Prior, 2008, p. 828). While researching documents as topic can be useful, my approach does not focus on the production of content/knowledge or documents as actors. My focus on public involvement in the Kāpiti expressway controversy means that I will examine documents as resources that can be evaluated, critiqued, and used to engage with the project.

Like documents as topic, Prior (2008) categorises research approaches that focus on documents as resource in terms of their content and use/function. Focusing on the content of a document can be used to discuss "what is 'in' the document" (Prior, 2008, p. 825). For 
instance, to understand how disputants evaluated the expressway project I have examined the content of the publicly available documents in order to discuss how the project was described, represented, and evaluated. Moreover, focusing on the use or function of documents can be used to discuss how "documents are used as resources by human actors for purposeful ends" (Prior, 2008, p. 825). For instance, documents and audio-visual displays played an important role in critiquing the expressway project and re-presenting it as an object of concern.

At first glance, examining the content and function of documents appears to have an affinity to socio-cultural approaches to public dispute, but not with object-oriented approaches. Examining the content of documents is an important aspect of socio-cultural research as it allows researchers to examine the modes of justification and arguments mobilised by the disputants (Thévenot et al., 2000, p. 236). However, in relation to object-oriented theories, focusing on documents as a resource used by human actors could overlook the active role that documents can play in controversies (Prior, 2008). For example, Rydin's (2013, p. 40) study of a low-carbon commercial development argued that the planning documents played an important role in "mediating and defining the relationships between planners, within and across local authorities, here enabling the GLA [(Greater London Authority)] to govern at a distance".

Focusing on the content of documents can overshadow the active role of documents, but examining documents as a resource remains an important approach within object-oriented and socio-cultural analyses of disputes. In relation to object-oriented studies, documents provide a record of the actors, associations, and heterogeneous (social, economic, technical, and so on) factors that contributed to the success, failure or shaping of a technology (Guy \& Karvonen, 2011). To clarify, analysing the content of a document does not simply mean that documents are analysed as reports on an event, but as an "enactment" of reality (Nimmo, 2011, p. 114). For example, the Kāpiti expressway project was not simply a road, but also a proposed alignment of human and nonhuman actors that was outlined in a large archive of documents. As Nimmo (2011) explains:

... texts are not dislocated from practice but are intrinsic to practices - indeed there is scarcely a practice in the modern world which does not have its accompanying texts, often a panoply of texts, without which the practice would be deprived of the oxygen of its networks. (p. 114) 
To investigate the Kāpiti expressway documents as a resource I analyse the documents and statements that have been released publicly by the people and organisations involved in the dispute. As a first step, I collected an archive of approximately 1,300 primary and secondary sources; namely, publicly available documents, audio-visual material, and statements produced by the actors involved in the project (primary sources), and reports from journalists who have documented the dispute and conducted interviews (secondary sources). The purpose of this exercise was to familiarise myself with the expressway project, and identify controversies and issues that could be analysed in relation to the research aim of public involvement in socio-technical controversies.

First, publicly available documents, evidence, and web-based resources that were produced from opposition groups and as part of the public consultation and planning process, Board of Inquiry, and High Court case are examined in relation to the dynamics of the controversy. I am unsure of the exact number of publicly available documents produced by the actors involved in the project as this involves deciding whether to include the documents that were published before the 2009 announcement of the project or after the decision to start construction in late 2013. However, for the years 2008 to 2013, I collected 962 documents.

Second, I collected audio-visual material produced by the public and the NZTA. I examine the audio-visual material in order to discuss the anti-expressway protests and how the potential impacts of the expressway were made visible to the public and relevant authorities. I focus on the NZTA's visual fly-through simulation and images displayed in their consultation brochures and information centre. I then compare it to a documentary produced by a local resident and several short videos and images that were uploaded to video-sharing websites and the websites of local opposition groups. To examine the anti-expressway protests that were held during my fieldwork (2013-2014) I rely on my own photographs of the events, but for the protests organised pre-2013 I have used publicly available images of the 2011 Waikanae railway station protest and an anti-expressway rally in Wellington.

Finally, I identified and collected public evaluations of the expressway project from news articles, letters to the editor, news wires, and government press releases. I selected 348 media items from the 1st of January 2009 to the 31st of December 2013 from the Newztext database using the key words "Kāpiti expressway".

To identify controversies and issues that surfaced in the media, I used a descriptive coding technique to organise the data into topics. Descriptive coding, as described by Saldana (2009, 
p. 70), "summarizes in a word or short phrase ... the basic topic of a passage of qualitative data". This coding method helped establish a foundation for further analysis of each topic. Opinions on the road project were assigned with descriptive codes using NVivo's qualitative data analysis software (opinions, descriptions and summaries from journalists were excluded from the analysis). Focusing on the opinions of the disputants involved in the project meant that I coded "lumps" of text (statements, sentences or paragraphs), rather than "splitting" or coding every line in the text (Saldana, 2009, p. 19). The selected codes were then compared and placed into broad categories and have been used to explore the research aims. To help avoid some of the limitations of relying on media reports, I compare, where appropriate, the topics identified in media reports with the documents produced by the NZTA and opposition groups. By identifying broad categories and topics with a descriptive coding method I was able to analyse each topic in relation to object-oriented and discourse-centred approaches to public involvement in socio-technical controversies.

There are limitations of using media reports to identify controversies as news articles tend to either focus on 'popular' controversies, scandals, rumours, or sensationalise issues to attract public interest. However, as I am discussing how the expressway was evaluated and publicised as an object of concern it is important to examine the stories that were published by digital and print media. In order to minimise the likelihood of identifying sensationalised controversies that were identified by a particular journalist as important I have coded direct quotes or paraphrased statements from people that appear in the news articles in order to identify recurring themes or concerns. While this does not avoid the issue that journalists use quotes or public statements selectively, the themes that I have identified do not simply reflect the interests of specific journalists because I have also crosschecked them with the NZTA's public consultation reports, the Board of Inquiry documents, and the web-sites of local opposition groups.

\subsubsection{Semi-structured interviews and qualitative observations}

Interviews and qualitative observations are also utilised to crosscheck and uncover any issues that did not surface in the published documents. Flyvbjerg (1997, p. 13) suggests that interviews and qualitative observations can help provide insights that are not found in official documents by uncovering the "non-discursive elements in the case, i.e., elements that had not previously been the subject of discourse but that were nevertheless important to the outcome of the case". In other words, talking to and observing the actors in the dispute can help the 
researcher understand what happened and why (Mabry, 2008, p. 218). In relation to this thesis, interviews and observations can help reveal details about proposed motorway projects that cannot be obtained from documentary research. By interviewing residents and opposition groups I was able to find out how they engaged with the project and their reasons for opposing it. Similarly, by observing the protests, High Court case, and other events I was able to provide a rich description of the key events, talk to people involved in the project, and observe aspects of the controversy as they happened. Observing the controversies and talking to the disputants helps respond to the criticism that "the analysis of 'mute' texts . . . [is] a poor substitute for interaction with reflexive subjects and 'proper' ethnographic observation of lived practices" (Nimmo, 2011, p. 113).

Observation and interview methods are also used to understand and describe how public involvement in the Kāpiti expressway controversy is accomplished. Interviewing disputants and observing key events helps describe the range of actions, actors, and objects that materialise and enact public concern with the expressway project. I use these two methods to create what Latour (2005b, p. 129) calls a narrative where the actors "achieve the social". In other words, each participant is treated as an unpredictable mediator that 'does something' rather than a passive intermediary that 'just sits there' (Latour, 2005b, p. 128). Moreover, observing the protests and events is used in this thesis to describe the "styles of expression" (Thévenot et al., 2000) or "repertories of contention" used to oppose the expressway (Tilly \& Tarrow, 2007).

Ten semi-structured interviews with residents and local groups involved in the expressway project were conducted during 2013-2014. The interviews were approximately one hour in duration and were conducted face-to-face. Additionally, the interviews were audio recorded and transcribed. The interview questions focus on the themes of the research. Specifically, I asked participants to talk about their opinions on the proposed motorway projects, their reasons for supporting or opposing them, their personal interest in the projects, the potential impact of the expressway on their community, and their thoughts on the public consultation and decision making processes.

Interviewees were selected from opposition groups using snowball sampling. A snowball sample involves participants referring people they know to the researcher. I was referred to potential interviewees by emailing an information sheet to three of the main locally-based opposition groups. This approach helped me locate and access residents who had been involved in the project. Due to confidentiality, I cannot identify the residents that I 
interviewed, but all my participants had been involved in the planning and consultation process and almost all of them had submitted evidence to the Board of Inquiry. However, I did conduct one named interview with the environmental group Generation Zero. I interviewed a member of this group because he was working closely with local opposition groups.

One potential problem with my decision to only interview residents and opposition groups involved in the project is that I can only provide a one-sided perspective of public involvement in the expressway controversy. My initial plan was to interview a diverse range of actors involved in the project, but as my research became focused on the issue of public involvement in socio-technical controversies I decided to only interview residents and opposition groups. Due to the complexity of the expressway project, the large archive of documents, and the considerable public opposition to the project it was not feasible for me to interview a representative sample of political actors, experts, and residents. Focusing on the opposition groups and residents associated with these groups was more manageable and has allowed me to provide an in-depth analysis of the actions and evaluations used by these groups.

Ethical approval for my research has been granted by the Social and Cultural Studies Human Ethics Sub-Committee. Participants were given the opportunity to not discuss any issues they felt uncomfortable talking about and informed consent was obtained through a signed consent form. Most of the interviews were confidential and the identities of the participants have been concealed. Some interviewees agreed to a non-confidential interview so that I could attribute a justification or opinion to an individual and/or organisation. However, I have not attributed personally sensitive information to an individual or organisation.

In addition to semi-structured interviews, I observed three protests, an all-day expressway hui, a High Court case, and a two-day social impact assessment conference. Using a list of key research themes and prompt questions, I recorded my observations in a notebook using a “jotted fieldnotes" technique. Tolich and Davidson (1998) describe jotted fieldnotes as a way of recording observations as they happen. The researcher uses his or her list of questions and themes for guidance and then jots down "as much information as possible, even if it seems nonsensical" (Tolich \& Davidson, 1998, p. 129). After attending the protests and meetings, I expanded my jotted notes by using complete sentences, adding reflective comments, and relating my notes to the themes of the research. 
I observed these events with the intention of being a nonparticipant. Because I wanted to focus on how the public engaged with and evaluated the expressway project I believed that not participating would be an appropriate strategy. However, the line between participant and nonparticipant was blurred when I attended these events. As I had interviewed some of the people present at the events I was unable to remain distant from the events I observed. By talking to locally based groups and residents at the events and disclosing my identity as a $\mathrm{PhD}$ researcher at the expressway hui I became, in a very small way, a participant in the events. However, as I attended these events as an observer rather than a participant I do not believe I had a significant influence of the types of action and arguments that I observed.

In relation to ethics, the observations used in this thesis do not identify or name any specific individuals. As the protests and meetings I attended were public events attended by a relatively large number of people (approximately fifty to one hundred), it was not practical or possible to obtain informed consent from all the attendees. To avoid or minimise any ethical issues from arising my observations are at, what Guest, Namey, and Mitchell (2013, p. 102) call, "the level of public behaviour - public speech, [and] the movements of people through the space and time of the event". No personal or private conversations were recorded or included in the thesis.

As I started this thesis in the final stages of the expressway planning process, I decided not to undertake an intensive ethnographic or participant-observation fieldwork. The time involved in obtaining ethical approval and formulating an appropriate research strategy meant that I was unable to conduct an in-depth ethnographic study. While ethnographies are commonly used in STS and ANT studies that research the making of science and technology, I focused on observing the events described above. The weakness of 'only' being able to observe these events is counterbalanced by my in-depth interviews and analysis of the large archive of documents and audio-visual material. By combining qualitative observations with interviews and document analysis I had a large, and almost overwhelming, amount of information to understand and examine.

\subsection{Conclusion}

As I have discussed, my methodology is underpinned by a constructionist epistemology and an actor-centred approach to socio-technical controversies. I identified two points of convergence between objected-oriented and socio-cultural theories of dispute: a constructionist epistemology that foregrounds the relational and material construction of 
reality and an actor-centred approach to knowledge generation that describes how actors explain and interpret the social world. Having identified two epistemological assumptions that inform my research, I then discussed why an actor-centred case study approach was used to research the Kāpiti expressway controversy. Although case studies are almost the default method for studying socio-technical controversies, I discussed how my actor-centred approach is useful for examining how actors engaged with and evaluated the Kāpiti expressway project. In relation to public involvement in the expressway project, the actions of three local groups will be examined: Save Kāpiti, ASK, and Raumati South Residents association.

In addition to a case study research design, I discussed how documentary research, qualitative observations, and in-depth interviews are being used to examine the public's involvement in the expressway controversy. Because of the large number of documents produced during the controversy and as part of the project, I will analyse published documents and statements to find out how disputants evaluated the expressway and to discuss the important role that they played in re-presenting the project as an object of concern. To uncover any issues that did not surface in the published documents, I will use qualitative observations and in-depth interviews to crosscheck the documents that I analyse. Moreover, I utilise observations and interviews to help examine how public concern with the expressway project is materialised and enacted. In the next chapter (Chapter Four), I map the dynamics of public involvement in the expressway project by identifying the controversies that surfaced during the planning stages of the project. This chapter sets the scene for the rest of the thesis by providing an overview of how local groups evaluated and publicised the expressway as an object of concern. 


\section{Chapter Four: A Road of National Concern}

\subsection{Introduction}

This chapter sets the scene for the rest of the thesis by outlining the controversies at the start and end of the consultation phases for the Kāpiti expressway project. To examine how the public engaged with the project over a four year period I compare the controversies that surfaced during the 2009-2010 planning phase with the Board of Inquiry in 2012-2013. I am interested in how concerned residents and opposition groups translated their initial reactions to the project in 2009-2010 as legal and technical issues with the design and planning of the expressway. Specifically, I am interested in how concerned citizens related their initial concerns to the Board of Inquiry's legal tests by providing proof that they were relevant to civic and industrial orders of worth.

Focusing on a local advocacy group, Save Kāpiti, I explore how they engaged with the various environmental, political, social, and techno-scientific issues that surrounded the proposed expressway project. While public participation in political controversies is a common practice, I am interested in how public participation is sustained as controversies become focused on "technicalities" or the scientific and technical literatures that are used to transform opinions into fact-like statements (Latour, 1987, p. 30). If the public engaged with the Kāpiti expressway project by re-presenting it as an object of collective concern, how do they sustain their arguments as the project becomes focused on technicalities?

To answer this question I draw on object-oriented and socio-cultural approaches to public involvement in political and socio-technical controversies. A key aspect of the public's involvement in the Kāpiti expressway project was their attempts to publicly re-present the expressway as an object of collective concern. As Latour (2005a, p. 16) suggests,

representation means not only ensuring that certain groups are gathered around an issue using the 'right' procedures, but also re-presenting "the object of concern to the eyes and ears of those who have been assembled around it". As discussed in Chapter Two, the significance of object-oriented approaches to public involvement in socio-technical controversies is that representation is expanded to include the re-presentation of objects and other beings as contested entities (Marres, 2007, p. 760). However, I also draw on Boltanski and Thévenot's socio-cultural approach to controversies by examining how the opponents made their initial concerns with the environmental, political, and social impacts of the project relevant to the legal and technical aspects of the project. Boltanski and Thévenot's orders of worth 
framework reveals how the expressway project was qualified as an object of concern from within diverse cultural modes of evaluation.

I argue that, as the expressway project became focused on technicalities, the disputants were obliged to demonstrate how the social and political concerns were connected to the design and planning of the road. To demonstrate the social and political problems of building an expressway, the disputants were obliged to translate these concerns as technical problems that were significant in terms of the expressway's design. First, I provide an overview of public involvement in the Kāpiti expressway project. Second, I identify the initial controversies that surfaced in 2009 and discuss the idea that the public engaged with the project by evaluating it as an environmental, political, and social issue. Finally, I discuss how the submitters at the Board of Inquiry translated their social and political concerns as legal and technical issues.

\subsection{Public Involvement in the Kāpiti Expressway Project}

In 2009, the government announced that it was planning to build a new state highway through Kāpiti. Like other road projects, local residents were concerned that their homes would be destroyed and that the decision-making process was undemocratic. These concerns reflect a common understanding of controversies surrounding proposed road projects: that they are about locals trying to stop a particular road from being built in their community, near their residential property, or, in some cases, through their home or 'back yard'. A number of studies on freeway revolts and anti-roads protest groups suggest that a concern with perceived threats to community (Gotham, 1999; Mohl, 2004), place, and the environment (Doherty, 1999; North, 1998) are important strategies for mobilising and engaging people with proposed road projects and other contentious issues. Like these previous studies, I suggest that local residents and opposition groups initially engaged with the project based on their concern with the possible impact that the Kāpiti expressway would have on their community.

The idea of the public engaging with a proposed road project based on their concern with broader political issues or desire to protect their community seems to be an intuitive response. I identified a number of environmental, political, and social issues when I analysed media reports on the first phase of the Kāpiti expressway project. Based on a keyword search of the Newztext database, from the $1^{\text {st }}$ of January 2009 to the $31^{\text {st }}$ of December 2013, I identified approximately 348 news articles, letters to the editor, news wires, and government press releases that either focused on, or made reference to, the issues that surrounded the Kāpiti expressway project. 
I focus on the news reports that were published during the first phase of the project (from August 2009 to December 2009) to identify the initial controversies that surrounded the expressway during the public consultation stages. I then analyse the news reports that were published during the final planning phase of the project (January 2012 to December 2013) to identify the controversies that surfaced during the Board of Inquiry and High Court case and to discuss how the controversies shifted focus. To help avoid some of the limitations of using media reports as a data source, I also compare the controversies identified in the news media with the NZTA's public consultation reports and the concerns identified by Save Kāpiti.

There are limitations of using media reports to identify controversies as news articles tend to either focus on 'popular' controversies, scandals, rumours, or sensationalise issues to attract public interest. However, as I am discussing how the expressway was re-presented as an object of concern it is important to not only analyse documentary sources and interviews, but also to examine stories about the expressway that were published by digital and print media. In order to minimise the likelihood of identifying sensationalised controversies that were identified by a particular journalist as important, I have categorised direct quotes or paraphrased statements that appear in the news articles to help identify recurring themes and concerns. While this does not avoid the issue that journalists use quotes or public statements selectively, the themes that I have identified do not simply reflect the interests of specific journalists because I have also identified them in the NZTA's public consultation reports and the claims publicised by Save Kāpiti.

From the expressway project's initial announcement in August 2009 through to the end of 2009 I identified several environmental, political, and social issues. The environmental and social issues focused on the perceived impacts of the expressway, and the political issues revolved around the decision-making and public consultation process. I identified controversies surrounding the Transport Minister's personal motivation behind the expressway project, the 'fast tracking' process, 'rubber-stamping', public participation in the selection of a 'preferred option', and the democratic aspects of the public consultation process. I focus here on the initial controversies over the environmental and social impacts of the expressway and public participation in the selection of the preferred option as they are two interrelated controversies that illustrate how citizens made their initial concerns with the project relevant to the legal and technical aspects of the project. 
It seems inevitable that the various environmental, political, and social issues surrounding a public infrastructure project will become focused on technicalities, but I suggest that, initially, local residents believed that pointing out the social and political issues associated with the project would reveal the insurmountable weaknesses with the project. However, as the Board of Inquiry and High Court case revealed, the disputants were required to test what Boltanski (2011) calls the "reality" of their claims by qualifying them within industrial/technical and civic/legal orders of worth.

\subsection{The Social and Environmental Impacts of the Kāpiti Expressway}

In 2009, one of the first controversies surrounding the expressway to surface was the impact that it would have on residents and the local environment. When the NZTA first announced the project they had not selected a route for the expressway or developed detailed design plans. The first visuals provided by the NZTA in August 2009 were in the form of concept maps that indicated where the expressway might be located. The proposed expressway is represented by the red dotted lines in the images (see Figure 5). While these maps do not seem controversial, the lack of detail around what an expressway would look like in Kāpiti and where it would be located seemed to prompt local residents to question what impact the expressway would have on their lives.

In media reports the controversy over the impacts of the expressway was framed as a concern with the uncertainty surrounding the expressway's impact on local residents, property values, and the environment. Residents did not know if they would have to relocate, receive compensation, or what impact the road would have on their property values, homes, or community. People were also concerned with the issue of protecting important aspects of life that would be affected by the expressway. Local iwi were concerned with protecting a traditional right of way, which was used to carry coffins to a family cemetery, while other residents were concerned that the expressway would 'shatter' Kāpiti's 'heartland' (that is, its peri-urban and tranquil feel), and would have negative impacts on local businesses, tourist attractions, and ecologically sensitive areas. 

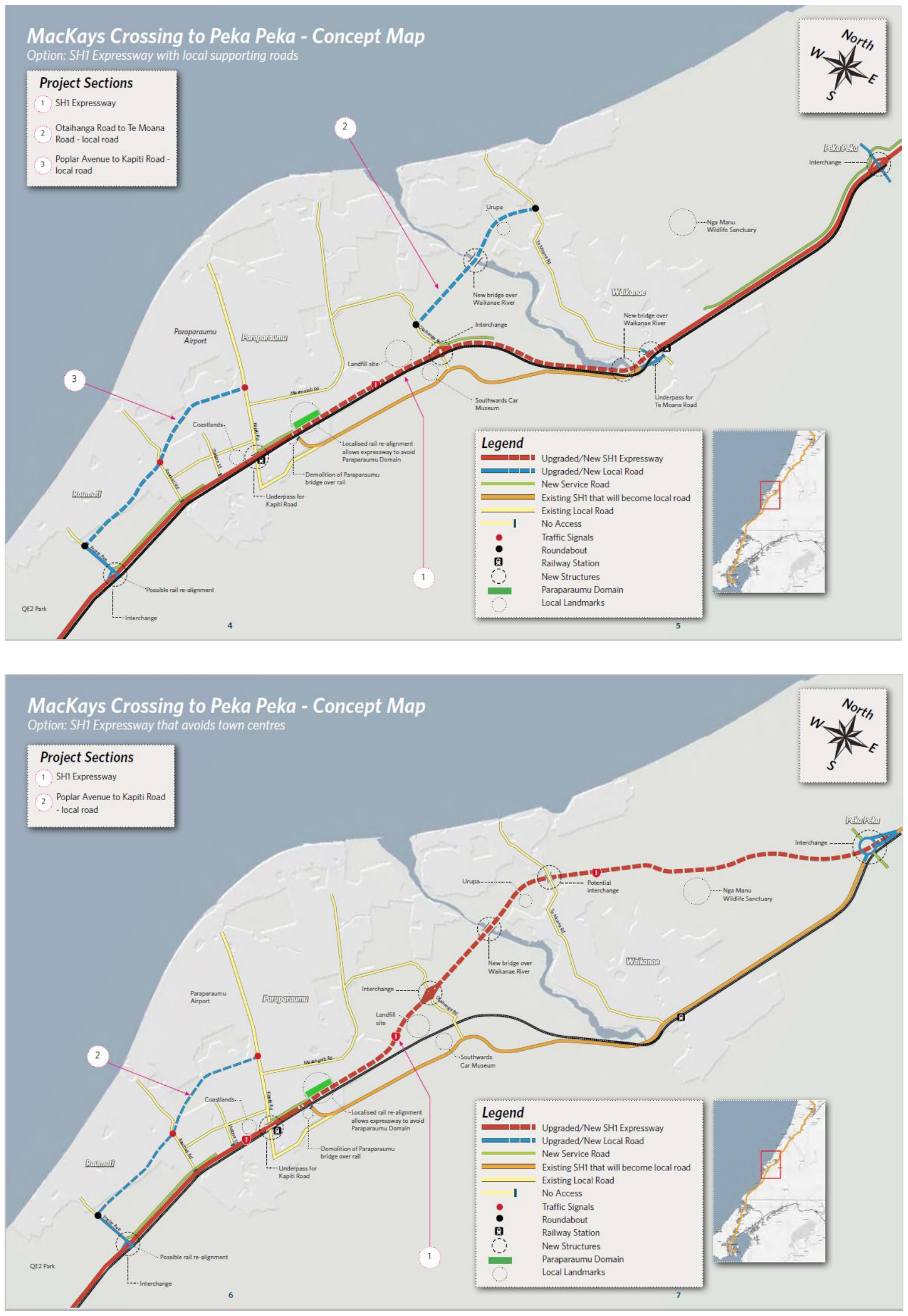

Figure 5. MacKays Crossing to Peka Peka - Concept map (New Zealand Transport Agency, 2009b, pp. 6-7). 
These concerns were not only raised in news articles by journalists interviewing distressed residents and in letters to the editor, but were also voiced by locals during public consultation. During the first phase of public consultation the NZTA received 4,446 submissions from feedback forms, emails, and phone calls (New Zealand Transport Agency, 2009a). 1,072 submissions commented on the expressway's impact on houses and property, and a further 1,747 submissions commented on the positive and negative impacts of the expressway (New Zealand Transport Agency, 2009a). While these comments on the impacts of the project could be connected to other submission themes, the NZTA's report indicates that this was an important issue during this phase of the project.

Similarly, Save Kāpiti's initial concern with the expressway, which they published on their website on the $23^{\text {rd }}$ of March 2010, focused on the social and environmental impacts of building an expressway through Kāpiti (Save Kāpiti, 2010). While Save Kāpiti listed a number of concerns that surrounded the expressway, such as the planning and decisionmaking process, their main concern at this time was their belief that an expressway on the land designated for the two-lane Western Link Road (WLR) would have detrimental effects on the environment and would divide local communities (Save Kāpiti, 2010). They argued that "the proposal will destroy the unity of the settlements on the Kāpiti Coast by brutally dividing the community" (Save Kāpiti, 2010). The idea that an expressway will 'destroy' social unity by physically dividing the communities on the Kāpiti Coast provides a powerful critique of the project. It helps highlight the idea that an expressway through the centre of Kāpiti would have adverse social impacts for many residents on the Kāpiti Coast. Moreover, Save Kāpiti's website highlighted that the project would have a significant environmental impact. They claimed that: "the commitment to enhance the environment of the Coast, to preserving its ecology, to maintaining its wetlands, and the implementation of the stringent environmental standards already in place for development practices, are all seriously threatened by the Expressway" (Save Kāpiti, 2010). This quote helps reinforce the idea that an expressway would threaten all aspects of life on the Kāpiti Coast: it would divide the communities and threaten the peri-urban environment.

To help strengthen their claim that the expressway would divide Kāpiti, and to mobilise support, Save Kāpiti and other opposition groups organised public meetings, protests, and other publicity material. I examine these events in Chapters Five and Seven, but the purpose of the meetings and protests was to point to the negative effects that the expressway would have on Kāpiti. Similarly, a number of Save Kāpiti's supporters made a documentary that 
explored the negative impacts of the expressway project. I examine this documentary in Chapter Six, but it was made to inform people about the project, mobilise action, and to raise funds for Save Kāpiti’s legal fees (Maxwell, 2011).

Not surprisingly, the belief that the expressway would be detrimental to the Kāpiti Coast was not shared by all residents. For example, in news articles on the expressway, one person critiqued arguments about the 'shattering' of Kāpiti as 'emotive nonsense' and a councillor suggested that an expressway would help create "economic growth and new jobs in Kāpiti, rather than it being a giant retirement village" (as cited in Blundell, 2009d, p. 2). These comments imply that the 'emotive' concerns from residents do not extend to the level of the public good as they are rhetorical appeals that help mobilise opposition and legitimise their self-interested goals. These criticisms highlight Moody and Thévenot's (2000, p. 276) idea that "extending the expression of one's interest beyond the particular to the general . . . is often necessary to give broad legitimacy to the group's claims". In this case, many residents did not believe that the arguments from the opposition groups extended beyond their personal interests in the project.

While the concerns from residents might appear self-interested, I suggest that their 'emotive' evaluations reveal that the public initially engaged with the expressway project by qualifying it as a public issue that is relevant to the civic, domestic, and green orders of worth.

Arguments that connect the expressway project to the threat of possible social dislocation and damage to Kāpiti's environment are relevant to these three orders of worth. The idea that the expressway would divide local communities is not simply emotive as it highlights the importance of collective welfare, community attachments and social networks in maintaining hierarchies of trust and respect for tradition/belonging, which are regarded as legitimate tests of worth within the civic and domestic worlds (Boltanski \& Thévenot, 1999). In the domestic order of worth, human beings are qualified as worthy subjects based on their dependencies to their estate, family, and lineage and any disruption to these dependencies can provide a powerful critique or evaluation of an issue. In contrast, the civic order of worth qualifies people as equal citizens that should not be denied access to important public facilities. For example, on Save Kāpiti's website, they claimed that the expressway would divide the communities on the Kāpiti Coast because "it will cut off present access to kindergartens, schools, swimming pools, parks, the beaches and, in short, the majority of the public facilities on the Coast" (Save Kāpiti, 2010). This quote points out that 'cutting' residents off from valued activities, facilities, institutions, and public spaces is problematic as it 'destroys' social 
unity within the community and threatens the welfare of local residents. Similarly, objects within these two worlds are qualified in terms of locality and heritage (domestic orders of worth) and in terms of rules, regulations, rights, and welfare policies (Thévenot et al., 2000). For instance, if an expressway threatens heritage and access, then it would not qualify as a worthy object in the domestic and civic worlds.

In relation to the environmental impacts of the expressway, the idea of protecting Kāpiti's environment provides a connection to the green order of worth, which assesses worth based on a test of sustainability or renewability (Thévenot et al., 2000). To qualify as a worthy object, an expressway would not harm the environment and would align with the environmental values of sustainability. If the expressway project threatens Kāpiti's ecology, wetlands, and environmental standards, then it can be critiqued from within the green order of worth.

The civic, domestic and green modes of evaluation utilised by residents and opposition groups illustrate how the public are able to challenge an issue that appears to be located within the market-industrial world. In this case, anti-expressway residents and groups seemed to engage with the Kāpiti expressway project by challenging the government's proposal to build a technically efficient road that supposedly improves economic development. From the government's perspective, the Kāpiti expressway is a "compromised" market-industrial road that meets their objectives of "moving people and freight between and within these centres more safely and efficiently ... [and enabling] economic growth rather than simply responding to it" (New Zealand Transport Agency, 2013). In economic terms, the government claims that the roads will deliver "faster, safer, lower cost freight links . . . [and] will deliver agglomeration benefits to businesses” (New Zealand Transport Agency, 2013). In this sense, the Kāpiti expressway, if I follow Thévenot's (2002, p. 64) argument, is a "compromised being" in the sense that it meets "the requirement for worth not only in market but also in industrial terms".

While this market-industrial expressway qualification is not uncommon, it seemed to be controversial as people were qualified as either road users who need to be transported 'safely and efficiently' or as business owners and customers who need to either enhance their interactions with other businesses/customers or have their freight delivered at a lower cost. Save Kāpiti and others did not disagree with these market-industrial qualifications in principle, but they were concerned that the focus on transporting people safely and efficiently 
would overshadow the importance of creating new community links, improving accessibility within local communities, and protecting the environment.

By evaluating the expressway project as an important social and environmental issue, Save Kāpiti and other anti-expressway residents were able to provide a radical critique of the government's market-industrial expressway project from within the civic, domestic, and green orders of worth. By critiquing the expressway from within these three worlds, the opponents illustrated that the government's market-industrial evaluation of the expressway was not appropriate. As discussed in Chapter Two, a radical critique challenges a testing system (for instance, cost and efficiency) from a common world that is external to its order of worth (Boltanski \& Thévenot, 1999). As people and things can be qualified within multiple orders of worth, a radical critique that questions market-industrial evaluations of an expressway, citizens, and the environment can be a powerful evaluation. For Save Kāpiti, a major problem with the expressway was that it would not maintain equality of access within Kāpiti and would threaten social unity; that is, it would 'divide' the community. Far from being simply an emotive argument, the issue of community division helped critique the NZTA's marketindustrial evaluation by highlighting that a road should not harm the local communities and environment. Save Kāpiti did not simply evaluate the road within, what Thévenot (2002, p. 62) calls, a "regime of planned action" (whether it will improve travel times, ease congestion, or improve economic development), but evaluated it within the three orders of worth outlined above. They evaluated the road according to civic, domestic, and green qualifications by linking it with the issues of local access to public facilities, the maintenance of "community links", the protection of "traditional cultural values", and the preservation of the local environment and ecology (Save Kāpiti, 2010).

Critiquing the expressway within civic, domestic, and green orders of worth demonstrates how people engaged with an engineering project that seemed to be firmly located within industrial and market modes of evaluation. Local residents and advocacy groups related to the expressway project by voicing their concerns about the expressway's potential impact on their associations with the environment and community, which Marres (2007) calls, "socioontological associations". Drawing on Dewey's idea of “public problems”, Marres (2007, p. 773) suggests that citizens engage with a public matter if "an association of actors who were not directly involved in its production . . . are jointly and antagonistically implicated in [it]". From this pragmatist perspective, people enacted their concern with the expressway project by evoking and mobilising their socio-ontological associations that would be negatively affected 
by it. Local residents and opposition groups objected to the idea that the expressway would sacrifice their associations with, and attachments to, their community, culture, and environment so that business-consumer and business-to-business relationships could be enhanced. Focusing on the social and environmental consequences of the expressway helped people engage with and evaluate the project as an important public issue.

\subsection{The Kāpiti Expressway as a Political Issue}

Alongside the social and environmental controversies, there were a number of political controversies surrounding the decision-making and planning process. The political controversies were characterised by populist appeals and a concern with the public's role in centralised decision-making processes that seek to 'fast-track' public infrastructure projects. A number of political controversies were publicised in media reports and press releases: controversies surrounding the Transport Minister's personal motivation behind the expressway project, the 'fast tracking' process, 'rubber-stamping', and the democratic aspects of the public consultation process. However, I focus here on the controversies over public consultation and the selection of the preferred option as they were key issues for Save Kāpiti and other advocacy groups and were points of contention at the Board of Inquiry and High Court case.

A key issue with the consultation process that surfaced was a concern with the two initial expressway options presented to the public. Several people commented that the options were flawed or problematic because they would have negative impacts on the community and were not supported by the local community. In response to public feedback and criticism, the NZTA "bowed to intense public pressure" and agreed to consult on a 'third option' and extend the consultation period (Blundell, 2009b). This 'back down' was seen by a number of journalists as restoring the democratic aspects of the public consultation process and demonstrating democracy in action. However, when the NZTA announced they had selected the preferred third option in December 2009, concerns surrounding its negative impact and unpopularity resurfaced. Moreover, people questioned why the NZTA decided to consult the public on this option when they had initially 'thrown it out'. In response to the lack of options, a number of people publicly supported alternative routes and road types. For instance, some people argued that a two-lane Western Link Road with an upgrade of SH1 would be a good solution and the Kāpiti Council developed an alternative expressway route which was called the 'fourth option'. 
While the issues surrounding participation did not surface in the NZTA's 2009 community engagement report, their report as well as a survey conducted by Colmar Brunton indicated that the issue of 'alternative options' was contentious. The NZTA's report indicated that, out of the 4,688 submissions received, the WLR Expressway Option was the most preferred option (1,609 submitters supported this option) and the Western Option was the least preferred (619 submitters supported this option). However, 1,177 submitters preferred alternative transportation options and 1,041 submitters preferred the Eastern Option (New Zealand Transport Agency, 2009a, p. 3). Similarly, Colmar Brunton’s (2009) “Kāpiti Coast Survey", which was commissioned by the NZTA, found that nearly half (49 percent) of the 1,000 respondents preferred the Western Link Road (WLR) Option and 33 percent of respondents preferred the NZTA's initial Eastern and Western Options. Interestingly, the report found little support for 'other options'. For instance, only 7 percent of respondents supported the two-Lane Western Link Road project, 5 percent supported upgrading the existing State Highway 1 into an expressway, and 2 percent supported improving train/public transport (Colmar Brunton, 2009, p. 7). Overall, these reports indicated that, while the WLR expressway route was the most preferred option by a narrow margin, there was no clear consensus.

The NZTA's survey findings did not simply reflect the public's preference, but helped mobilise action by quantifying their preferences. Their finding that local residents preferred the WLR Expressway option over alternative transport options, helped engage antiexpressway residents with the project. Local residents and advocacy groups, such as Save Kāpiti, were concerned that the government's decision to build an expressway was based on a flawed public consultation process. Save Kāpiti and others engaged with the project by challenging the government's decision-making process. For instance, Save Kāpiti’s second protest in July 2011 was organised to present a 4,000+ signature petition to parliament, which urged the government to reconsider its decision to build an expressway along the WLR route. A key issue for the protestors was that the decision to build an expressway was "made without genuine public consultation” (Senjmito, 2011). Save Kāpiti disagreed with the NZTA's finding that there was greater public support for the WLR expressway compared to alternative transport options. They argued that the NZTA's consultation process was flawed because "only 34 percent actually supported the outcome selected in 2009, leaving the vast majority (64 percent) preferring other options, with many of those not wanting an expressway at all!" (Save Kāpiti, 2011). 
This controversy over the public's preference was not simply about the problems and difficulties of measuring and representing the public's opinion, but was also a debate over whether the expressway qualified as a road for 'the people'. The NZTA's controversial finding was not simply seen as a decision regarding where to locate the expressway, but was also seen by Save Kāpiti as an issue of whether an expressway would "best serve both the local community and the wider public of New Zealand" (Save Kāpiti, 2010). Here, Save Kāpiti were suggesting that accurately measuring and representing the public's preference is important as it has significant implications for the planning of the road. Their initial argument was that the expressway project's "focus on speed and the fewest number of linking roads possible means that it provides little to the local communities affected by it" (Save Kāpiti, 2010). This is problematic, according to Save Kāpiti, as the expressway "runs counter to the principles concerning the relationship between roads and communities which are expressly stated in NZTA policies" and "the established District Plan - a plan endorsed by the people of the Coast after considerable discussion" (Save Kāpiti, 2010). In this case, the NZTA's market-industrial expressway might improve traffic flow and economic growth, but this is at the expense of its civic worth; that is, whether it meets the needs of the local community and the wider public.

If the social and environmental impacts of the expressway revealed how people initially engaged with the project, the controversy surrounding the preferred option also illustrates how local residents and advocacy groups engaged with the project by relating it to what they believed were broader political issues. The issue of public preference helped engage Save Kāpiti and other residents because it provided them with an opportunity to connect their objections to a local issue (where to locate a road) with a more universal demand (participatory politics) that resonates with the general public (Laclau, 2005). The meaning of "universal demand" is outlined in Chapter Seven, but for the purposes of this discussion, the process of linking objections to a universal demand, order of worth, or meaningful frame, highlights how local residents engaged with the preferred option controversy by relating it to the wider issue of the public's role in centralised decision-making processes that seek to fasttrack public infrastructure projects. Save Kāpiti and other residents enacted their concern with the NZTA's preferred option by appealing to the populist idea that the 'people' or 'majority' should have a greater influence in government projects and decision-making processes. The practice of consulting the public on the preferred option helped open the idea that the 
expressway was not simply a market-industrial road that was designed by transport experts, but also a civic road - a road for the people that is chosen by the people.

\subsection{The Board of Inquiry}

As the project became focused on the design and planning of the expressway, the opponents were obliged to translate their concerns with the environmental, political, and social aspects of the project as legal and technical issues. During the Board of Inquiry in 2012 and 2013, the initial concerns raised by concerned citizens remained publicly visible, but they became closely aligned with design and planning issues. I focus here on two controversies during the BOI that were closely aligned with the issues of the expressway's social and environmental impact and the public's involvement in selecting the preferred option: a controversy over urban design and a controversy over the NZTA's social impact assessment. Rather than critiquing the expressway project from common worlds outside of the NZTA's marketindustrial order of worth, the opponents were obliged to demonstrate how an industrial/planning order of worth could be made compatible with civic, domestic, and environmental modes of evaluation. I argue that, in this case, Save Kāpiti related their environmental, political, and social concerns with the project to its design and planning aspects by creating a compromise between an industrial/planning mode of evaluation and the civic, domestic, and green orders of worth.

In their opening submission to the BOI, Save Kāpiti related their concerns with the project to section 171 of the Resource Management Act, which states that "the effects on the environment of allowing the requirement" are to be considered by the territorial authority (the decision-maker) (Resource Management Act, No. 69, 1991). Save Kāpiti connected their civic/equality, domestic/social, and green/environmental evaluations to section 171 of the RMA by claiming that these issues have implications for the selection of alternative transport options, land use planning instruments, and whether the expressway meets the NZTA's objectives; that is, whether it meets regional objectives at the expense of local objectives (Save Kāpiti, 2012, pp. 4-5). As I will discuss, Save Kāpiti’s attempt to make their concerns relevant to the industrial order of worth reveals how the dynamics of the dispute shifted from re-presenting the expressway as a public issue to staging matters of collective importance as legal and technical problems with the expressway project. 


\subsection{1: Social impact as an urban design issue}

To explore how Save Kāpiti's initial concern with the socially divisive effects of the expressway was translated as legal and technical problems, I examine their submissions on urban design. Save Kāpiti argued that the problem of community division could be made compatible with an industrial test of long-term planning by focusing on whether the expressway was necessary for meeting the NZTA's objective of balancing "the competing functional performance requirements of inter-regional and local traffic movements" (Board of Inquiry, 2013, p. 5). Save Kāpiti made a civic-industrial compromise by arguing that an expressway would benefit people travelling through Kāpiti at the expense of people who travel within Kāpiti. Rather than being a long-term transportation solution, Save Kāpiti highlighted that local residents would not benefit from the project. Moreover, they created a second, domestic-industrial compromise, by claiming that the expressway would not only affect equality of access, but also social unity within the communities on the Kāpiti Coast. While Save Kāpiti's urban planners presented a number of arguments to the Board, I focus here on their urban planning expert's argument that the proposed expressway sacrifices local (east/west) connectivity for regional (north/south) connectivity.

In a nutshell, whether or not the expressway would divide the community was debated by Graeme McIndoe (one of Save Kāpiti's urban planners) as a technical matter of deciding the appropriate number of intersections/connections planned for the expressway. Connectivity was discussed in relation to a number of other matters, such as the 'barrier effect' created by the expressway and safety and security issues. However, when debating the socially divisive effects of the expressway, McIndoe created a domestic-industrial compromise by examining the number of planned intersections/connections that would not adversely affect social unity in the communities on the Kāpiti Coast. Based on a quantitative assessment, he argued that the expressway project's 11 connection points "provides between one third and one quarter of the east-west connectivity that would be consistent with good urban planning and design practice" (McIndoe, 2012b, p. 3). Indeed, in the Board's final report, they noted that McIndoe's benchmark for improving neighbourhood connectivity derived from the "number of connections per linear metre" (Board of Inquiry, 2013, p. 209).

Similarly, McIndoe created a civic-industrial compromise that highlighted the importance of equal access by outlining how many intersections would be needed to ensure that local residents were not cut off from important public facilities and areas. After reviewing the 
various tools for measuring connectivity, McIndoe (2012a, p. 18) concluded that "it is reasonable to use variously 200 and 400 metre street spacings as 'indicative' and 'conservative' measures ... to determine the extent of interconnection that should and possibly might be achieved”. Using a visual map of Save Kāpiti's preferred two-lane local road project, he pointed to the numerous (36 in total) local intersections/connections that had been planned for this road as a way of demonstrating the shortfalls of the NZTA's marketindustrial expressway, which had only 11 planned local intersections. As can be seen in this visual map (see Figure 6), there are nine intersections (symbolised by the numbers) on this section of Save Kāpiti's preferred road, which McIndoe pointed to, but only three intersections on the NZTA's market-industrial expressway (symbolised by the red letters and lines).

The socially divisive effects identified in McIndoe's assessment reveals how the technical planning aspects of the project were made compatible with the civic and domestic orders of worth. It highlights Law and Callon's (1988, p. 284) idea that engineering projects have both technical and social implications. In this case, the social and technical aspects of the project were aligned within the process of justification and the creation of compromises (Thévenot, 2002). Save Kāpiti's urban planning evidence created compromises between the civic, domestic, and industrial worlds by pointing to the social implications of building a small number of intersections on the expressway. It is important to note that some submitters (including Save Kāpiti's urban planners) continued to mobilise civic and domestic evaluations that pointed to the imposing nature of the expressway and the impact this can have in terms of connecting or dividing communities. However, McIndoe's argument demonstrates how staging social concerns to the Board involved creating a compromise that made them compatible with the technical issue of the optimal number of intersections/connections. That is, rather than pointing out the social problems that can arise due to the "ontologically fixed" or essential properties of an expressway (Hawkins, 2010, p. 120), McIndoe related Save Kāpiti's social concerns to a debate over the number of intersections planned for the expressway. 


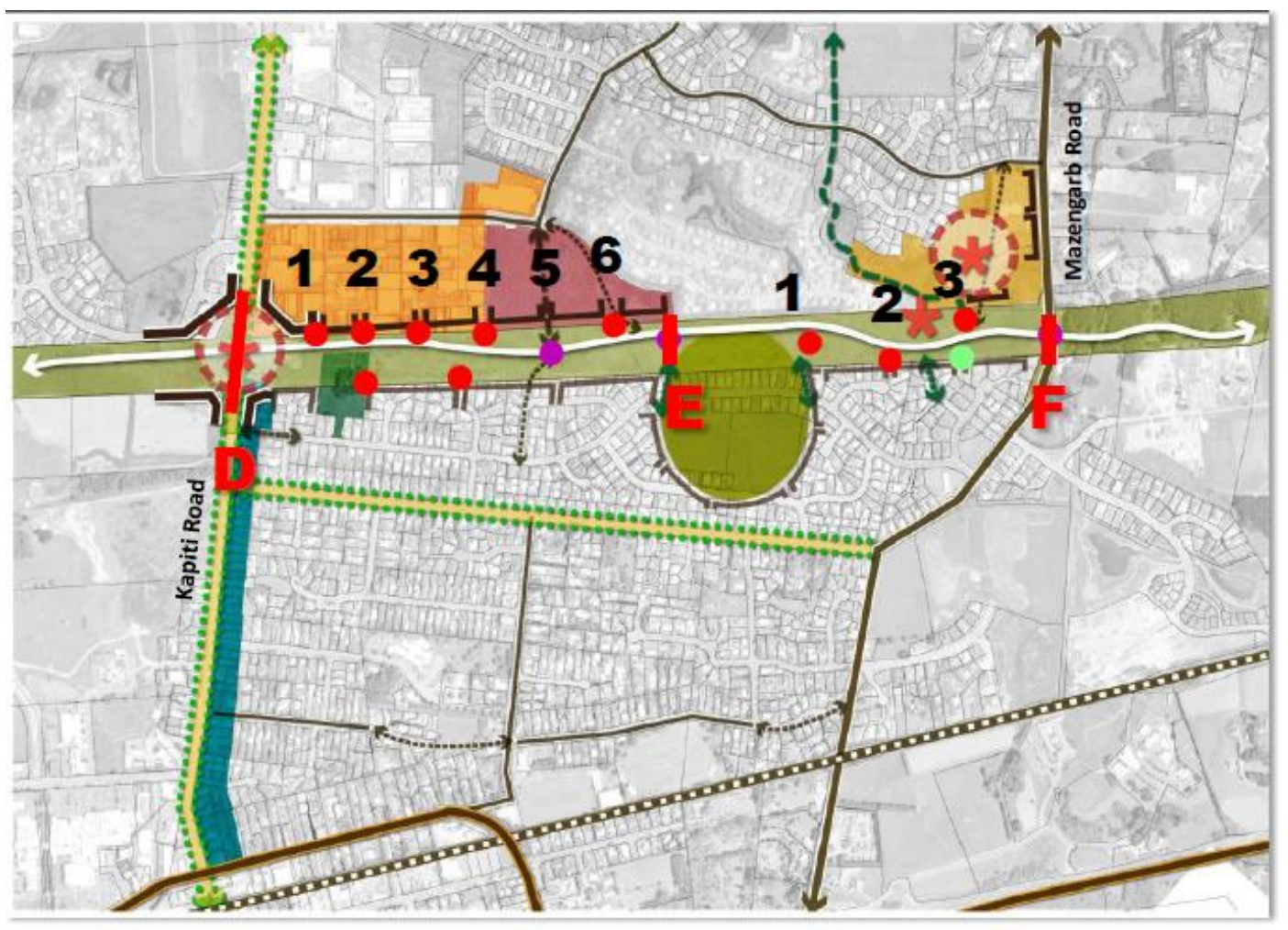

SLIDE 4 Connections: Kapiti Road to Mazengarb Rd

Figure 6. Connections: Kāpiti Road to Mazengarb Rd (McIndoe, 2012a).

\subsection{2: Public consultation and social impact assessments}

While the issue of social division was connected to the design of the expressway, Save Kāpiti's initial concern with public consultation and selection of the preferred option was translated as an issue with the NZTA's social impact assessment. They evaluated their social impact assessment by evaluating it from the civic world's test of collective welfare (Thévenot et al., 2000). Like many other expressway opponents, Save Kāpiti were not convinced that the NZTA had "adequately considered" alternative routes. As decision-makers are required by section 171 of the RMA to "pay particular regard" to alternative routes, Save Kāpiti argued that the NZTA's social, transport, and urban planning analyses failed to adequately consider alternatives. They claimed that the content and methodology of the NZTA's social impact assessment was flawed, which "affect[ed] both the justification of the proposal and the consideration of alternatives" (Save Kāpiti, 2012, p. 3). That is, if a large number of residents would be negatively affected by the expressway, then the preferred expressway option would not qualify as a "civic" road that enhances collective welfare and well-being. 
Indeed, Save Kāpiti's social impact expert, Dianne Buchan, argued that the social effects assessment that informed the NZTA's selection of the preferred option in 2009 was based on public feedback recorded during the community consultation process, but was not followed up by a social impact assessment (Buchan, 2012, p. 8). She claimed that the NZTA's social impact assessment, which was conducted several months after the NZTA had selected the preferred route, was a "mopping up exercise ... focused on finding justification for the decision that had already been made and announced" (Buchan, 2012, p. 9). As the NZTA's assessment was conducted after the preferred route had been selected, her argument helped point to the idea that they did not adequately consider alternative options that would enhance the well-being of local residents.

The issue of public input into the selection of a preferred option was not only debated as an issue with the NZTA's social impact assessment, but was also connected to the wider issue of government agencies ignoring the concerns of local residents. There were many arguments surrounding the idea that the NZTA were 'not listening' to the public's views on alternative routes for the expressway. However, as the Board noted, this concern "can be summarised as a criticism of NZTA for misleading people" by referring to the four-lane expressway project during the first consultation phase as the Western Link Road, which is often associated with the previous two-lane road project (Board of Inquiry, 2013, p. 34). The issue of misleading the public seemed to be important for many submitters as it suggested that the NZTA did not adequately consider the social impacts of the selected expressway option. That is, if the majority of local residents did not support the project then this suggests that it would have negative social impacts and should be abandoned (Board of Inquiry, 2013, p. 37).

In contrast to the issue of public deception, Buchan's critique of the NZTA's social impact assessment reveals how a broad concern with the public's preference was made compatible with a measurement issue, which is a relevant form of proof within the industrial order of worth (Thévenot et al., 2000). Buchan demonstrated that the issues surrounding the public's preference was a technical matter of evaluating the methodology and techniques used to measure and assess the positive and negative social effects of the proposed expressway. Rather than continuing to focus on whether people were misled by the NZTA, Buchan (2012, p. 13) argued that their assessment relied on demographic data that was too generalised or "crude", which meant that it failed to "identify and quantify the real social costs and benefits" and develop "accurate judgements on the nature of the effects". What mattered was not the public's opinions per se, but the accuracy of the techniques used to represent "the nature, 
probability and scale of the social effects likely to be generated during both the construction and operation phases" (Buchan, 2012, p. 6).

The controversies over the techniques of measuring and assessing social impact helped translate the issue of public preference as a relevant industrial/technical problem that had implications for the design and planning of the road. Issues surrounding measurement and calculation, as Barry (2002, p. 274) suggests, can "provide the basis for an opening up of new objects and sites of disagreement" by revealing, in this case, the problems with the assessment tools that were utilised. While the NZTA's social impact analysis, as Buchan (2012, p. 6) suggested, might have been a "mopping up" exercise that helped justify the selection of the preferred option, the problems with their assessment tools helped reopen the debate over the contentious selection process.

\subsection{Conclusion: Public Involvement in Socio-Technical Controversies}

As discussed above, Save Kāpiti and other local residents initially engaged with the expressway project by aligning it with a range of environmental, political, and social issues. However, as the planning of the project became focused on its design and planning, Save Kāpiti translated their initial concerns with the legal and technical aspects of the project. In this case, the issues of social division and public participation in selecting the preferred option were translated by Save Kāpiti as being important concerns for where the road should be located (that is, assessing the social impacts of each route) and how it should be designed (in terms of the number and type of intersections/connection points).

My finding that local residents and advocacy groups engaged with the expressway project by translating their initial concerns with the legal and technical aspects of the project was shaped by my analysis of the media reports and public documents on the Kāpiti expressway. My investigation into the first planning phase of the project in 2009-2010 revealed a number of social and political disputes that surrounded the expressway project, while the final planning phase of the project in 2012-2013 focused on its design and planning. Before I started my analysis I thought that analysing the technical controversies surrounding the project (such as the design of the road) might not illuminate the broader social or political aspects of the project. Similarly, I thought that analysing the social and political aspects of the project (in particular, the issue of public or political representation) would overlook the important technical controversies surrounding the road. 
While focusing on the issue of political representation in the planning of the project is important, I would, as Latour (2005a, p. 16) claims, be telling only half of the story, as "when it comes down to what is at issue, namely the object of concern that brings them together, not a word ... [will be] uttered". Similarly, I could focus on the technical controversies and bracket-out the social and political issues, but this approach would overlook how technology relates to social and political life. As Barry (2001, p. 9) argues, "technical controversies are forms of political controversy" because "technical designs and devices are bound up with the constitution of the human and the social”. Moreover, technical controversies, as Latour (1987, p. 62) suggests, are 'social' in the sense that they involve making persuasive arguments that are supported by allies.

Save Kāpiti's dispute over the design of the expressway was, for them, not only relevant to an industrial/technical order of worth, but was also about the fracturing of Kāpiti and the limited role the community played in the decision-making process. Their engagement with the expressway project highlights the idea that public involvement in socio-technical controversies involves re-presenting an object of concern to the people who gather around it by making it compatible with the orders of worth that are seen as legitimate in a specific testing situation. However, as I will discuss in the next chapter, to re-present the expressway as a public issue, residents and opposition groups had to find creative ways of publicising it as a national, rather than local, problem. 


\section{Chapter Five: M2PP or the Kāpiti 'Distressway'}

\subsection{Introduction}

In the previous chapter I explored how local residents engaged with the Kāpiti expressway project by re-presenting it as an object of public concern. However, I did not explore how the expressway was publicised as an object of concern. To help fend off accusations of NIMBYism, opponents of the project had to find ways of publicising their concerns in a way that demonstrated why the expressway was a significant public issue. To do this, local residents and several opposition groups organised protests or site-specific demonstrations that pointed to the negative impacts of the project. By pointing out the issues that they were concerned with, the protestors helped make the expressway visible as an object that could be questioned and publicly critiqued. This was an important challenge because the NZTA's public consultation exercises, which helped regulate public disagreement, made the expressway project seem inevitable or fact-like.

In this chapter I suggest that re-presenting the expressway as either a matter of collective concern or inevitability was not simply achieved by articulating different claims or points of view, but was accomplished through, what Barry (2001) calls, technical practices and demonstration sites. Rather than simply 'telling the truth' about the expressway, I argue that socio-technical arrangements made it possible to articulate truths about the expressway project. This highlights Barry's (2001) idea that:

Telling the truth is always going to be a difficult matter ... [as it] requires work to set up a site where the truth can be demonstrated. It requires the appropriate witnesses to be present. It involves the development of instruments with which the truth can be made visible. (p. 192)

The NZTA's re-presentation of the expressway as an inevitability was accomplished through a range of technologies (such as brochures and feedback forms) that made the expressway project appear as a matter of fact. To challenge the fact-like status of the expressway, face-toface public meetings helped residents and opposition groups articulate their concerns in a public forum. Yet, rational arguments were not enough to persuade the NZTA to change their proposal or to convince the general public that the expressway was a bad idea. Moreover, as the planning stages of the project became focused on the legal and technical aspects of the 
project, it became difficult for residents and opposition groups to articulate why the expressway was problematic. By organising site-specific demonstrations, concerned residents created persuasive evaluations that would, in theory, stand up to public scrutiny. However, in practice, the site-specific protests re-presented the expressway as a significant local, rather than national, problem.

This chapter is divided into four sections. First, I briefly discuss social theories of protest and demonstration. Second, I explore the NZTA's public consultation exercises as demonstration sites that publicised the expressway as an inevitability or 'matter of fact'. Third, faced with the limitations of the NZTA's consultation exercises, I investigate how anti-expressway groups organised site-specific demonstrations that publicised the expressway as a matter of concern. Finally, I discuss the limitations of site-specific protests by examining the criticisms from expressway supporters and the $100 \%$ Possible climate change campaign, which helped connect the expressway project to environmental issues.

\subsection{Protests and Demonstrations in Socio-Technical Controversies}

A standout feature of the expressway project was the wide range of public consultation exercises, community organised events, and protests that were set up to involve local residents and publicise the concerns surrounding the project. An important function of these exercises, events, and protests was to allow the local community and general public to be represented in the project. That is, they helped include the public in the planning of the project and the decision-making process. While public representation was an important issue, the focus of these events seemed to be on demonstrating to others the benefits and problems associated with the expressway project. For the NZTA, the expressway's benefits were highlighted and the project was presented as if it was an inevitability. In contrast, opponents of the project advocated for alternative transport options and highlighted the negative impacts that would be caused by the project.

The actions of the NZTA and the opponents of the project highlight the importance of demonstrations in socio-technical controversies. As discussed in Chapter Two, motorway protests help social groups demonstrate their claims publicly; represent their interests and concerns; and mobilise action. However, in the Kāpiti expressway controversy, the protestors and NZTA were not simply representatives, but were also "articulators" who pointed to the problems with, and benefits of, the expressway project (Callon, 2004, p. 124). That is, the demonstrators were not only, what Barry (1999, p. 77) calls, "markers of the unacceptability 
of another's actions", but were also "making visible a phenomenon to be witnessed by others". The NZTA's public consultation exercises and events were demonstrations in the sense that they publicised the expressway as an issue that the public could engage with. That is, the NZTA's demonstrations pointed to the aspects of the project that required feedback from the public. In contrast, the opponents organised protests that pointed out the problems with the project. As I will discuss, while the actions of both groups seem unconnected, their demonstrations can be examined as activities that made the expressway project visible as a public issue.

The parallels between the NZTA's technical demonstrations and the opponents' political demonstrations is not peculiar to the Kāpiti expressway controversy, but is an important theme within studies of science and technology. The shared practices and forms of action in the worlds of science and politics is a key issue in STS, but recent studies have examined the similarities between scientific, technical, and political demonstrations (Barry, 1999; Girard \& Stark, 2007; Rosental, 2013). For example, Barry (1999, p. 77) argues that, while political demonstrations "emerged in the nineteenth century in connection with the Chartists and the revolutions of 1848 ", the notion of demonstration has an older notion that has a scientific meaning. Barry (1999, p. 77) suggests that, since the Middle Ages, university lecturers and scientists would demonstrate their findings to provide public proof or to display the possibility of something. Indeed, this has been a central theme in the history of scientific experimentation (Collins, 1988; Shapin \& Schaffer, 1985).

The sociological literature on public demonstrations is diverse, but Rosental (2013, pp. 344346) suggests that a common feature of these studies is their focus on the importance of proof and persuasion: that is, as "rhetorical devices"; "demonstrative performances", which are similar to experiments and lectures; activities that can open or close political spaces; and "public dramas" that have teaching and evidential roles. Rosental's (2013, p. 359) own research suggests that, "depending on the social spaces in which they are enacted, demonstrations may play less celebrated, more creative, and varied roles that help to manage social and political orders". For instance, demonstrations can be used to gain information, maintain partnerships, coordinate action with others, gauge an audience's reaction, or collect feedback (Rosental, 2013, p. 359).

In this chapter I utilise Barry's (1999) understanding of demonstration as it highlights an important issue in relation to the public's involvement in the expressway controversy: how 
can concerned residents make the project visible as a national, rather than local, issue? As Barry uses the concept of demonstration to research the anti-road protests in Britain, it is suitable for examining the Kāpiti expressway controversy. Barry's research illustrates how scientific understandings of demonstration can be a useful tool for examining public involvement in socio-technical controversies. Moreover, his idea of making a phenomenon visible to others is now a key theme in object oriented studies of public involvement in science and technology (Marres, 2007; Marres \& Lezaun, 2011). That is, if an issue is not made publicly visible, then it does not become open for debate and public involvement (Hird et al., 2014).

\subsection{NZTA's Demonstration Sites}

The planning stages of road projects in New Zealand involve a series of public consultation phases, which I will investigate as demonstration sites that were used to publicise the proposed expressway as an object of public concern. There were four public consultation phases organised by the NZTA for the Kāpiti expressway project. The first two consultation phases in 2009-2011 focused on the issues of selecting a route for the expressway and deciding on the 'preferred alignment', while the final two phases (2011-2012) focused on design development and proposed modifications to the current State Highway 1. For the NZTA (2009a, p. 6), the public consultation meetings enabled them to not only meet their legal obligations under the Land Transport Management Act, but also to inform people about the expressway project; engage with the local community and other key stakeholders; and to gain feedback that would provide the NZTA with an understanding of the public's views. While the public had different opinions on the public consultation process, for Save Kāpiti, and others, public consultation was an opportunity to not only gather more information about the project, but also to express their concerns to the NZTA and the wider public.

Each public consultation phase provided citizens with the opportunity to evaluate the project, but various socio-technical arrangements shaped and constrained how the Kāpiti expressway was re-presented as an object of concern during these consultation phases. An important part of the consultation phases was to 'inform' the public about the project and consultation process so that they could engage with the project. At first glance, the NZTA appears to have gone to great lengths to notify and inform the public about their proposed project. The NZTA established a project website that provided information about the expressway, consultation, and enquiry information. During the first consultation phase, information about the 
consultation process was published in local newspapers, and consultation brochures and feedback forms were mailed in late August 2009 to "all potentially affected parties, organisations and to every postal address in the Kāpiti Coast District at the commencement of consultation" (New Zealand Transport Agency, 2009a, p. 6). "Potentially affected residents" also received two letters that "offered opportunities for further communication" (New Zealand Transport Agency, 2009a, p. 6).

\subsubsection{Demonstrating matters of fact: Public consultation 'at a distance'}

The NZTA's brochures not only informed local residents, but also demonstrated or pointed out the aspects of the project that were to be commented on by the public using a feedback form. NZTA's brochures, which were sent to residents in August 2009, asked the public to express their opinion on two possible expressway routes (the 'eastern' and 'western' options). The 10 page brochure outlined why they were consulting the public on these two options and not alternative options, such as upgrading the existing state highway or building an expressway on the land that had been designated for the smaller two-lane Western Link Road (WLR) project. By doing this, the NZTA were pointing out what was being consulted on. For instance, the NZTA were not asking the public to discuss alternative transport options or road types, but were asking them to comment on where an expressway should be located from amongst a limited range of choices. If the public required further information, the NZTA advised them to view the technical reports, which examined the routes in greater detail.

The practice of pointing out what is to be consulted on, therefore, can be seen as a technique for demonstrating that the expressway is an inevitability or matter of fact. Before the project was publicly announced in August 2009, the NZTA had already researched alternative transport options and routes for an expressway through Kāpiti. A strategy study published for the NZTA recommended building an expressway and consulting the public on two options that were seen as "worthy of further investigation and discussion with the community" (Opus International Consultants, 2009, p. 60). The decision-making process behind the selection of the expressway options is discussed in Chapter Eight, but, in this chapter, I examine the options that were presented to the public during the first consultation phase. By not including alternative routes or transport modes in the brochure, the NZTA did not make the expressway visible as an object of public concern; that is, it is taken as a given that an expressway is required and will be built. Indeed, the attached feedback form (see Figure 7) only asked respondents to express their support for either the 'eastern' or 'western' expressway options. 
While the form allowed respondents to tick the 'I have other views' checkbox and write their comments/suggestions, alternative routes or transport modes were not included as 'options' that required feedback. While this is not surprising, I suggest that consultation procedures and techniques, such as feedback forms, made the expressway appear as a matter of fact by constraining public disagreement. The feedback forms allowed public consultation to occur 'at a distance', which arguably helped regulate the intensity of, what Barry (2013, p. 11) calls, "passionate disagreement" by channelling the public's opinions through a one page feedback form.

\section{Feedback Form}

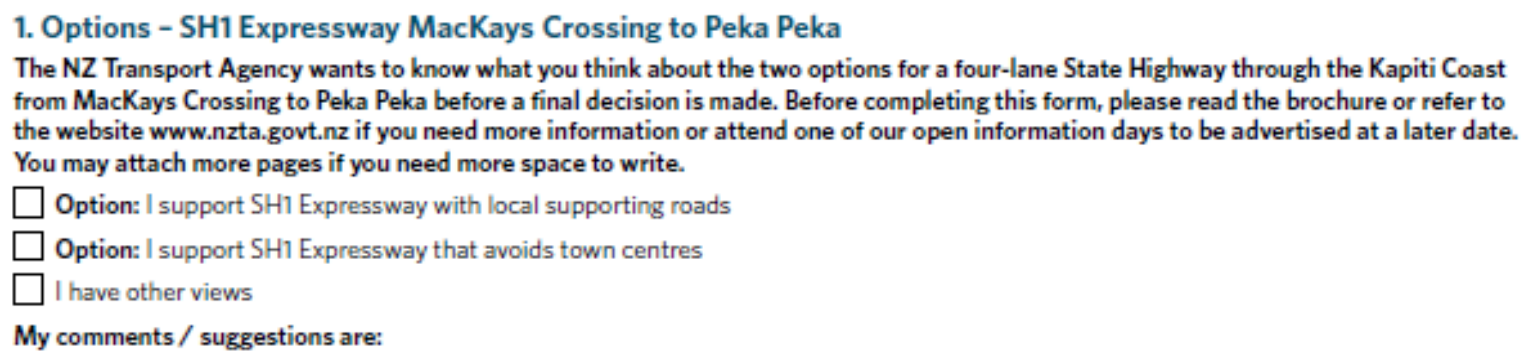

Figure 7. Feedback form (New Zealand Transport Agency, 2009b).

However, public disagreement was not simply channelled through a one page feedback form as the NZTA also allowed the public to email their concerns or make verbal submissions by calling a 0800 number. Email and verbal submissions allowed the public to provide relatively in-depth reasons and evidence. However, the responses were processed in the same way as the feedback forms: the responses were categorised as either supporting the NZTA's options or supporting 'other options', and the concerns about the possible impacts of an expressway were categorised according to themes, which were then briefly mentioned in the NZTA's engagement report. For example, a person could write a 1,000 word email explaining why an expressway would divide the local community, but this response would be recorded under the 
'community severance' theme and the engagement report would not mention the reasons that support this issue.

Although the NZTA were only formally consulting on two expressway options, residents and concerned citizens seemed interested in making alternative routes and transport options visible to the NZTA and the wider public (New Zealand Transport Agency, 2009a, p. 5). That is, the public's responses indicate that publicising the expressway as an object of concern was a key element in the controversies surrounding this project. As Barry $(2013$, p. 8) suggests, "the very question of whether such controversies are framed as 'political' or not is commonly itself a vital element in the dynamics of the controversy" because it can make certain problems visible and can revive "controversies that might otherwise be ignored or lie dormant". In this case, while a large number of people (1,660 respondents) supported the NZTA's two options, the majority of respondents expressed their support for the WLR Expressway (1,609 respondents) or 'alternative transport solutions' (1,177 respondents) (New Zealand Transport Agency, 2009a, p. 3). It is interesting to note that at least 3,269 people supported an expressway, which suggests that, for them, the issue was about evaluating the possible expressway routes, rather than the expressway itself. This divide between the pro-expressway public and anti-expressway public reveals that evaluating the expressway as a public issue would require more work than simply publicising the negative impacts of an expressway through a feedback form. Because a large number of people were aware of the project and supported it, publicising the expressway as a matter of public concern would require work that persuaded the NZTA and the pro-expressway public that an expressway is problematic and should not be built.

\subsubsection{Demonstrating matters of public concern: Face-to-face public consultation}

If the techniques of conducting public consultation at a distance helped make the expressway project appear inevitable and regulate the intensity of disagreement, the open days, public meetings, and expos can be seen as sites that allowed people to develop and articulate a persuasive demonstration. These public consultation events can be seen as the first sites set up by the NZTA that allowed face-to-face, interactive consultation to occur. If ticking a check box and writing a brief statement on why an expressway was problematic failed to convince the NZTA or the wider public that alternative transport modes were needed for Kāpiti, then open days and public meetings can be seen as sites where more persuasive claims could be articulated. 
A week or so after the brochures were sent to local residents, the public had the opportunity to attend open days. Rather than being a site where the public could gather to publicly voice their concerns, the first face-to-face open days were set up as information stands where people could find information and ask NZTA staff questions (see Figure 8). According to the NZTA (2009a, p. 7), the open days provided information about the project and the two options. Also, information about the third WLR Expressway Option was on display during the extended consultation period during October 2009.

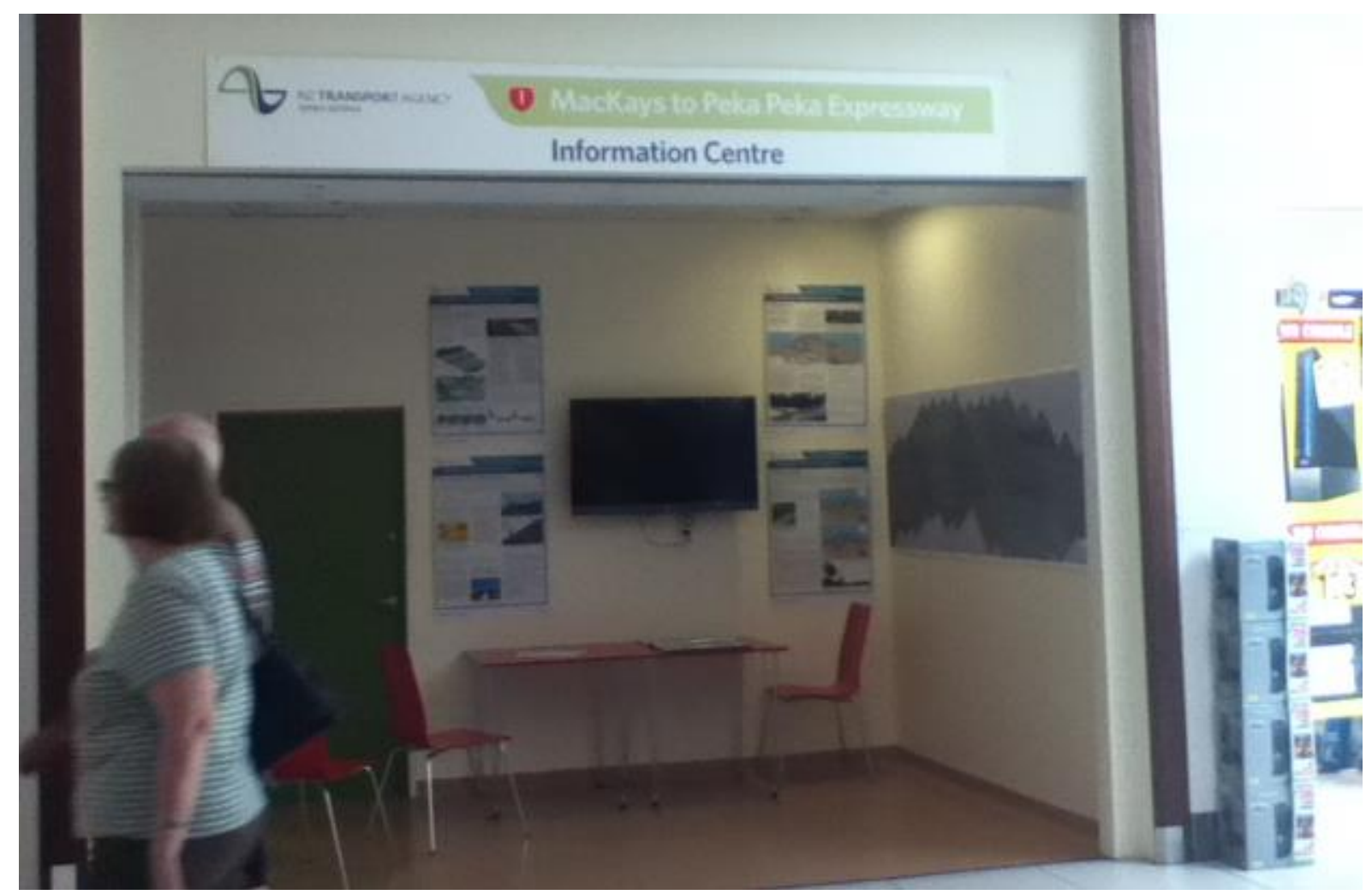

Figure 8. MacKays to Peka Peka Information Centre.

While these open days might be a crucial part of the public consultation process, they can be seen as another type of demonstration technique that pointed to the inevitability of the project. The public were unable to submit verbal feedback to NZTA staff and the open days only provided information on the expressway options that were being consulted on. My interviewees informed me that the staff did not seem to be knowledgeable about the other details of the project, its potential impacts, and alternative options. Indeed, the NZTA stated that the open day staff were there to help the public fill out a feedback form and assist property owners who might be affected (New Zealand Transport Agency, 2010c). 
In another sense, the open days were a technique for demonstrating matters of fact as the NZTA's staff members, as revealed by my interviewees, were not expert planners or engineers who could provide answers to questions regarding the legal and technical aspects of the project. The open days informed the public about the three expressway routes and staff helped the public find information about the proposed routes. Several local residents who I interviewed claimed that the open days were simply a 'box ticking exercise' or a 'farce' as the NZTA's staff members could not adequately answer their questions. One respondent described how she tried to gain 'real information' about the project and ask questions, but the staff either could not answer her questions or they all had differing opinions and no definitive answers. While it is not surprising that the staff did not have definitive answers for every question, these comments highlight how the open days were not intended to respond to the public's concerns about an expressway, but receive written feedback that would be processed by the NZTA and summarised in their consultation report.

If the anti-expressway public were unable to publicise the expressway as a public issue during the open days, the public meetings provided an opportunity for citizens to articulate their concerns to the NZTA, MPs, journalists, and other local residents. The public meetings departed from the consultation procedures as they enabled people to voice their opinions directly to the Minister of Transport Steven Joyce and to Otaki MP Nathan Guy. Rather than consulting the public from a distance and channelling their concerns through a feedback form, the public meetings allowed face-to-face consultation to occur for the first time.

The meetings publicly revealed how pro-expressway and anti-expressway residents not only articulated their concerns over the lack of options, but also pointed to the potential problems and impacts associated with the Kāpiti expressway. From media accounts of the first meetings, a journalist described how anti-expressway residents were "calling for a third option that would save their properties" (Blundell, 2009a). A local resident claimed that "we do not want either of them, we do not want an expressway, we want a third option that will suit local residents and keep us off the state highway" (Blundell, 2009a). Like the antiexpressway residents, the pro-expressway residents were also calling for a 'third option'. A local lobby group, called The Third Option, wanted the NZTA to build an expressway on the land designated for the two-lane Western Link Road (Blundell, 2009b). While local residents voiced their opinions over the lack of options during these meetings, the pro- and antiexpressway residents both pointed to the impacts that an expressway on the NZTA's proposed routes would have on the community, which I have discussed above. That is, the public 
meetings allowed the public to make the initial expressway options visible as objects of public concern.

Steven Joyce publicly responded to the concerns raised at the meetings by stating to journalists that "there was a strong body of opinion coming out of the meetings that the highway should be shifted and that should be considered" (Blundell, 2009b). This comment from the Transport Minister suggests that the NZTA's efforts to point out plausible routes for the expressway failed to convince local residents. In response, the NZTA extended the consultation period and included a 'new', 'WLR option', which it rejected in the first brochure because of the Kāpiti Council's plans to develop this area and because it would create "too great a division through the centre of Paraparaumu" (New Zealand Transport Agency, 2009b, p. 2). A new brochure was mailed to residents explaining that consultation had been extended and that a 'new option' was being considered. Joyce's announcement was not followed by further public meetings, but followed the NZTA's previous approach where the public could make a submission using a feedback form, email, or talking to NZTA over the phone.

\subsection{Community Organised Demonstration Sites: Public Meetings and Protests}

After the first consultation phase, many people did not think that the NZTA's public consultation procedures allowed them to adequately express their view that the expressway was an object of concern. The public meetings pressured the NZTA to investigate alternative expressway routes. This was a small victory for pro-expressway residents, but the meeting did not persuade the NZTA to investigate alternative road types or convince the wider public that an expressway would be problematic for Kāpiti. While some residents formed lobby groups to pressure the NZTA to consider alternative routes for the expressway, I focus here on the antiexpressway groups (in particular Save Kāpiti) that organised their own demonstrations.

While the NZTA's consultation exercises constrained the ability of anti-expressway disputants to publicise the expressway as an object of concern, I suggest that the disputants faced a new challenge of creating persuasive demonstrations that would not only be publicised by the media, but would also stand up to public scrutiny. As Callon (2004, p. 126)

suggests, if a demonstration does not withstand public examination, then it will point, not to an object of public concern, but to an "inarticulable object". To frame the discussion, I compare the public meetings with the protests that were organised by local anti-expressway groups. The initial meetings and protests in 2010 publicised the concerns from local residents. 
However, as the planning stages of the expressway project became focused on its legal and technical aspects, residents and opposition groups faced the daunting challenge of engaging with these issues and publicly demonstrating why they were problematic.

From 2010 to 2013 local community groups organised seven public meetings that were publicised in press releases or reported by journalists. Based on a keyword search of news articles on the Kāpiti Expressway, the first community organised public meeting that was reported in the media occurred on August 2010: 10 months after the NZTA's initial public consultation phase concluded. The last public meeting, which I attended, was held on 7 June 2013.

The first community organised meeting was convened by the Alliance for Sustainable Kāpiti (ASK) and "was held to allow questions to be aired, many for the first time in a public forum, about the implications of decisions taken by NZTA" (Alliance for Sustainable Kāpiti, 2010). Unlike the meeting organised by the NZTA, where people pointed to the problems associated with the Kāpiti expressway, presentations were given by experts and political leaders that stated their position and gave their personal views. While the NZTA representatives at the meeting outlined their plans and responded to questions, they admitted that the project was not popular and that it was a 'big issue' for the community (Alliance for Sustainable Kāpiti, 2010). It seems that the meeting used politicians and experts to attract attention to the expressway as an important public matter by publicising what they thought were the key concerns of the community.

In contrast to the NZTA's public consultation exercises, which focused on gathering public feedback, a key part of the community organised meeting was its publicity function. The 400 or so people who attended the meeting were part of the audience, but the media played a crucial role in publicising the expressway as an object of concern to the wider public. Because the media witness and report the 'truth' about public events or demonstrations (Barry, 2001), I suggest that a key challenge for anti-expressway groups was to organise an event that could persuasively demonstrate their claims to the media, who would then publicise the expressway as an important issue. Gathering experts and political leaders to point out the problems associated with the expressway to local residents and the media can be seen as a form of publicity that "open[s] an issue up for public involvement" (Marres, 2007, p. 772).

While the first meeting was about publicising the expressway as a matter of concern, the last meeting focused on the issue of how to demonstrate that the expressway was problematic 
from a legal standpoint. In June 2013, two months after the Board of Inquiry released its decision, Save Kāpiti organised an 'expressway hui'. Like the first meeting, a number of political leaders evaluated the expressway from their political standpoints. However, unlike the first public meeting, I suggest that this hui was not only about communicating the community's concerns to the media, as these were already known, but about demonstrating that the expressway remained a problem for local communities even though the Board of Inquiry approved the project. Several speakers suggested that a change in government was needed to stop the project, but Save Kāpiti and others claimed that a legal appeal would help re-open the expressway as a public issue. During the hui, I noted that one of the speakers suggested that residents needed to articulate a point of view that sounds 'rational' as protests can 'put people off' or can communicate the 'wrong message'. This comment implied that disputants should evaluate the technical and legal issues with the project. Indeed, Save Kāpiti's spokesperson talked about how their appeal to the High Court would focus on the legal errors in the Board's reasoning and why they failed to consider the two-lane WLR project as a viable alternative to an expressway. By pointing out the legal errors behind the Board's decision, Save Kāpiti hoped this approach would re-open the expressway as a matter of public concern.

The ability of the community organised meetings to publicise the expressway as a matter of concern was constrained by whether or not it would gain widespread media coverage. Public meetings are not known for generating wide spread news coverage as the issues discussed are usually seen as local problems. To combat this limitation of public meetings, well-known political leaders were invited to speak, which helped attract journalists and spark public interest in the project. However, even if the media publicised the problems associated with the expressway this did not automatically demonstrate that the expressway was a matter of public concern. As Callon (2004, p. 127) suggests, "the production of an event and its publicization do not lead mechanically to a re-casting of the political debate" as it can simply strengthen "pre-existing political facts" or can provide support for pro-expressway arguments. In this case, the meetings relied on claims made by political leaders, experts, and spokespeople to demonstrate the problems associated with the expressway. While articulating these claims might resonate with some people, the uncertainty surrounding the impacts of the expressway made it difficult to make a persuasive demonstration based on public statements alone. For example, in the comments section on a letter to the editor of The Dominion Post, an expressway supporter ignored the claims that were made at the meeting and stated that the 78 
anti-expressway residents who attended the meeting was a "miniscule ratio" compared to the "several thousand residents" who support it and that the "project is one of local and national importance and the sooner it gets under way the better" (as cited in Wheeler, 2011).

\subsubsection{Community organised protests}

The protests that were organised by Save Kāpiti and other local groups can be seen as a way of overcoming the limitations of using meetings to publicise the expressway as a matter of concern. The first protest that was publicised in the media occurred on the $2^{\text {nd }}$ of November 2010 and the last protest occurred on the $31^{\text {st }}$ of October 2013. In total, nine protests were organised and publicised in the media. Save Kāpiti and other local groups organised most of the demonstrations. The environmental group, Generation Zero, also became involved and helped organise several protests in 2013. Here, I focus on the first protest that was organised by Save Kāpiti in February 2011 and their second to last demonstration in July 2013.

Following Barry (2001, p. 182), I suggest that the anti-expressway protests can be seen as demonstration techniques that point directly to the potential impacts that the expressway would have on the community. If the meetings allowed concerned citizens to re-present the expressway as an object of concern by publicising their arguments and assembling antiexpressway residents, the protests allowed them to make their demonstrations site-specific (Barry, 2001, p. 183). Being located near the site of the proposed expressway highlights the idea that the protestors were not only representatives, but demonstrators that were making the expressway visible as an important issue by attracting media attention and directing the general public to take notice of the expressway's impact on Kāpiti (Barry, 2001). By pointing to the expressway's impact, the demonstrators could make their point without being dependent on complex arguments that might not resonate with the general public and without relying on a "display of force" to highlight a high level of opposition (Barry, 1999, p. 81).

Initially, an important aspect of Save Kāpiti's protests was to represent the affected residents who live in Kāpiti by articulating their concerns through a display of numbers. Save Kāpiti's first protest in 2011 publicised the expressway as an issue by pointing to the impact it would have on residents' homes and lifestyles. The protest was staged at the Waikanae Railway station on the $21^{\text {st }}$ of February 2011. According to media reports, the 200 protestors directed their concerns to the politicians and local residents who were there to re-open the new Waikanae railway station. Like the public meetings, the protest allowed the opponents to articulate their concerns in public by using placards and voicing their grievances to the crowd, 
politicians, and journalists. One of the organisers, Jonathan Gradwell, used the protest to express the concerns of Save Kāpiti by stating that "it is not just people losing their homes, it's also the noise and pollution, the effect on our lifestyles" (as cited in Blundell, 2011). The large gathering and the focus on property, lifestyle, and health highlighted that the expressway would not benefit the interests of Kāpiti Coast residents. That is, the protest brought into focus the idea that local residents were not being represented by the government and in the planning process. For instance, several banners and placards stated that the government "does not listen" because they are "riding roughshod over Kāpiti". The idea of riding roughshod highlights the idea that government is carrying out its plans despite public opposition.

However, the protestors did not simply represent affected residents, but pointed to the damage that the expressway would cause. As the expressway was in the planning stages, the protestors could not point to the tangible impacts of the expressway. That is, they could not point to a large concrete structure that would destroy family homes and Kāpiti's tranquillity. To make the expressway's impact appear tangible, the protestors used balloons to illustrate how many homes would be affected and pointed to tall objects (such as trees) to illustrate its physical size. According to one journalist, the protestors carried 60 balloons, which represented the houses that would be demolished (see Figure 9, (Shipman, 2011)). Compared to the Kāpiti Coast's population of 50,000 people, the demolition of 60 houses does not seem to be a significant number. However, by making this 'small' number publicly visible as collection of tangible objects, the audience witnessing the protest or viewing it on a news broadcast could 'see' that the expressway would destroy people's homes. Moreover, one of the protesters was filmed and interviewed at his home by 3 News, which enabled him to point out that the expressway would go directly over his property and would be as high as one of the trees in his backyard (which looked to be 20 metres high). This action helped highlight the idea that the expressway would not be an invisible infra-structure, but would have a significant presence in Kāpiti. He demonstrated that the expressway was an object of concern because it would be a large structure that would destroy the tranquil feel of Kāpiti and would have a negative impact on the peri-urban lifestyles that residents enjoy. 


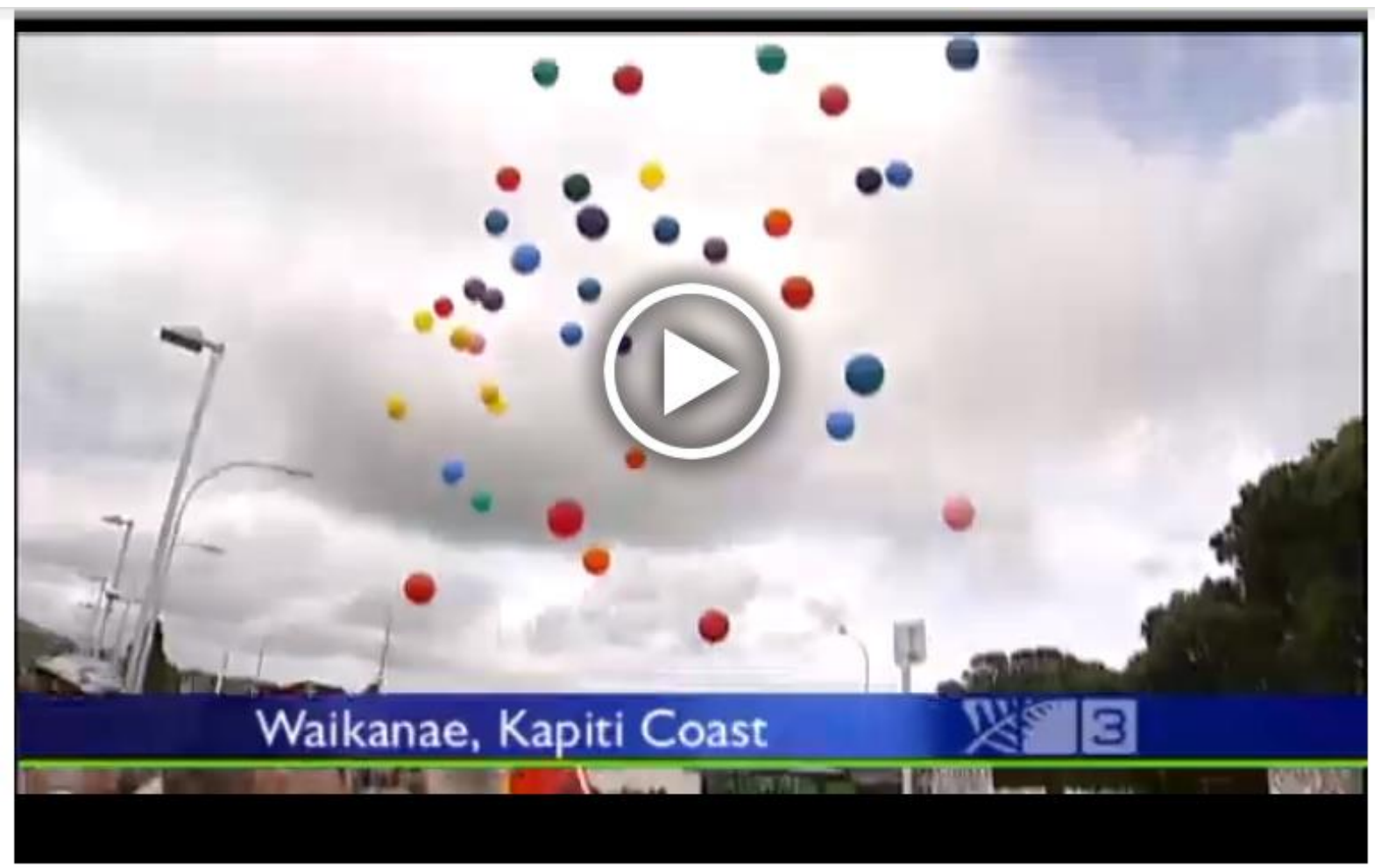

Figure 9. Waikanae Railway station protest (Shipman, 2011).

As discussed in Chapter Two, motorway protests help social groups demonstrate their claims publicly, represent their interests and concerns, and mobilise action. However, in the Kāpiti expressway controversy, the protestors and NZTA were not simply representatives, but were also "articulators" who pointed to the problems with, and benefits of, the expressway project (Callon, 2004, p. 124). The demonstrators were not only, what Barry (1999, p. 77) calls, "markers of the unacceptability of another's actions", but were also "making visible a phenomenon to be witnessed by others". The NZTA's public consultation exercises and events were demonstrations in the sense that they publicised the expressway as an issue that the public could engage with. That is, the NZTA's demonstrations pointed to the aspects of the project that required feedback from the public. In contrast, the opponents organised political protests that pointed out the problems with the project. As I will discuss, while the actions of both groups seem unconnected, their demonstrations can be examined as activities that made the expressway project visible as a public issue.

As the planning of the expressway project focused on its legal and technical aspects in 20122013, the demonstrations organised by local opposition groups focused on the issues surrounding the Public Works Act and the legality of starting the project while it was before the High Court. Due to the complexity of road projects and the difficulty of debating legal 
issues in a public space, Save Kāpiti organised two site-specific demonstrations that pointed to the issue of residents losing their homes for an expressway that was under appeal. The protests took place on July 1 and October 31,2013 . They were both relatively small-scale events that were attended by approximately $20-40$ protestors and publicised in two national media outlets: 3 News and The Dominion Post. I examine the July 1 protest because I attended it and took field notes.

Like the earlier demonstrations in 2011, the July 1, 2013 protest helped represent affected residents by highlighting the unacceptability of the NZTA's actions (see Figure 10). The protest was a 'sit-in' that was organised at a four acre property that was in the path of the planned expressway. The property in question was a garden centre and home of a local Raumati South resident who had lived on the Kāpiti Coast for over twenty years and who had a strong connection with the area. By organising the event at a well-known garden centre and home that was supposedly being forcefully acquired by the government, Save Kāpiti and the owner of the property were able to demonstrate to news reporters and passers-by that the NZTA's actions were legally questionable. The protestors (approximately 40 people) stood outside the front entrance of the garden centre holding their placards and talking to the news media. The placards made reference to the issue of representation by claiming that the National Government 'does not care' and that Kāpiti is being 'sacrificed' because of a 'political agenda'. More formally, Save Kāpiti's press release explained that an owner of a local garden centre had been ordered by the NZTA to leave his land "even though the road plans are under appeal and not formally approved yet" (Save Kāpiti, 2013). The owner of the property was interviewed by several journalists to explain why the NZTA's actions were problematic. Based on the style of protest action, my conversations with the protestors, and what I heard at the event, the plight of the garden centre owner brought into focus the lack of public representation in the planning process and the disadvantage, intimidation, and sense of injustice experienced by affected residents. 


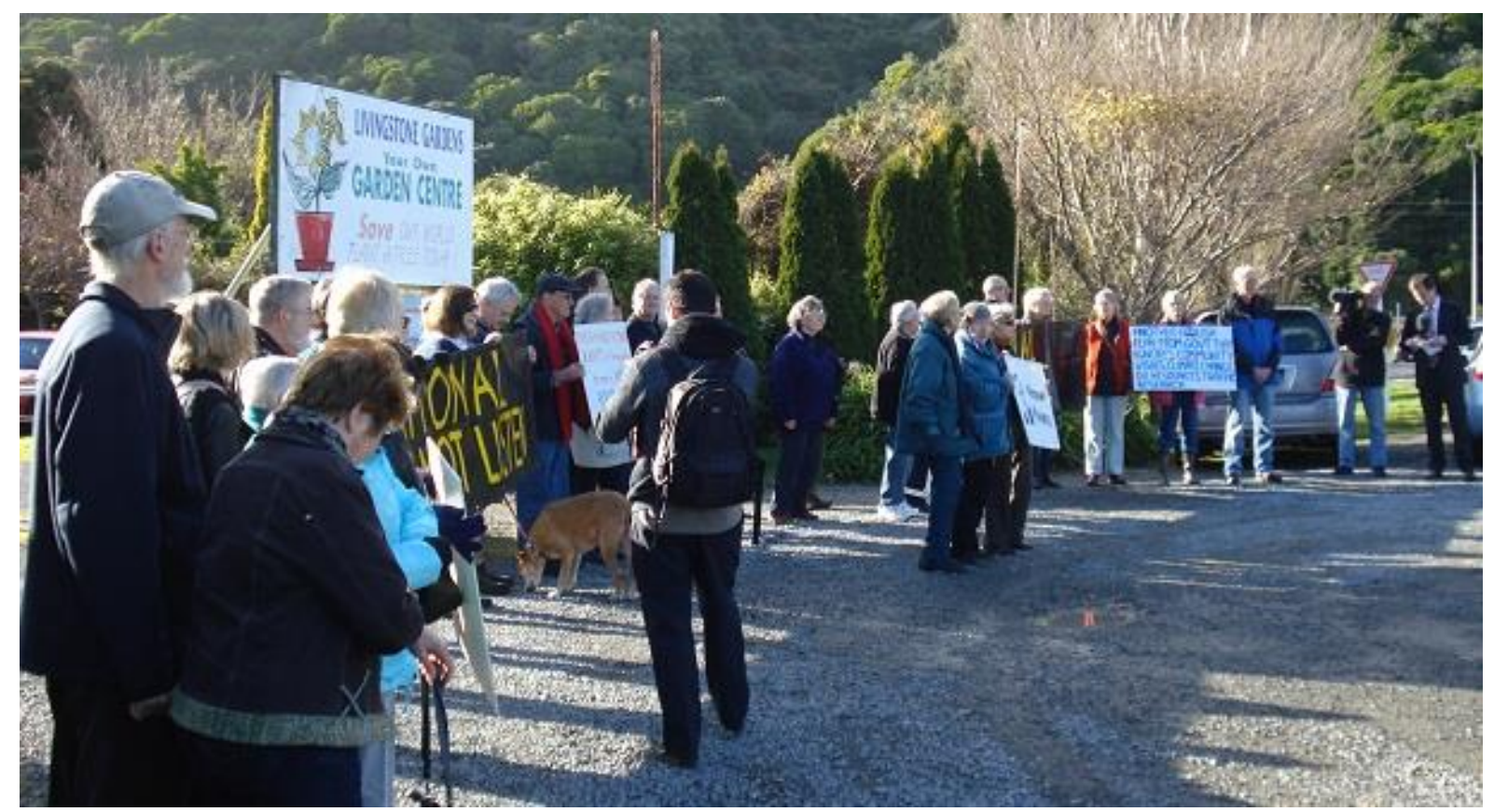

Figure 10. Raumati South protest, July 1, 2013.

Beyond the issue of representation, the sit-in also pointed to the damaging effects of the expressway. The protestors made the expressway visible as an object of concern by pointing to, what Barry (1999, p. 81) calls, "an emerging reality": the reality of people losing their homes and businesses because of an expressway. The sit-in revealed that drastic action would be taken to stop an expressway from destroying the lives of Kāpiti Coast residents. By attracting media attention and being located at a site that would be demolished for the expressway, the protestors pointed to the damaging impacts the project would have. Unlike the 2011 protests, which had trouble highlighting the tangible impacts of a planned expressway, the sit-in helped point to the imminent damage and dislocation that was about to occur: the eviction of a local resident and businessman from his property. This imminent threat helped bypass any uncertainties regarding the arguments surrounding the traffic and economic justifications of the project and the uncertainties surrounding the levels of public opposition. Instead, the protestors pointed to the imminent damage and social dislocation that a large concrete expressway would cause.

However, because the NZTA's representatives did not arrive to hand an eviction notice to the owner of the garden centre, the imminent threat of damage and social dislocation was not made visible to the general public. Due to a mix-up surrounding the eviction date, there was no confrontation between the owner, protestors, and the NZTA. A dramatic confrontation would have helped justify a potentially lengthy sit-in at the garden centre and would help gain 
wider public interest in the project. However, to compensate for this anti-climax, the protestors sat in the garden centre's car park and held their placards while the local journalist took photos. I noted that the journalists and photographers helped the expressway's event appear more 'newsworthy' by encouraging them to chant and raise their hands. After 30 minutes of posing for, and talking to, journalists and news crews, the protestors walked approximately 50 meters to the state highway where they attempted to gain public support by holding up their placards to passing motorists. Importantly, the journalists and media crew recorded their actions to highlight the impact of the project on affected property owners. Overall, the protest lasted for approximately one hour as there was no confrontation and the protestors had managed to communicate their message to the news crews and journalists. Despite the mix-up with the eviction date and lack of confrontation, the protestors were able to point to the damage and dislocation that would occur in the near future.

\subsection{The Limitations of Site-Specific Protests}

Like the community organised meetings, Save Kāpiti's ability to publicise the expressway as an object of concern was constrained by whether their demonstrations resonated with the wider public. Relying on public statements at the community organised meetings seemed to place limitations on the anti-expressway group's ability to persuasively articulate the project as an object of concern due to the uncertainty surrounding its potential impacts. As discussed above, the protests bypassed this issue by pointing directly to the impacts that would be caused by the expressway. That is, the expressway's destructive impacts were not only made visible through words and protest actions, but were being pointed to by the protestors. By organising the protests at various sites around Kāpiti the protestors made the negative impacts of the proposed expressway visible by displaying what might happen to the community. The display of balloons, media interviews and coverage on affected properties helped publicise the expressway as an object of concern in a way that was not dependent on the claims made by political leaders, experts, or local residents in public meetings.

While Save Kāpiti's demonstrations helped overcome some of the limitations of public meetings as sites for publicising the expressway as an important issue, their site-specific demonstrations did not seem to challenge the view that the negative impacts on local communities should not halt the construction of a 'nationally significant' infrastructure project. Letters to the editor and opinion pieces by expressway supporters illustrate the difficulty of publicising, what appears to be, a local problem as a national issue. For instance, 
an editorial in The Dominion Post claimed that home "owners are understandably upset by the prospect of losing not only their properties", but as "Wellington is the nation's capital. It needs a $21^{\text {st }}$-century road to service a $21^{\text {st }}$-century city" ("Editorial: Bring on the expressway," 2011). In an article on Save Kāpiti’s final protest, a commenter wrote: "why don’t protesters ever think about others! Why do they only think about themselves!! This highway will serve the people of New Zealand!! All will benefits [sic] from this!!” (as cited in Blundell, 2013b). Another expressway supporter responded to these questions by writing:

. . because they're selfish. They want Kāpiti to return to the 1970's with a dusty unsealed road between the main road and the beach. Absolutely agree that the expressway will serve the country, you only have to look at Labour weekend for yet another example of what is wrong with status quo. Save Kāpiti seem hell bent on harming not only the economy, but the environment from emissions caused by vehicles stuck in congested traffic. (as cited in Blundell, 2013b)

These comments by expressway supporters reveal that, although Save Kāpiti might be pointing out the possible negative impacts of building an expressway, site-specific actions were seen by some people as 'selfish' as they were fighting against a project that would have national benefits. As the project, according to these comments, would boost economic growth, reduce congestion, and lower carbon emissions, the local objections from the protestors appeared to prioritise site-specific issues over national issues that seem more important.

The challenges involved in publicising local objections as national issues, suggest that the site-specific protest actions did not overcome the NIMBY label that is often associated with local opposition to urban development and infrastructure projects (Boudet, 2011; Burningham, 2000). Appealing to the direct impacts on quality of life and property can help local opposition groups receive compensation from the project sponsor or demand an authority to make changes to a project (Burningham, 2000). In this case, however, the protest's site specificity (Barry, 2001) constrained the protestors' ability to challenge the idea that national concerns are more important than local issues. The protestors and their placards did mention broader concerns, such as climate change, the questionable economic benefits of the expressway, and the democratic aspects of the decision-making process. For example, one placard referenced these wider concerns by stating that that the expressway was "another foolish plan from govt [sic] that ignores community wishes, climate change, oil resources, traffic research ...”. But, these wider concerns were not the focal points of the protest. By 
focusing on the local impact on property owners and the character of the beach-side communities, the local opposition groups indicated that they were not expanding beyond the single issue of opposing the Kāpiti expressway.

Specifically, anti-expressway opponents did not seek to strengthen their alliances with an environmental group that were using the expressway as an example of the National Government's inaction on the issue of climate change. The environmental group Generation Zero linked the Kāpiti expressway project to the wider 100\% Possible climate change campaign that aimed to shift New Zealand 'beyond fossil fuels' and the demands from other environmental groups, such as 350 Aotearoa and the World Wide Fund for Nature (WWF) (“About - 100\% Possible," n.d.). Rather than organising their protests at the site of the proposed expressway, Generation Zero organised their events next to the Parliament Buildings in Wellington and in two other major cities in New Zealand. The 'Kāpiti Expressway: Prehistoric Policy' protests in Wellington, Auckland, and Dunedin used the Kāpiti expressway as an example of the "wasteful spending on dinosaur motorways" (see Figure 11). This quote, which is taken from a pamphlet I received at their dinosaur-themed protest in Wellington, was used to encourage the public to tell Prime Minister John Key that the 630 million dollars that is being used to build the expressway should be used for a more cost-effective road and investments in cycleways and light rail. The protestors held placards that highlighted the wider issues of the government not addressing climate change through its policies and the lack of funding for 'vital' rail projects. Furthermore, staging this protest in three major cities helped publicise the Kāpiti expressway as a national, rather than local, issue. In other words, while the protest emphasised the importance of stopping the Kāpiti expressway in particular, its focus was on the wider, national issue of investing in 'smart', low-carbon transport projects to address climate change. 


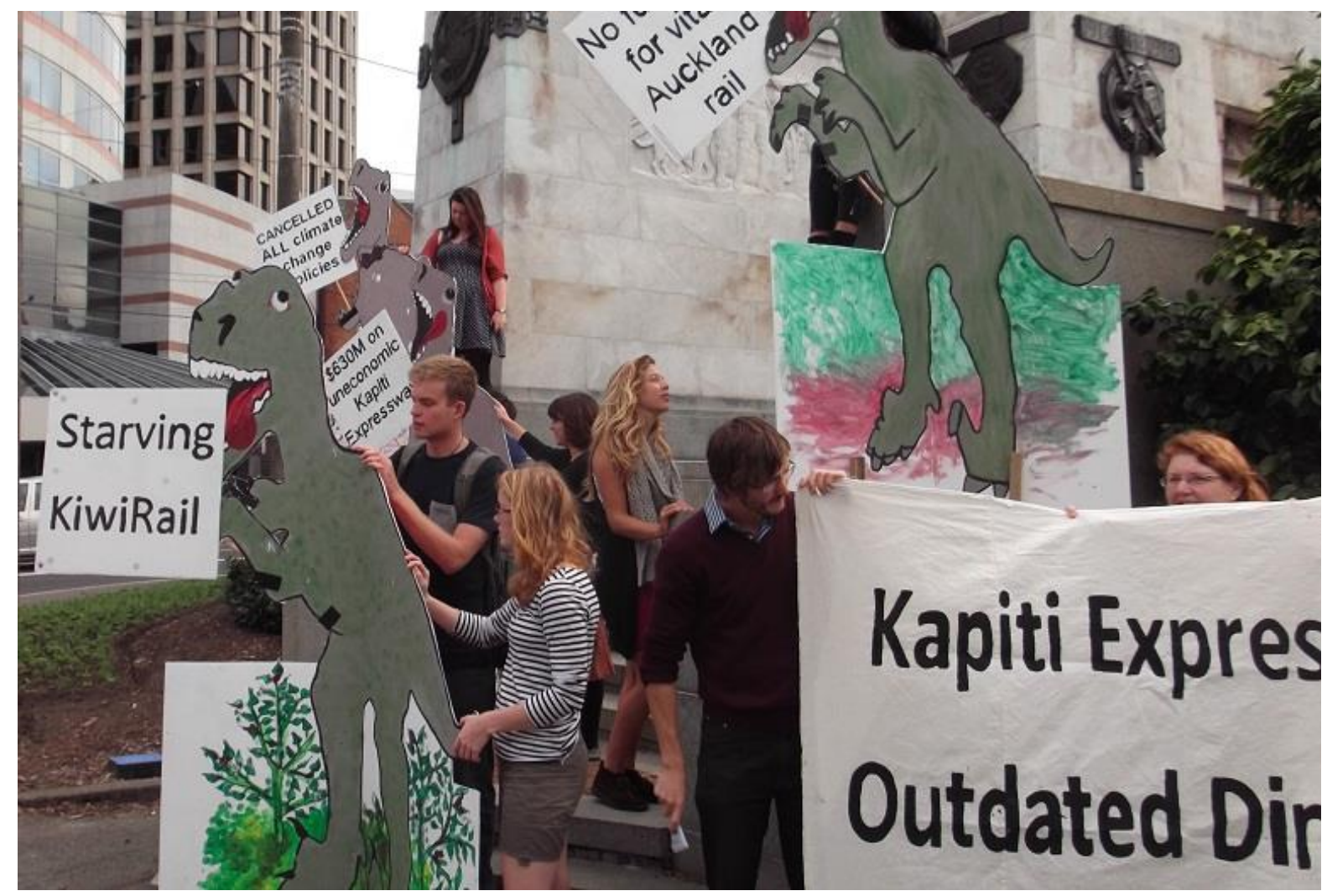

Figure 11. 'Kāpiti Expressway: Prehistoric Policy' protest.

While it is beyond the scope of this chapter and thesis to provide an in-depth examination of the alliances between anti-expressway and environmental groups, the $100 \%$ Possible campaign and the responses from expressway supporters reveal the difficulties locally-based groups can encounter when they publicise an issue as an object of public concern. The sitespecific protests pointed directly to the impacts that the expressway would cause. However, as they were local protests organised by locally-based groups and residents, expressway supporters could easily dismiss the issues they were pointing to as local concerns that appear to be selfish when compared to the national benefits of the project. The $100 \%$ Possible campaign helped highlight the wider implications of the expressway project by connecting it to climate change, but this did not prevent supporters of the project pointing out the weaknesses of site-specific protests. Rather than pointing to an object of concern, the sitespecific protests pointed to the existence of an object that could be beneficial, rather than detrimental. That is, if the wider benefits of the project can be made visible, then the connection between the request to stop construction and a demonstration that points to the expressway's impact collapses by pointing to an inarticulable object (Callon, 2004, p. 126). 


\subsection{Conclusion}

The issue of how opponents of a public infrastructure project are able to publicise their concerns without being labelled as selfish NIMBYs is a key problem faced by residents and local groups who want their concerns to resonate with the wider public. As I have discussed, opponents of the Kāpiti expressway project went well beyond the difficult challenge of voicing their concerns in public by organising site-specific demonstrations that pointed to the communities and land that would be directly affected by the expressway. By pointing to the destruction that they believed would be caused by the expressway, the opponents helped make the expressway visible as a matter of public concern. The practice of 'pointing' highlights the idea that socio-technical arrangements made it possible for the opponents to re-present the expressway as an object of concern. While their site-specific protests were publicly criticised, the protestors were able to communicate their concern with the technical and legal issues with the project by pointing to the impacts that it would have on Kāpiti.

By examining demonstrations as political and technical practices, I have highlighted the idea that the devices and technologies of politics can play a central role in controversies. For the NZTA, their public consultation exercises made the expressway appear fact-like by pointing out what the public could comment on. It was only when a public meeting was held that the NZTA's re-presentation of the expressway as a matter of fact began to crumble. During these meetings, the public were able to voice their concerns to journalists as they were not limited by feedback forms or other techniques that regulated disagreement. However, while the public meetings helped concerned residents publicise the expressway as a serious issue, they faced the daunting challenge of creating persuasive evaluations that could persuade the general public that the expressway was a bad idea. As rational arguments alone did not lead to wide spread public opposition or a reframing of the expressway as an important problem, the opponent's site-specific protests helped make the project visible as a significant public issue.

On reflection, Save Kāpiti's site-specific protests appeared to be too specific to the Kāpiti Coast. Their demonstrations publicised the expressway as a significant local issue, but they were unable to evaluate it as an object of national concern. Comments in the news media pointed out that the impacts of the project were relatively minor compared to its national benefits. The protest actions from the local groups reveal the challenges that surface when political actors attempt to make a particular issue relevant to a wider public issue. Generation Zero helped connect the project to their climate change campaign and the site-specific protests 
referenced the wider issues surrounding the project, but the locally-based groups were unable to challenge the idea that the project would be nationally significant and, therefore, more important than the concerns of local residents. 


\section{Chapter Six: Visualising Distress}

\subsection{Introduction}

In the previous chapter I argued that publicising the Kāpiti expressway project as an object of collective concern was accomplished through a range of technical practices and demonstration sites. An important aspect of this publicity process, which I have not yet examined, was the important role that visual representations of the expressway played in the controversy. In this chapter I focus on how the expressway's environmental, landscape, and social impacts were visualised, publicly displayed, and debated. Publicising and debating the potential impacts of the expressway involved not only speaking on behalf of affected communities and environments, but also visualising these concerns using various "tools of representation" (Girard \& Stark, 2007, p. 148). Visual materials were used to make the expressway's impact on the affected communities visible by showing them to various audiences. Rather than only protesting the impact of the expressway, visual representations and simulations were used by the NZTA and oppositional groups as rhetorical devices that could demonstrate the benefits and problems of the project. As Stark and Paravel (2008, p. 31) claim, "in an era when policy decisions involve complex technical questions, demonstrations are as likely to marshal charts, figures, models and simulations as to mobilize popular movements in the street [emphasis in original]".

In this chapter I examine the idea that visualising the potential impacts of the expressway played an important role in making it visible as a public issue. The use of visual material was an important tool for persuasively demonstrating to others the possible social and environmental impacts of the expressway. Visual representations did not simply allow the public to 'see' the expressway's impact on the affected communities, but also provided clues as to what it would 'feel' like. As the NZTA's visuals did not illustrate the lived impacts of the expressway, I suggest that a challenge for concerned residents was to demonstrate what it would be like to live with the proposed expressway in the community. I argue that the role of visual imagery in socio-technical controversies can influence how people learn about, and engage with, important public issues. In this case, the visual images produced by the local activist groups played a key role in creating competing interpretations of the expressway project and mobilising the community to take action against it.

This chapter is divided into three sections. In the first section, I briefly review the sociological literature on visual representation and public demonstrations in scientific, socio-technical, and 
urban planning controversies. In the second section, I analyse the visual images that were displayed in the NZTA's public consultation brochures and information centre. I examine how the NZTA publicised what effect the expressway would have on Kāpiti's urban environment. At first, this involved representing it as a line on a map to demonstrate what properties would be affected, but people were also interested in what it would be like to live with an expressway in their community and environment; that is, how it would affect the attractiveness of Kāpiti. So an important problem for the NZTA was how to 'see like the community' - how to publicly demonstrate that the expressway's visual or amenity impacts could be 'seen' and, therefore, managed or mitigated. This involved a shift in perspective from, what Thévenot (2007) calls, "professional" or "planned" formats of engagement to "familiar" forms of engagement. I argue that the NZTA allowed the public to see the impacts of the expressway by aligning professional and familiar formats of engagement, but this form of engagement purified the lived aspects of the project from its visual aspects.

In the third, and final, section I compare the NZTA's visual material with the visuals produced and publicised by local residents and opposition groups. Specifically, I examine a documentary produced by a local resident as a counter-demo that visualised familiar attachments to Kāpiti while also persuading the public to take action against the expressway project.

\subsection{Visual Representations and Demonstrations in Public Disputes}

The importance of visual representations in public disputes is not a new phenomenon. Images, photos, diagrams, videos, and the like play a central role in contemporary societies that rely on the use of visual technologies to communicate meaning (G. Rose, 2001). New visual technologies (such as computer graphics and digital video) and communication mediums have helped change the dynamics of public disputes. For instance, the video footage of Rodney King's violent beating in 1991 was a key piece of evidence in the trial. It was used by the prosecution as conclusive proof of the police officer's wrongdoing and by the defendants as evidence of legitimate police work (Goodwin, 1994). More recently, and in relation to infrastructure disputes, computer generated images that visualise impacts of projects are used by supporters and opponents to make persuasive claims.

However, the importance of visual representations and technologies in sociological studies of dispute, and the social sciences more generally, was not recognised until the late-twentieth century, when social scientists began to focus on how people make sense of their worlds 
through diverse "representational systems" (sounds, images, inscriptions, and communication channels) that help produce meaningful reality (Hall, 1997). This shift is associated with the turn to constructionist approaches to knowledge that claim representations do not simply mirror what exists in the 'real' world, but provide culturally specific constructions of it through the collective codes, conventions, and rules of language (Hall, 1997, p. 25). In cultural sociology and studies of visual culture, the effects of visual representations and mass media on social life have been a key focus since the 1970s. For instance, feminist and postcolonial researchers have highlighted how images construct social difference and reinforce dominant visions of gender, ethnicity, and sexuality (G. Rose, 2001, p. 11). And, British academics from the Birmingham Centre for Contemporary Cultural Studies (CCCS) examined the mass media's role in reproducing the hegemony and ideologies of dominant groups (G. Turner, 2003). Around the same time (late 1970s and 1980s), STS researchers were examining the role of visuals and technologies of visualisation (such as graphs, tables, and imagery) in scientific practice and in the work of engineers and technologists (Fyfe \& Law, 1988; Latour \& Woolgar, 1986; Lynch, 1985; Lynch \& Woolgar, 1990).

Like visual representations, public demonstrations, which I have discussed in Chapter Five, play a key role in socio-technical controversies. Project sponsors of infrastructure projects, urban developments, and new technologies are obliged to provide visual simulations or demos of the completed project or technology. The term "demo", according to Rosental (2013, p. 349), is a specific type of demonstration that exhibits a technological device in action. In the applied sciences, they are used "to demonstrate the feasibility of a technological approach, the value of a specific theory, or the proper running of a prototype or product" (Rosental, 2013, p. 349). In everyday life, they are used to "share excitement or provide instruction in a product, or to promote adoption or sales, as in Tupperware meetings" (Rosental, 2013, p. 348).

As I will discuss, the public demonstrations and visuals used by actors involved in the Kāpiti expressway project functioned as rhetorical devices and "cognitive tools" (Rosental, 2013). Demo-models of the expressway were used by the NZTA and other opposition groups during the early stages of the project to persuasively 'show' their ideas to others. While demonstrations are used for a range of scientific, commercial, and political purposes, they are, according to Rosental (2013, p. 344), often seen as an exercise in proving or convincing. As Latour (1990) suggests, the images and inscriptions used by scientists and engineers provide them with a unique advantage in a dispute: 
'You doubt what I say? I'll show you.' And, without moving more than a few inches, I unfold in front of your eyes figures, diagrams, plates, texts, silhouettes, and then and there present things that are far away and with which some sort of two-way connection has now been established. (p. 36)

Moreover, Collins (1988, p. 728) suggests that demonstrations are "post-closure phenomenon" that are often "designed to educate and convince once the exploration has been done and the discoveries have been made". Demonstrations, according to Collins (1988, p. 728), are "displays of virtuosity" that seem convincing due to the 'smoothness' of the presentation and performance. For instance, visual demos of proposed infrastructure projects seem to function as cognitive tools that allow the audience to 'see' the road project and learn about its impacts on the community and environment (Rosental, 2013). In the case of the Kāpiti expressway, the NZTA's visual demos allowed the public to see, and learn about, the expressway as a functional object that improves transportation efficiency.

In the case of infrastructure projects, visual demos are designed to persuade the public during the development of the project, not after or post-closure. And, counter-demos are often used by activist groups to be persuasive about matters that are both political and technical: they are used to "speak to ... the political interests and the technical questions at stake" (Stark \& Paravel, 2008, p. 31). Counter-demonstrations are often used by actors to produce competing interpretations of infrastructure projects and to mobilise action. According to Stark and Paravel (2008, p. 49), counter-demos are demonstrations that have "slipped out of the control of the initial demonstrator". Rather than being a "display of virtuosity", counter-demos function as "displays of volatility" that introduce elements of uncertainty and scepticism (Stark \& Paravel, 2008, p. 49).

As suggested above, the literature on visual representation in socio-technical and urban planning issues tend to focus on the rhetorical power of visual imagery. Rhetorical approaches to urban planning focus on the idea that images and urban designs are stories about the future (van Dijk, 2011). Similarly, other urban planning approaches focus on how visuals influence perceptions and decisions at an emotional level (Sheppard, 2001). Sociologically, the production of visual representations is often analysed as an ideological practice that not only re-presents certain understandings of the world (Jansson \& Lagerkvist, 2009; Waterton, 2009), but can also play an important role in making society "legible" and, therefore, manageable for authorities and political groups (J. C. Scott, 1998). 
In contrast, ethnomethodological studies of professions and work have examined how visual representations complement spoken language and "organize phenomena in ways that spoken language cannot" (Goodwin, 1994, p. 611). Rather than obscuring other understandings of the world, Goodwin (1994, p. 619) focuses on how "the coding of events within a relevant perceptual field" is contested in professional settings. In terms of urban planning issues, Büscher (2006, p. 282) examined how landscape architects "actively shape a sense of place through design suggestions and assist others, including the general public, in making sense of place as part of their assessment”. In other words, she explores how landscape architects "proof professional vision and make it portable for repeat performances with different actors" (Büscher, 2006, p. 289).

Similarly, socio-cultural approaches to urban politics and social movements have focused on how visuals images are used to frame issues, mobilise action, and strengthen arguments (D’Angelo \& Kuypers, 2010; Doerr \& Milman, 2014; Jasper, 2014). As outlined above, cultural sociological approaches to politics examine how the meaning of an event or issue plays a key role in political life. This means that the framing of an issue using certain words, visuals, and communication mediums plays a key role in making it political or "visible and relevant to visions of how social relations are and could be organized" (Nash, 2010, p. 2). For example, in relation to Boltanski and Thévenot's pragmatic sociology, Blok and Meilvang (2014, p. 3) used their theoretical insights to "highlight how photographs, drawings, and other forms of visualization allow for the shared expression and translation of embodied forms of attachments not well accommodated by the semantic apparatuses of expert urban planning”. In other words, visuals can help activists make familiar attachments to place relevant to public claims and common concerns (Blok \& Meilvang, 2014, p. 15). Socio-cultural approaches to visual representations, therefore, share similarities with Rosental's (2013) understanding of demonstrations as rhetorical devices and cognitive tools that can help open new political spaces, mobilise allies, and create persuasive evaluations and critiques of urban plans.

In this chapter, I utilise the diverse approaches to visual representations and demonstrations outlined above, but primarily I will be drawing on Boltanski and Thévenot's cultural approach to visual representations. Given my focus on how the public engaged with and evaluated the options for the Kāpiti expressway project, Boltanski and Thévenot's theoretical approach helps emphasise the importance of visuals in public involvement in issues involving science and technology. In particular, Thévenot's (2007) research into "regimes of engagement" provides insight into how the NZTA and local residents understand and engage with road 
projects. And, Boltanski and Thévenot's (2006) sociology of justification can help us understand how residents and opposition groups tried to persuade the public to take action against the project by making their concerns relevant to publicly justifiable forms of action.

\subsection{NZTA's Professional Vision}

The problem of what it would be like to live with an expressway in a semi-urban environment was a key issue for many people. As discussed in Chapter Four, when the expressway project was first made public in the NZTA's August 2009 public consultation brochure it was visualised as a line on a map, which made it difficult for the public to see or imagine what impact it would have on their lives and community. As a route had not been selected, the NZTA used aerial maps with superimposed lines along the proposed routes to visualise the expressway's impact on affected properties. These images provided a very general picture of where the expressway could go and who or what might be affected.

While the use of maps might not help the public see the impacts of the expressway, using maps to represent the expressway aligns with professional or planned regimes of engagement. The concept "regime of engagement" was developed by Thévenot (2007, p. 415) to understand the various cognitive and evaluative formats that are used to "access" and "grasp" reality so as to coordinate behaviour or action within apprehension frames. In contrast to public justifications, which make reference to the common good, planned and familiar regimes of engagement are situated below the level of public judgement and critique (Blok \& Meilvang, 2014, p. 4). According to Thévenot (2002, p. 73), a regime of engagement in a plan involves intentional human agency and functional objects. In other words, "analysis of this regime of engagement brings out the complementarity between [an] agent's power as an individual engaged in realizing his project and a grasp of the object in functional terms" (Thévenot, 2007, p. 417). For example, the NZTA aims to improve transportation efficiency (intentional agency) by building an expressway, which is a functional object that is planned and designed to achieve this aim (Thévenot, 2002, p. 72).

In contrast, in a regime of familiar engagement, human agency is not intentional but is dependent on idiosyncratic linkages with familiar surroundings (Thévenot, 2002, p. 71). Within this regime of engagement, objects are not used for their planned or conventional functions, but are used for a range customised purposes (Thévenot, 2002). For example, residents use roads and paths in ways that deviate from its functional purpose of transporting people from one place to another. 
Not surprisingly, the use of aerial maps visualised the expressway as a functional object - a means for reaching the government's objective of improving transportation efficiency. The aerial maps, which were publicised during the initial stages of the project in 2009 and 2010, visualised the expressway's territorial or property impacts (see Figure 12). Rather than focusing on the scenic and lived aspects of the project, which is, arguably, of more interest to the local communities, the use of aerial maps visualised the expressway's location and the affected properties (Lindholm, 2012, p. 10). Publicising the expressway as a functional object that will affect property owners reveals how the NZTA grasps reality in terms of successfully realising its plan to improve transportation efficiency: they are concerned with identifying an area of land or route that can be utilised for the transportation of vehicles. For example, while the land is used by the community for a variety of recreational and cultural purposes, the NZTA did not visualise familiar utility during the early stages of the project - they focused on identifying areas of land that could be used to transport vehicles between places (Thévenot, 2001, p. 71).

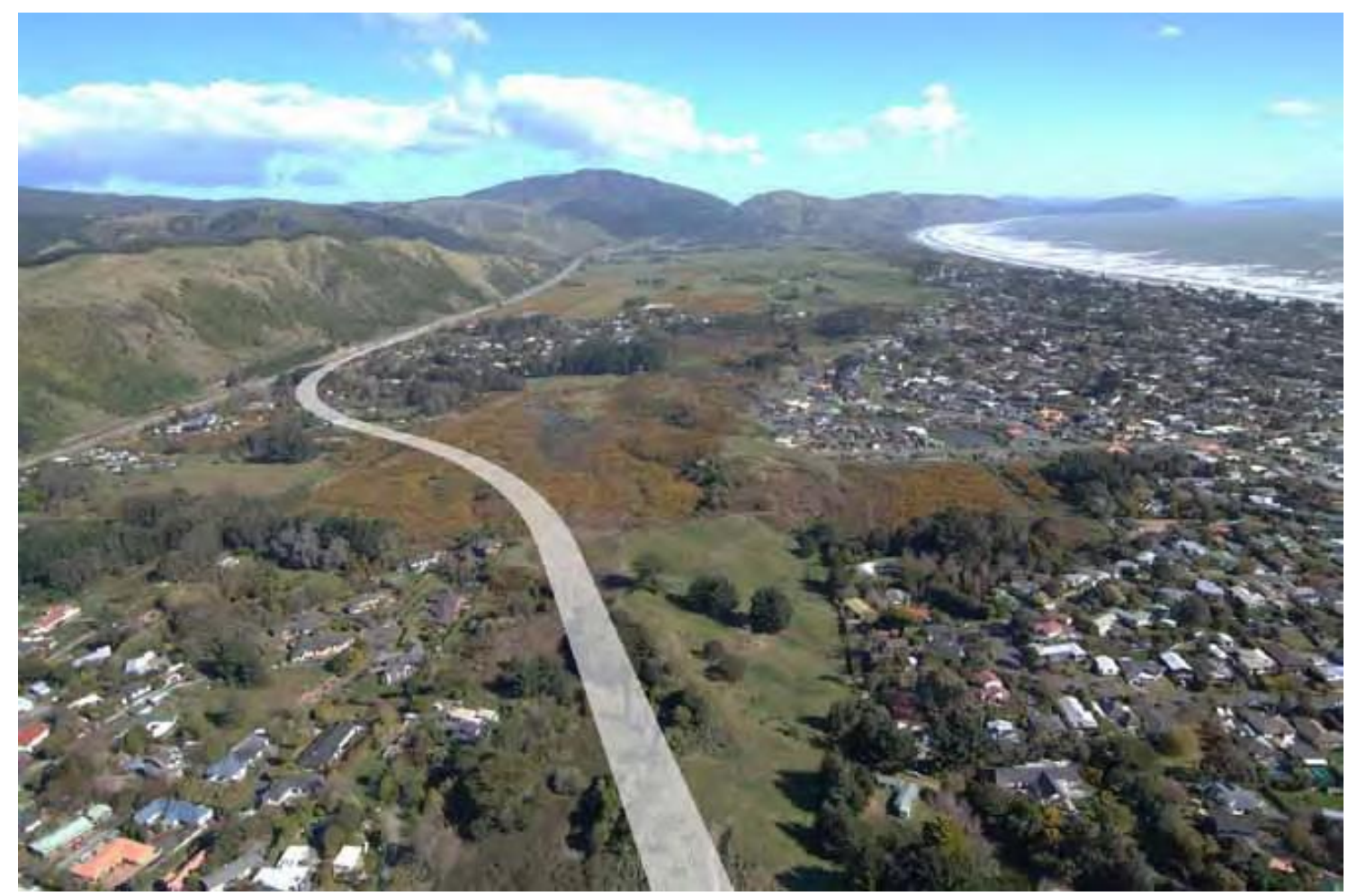

Figure 12. "indicative road carriageway alignment" (New Zealand Transport Agency, 2010b, p. 9).

The contrast between planned and familiar formats of engagement surfaced in news reports from 2009 and in my interviews with local residents and activists. When coding news reports 
on the expressway project, the clash between conventional and familiar utility emerged as an issue of conserving or protecting important aspects of life that would be affected by the expressway. Local iwi were concerned with protecting a traditional right of way, which was used to carry coffins to a family cemetery, while other people were concerned with protecting Kāpiti's 'heartland'. Residents were also concerned about emergency services being compromised due to the limited number of access points and congestion. Other concerned citizens also highlighted that an expressway might go through a local car museum and Queen Elizabeth Park, which are important tourist attractions for Kāpiti. However, a recurring concern was the protection of local business and trade. People were concerned that an expressway with limited on- and off-ramps would have a negative impact on local businesses - they were afraid that the expressway traffic would bypass Kāpiti due to the limited number of on- and off-ramps. These examples illustrate that, while residents were concerned with the territorial impacts of the expressway, they were also concerned that the expressway project would threaten the familiar utility of land by restricting its use to transportation between places. The criticisms from the community suggest that residents do not simply see roads as functional objects: they see roads as familiar objects that connect people while preserving the familiar utilisation of the land.

My interviews with local residents also illustrate the contrast between familiar and planned formats of engagement. When asking my participants to reflect on what Kāpiti would be like if an expressway was built, two recurring themes were the issues of connecting local communities and preserving the landscape and sense of place. My participants were concerned that the expressway project would not be user friendly for local residents due to its relatively small number of intersections. They were concerned that the ability to easily move within and between the communities in Kāpiti would be threatened by an expressway that was designed to transport vehicles through the district. In other words, the expressway was seen as a barrier that threatened the familiar utility of the land. Rather than being a residential object that connected local communities, the expressway was seen as a functional object that was designed to move vehicles through Kāpiti at the expense of local connectivity. As one of my participants explained:

Kāpiti will never be the same. People don't realise, a lot of people don't realise what this will do to east-west traffic and congestion, and their lifestyle. It will just screw everything. (Research Participant, personal communication, August 22, 2013) 
In contrast to the expressway project, the participant describes the two-lane Western Link Road project as an ideal residential road:

[It] connected all of the suburbs right throughout Kāpiti and all of the streets, you could just hop on here, there and everywhere, there were so many connections, you didn't have to go for miles to get on it. It was part of the community, it was integrated, it was more than a road, it was a lifestyle. (Research Participant, personal communication, August 22, 2013)

The issue of preserving the landscape and sense of place also revealed the contrast between planned and familiar formats of engagement. My participants suggested that the expressway project was a 'concrete monster' that would change Kāpiti's landscape 'forever'. The following quote illuminates the idea that the expressway was a functional object that threatens resident's familiar attachments to Kāpiti as a place:

When you've got something that big, and that high, the shade will be phenomenal for people, they won't get all the sun they get, and when you're on the hill you want the view of Kāpiti Island, that thing will be running right through your vision. People . . . haven't figured out how different it will be, it will just destroy us. It will not be a seaside suburb. (Research Participant, personal communication, August 22, 2013)

\subsection{NZTA's Community Vision}

In response to the community highlighting their concern with the lived aspects of the project, the NZTA attempted to align planned and familiar formats of engagement by visualising the lived aspects of the project. Once the route for the expressway was finalised in 2010, a key issue for the NZTA was to design the expressway in a way that demonstrated to local residents how it would affect the community and environment. Rather than simply identifying affected properties, which was the focus of the previous public consultation exercises, the NZTA produced a number of visual simulations and a 'fly-through' video that demonstrated what the expressway would look like in the community and environment. The NZTA also explored the issue of how the expressway would affect the community and environment by providing information on noise, vibration, air quality, ecology, storm water, cultural heritage, 
and walking and cycling. However, as I am interested in examining the issue of what it would be like to live with a large concrete structure in the community I focus on the NZTA's visual simulations and fly-through video.

In particular I examine the NZTA's visual simulations as cognitive tools (Rosental, 2013) that provide the public with an opportunity to learn about the project and to see how the project might affect them. Unlike planning documents and maps, the fly-through and visual simulations helped illustrate the technical aspects of the project and visualise a future scenario (Lewis, 2012, p. 552). Indeed, Sheppard (2001, p. 187) suggests that the use of realistic images help persuade the public and decision-makers by influencing perceptions and "emotions much more than the products of other visual technologies such as GIS maps". Moreover, rhetorical approaches to urban planning claim that the images, plans, and texts produced by urban planners are "essentially an intervention at a deep level that is meant to change perceptions, expectations and the intentionality behind human behaviour" (van Dijk, 2011, p. 127). Compared to the NZTA's aerial maps, the use of aerial imagery in the flythrough and visual simulations demonstrates the expressway's impact by visualising the expressway in the community and environment.

However, rather than simply allowing the public to see the lived impacts of the expressway, I argue that the NZTA's simulations enacted a professional regime of engagement which purified the lived impacts of the expressway from its visual aspects. That is, the visual simulations enacted a reality that purified 'vision' from 'feeling' (Latour, 1990, p. 27). This purification, I suggest, reveals how visual demos act as rhetorical devices that communicate familiar forms of engagement from within professional approaches to the project. That is, rather than shifting from professional to familiar formats of engagement, the visual simulations created a visual model of the expressway as a functional object which allowed the audience to see the expressway's visual impact without revealing its impact on the “experienced milieu” (Blok \& Meilvang, 2014, p. 5). I suggest that purifying vision from feeling helped persuade the public and decision-makers that the impacts of the expressway could be seen and, therefore, managed and mitigated.

During the design and development consultation phase in May 2011 the public could see, for the first time, the expressway as a residential, rather than functional, object. This consultation phase consisted of four one-day project expos and individual meetings that were held at various locations on the Kāpiti Coast. The 908 attendees were asked to provide feedback on 
the design of the proposed expressway (New Zealand Transport Agency, 2011c, p. 31). Additionally, the information from the expos was displayed at the Coastlands Mall information centre and on their project website. An estimated 2,750 people visited the information centre from May 2011 to June 2011 and the home page of the project website received 2,069 page views (New Zealand Transport Agency, 2011c, p. 32).

In addition to the maps of the expressway, the design and development expo had a fly-through video and information panels that provided visual simulations of the expressway and its possible impacts. The fly-through was a short computer-generated video that provided an aerial view of the proposed $18 \mathrm{~km}$ expressway and its landscape and visual effects (see Figure 13). The visual fly-through of the expressway was viewed 1,089 times from the project website and it was also viewed by the thousands of people who visited the information centre (New Zealand Transport Agency, 2011c). In contrast to the initial maps, the fly-through enabled the public to see what the completed expressway would look like in their community: it provided a demo or functioning model of the expressway that highlighted how many lanes, off-ramps, and bridges were proposed for the expressway. Moreover, simulated cars and trucks can be seen travelling on the expressway, which demonstrated what the expressway would look like 'in-use'. However, as the fly-through was produced by the NZTA, it emphasised the positive, rather than the contested, aspects of the project. That is, the flythrough did not provide a "contested vision" of the project by visualising smog, traffic congestion, and other issues associated with expressways (Goodwin, 1994). Rather, the flythrough reinforced the NZTA's professional vision of the project by depicting an aerial view of the expressway with free flowing traffic. For example, it is interesting to note how few cars and trucks there are travelling on the expressway. From personal experience, the current State Highway through Kāpiti is very busy, but this visual simulation implies that the traffic volume will be minimal on the Kāpiti expressway ${ }^{4}$. The visual fly-through, therefore, encouraged the public see the expressway as a residential object that they would see and use in their daily lives, but it did not highlight the problems associated with large expressway projects.

\footnotetext{
${ }^{4}$ The NZTA's other visual simulations also depict relatively empty expressways, which raises questions about the accuracy of the simulations.
} 


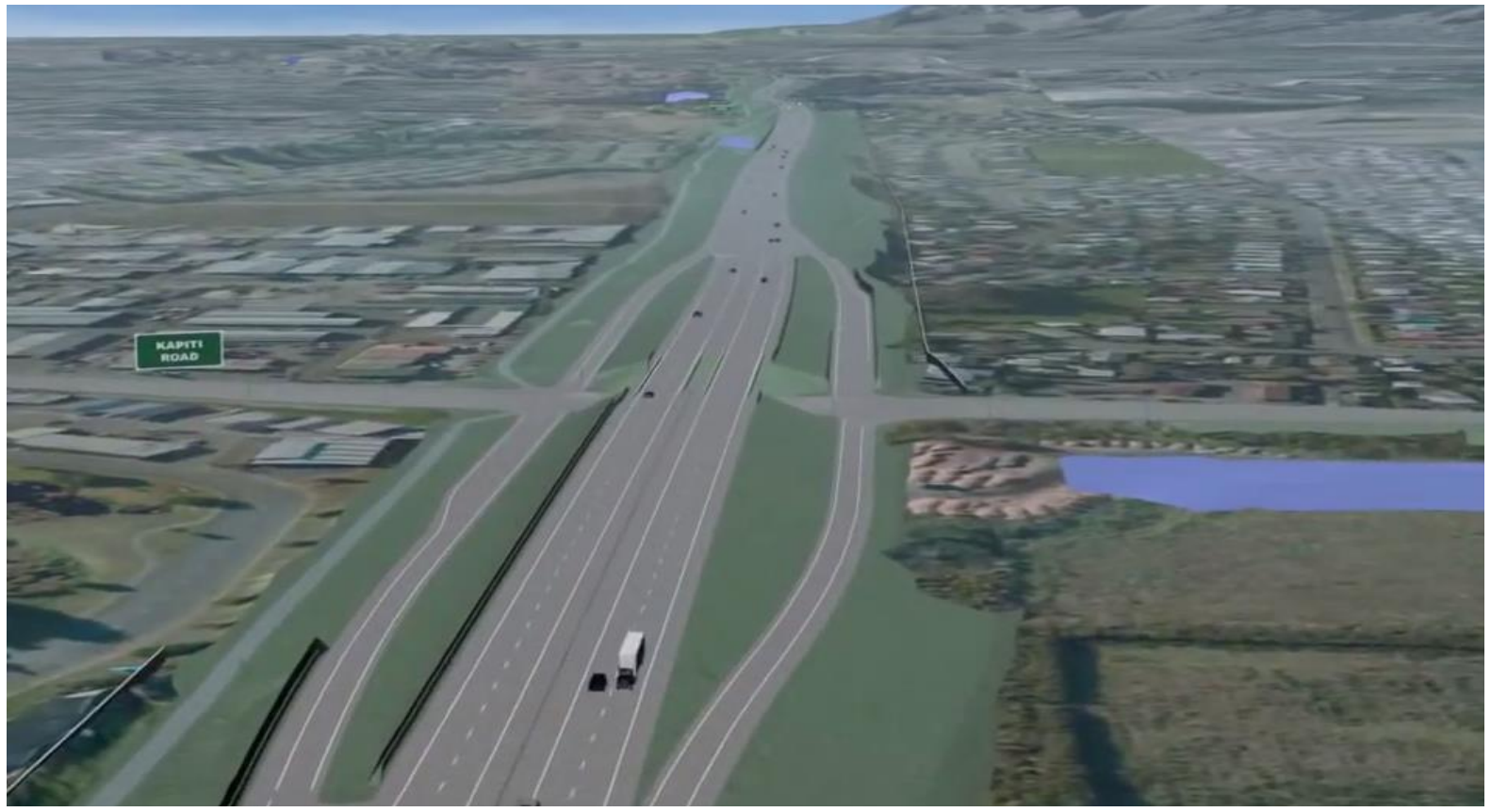

Figure 13. "MacKays to Peka Peka visual fly-through” (New Zealand Transport Agency, n.d.-b).

Additionally, the possible impacts on the environment and community surrounding the expressway are not brought into focus in the fly-through model. It is possible to see main roads, houses, and landscape features, but, compared to the visuals of the expressway, the level of detail is minimal. The levels of realism in this visual simulation allow the audience to see the expressway's visual impact without revealing its lived impacts. The audience can see that the expressway is a large structure that will have a significant presence in Kāpiti, but the absence of people and lack of detail means that it is difficult to see its impact on everyday life.

Like the fly-through, the NZTA's visual simulations continued to enact a regime of familiar engagement that purified vision from feeling. The visual simulations consisted of aerial and street-level images that visualised the expressway's impact on the landscape and community (see Figure 14). Compared to the fly-through, the aerial simulations provided the public with a more realistic view of the possible impacts of the expressway: the surrounding environment is not 'fuzzy' or blurred and it is possible to see surrounding houses, trees, and other distinctive landscape features. The 15 visual simulations show computer generated images of the expressway that have been drawn on top of a series of aerial photographs. Unlike the flythrough, the visual simulations reveal that the expressway's impact on the surrounding environment would be significant: the audience can see that the expressway is a large 
concrete structure that will change Kāpiti's rural and urban character. However, because of the aerial perspective, it is difficult to imagine the expressway's impact on the "lived-in environment" (Blok \& Meilvang, 2014, p. 5).

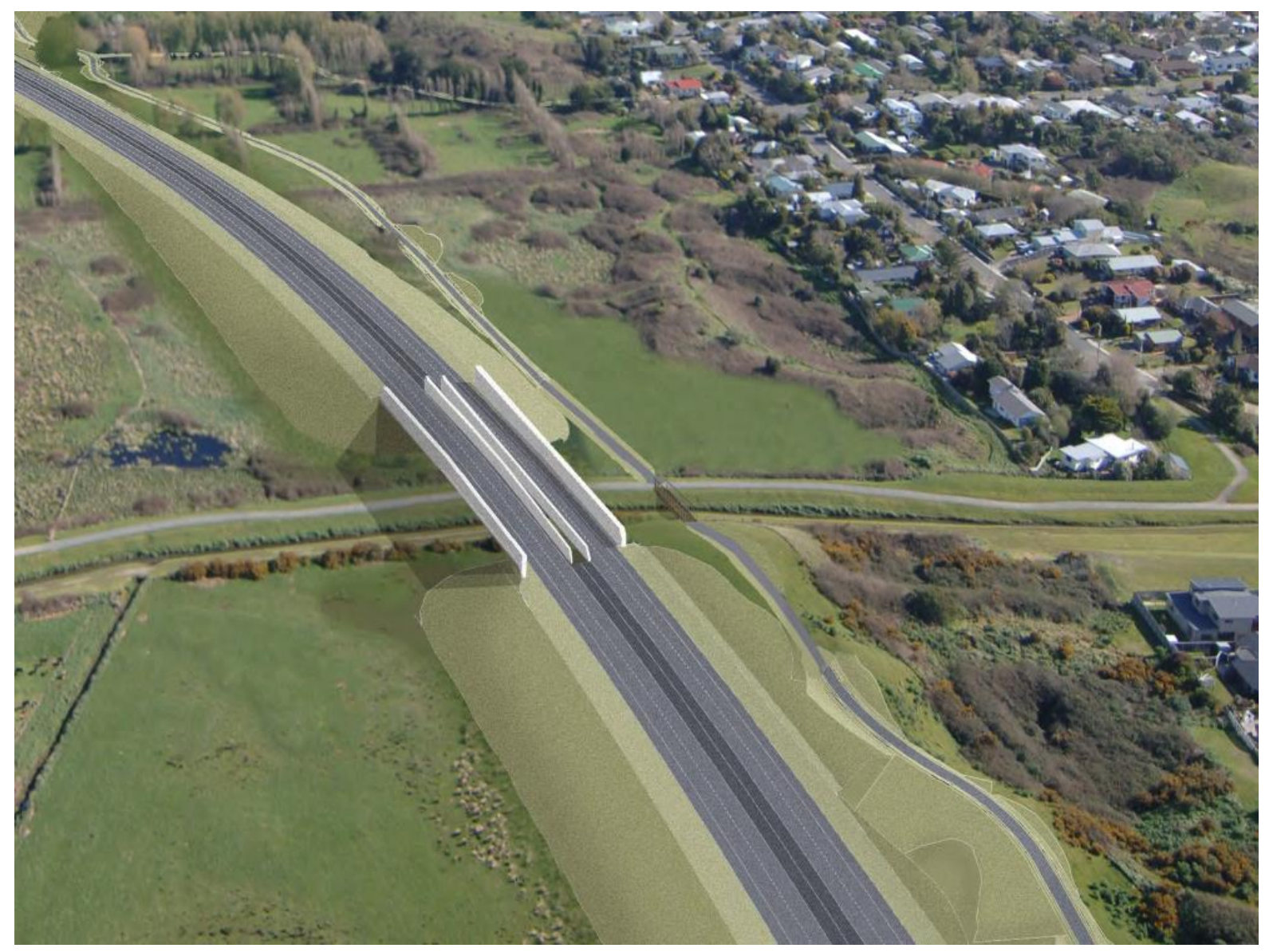

Figure 14. "Indicative aerial view of the Wharemauku Stream expressway bridge" (New Zealand Transport Agency, 2011b, p. 4).

To help overcome the limitations of aerial imagery, the street-level simulations enact a familiar regime of engagement by visualising the expressway's impact on everyday life in Kāpiti (see Figure 15). In contrast to the aerial images, the street-level simulations allowed the public to see what the expressway would look like in the community. The information panels displayed 15 street-level images from public locations. The street-level images show what the expressway would like in the community by placing computer images of the expressway into the photos taken by the NZTA's landscape experts. By visualising the expressway in these public locations, residents can see what it would be like to live with the expressway in their community. The images enact a familiar regime of engagement by visualising the expressway as a structure that people will drive, walk, or cycle under as they go about their daily lives in Kāpiti. Moreover, two images of the ground level sections of the expressway demonstrate 
how the ground level sections of the expressway will 'blend in' with its surroundings (see Figure 16). By visualising the expressway as an object that will not significantly disrupt the familiar surroundings in Kāpiti, the audience can see that an expressway retains a number of existing local roads, paths, and landscape features, such as streams and parks.

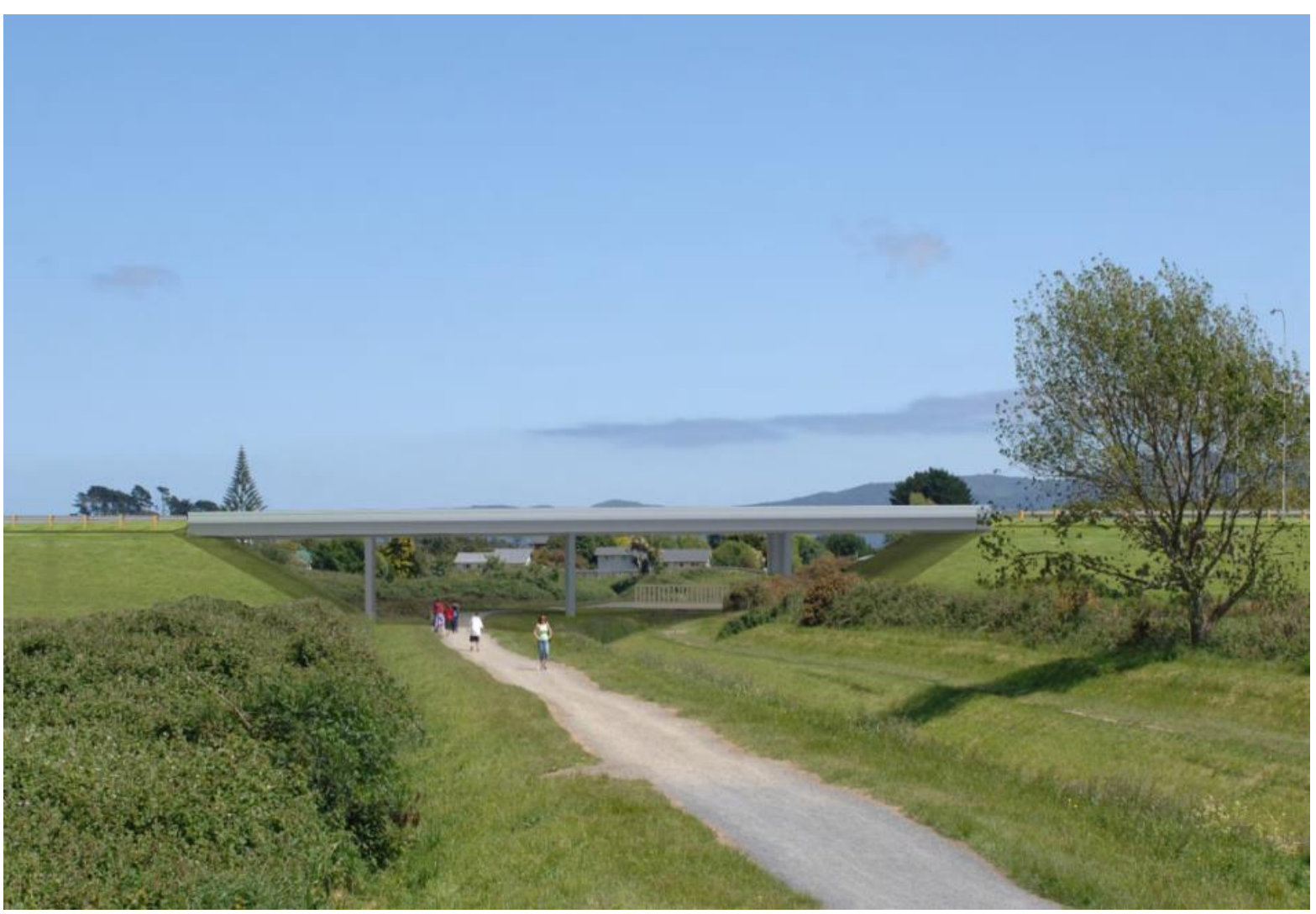

Figure 15. "Indicative view looking west on the Wharemauku Stream path - before mitigation work" (New Zealand Transport Agency, 2011b, p. 4).

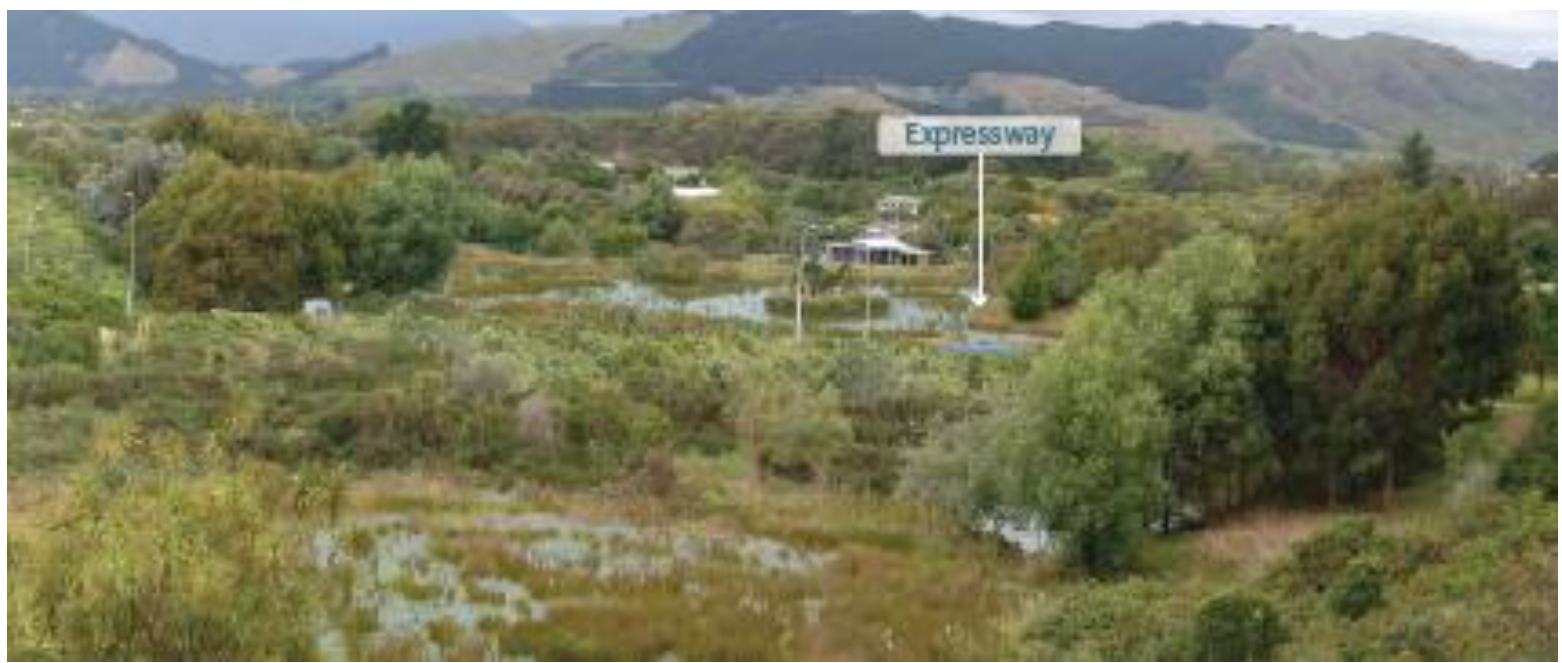

Figure 16. "Mitigation treatment" (New Zealand Transport Agency, 2011a). 
However, while the street-level simulations allow the audience to see the lived impacts of the expressway, the visual simulations do not communicate what it would be like to experience the expressway in-use. That is, the visual simulations, as a medium of expression, purify the visual impacts of the expressway from other sensory cues that are important for sustaining familiarity with the environment (Thévenot, 2001, p. 70). While the NZTA provided the public with information about noise, vibration, and air quality management, some of these issues, such as noise, cannot be portrayed visually. Without a wider range of sensory cues it is difficult for the audience to imagine what impact the expressway would have on their lives. In other words, while the NZTA attempted to 'see like a community', their visual simulations enacted a professional vision that purified the visual impact of the project from its lived aspects.

I suggest that separating the visual from the lived aspects of the expressway created a visual model of the expressway as a functional object, which closely aligns with the NZTA's professional vision of the project: a vision that is oriented to a regime of engagement in a plan (Thévenot, 2007). The demo model of the expressway visualises the NZTA's intention to improve transport efficiency between and within New Zealand's largest population centres (New Zealand Transport Agency, 2013). When watching the fly-through, I noted that no vehicles exited the expressway, which suggests that its main function is to facilitate transportation between towns or cities. Moreover, buses, cars, and trucks can be seen travelling on the expressway in the fly-through video, but no people, cyclists, or animals are present. While the street-level simulations show local residents using a popular walking track and the aerial simulations reveal a shared cycle/walk path, the expressway is visualised as an object that pedestrians and cyclists will not use: they will go under it or alongside it, but will not be able to use it. In other words, the fly-through demo and visual simulations encourage the audience to see the expressway as a functional object or a means to an end: it is designed to allow vehicles to travel through Kāpiti while minimising disruption to local residents that travel within their community. While the focus on functionality is not surprising, the NZTA's instrumental/professional format of engagement tended to overlook familiar formats of engagement. That is, the fly-through and visual simulations did not demonstrate what it would be like for local residents to live with a large concrete structure in their community. 


\subsection{Community Counter-Demos}

Local opposition groups seemed to pick up on the NZTA's instrumental approach to the expressway project by creating counter-demos that visualised the lived impacts of the Kāpiti expressway and their attachments to the community and environment. While local residents and activists seemed to share the NZTA's view of roads as functional objects - as a means for transporting vehicles - they seemed concerned that the NZTA had not adequately considered what it would be like to live with an expressway on the proposed route. In other words, local residents were concerned with how it would be accommodated into familiar surroundings that are dependent on sensory cues (Thévenot, 2001, p. 70).

In this section I examine the visual material produced and publicised by local residents as counter-demos that visualised their familiar attachments to Kāpiti while also functioning as rhetorical devices. I provide an overview of the counter-demos produced and publicised during the early stages of the project (between 2009 and 2012). I then examine a documentary produced by a local resident as a counter-demo that was used to demonstrate the impact of the expressway to other local residents and the public.

During 2009 to 2013 a number of locally-produced counter-demos of the expressway project visualised the expressway's impact and what it would be like to live with it. The counterdemos took the form of documentaries, short video clips, and visual images and were publicised by local residents and community groups on flyers and websites. Because some of the locally-produced counter-demos were not formally publicised on news sites or other publicly accessible web-sites I am unable to provide an exhaustive list of counter-demos that were produced. Despite this limitation, I was able to find a number of locally-produced counter-demos. As the project was first publicly announced in August 2009, I have searched the web and news archives using the names of the activist and community groups in order to find any counter-demos that they might have produced. I also searched Youtube, Vimeo, and other video-sharing websites using the keywords "Kāpiti expressway”, "Sandhills expressway", "Kāpiti motorway", "Western Link Road", and "MacKays to Peka Peka" to find any video demonstrations that had been uploaded.

Some of the first counter-demos to emerge publicly focused on the expressway's impact on sacred land. The earliest counter-demo of the expressway project that I could find was uploaded to Youtube on the $10^{\text {th }}$ of September 2009 by a concerned resident - just 21 days after the project was publicly announced by the Transport Minister (Takamore Urupa $V$ 
Western Link Road, 2009). The video demonstrates how the proposed expressway project would negatively impact the wahi tapu (sacred land) and urupa (cemetery) in Waikanae. Using a hand-held camera, the concerned resident provides a tour of the urupa while pointing to where the expressway would be located. As the expressway is adjacent to the urupa the concerned resident says that he opposes the project as it is too close to the sacred land and cemetery. In May 2011, another video on the expressway's impact on the wahi tapu and urupa was uploaded to Youtube (Ben Ngaia - Takamore Trust, 2011). Like the previous video, it tells a story about the cultural and historical significance of the Takamore wahi tapu and explains the problem of building an expressway through it. While these videos do not provide the audience with visual images of the expressway, the 'tour' of the urupa and visuals of the landscape helps the audience see how an expressway on the proposed route would negatively affect the sacred land and special character of the place.

The first counter-demos that visualised the expressway surfaced in 2010 on the websites of two local opposition groups: The Sustainable Option and Save Kāpiti. Based on my interviews, I found out that Save Kāpiti distributed flyers that provided visuals of the negative impacts of motorways to local residents in 2010, but, as they were not archived, I focus on the visuals publicised on websites. Although The Sustainable Option's website was removed from the web in 2012, using an internet archive website there is a screen capture of the website that was taken in May 2010. The home page of The Sustainable Option's website features three photographic images of Poplar Avenue in Raumati South with a digitally altered image of an expressway passing across it (The Sustainable Option, n.d.). The images provide the public with a realistic street-level view of what the Kāpiti expressway could look like (see Figure 17). The expressway has an imposing presence and this is highlighted by The Sustainable Option (n.d.), who claimed that a raised expressway "will be a constant disturbance to both pupils of the schools and local residents. The expressway will be lit through the night and will be visible to many Raumati residents". The images also highlight the lack of on- and off-ramps on the expressway, which means that "the road is not designed to provide connectivity within Kāpiti for local residents, but to provide a faster route through Kāpiti for traffic especially large trucks" (The Sustainable Option, n.d.). 


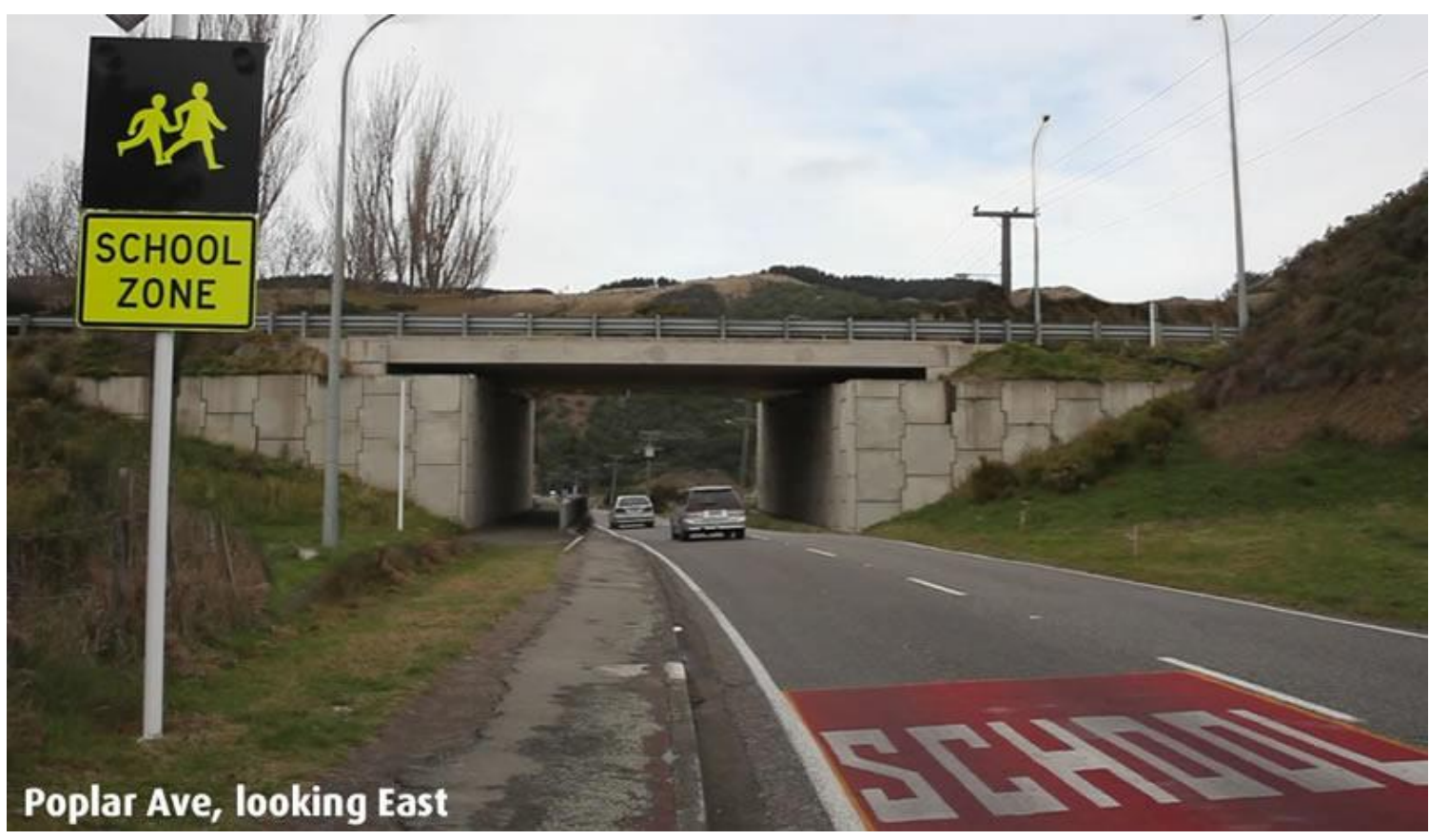

Figure 17. "What will the proposed expressway look like?" (The Sustainable Option, n.d.).

Rather than superimposing images of an expressway onto Kāpiti's environment, Save Kāpiti (n.d.-b) uploaded a PowerPoint (dated June 2010) to their website that provided images of expressways that go through urban areas. The slide show provides an image of an existing local road in Kāpiti and then provides seven photos of expressway crossovers and intersections to demonstrate the visual impact it would have. The images reveal the imposing size of the Kāpiti expressway by measuring the height of its crossovers. For example, one image points out that an expressway would be approximately eight meters above the local road it passes over. The slide show also displays several images of expressway construction sites to highlight issues of noise, pollution, 'big box' commercial development, and the environmental impact on Kāpiti’s wetlands.

While it is not surprising that concerned residents and anti-expressway groups produced counter-demonstrations and visuals, I found only one locally-produced video that supported the project. The Youtube video (uploaded on October 12011 ), demonstrates "why we need an Expressway on the Kāpiti Coast” by driving past a long queue of traffic. Rather than pointing to the negative impacts on the land and community, the video simply shows the traffic problems that occur when there are accidents on Kāpiti's State Highway. The video is relatively short (four minutes), but it demonstrates why an expressway is 'needed'. As one commenter suggests: "wow, that is a lot traffic... You are right, expressway is needed" (Robertson as cited in foxpine, 2011). While there is no mention of the negative impacts that 
an expressway could have on Kāpiti, it demonstrates what it is like to live with the existing motorway - it reveals that using the existing motorway can be a frustrating experience for commuters and local residents.

While these locally-produced counter-demos reveal a concern with how a road would be accommodated into Kāpiti's familiar surroundings, I focus on a documentary produced by local Kāpiti residents and members of Save Kāpiti as it provides an in-depth investigation of the impacts of the expressway and what it would be like to live with an expressway. And, compared to the other web-based counter-demos, the documentary was publicised using a range of communication mediums and publicity channels: public cinemas, newspapers, radio, DVD, Youtube, and on its own promotional website. The comparatively wide appeal of the documentary posed a serious challenge to the NZTA's visuals, which had been viewed by thousands of local residents. The documentary, called 'Through the Heart', was filmed over 18 months and premiered to 475 residents at a local theatre in Kāpiti on October 292011 (Maxwell, 2011). I was also informed from my participants that additional screenings were held at small community theatres in central Wellington. The documentary's promotional website provided information about the film, how it could be purchased, how to get involved, and web-links to additional resources. Additionally, the director of the film was interviewed on local radio stations, the film was publicised in local newspapers, and it was eventually uploaded to Youtube (see Figure 18).

\section{A Documentary of National Significance THROUGH THE HEART}

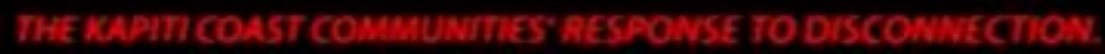

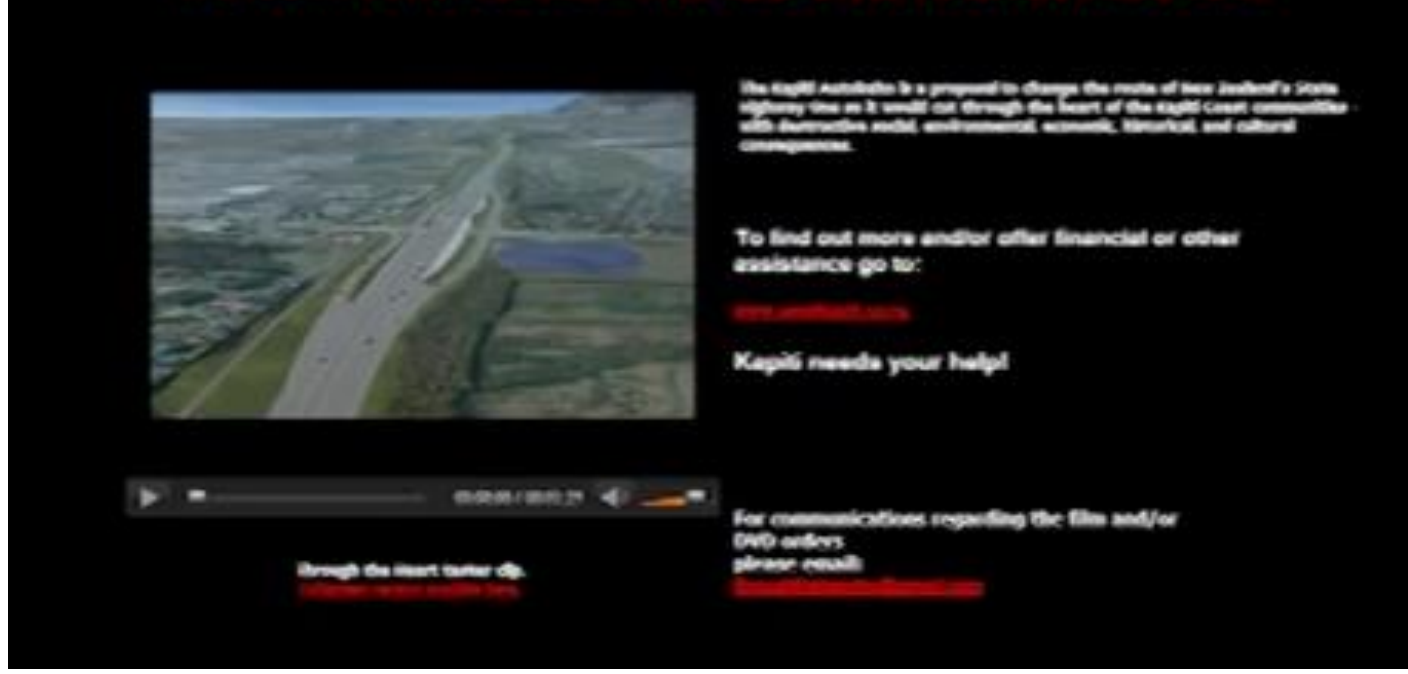

Figure 18. Through the Heart website (Sun Harvest Media, 2012). 


\subsubsection{Counter-demos as cognitive tools}

Through the Heart is a documentary that demonstrates how familiar attachments to community and place can be an important aspect of public engagement in socio-technical controversies. It is a documentary about a proposed expressway project that is designed for trucks and the actions of central and local government. It tells the story of ordinary local residents who are alarmed by the government's planned Kāpiti expressway project that will divide the communities of Kāpiti. The narrators of the documentary describe how the community's plans for the designated Western Link Road project were "hijacked by central government politicians" who were intent on building an expressway that would "bull doze" or nullify the plans for the WLR project (Sun Harvest Media, 2012). The documentary explores the "underhanded tactics" used by central government and how the local council turned its back on Kāpiti when it decided to support the expressway project (Sun Harvest Media, 2012). The themes of the documentary reveal how perceived threats to familiar attachments helped enact and express their concern with the road project.

The documentary was an important cognitive tool that enabled the public to learn about the project and how it might affect them. Unlike the NZTA's visual simulations, which visualised future scenarios and the technical aspects of the project, the documentary helped the public learn about the lived aspects of the project by walking through 'affected' sites and 'pointing' to the negative impacts it could have on the community and environment. The documentary follows a group of concerned residents (the narrators and their friends) who point to the possible impacts of the proposed expressway on resident's familiar attachments as they walk along the designated route of the WLR project. As the walkers reach intersections and important cultural sites along the route, the documentary cuts to footage that explores the various issues with the expressway and/or the impact it would have on the community and environment. Interviews with local residents, political leaders, and experts are used to explore the key themes of the documentary, and the walking group or 'trekkers' help the audience 'see' the potential impacts of the proposed expressway. By walking along the route the trekkers demonstrate that road projects are not simply instrumental objects that help move vehicles efficiently, but are also familiar objects that connect communities while preserving the landscape. In other words, the documentary demonstrates what it would be like to live with a road that was visualised by the NZTA as an instrumental object. 


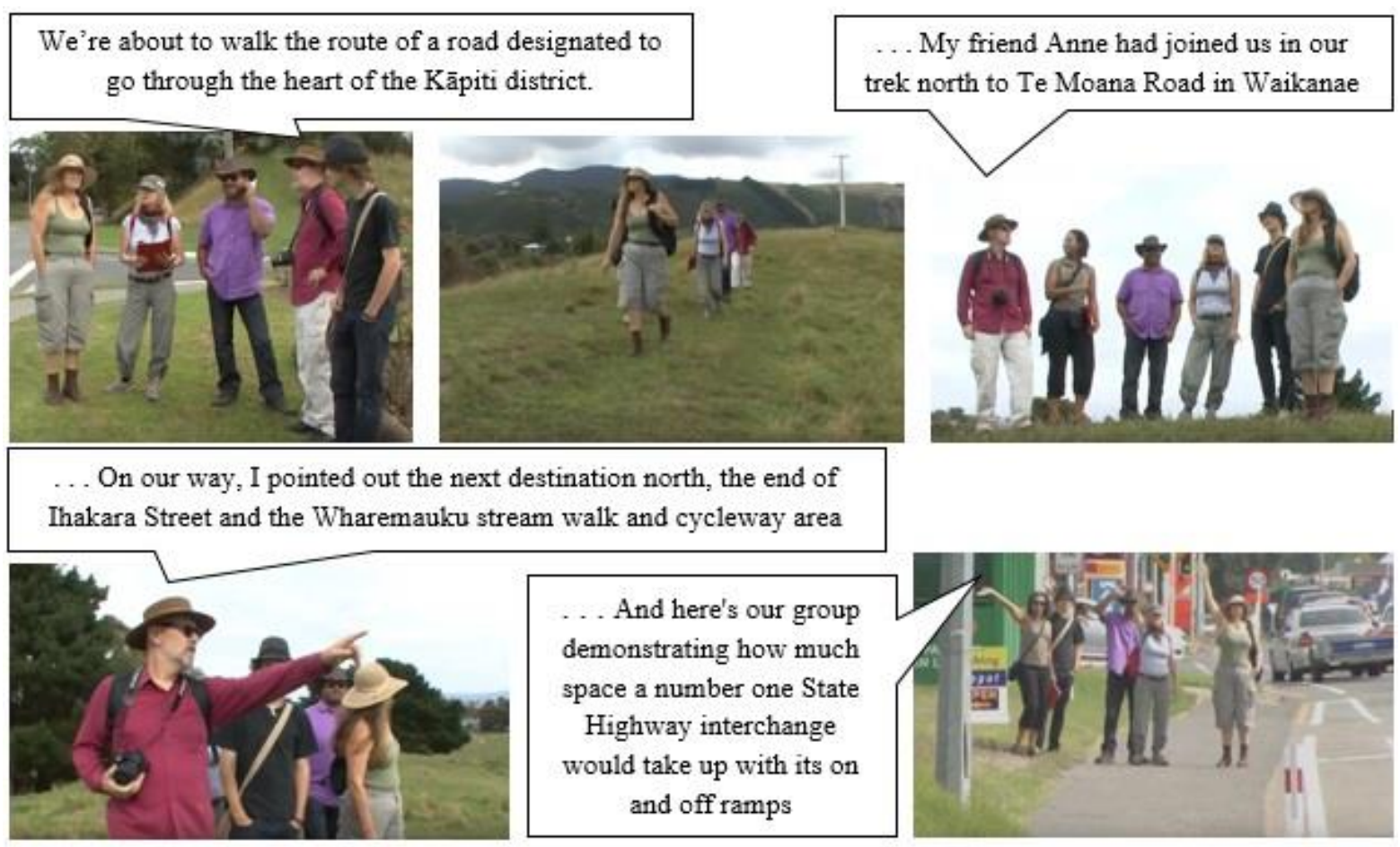

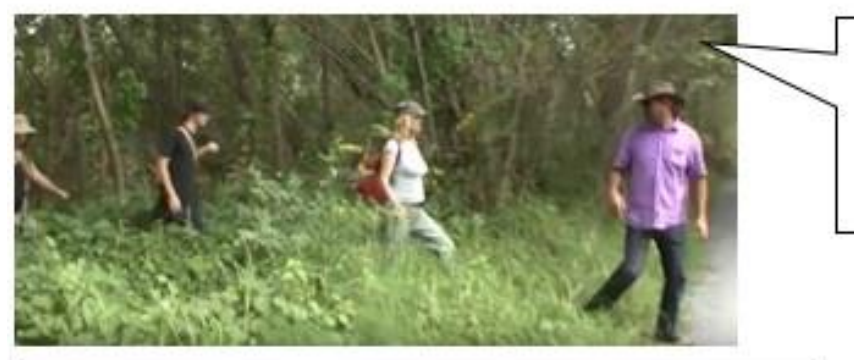

\begin{tabular}{|l|}
\hline ... Mark's showing us where the Sandhills Motorway or \\
Kappiti Autobahn would intersect with Te Moana Road.
\end{tabular}

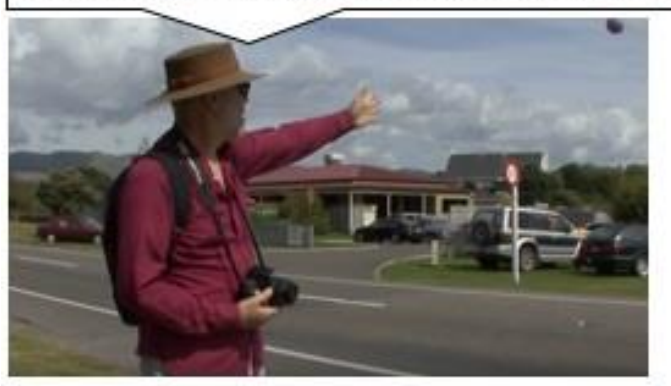

... We headed on to the road leading up to the urupa. ...It's rich with history, a site of numerous ceremonies and a place where many stories of the Kāpiti district originate.

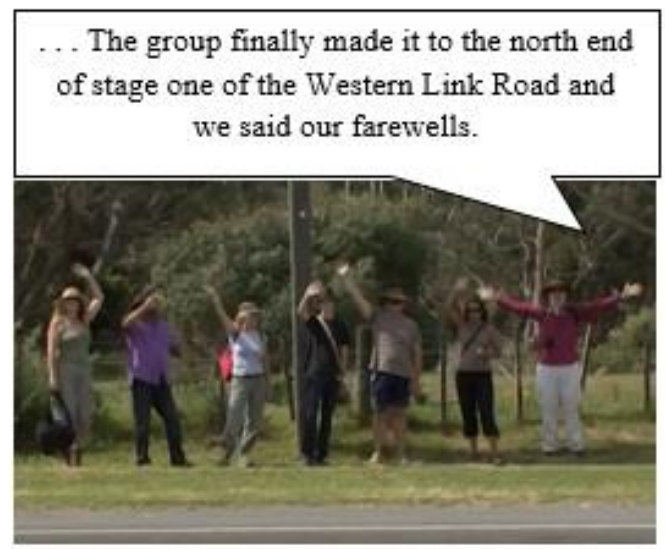

Figure 19. Through the Heart documentary (Sun Harvest Media, 2012).

The trekkers help the audience see the lived impacts of the expressway by pointing to its impact on the landscape, amenity values, and community (see Figure 19). First, walking on land that has a rural character demonstrates that a large expressway would negatively affect the landscapes of Kāpiti and, therefore, its unique character. Walking along the route of the proposed expressway highlights that the designated route is not simply vacant land devoid of meaning, but is an ecologically sensitive area that is important to Kāpiti residents. The trekkers point out that the rural character of Kāpiti adds to the peaceful atmosphere of Kāpiti 
and it is a reason why some people move to the district. The narrator suggests that "many retired folk have decided to live here for tranquillity and peace of mind" (Sun Harvest Media, 2012).
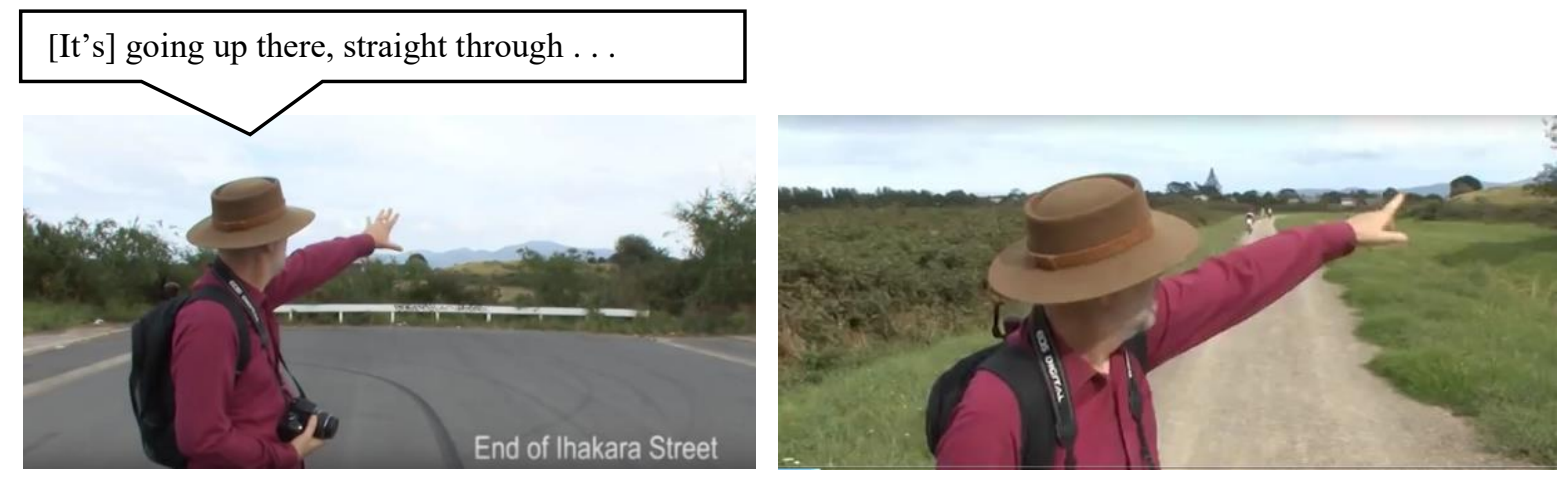

Figure 20. 'Pointing' (Sun Harvest Media, 2012).

Second, the trekkers reveal the visual or amenity impacts of the expressway project by comparing a proposed overpass design with the Western Link Road overpass illustration. When the trekker points to a specific location on the route, the documentary cuts to visual simulations of the expressway and the WLR project (see Figures 20, 21, \& 22). This scene encourages the audience to see the expressway as a large, imposing structure that is not incorporated into the environment. It helps provide the audience with a before and after perspective by pointing to the pre-expressway landscape and then comparing it to a postexpressway landscape. Although no commentary is provided, the image of Save Kāpiti's preferred WLR road project appears to blend-in with the Kāpiti environment as it is a smaller structure and it seems to incorporate organic materials into its design, such as wood and stone.

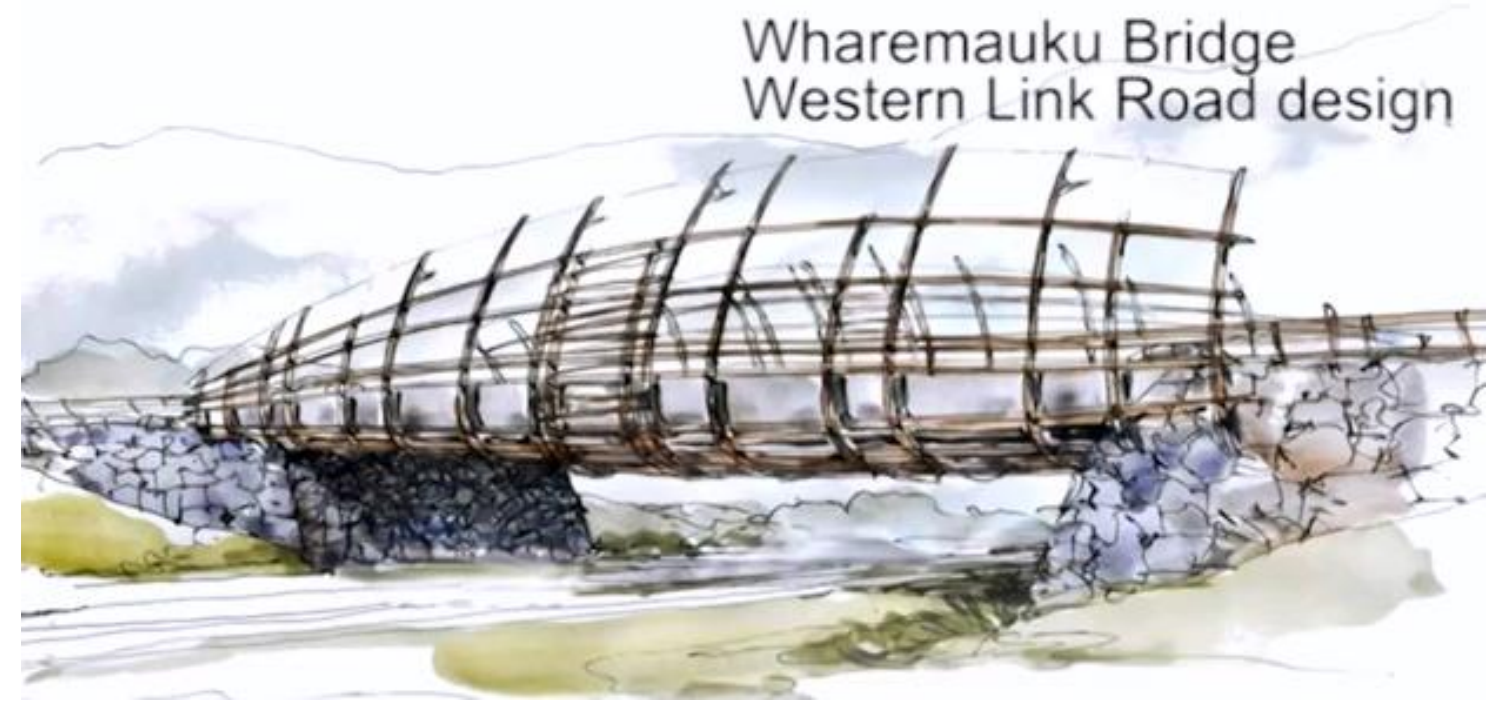

Figure 21. "Wharemauku Bridge: Western Link Road design” (Sun Harvest Media, 2012). 


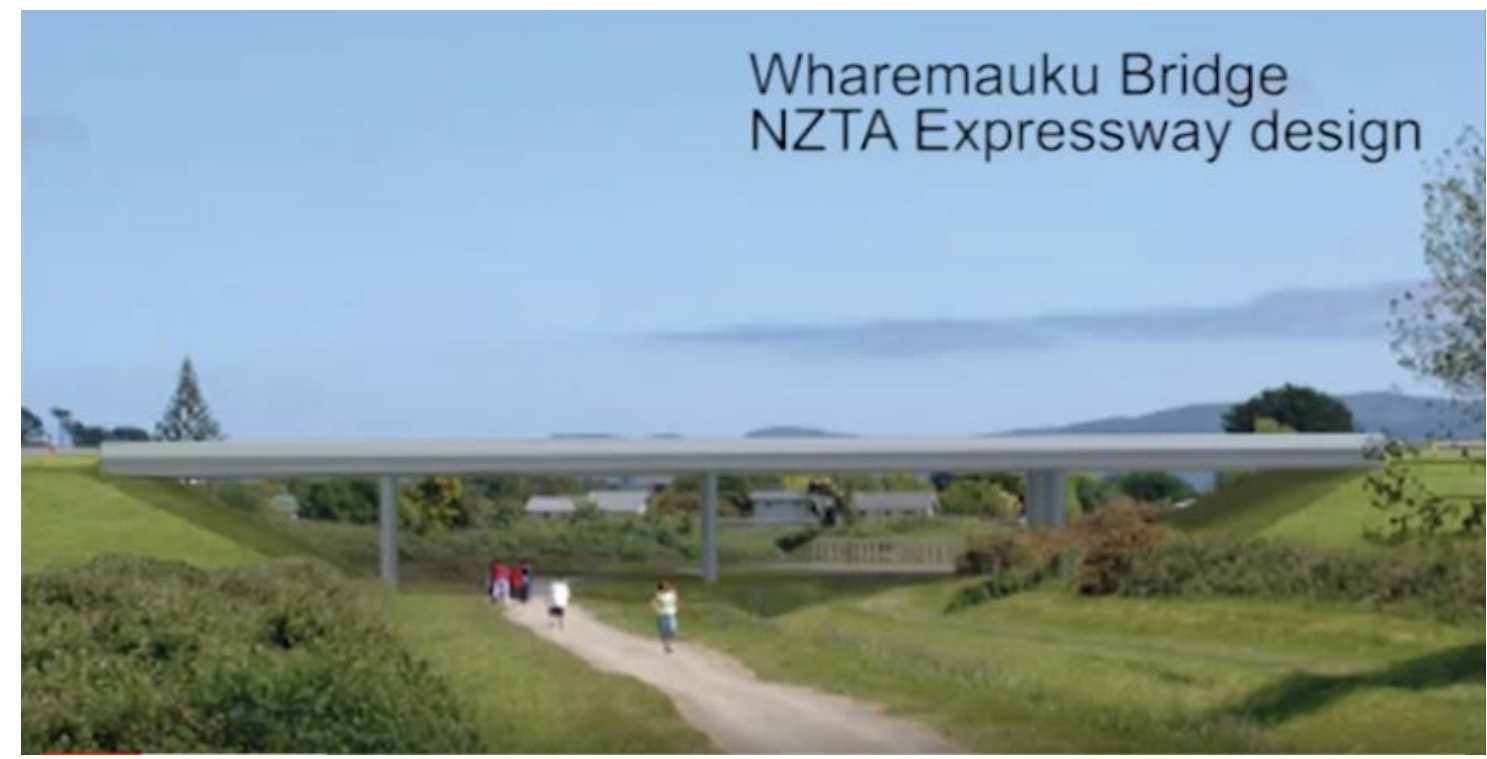

Figure 22. "Wharemauku Bridge: NZTA Expressway design” (Sun Harvest Media, 2012).

Third, the trekkers continue to point to the imposing presence of the Kāpiti expressway by standing at the site of a proposed interchange and modifying the NZTA's visuals to make them more 'realistic'. The trekkers stand on the site of a proposed interchange to demonstrate how much space is required for the expressway's on- and off-ramps (see Figure 19). The documentary shows one of the NZTA's proposed visual simulations, but it modifies it by adding additional 'screens' that add to the expressway's imposing presence (see Figure 23). By providing in-situ demonstrations that reveal the size of the interchanges and modifying the NZTA's design, the documentary reveals what the expressway would 'really be like' in the communities along the Kāpiti Coast. That is, the trekkers reveal, in-situ, the significant visual impact of the proposed expressway.
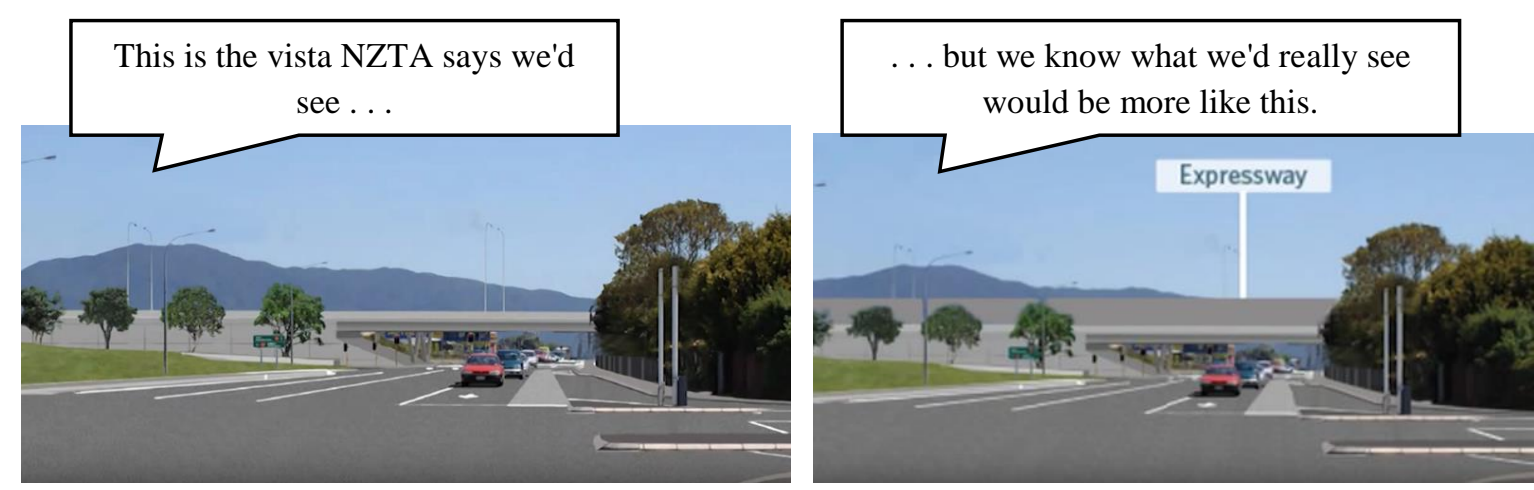

Figure 23. Kāpiti Road interchange (Sun Harvest Media, 2012).

Finally, the trekkers reveal the cultural and social impacts of the project by walking through a popular holiday park, wahi tapu, and urupa. By showing images of people enjoying the 
holiday park and interacting with others, the audience can see the lived impacts of the expressway project. The images of people engaging in various recreational activities (such as canoeing, camping, and horse riding) and spiritual exercises (such as prayer) reveal how the expressway threatens the tranquillity of the holiday park. The trekkers then walk to the urupa, which is located on a hill next to the park. The camera zooms in on two helium balloons that were used by local residents to demonstrate the height of the expressway lights (see Figure 24). The balloons reveal the proposed expressway's imposing presence and its negative impact on the special atmosphere of this scared site. The documentary then cuts to an aerial image of the wahi tapu and urupa with a superimposed line that shows the walking route the trekkers used to reach the urupa and a historical cart route that was used to bring bodies to the burial site (see Figure 25). Using NZTA's visual simulation of the expressway project, the narrators describe how the road would "cut between" the urupa and wahi tapu and would "destroy the historical hill and the cart track used by burial wagons" (Sun Harvest Media, 2012). The contrast between the trekker's walk-through of these sites and the NZTA's visual simulation of the expressway reveals the cultural and social impacts of the expressway that were absent in the NZTA's demonstrations. Walking through the affected sites reveals how the familiar utility of the land is under threat by an expressway that is designed to move people through this area.

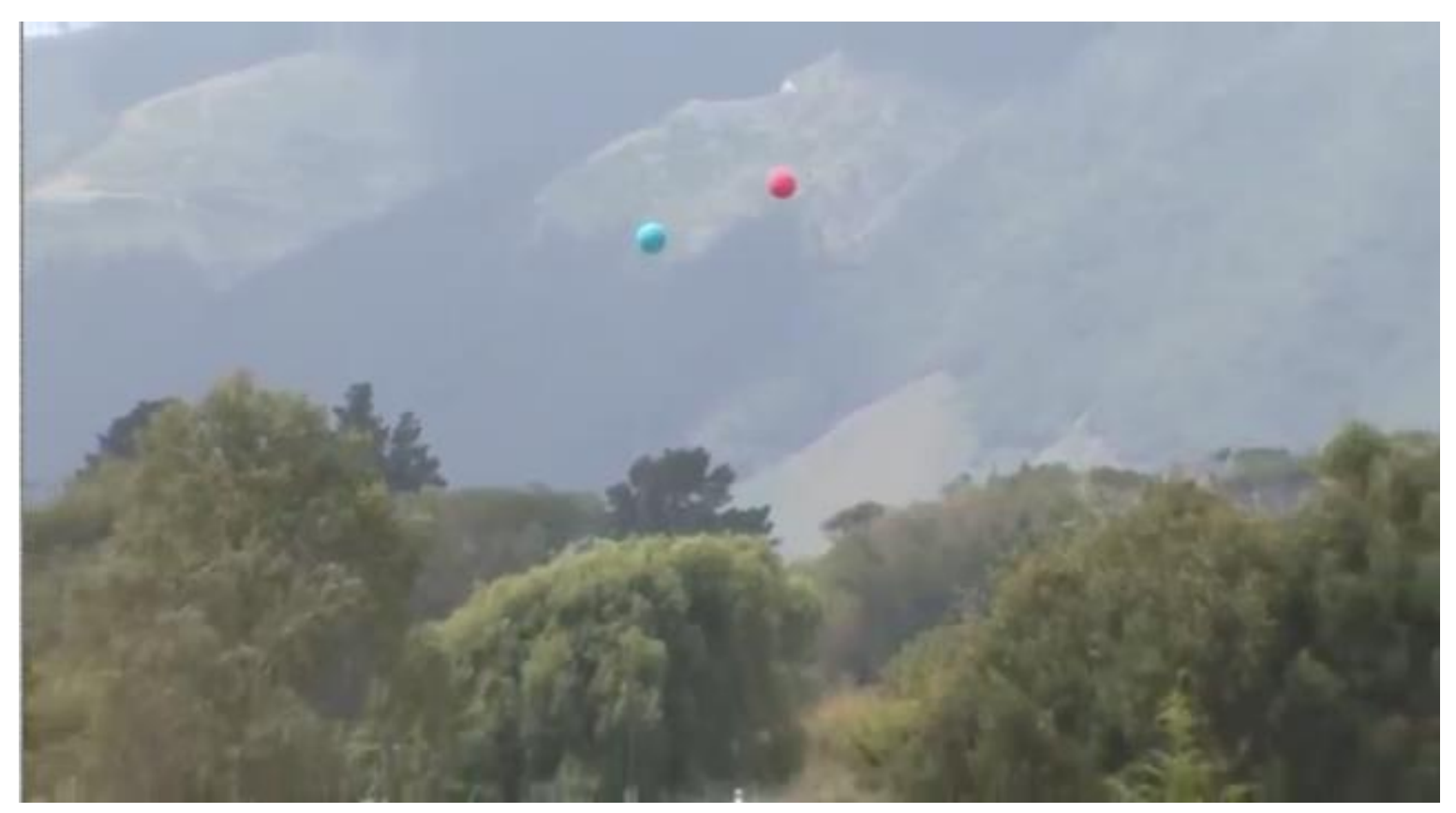

Figure 24. Balloons (Sun Harvest Media, 2012). 


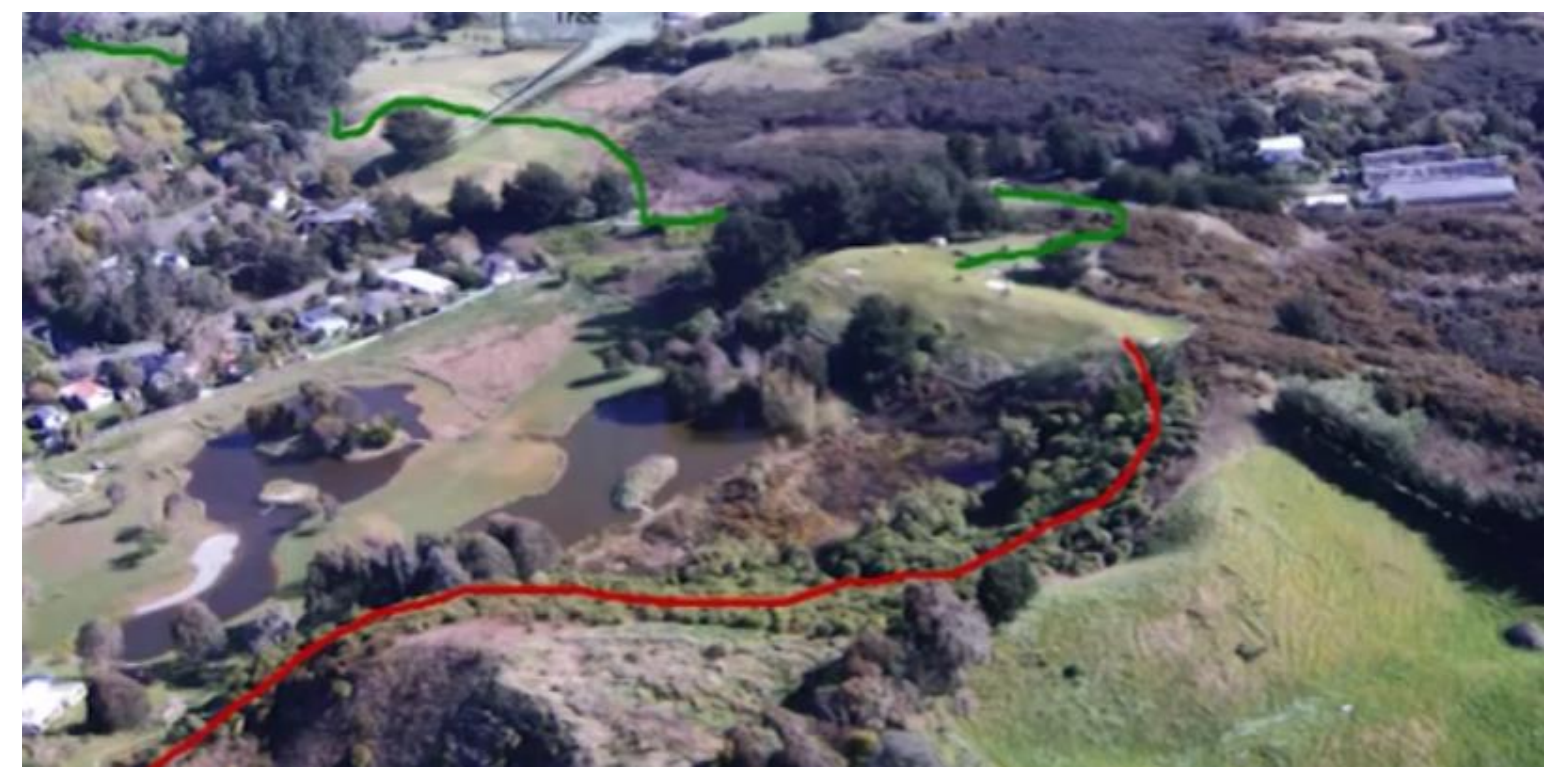

Figure 25. Historical cart route (Sun Harvest Media, 2012).

Overall, the walk-through reveals how visuals can function as cognitive tools by influencing how an audience understand public issues. The NZTA's simulations illustrated their expressway project without contrasting it with alternative designs or in-situ demonstrations. As discussed above, their visuals helped the public see the expressway project as a functional object by separating the visual aspects from its lived impacts. However, the visuals produced by concerned residents and opposition groups provided an alternative interpretation of the expressway project by using in-situ demonstrations that pointed to its imposing size and juxtaposed the NZTA's professional simulations with alternative designs and more realistic images of the completed expressway. Providing an in-situ demonstration and juxtaposed visuals reveals how familiar attachment can play an important role in helping the public learn about the expressway as a significant issue and to encourage them to become involved in it.

\subsubsection{Counter-demos as rhetorical devices}

While the documentary was an important cognitive tool that enabled the public to visualise how the expressway project would threaten familiar attachments to community and place, the documentary also functioned as a rhetorical device - a tool to persuade the public to take action against the expressway project. Its initial purpose was to encourage people to take action against the project and/or to support local opposition groups. The documentary wanted to not only convince people that the expressway is a "bad idea", but to also "inform people about what they can do to make sure that our children don't turn to us in the future and say 'how did you let this happen?'” (Sun Harvest Media, 2012). The producer of the documentary 
told the Kāpiti Observer that the documentary is "a documentary to persuade": a documentary that "could 'absolutely' change the minds of people who are undecided about the expressway, or even pro-expressway" (Maxwell, 2011).

Visualising the lived impacts of the expressway partially accounts for the persuasiveness of the documentary, but I suggest that problematising the NZTA's visual simulations within a counter-demonstration helped create competing interpretations of the project (Stark \& Paravel, 2008, p. 48). By juxtaposing the NZTA's lifeless images of the expressway with a walk-through of Kāpiti, the documentary creates a counter-demonstration that helped problematise the expressway project as an object of residential concern. The documentary reveals how the NZTA's visual demonstrations were re-circulated in counter-demonstrations that were no longer controlled by them - the producers of the initial demonstration (Stark \& Paravel, 2008, p. 49). Rather than being used to reinforce a professional vision of the expressway project, the NZTA's visual simulations were used to persuade the public that the expressway was a 'bad' idea.

If the documentary was a rhetorical device, then it did not simply visualise familiar attachment, but also made these attachments relevant to justifiable forms of action and common concerns (Blok \& Meilvang, 2014, p. 15). The documentary can be seen as a rhetorical device that links regimes of familiar engagement to regimes of publicly justifiable action. Visualising the lived impacts of the expressway, the documentary linked familiar attachments to the community and environment with domestic, civic, and green orders of worth. The documentary qualifies the social and cultural spaces of Kāpiti in terms of a domestic order of worth by pointing to the importance of preserving traditional or "domestic" spaces that retain customary practices and the virtues of proximity and community (Thévenot, 2002, p. 66).

However, as domestic orders of worth are easily critiqued for being focused on specific communities, the documentary also created market and civic compromises that helped justify the idea that traditional spaces in Kāpiti should be preserved. The narrators explain that an expressway designed to move vehicles through Kāpiti would have a negative impact on local businesses, property values, and the local economy. The documentary suggests that preserving and connecting the traditional spaces in Kāpiti is important economically because connected communities will help improve local trade while maintaining property values. In terms of the economic benefits of the project, the narrators suggest that the valued areas of 
Kāpiti would be sacrificed for a project that has a low benefit to cost ratio - 0.6. This "means that the benefits gained from it will generate only a 60 cents return for every one dollar spent to build it" (Sun Harvest Media, 2012). The narrators suggest that the Western Link Road project would preserve and connect Kāpiti's valued spaces while providing local and national economic benefits in the form of easing congestion on the state highway and creating jobs during the construction period. These various market justifications provide a critique of the expressway project and provide market-based reasons for why the 'domestic' spaces of Kāpiti need preserving.

The documentary aligns domestic with civic orders of worth by focusing on the issue of civic equality. According to the narrators, the expressway would "dominate the communities it passed through and it would sever the coastal communities" (Sun Harvest Media, 2012). An urban expressway that dominates the domestic spaces of Kāpiti would negatively impact on the health of local residents and local traffic and pedestrian movements within the district. The idea of residents being negatively affected by the government's project connects with civic equality justifications that appeal to collective welfare and equal access (Thévenot et al., 2000 , p. 246). In this case, the documentary appeals to the idea that building a road that connects, rather than dominates, the communities in the Kāpiti Coast will help improve access, mobility, health, and the welfare of local residents. That is, road projects should meet the needs of citizens collectively and equally: they should equally benefit residents and the public in general.

Finally, the documentary aligns familiar attachments to Kāpiti with green orders of worth by focusing on the issue of environmental preservation. The documentary uses interviews with residents and environmental science experts to highlight the idea that preserving Kāpiti’s ecologically sensitive areas is not only important for the rural character of Kāpiti, but is also connected to the environmental issues of wetland loss, wildlife movement from Kāpiti island, and local marine life. The argument over the issue of wetland loss can be seen as an appeal to environmental 'uniqueness' in the sense that Kāpiti will not be able to restore them once they have been 'lost' to the expressway project. According to Thévenot, Moody, and Lafaye (2000, p. 257) uniqueness arguments are often mobilised by opponents of infrastructure projects to highlight the singularity of ecologically sensitive areas and endangered species. 


\subsection{Conclusion}

I have examined how the Kāpiti expressway project was visualised and displayed as an object of concern. The use of visual imagery suggests that publicising and debating the potential impacts of a large infrastructure project was dependent on various tools of representation. Visual material played an important role in making the potential impacts of the expressway visible to the public and decision-makers. As local residents were interested in what it would be like to live with an expressway in the community, visuals of the expressway allowed the public to see the expressway and its impact on everyday life. However, because the NZTA's visuals did not illustrate the lived impacts of the expressway, concerned residents and activist groups created counter-demonstrations and visuals that offered competing interpretations of the expressway project and helped mobilise the community to take action against it. The role of visual imagery in socio-technical controversies, therefore, can influence how people learn about important public issues and can reveal how seemingly personal attachments to community and place connect with justifiable forms of political action.

Specifically, examining the differences between professional and community visuals of the expressway revealed how different actors engage reality and coordinate action. The NZTA's visualisation of the expressway as a functional object enacted a planned format of engagement that purified the visual aspects of the project from its lived impacts. That is, the NZTA visualised the expressway as a means for improving transport efficiency without visualising what it would be like for local residents to live with a large concrete structure in their community. While the NZTA produced street-level simulations that allowed the public to see the lived impacts of the project, their images visualised the expressway as an object that would 'blend in' with the surroundings and not disrupt daily life on the Kāpiti Coast. Rather than being an object that pedestrians and cyclists would use, it was visualised as a functional object that would allow vehicles to travel through Kāpiti. In contrast, the visuals and counterdemos produced by local residents and activist groups challenged the idea that the expressway would not disrupt life on the Kāpiti Coast. Their visuals enacted familiar formats of engagement that visualised the expressway as an object that would threaten Kāpiti's familiar surroundings. In particular, the documentary, Through the Heart, visualised the problems with the expressway project by showing concerned residents walking along the designated route and pointing to the impacts that it could have on the community and environment. 
Visualising the expressway as either a functional or residential object influenced how the public understood and engaged with the project. As cognitive tools, the NZTA's visual simulations helped the public see the expressway and its technical/design aspects. In contrast, the visuals produced by local residents encouraged the public to think about its impact on the landscape, amenity values, and community. Moreover, the locally-produced visuals and demonstrations functioned as rhetorical devices by creating competing interpretations of the expressway project, persuading people that it was a bad idea, and making familiar attachments to Kāpiti relevant to common concerns and justifiable forms of action.

More generally, visualising familiar attachments to place and community suggests that public involvement in socio-technical controversies can be seen as performances that mobilise, what Marres (2007, p. 776) calls, socio-ontological associations and "endangered attachments". The visuals and demonstrations communicated a sense of familiar attachment to Kāpiti and revealed how local residents relate to and engage with socio-technical issues. As Marres (2007, p. 774) argues, "the enactment of public concern involves the articulation of threats to actors' livelihoods, in the broadest sense of that term". However, rather than only articulating threats to familiar attachments verbally, which seems to be the focus of object-oriented approaches to public involvement, my analysis suggests that visuals also play an important role in enacting public concern and connecting familiar attachments to justifiable forms of action and critique. As Blok and Meilvang (2014, p. 14) argue, "practices of visualization . . . allow activists to express, share and render publicly visible a range of embodied attachments otherwise not easily accommodated in the semantic apparatuses of urban planning”.

Moreover, the visuals of the expressway reveal that actors utilised 'realistic' images of the project for very different purposes. That is, the visual images of the Kāpiti expressway were mobilised for 'political' and 'anti-political' purposes in the sense that they helped supress and open spaces of contestation (Barry, 2002). The NZTA's visual images had anti-political effects in the sense that they downplayed the lived reality of a large expressway through the centre of the Kāpiti Coast. The NZTA's visual simulations visualised the expressway as an object that would not significantly disrupt the lives of local residents. In contrast, the locallyproduced visuals had political effects by opening possibilities for debate and creating competing interpretations of the project. In particular, the documentary emphasised, in a negative way, the lived reality and impact of a four lane expressway in a semi-urban environment. In terms of public involvement in socio-technical controversies, the locallyproduced demonstrations and visuals helped create possibilities for public debate by bringing 
to the surface the "endangered" associations and attachments entangled in and affected by the expressway (Marres, 2007, p. 774). The demonstrations and visuals, therefore, played an important role in publicising and representing the Kāpiti expressway as either a functional object that requires public input, or as an object of residential concern that should be publicly debated and opposed. 


\section{Chapter Seven: A Road for the People}

\subsection{Introduction}

In the first three empirical chapters I examined how concerned citizens engaged with the Kāpiti expressway project by evaluating and publicising it as an object of concern. In the final three empirical chapters, I shift focus by discussing how residents and opposition groups translated their concerns with the project in the Board of Inquiry and High Court. In this chapter I explore how the public engaged with the preferred option controversy. My interest in this issue was sparked by my observation that the opposition groups utilised popular appeals to democracy, the environment, and meaningful public participation when evaluating the preferred option for the expressway. However, I also noted that these popular appeals were not simply rhetorical. During the Board of Inquiry, opposition groups related their concerns to the technical and legal aspects of the project. I utilise Laclau's (2005) notion of populism to understand how local groups engaged with the preferred option issue and devicecentred approaches to politics to examine the technologies of political engagement.

Specifically, I investigate the NZTA's public consultation exercises as "public-making" practices (Barry, 2013) and as rhetorical devices that allowed the public to engage with the Kāpiti expressway project. In socio-technical controversies, different conceptions of 'the public' are often mobilised to make persuasive claims. However, as I will argue, persuasive appeals to the public or 'majority' are not simply rhetorical, but also involve disputing the devices and techniques used to assemble publics (Barry, 2013) and materialise participation (Marres \& Lezaun, 2011). In this case, the public-making practices and measurement devices used to gauge public opinion on the preferred option allowed actors to enact populist forms of political engagement.

I start by reviewing sociological theories that examine public consultation exercises and surveys as public-making practices and rhetorical devices. I then analyse the NZTA's public consultation on the preferred option as a public-making practice that assembled and made real 'affected communities' and the 'general public'. If public consultation exercises helped make publics real, they also allowed disputants to link their personal objections to a majority figure that should be involved in the decision-making process. Public-making practices used by antiexpressway groups functioned as rhetorical devices that allowed them to engage with the preferred option controversy and enact a populist form of political engagement. Finally, I argue that the enactment of populist forms of political engagement involved not only the 
rhetorical construction of a community that has been treated 'shoddily' by the government, but also involved questioning the public-making techniques used to assemble publics and measure their opinions.

\subsection{Public-Making Practices and Political Engagement}

Typically, the stated aims of public consultation exercises are to inform the public about an issue or decision and to hear their opinions. Public consultation exercises, as Barry (2013, p. 97) suggests, tend to assume that the public is an entity that will address themselves to the problems that affect them or will be activated when called upon. That is to say, the public is often understood as a social totality or "the people in general" (Warner, 2002, p. 413). In this sense, the public's "unity and existence can be taken for granted, only to be consulted, more or less imperfectly, on appropriate occasions" (Barry, 2013, p. 97).

Sociologically, public consultation exercises and the techniques used to gather their opinions do not simply address already-existing publics, but also make them 'real' by assembling them and measuring their opinions (Barry, 2013; N. Rose, 1999, p. 189). According to Barry (2013, p. 98), "generic" forms of public consultation exercises used in infrastructure projects are public-making "genres" that assemble and perform publics, and gauge and articulate their opinions. Barry (2013, p. 98) uses the term "genre" to direct attention "towards the existence of a great diversity of ways in which publics are assembled and speak or are spoken for, and the need to identify and interrogate these specific means in relation to any genre". For example, Barry (2013, p. 99) argues that the public consultation practices used in the BakuTbilisi-Ceyhan (BTC) oil pipeline project were performative in the sense that they assembled and addressed collectivities (such as 'affected communities') that "were understood to be social groups defined by their relation to an evolving object, not by reference to their membership of a state".

Moreover, public consultation exercises do not only gather opinions, but also materialise participation. In contrast to discursive theories of citizenship and participation, Marres (2011, p. 511) argues that public participation is "an embodied activity, taking place in particular locations and involving the use of specific objects and technologies". That is, public participation is materialised, accomplished, and performed through a range of procedures, activities, instruments, and technical devices (Barry, 2013; Marres, 2011). For instance, previous device-centred studies have examined the important role that opinion polls (Osborne \& Rose, 1999; N. Rose, 1999), voting machinery (Lynch, Hilgartner, \& Berkowitz, 2005), 
and anti-road protests (Barry, 2001) play in enacting citizenship and materialising participation in political and socio-technical controversies.

While publics are assembled through practices of public-making that gather and publicise opinions and demands, public consultation exercises and surveys also function as rhetorical devices that can strengthen arguments and make persuasive claims (Throgmorton, 1993). That is to say, public-making practices provide actors involved in socio-technical controversies with an opportunity to connect the road project to more common or general concerns. Here, I review theories that examine public consultation exercises and surveys as sites and devices that enable actors to make persuasive arguments in political and socio-technical controversies by appealing to the public good and the 'people' or 'majority'.

Social science research on the role of public consultation and surveys in planning controversies have used the theoretical resources from rhetorical planning theories, postMarxism, and French pragmatism. The role of rhetoric in planning and politics has been studied extensively by planning theorists (Healey, 1993; Stone, 1988), but there are only a few studies that have examined public consultation exercises and surveys as rhetorical devices. One influential approach to the study of consultation exercises and surveys as rhetorical devices has been developed by Throgmorton. Throgmorton's (1993, p. 335-336) rhetorical approach to planning examines public consultation exercises and surveys as rhetorical devices that not only persuade an audience to accept an explanation, vision, or course of action, but also constitute communities or audiences. As persuasion involves the use of tropes, Throgmorton (1993, p. 335) suggests that a number of rhetorical devices - such as metonymy, metaphor, and synecdoche - can be used to analyse the persuasive power of planning narratives. For example, according to Throgmorton (1993, p. 335), “using survey samples to represent entire populations ... is speech by synecdoche or substituting parts for wholes". Moreover, as rhetoric is constitutive, literary tropes can be used to examine the character roles that are created or transformed in planning projects. For instance, if a planner "speak[s] metaphorically of the city as a machine ... they are thinking of themselves as akin to the scientist, engineers, and technicians who make machines run more efficiently, and of their audiences as passive and manipulable parts of the machine" (Throgmorton, 1993, p. 336).

The use of rhetoric in planning controversies is not only examined by Throgmorton, but also by post-Marxist theorists. Using the theoretical resources from Laclau's research on populism, 
Griggs and Howarth (2008, p. 125) argue that public consultation exercises can provide actors with an opportunity to pursue populist forms of politics that link their singular demands to more universal demands through the production of equivalential chains, which refers to the process of creating equivalences or connections between seemingly unrelated elements. Equivalences are formed through the production of empty signifiers, which are forms of representation that groups with diverse identities or interests can identify with. In other words, an empty signifier is a word or sign that has many meanings. As public consultation exercises gather opinions and feedback, they can allow actors, through equivalential articulation, to create popular demands that link the individual demands from local residents. According to Laclau (2005, p. 73) a "social demand" can refer to an unsatisfied request and/or claim. For instance, if a road is being built through a community, local residents might translate their frustration or sense of grievance into either a request that asks the project managers or authorities to stop construction or a claim that focuses on an error in the planning process or other legal wrong (Griggs \& Howarth, 2008, p. 127). Demands are "popular" if they form a wider collective subjectivity and are linked into an equivalential chain, and they are "institutional" or "democratic" if they remain isolated from other demands (Laclau, 2005, p. 74). The idea of a democratic demand is controversial, but Laclau (2005, p. 125) argued that he used it as a descriptive term to highlight how particular demands do not simply emerge in an isolated environment, but "are formulated to the system by an underdog of sorts ... [and] that their very emergence presupposes some kind of exclusion or deprivation". Public consultation exercises, therefore, can be an important site where actors and activist groups can mobilise populist rhetoric and link singular demands to a collective discourse of what road is 'best' for the general public.

To clarify, demands that remain isolated from each other can be described as an institutionalist mode of politics that is based on the logic of difference, rather than the logic of combination or equivalence. If particular demands are addressed to a political authority without being combined with other demands then this aligns with an institutionalist mode of political engagement that is based on a logic of differential incorporation. This means that demands that are addressed to an institution are incorporated differentially or in a way that does not disturb the existing system (Griggs \& Howarth, 2008). For example, in New Zealand, the public consultation and planning process for road projects are forms of institutionalist politics that provide concerned citizens with an opportunity to address their 
concerns to an authority that will process their requests by providing an explanation, compensation, or a compromise that alters an aspect of the project.

In contrast to the logic of differential incorporation, the populist logic of equivalence links unsatisfied demands while revealing a widening rift between citizens and the system (Laclau, 2005). As an academic concept, populism can be used to understand how diverse groups join forces against a common enemy by connecting their seemingly unrelated demands to a wider discourse that subjects can identify with. It is important to note that the ideological content (such as appeals to 'the people') and certain types of movements or organisations (such as New Zealand First) can be an important part of populist forms of politics. However, as a theoretical concept, populism refers to a mode of politics that creates an antagonistic frontier that divides society into two hostile camps in order to reveal the divide between 'the people' and an authority. The creation of a political frontier, as Griggs and Howarth (2008, p. 129) suggest, helps "galvanize a common set of values, beliefs, and symbols" and can be used to advance the interests of 'the people' as collective subjects.

The mobilisation of populist discourse in planning controversies is rhetorical in a number of ways. First, populist discourses are rhetorical in the sense that they create a political frontier that divides society into two opposed groups. By symbolically dividing society into two hostile groups, populist discourses mobilise anti-status quo appeals that name the enemies of 'the people' (Panizza, 2005, p. 3). For example, actors in planning controversies often use 'us' vs 'them' rhetoric to mobilise support for a cause or to make a claim. Secondly, populist discourses act synecdochally in the sense that demands from one group can stand for 'the people' while masking competing demands from other groups (Griggs \& Howarth, 2008, p. 132). Finally, populist discourses mobilised in planning controversies are rhetorical in the sense that they produce empty signifiers - such as 'a road of national significance' or 'preferred option' - that people can identify with and that can be attached to demands (Griggs \& Howarth, 2008, p. 128).

Like rhetorical and post-Marxist approaches to planning controversies, Boltanski and Thévenot's sociology of justification has been utilised to examine how actors legitimate their personal viewpoints by appealing to different orders of worth or collective goods. Examining a dispute over the construction of a dam, Thévenot, Moody, and Lafaye (2000, p. 247 \& 254) claim that arguments over which group has the majority of public support reveals 'a 'civic' mode of arguing based on a figure of 'majority' commitment" and a mode of arguing based 
on 'opinion' or 'renown'; a mode of argument that "point[s] to the importance of public knowledge for determining the worth of a cause".

Unlike Throgmorton's and Laclau's approach, Boltanski and Thévenot's sociology of justification also aligns with object-oriented approaches to socio-technical controversies. Their approach highlights that persuasive appeals to a majority figure or other common good involves engaging with the objects and techniques that support this type of justification. Moreover, it can be used to highlight how things are qualified or made relevant to public issues and in particular situations (Thévenot et al., 2000, p. 267). Appeals to a common good often involve not only articulating demands, but also engaging objects and techniques that offer proof that is considered legitimate within a certain mode of evaluation (Thévenot et al., 2000, p. 237). While Laclau and Mouffe (2001, p. 108) agree that every articulatory practice and discourse is 'material', their approach tends to overlook the material devices and technologies associated with political activity (Barry, 2002).

However, while Boltanski and Thévenot's sociology of justification has been useful for examining the issues in the previous chapters, I suggest that, in the case discussed here, there are several problems when using it to examine populist forms of political engagement. Boltanski and Thévenot's orders of worth framework tends to align populist rhetoric with "civic" and "renown" orders of worth, but it does not capture what is distinctive about populist forms of political engagement. Populism might have some similarities with the issues of equality, solidarity, popularity, and recognition, which are important in these two orders of worth, but it cannot be reduced to these concerns. The civic order of worth is characterised by institutionalist, rather than populist, appeals to the law, procedures, formal rules, or officials. In contrast the "renown" order of worth aligns more closely with populist demands in the sense that appeals to popularity and public opinion are used to evaluate a claim (Thévenot et al., 2000). However, as popularity refers to the process of gaining public and media attention, it is only loosely connected to populist forms of political engagement that link particular demands to wider, universal demands. For these reasons, Laclau's approach to populism is used here to examine the public-making practices as rhetorical devices.

The three theoretical approaches discussed above all illuminate the idea that public-making practices used in planning controversies do not simply assemble publics and materialise participation, but also act as important rhetorical devices that can be mobilised to make persuasive claims and to pursue populist forms of political engagement. While Throgmorton, 
Laclau (2005), and Thévenot et al.'s (2000) approaches to public-making practices have different emphases, they all highlight the idea that public engagement in socio-technical controversies is not very different from classical forms of political engagement outlined by Rousseau, Marx, and other political theorists (Griggs \& Howarth, 2008, p. 125). That is, the classic issue of how to link particular interests to the common good is not side-lined in sociotechnical controversies, but is an important issue that can help actors make legitimate and persuasive claims, and mobilise support. I suggest, therefore, that analysing the rhetorical appeals to 'the people' and the common good are important when examining the practices that assemble publics and materialise participation.

While public-making practices are often used to pursue populist forms of political engagement, the persuasiveness of populist rhetoric can depend on the issues of measurement and the suitability of the methods used to gather public opinions. Populist forms of political engagement and rhetorical appeals to 'the people' might help mobilise support and strengthen claims, but in planning and socio-technical controversies, appeals to a majority figure are often framed as debates over the methods and techniques that are used to assemble publics and measure their opinions.

In general, the social science literature on the role of numbers and measurement in political and socio-technical controversies has been examined from Foucaultian, STS, and policy perspectives. Foucaultian approaches to numbers in controversies have examined "the numericization of political argument" in debates over political representation and the counting of populations (N. Rose, 1999, p. 215); the political and "anti-political" effects of calculation (Barry, 2002); and the use of surveys and measurement procedures in the creation of public opinion (Osborne \& Rose, 1999).

Policy approaches to numbers have focused on its political uses. According to Rose (1999, p. 205), a number of policy approaches have focused on how numbers "displace political disputes into technical disputes about methods" (see Alonso \& Starr, 1987; Prewitt, 1987). For instance, "arguments about numerical quotas, availability pools and demographic imbalance [can] become a substitute for democratic discussion of the principles of equity and justice" (Prewitt, 1987, p. 272). More generally, Stone (1988, p. 127) argues that "the fundamental issues of any policy conflict are always contained in the question of how to count the problem". 
Rather than focusing on the displacement of political problems, STS theories tend to focus on the measurement of issues and phenomena as integral to political and socio-technical controversies (Barry, 2013; Latour, 2005a). Because numbers, measurements, and calculations are often used as a persuasive method of re-presenting issues to the people gathered around it, political and socio-technical debates often focus on the 'accuracy' and appropriateness of measurements (Latour, 2005a, p. 16). For example, analysing the controversy surrounding the Florida vote in the 2000 US presidential election, Lynch, Hilgartner, and Berkowitz (2005, p. 825) argued that reaching a final or credible election result "rested not on numbers alone but also on debates about the means through which they were generated".

While these three approaches to numbers and measurement inform the discussion below, I primarily draw on STS theories as they can be used to understand how the anti-expressway groups used numbers and measurements to translate their populist rhetoric as an issue with the NZTA's public-making practices and measurement devices. If populist forms of political engagement are rhetorical and technical, then it is important to examine the technologies of populist politics. Barry (2002, p. 269) argues that focusing on the technologies of politics "points to the fact that politics, as conventionally understood, is actually a rather specialist activity, which is associated with particular techniques and practices". Here, Barry (2002, p. 269) is arguing that discursive theories of politics, such as Laclau and Mouffe's approach, tend to "focus on questions of identity and discourse at the expense of an analysis of the technical and institutional forms which politics takes”. Understanding popular forms of political engagement as a specialist activity is useful because it suggests that technical issues of measurement and counting are not simply incidental to populist forms of political engagement.

\subsection{Assembling the Public and their Opinions}

As discussed in Chapter Five, the NZTA's consultation exercises focused on the issues of selecting a route for the expressway and seeking public feedback on the design development aspects. In this section I examine how residents, stakeholders, interest groups, and 'potentially-affected' landowners were assembled and addressed through the NZTA's public consultation on the selection of the expressway's route and preferred alignment (New Zealand Transport Agency, 2009b). I suggest that the NZTA's public consultation techniques did not 
simply inform, engage, and gather feedback from ready-made publics, but made them real by assembling them, measuring their opinions, and materialising their participation.

The NZTA's four public consultation phases were designed to assemble and inform, what Barry (2013, p. 99) calls, "new collectivities" (affected communities, stakeholders, and iwi) and "pre-existing collectivities", which were called 'the general public'. According to the NZTA (2009a, p. 6), the consultation exercises were organised to inform, engage, and gather feedback from "affected communities, key stakeholders, iwi and other members of the general public". For example, the first phase of public consultation involved mailing 26,500 consultation brochures to "all potentially affected parties, organisations and to every postal address in the Kāpiti Coast District" in order to gain feedback on the expressway options (New Zealand Transport Agency, 2009a, p. 6). Additionally, the NZTA publicised the project through a range of media channels, such as open days, public notices in newspapers and a project website. Of course, the stakeholders and iwi identified by the NZTA pre-existed the expressway project, but affected communities, stakeholders, and iwi were 'new' in the sense that their identities were defined by their interest in the project and their location to the proposed expressway.

The techniques and methods used to inform and engage affected collectivities did not simply address them, but performed them into being. As Barry (2013, p. 102) suggests, affected communities are often performed into being so that they can "be informed and consulted, and the impacts on them assessed". In this case, the NZTA's consultation process, which is outlined in their consultation reports, helped bring affected collectivities into being in at least two ways. First, defining affected communities and stakeholders in terms of their proximity to the expressway and interest in the project creates an identity for the affected collectivities that are based on these issues. For example, the NZTA defined a directly affected landowner as someone who owns property that "may be required by any of the options of the preferred alignment route directly affecting their property" (New Zealand Transport Agency, 2011c, p. 9). Similarly, affected "business owners and residents adjoining the proposed Expressway" were defined in relation to "the effects of the road on their properties" (New Zealand Transport Agency, 2011c, p. 33). In contrast, stakeholders and tangata whenua were defined in terms of the potential impacts that an expressway could have on them.

Second, the NZTA's stakeholder meetings, letters, brochures, feedback forms, and other consultation techniques identified or named them as groups that need to be informed and 
consulted. In a sense, the consultation devices and techniques made the affected groups real by identifying, analysing, and publicising their concerns, preferences, and interests. As Rose (1999, p. 189) argues, surveys, opinion polls, and other small devices and techniques make communities real by segmenting them and bringing their "values and virtues into visibility and ... into the deliberations of authorities". While the concerns of affected residents were grouped with the opinions of the general public, affected stakeholders were made real by being identified in the NZTA's 'key stakeholder list'; hearing their concerns at meetings and public expos; and having their interests and concerns identified and published in the NZTA's consultation reports.

In contrast to the affected groups, the general public were pre-existing or ready-made in the sense that its existence was taken for granted and that it could be activated for the purposes of being informed and consulted about issues that might affect them (Barry, 2013, p. 97). In line with their public engagement policy, the NZTA consulted the general public in order to inform them about the project, gain feedback, and to enable them to communicate their concerns (New Zealand Transport Agency, n.d.-a, p. 259). While the NZTA refer to the wider community as a stakeholder that has an interest in how the project will affect their daily activities and the local roads that they use, the general public is not identified as an interest group (New Zealand Transport Agency, n.d.-a, p. 263). Instead of being defined in terms of their distance from the proposed expressway or their interests, the general public were defined in terms of residency (as residents of the Kāpiti District) and citizenship (as a citizen who should engage with public issues). The NZTA's understanding of the general public, therefore, aligns with liberal understandings of the public as a group of citizens who pay attention to or who actively engage with an issue (Warner, 2002, p. 419). In this sense, as the general public pre-exist the expressway project, it should manifest when problems arise that cannot be settled by existing institutions or when a matter affects "an association of actors who were not directly involved in its production" (Marres, 2007, p. 773).

While the NZTA addressed the general public as a ready-made entity, the consultation techniques did not simply gather their opinions, but helped bring them into being as a readymade or pre-existing entity. Like the affected groups, the general public were made real when the NZTA and Colmar Brunton (who were commissioned by the NZTA) collected feedback from Kāpiti residents and identified their preferences, concerns, and common issues in their reports. For instance, when the NZTA (2009a) requested public feedback on the preferred route for the expressway, they found that the majority of submitters (local residents) preferred 
the 'WLR Expressway Option'. Similarly, a Colmar Brunton (2009) survey found that 49 percent of Kāpiti residents preferred the Western Link Road option. The NZTA's (2009a) first consultation report also identified nine common submission themes and found that a concern with the expressway's adverse effects on property received the largest number of comments. By identifying and measuring the general public's preferences and common concerns, the NZTA's consultation techniques helped make the general public real. The consultation techniques used by the NZTA, therefore, reveal that the general public did not simply preexist the expressway project, but were assembled and enacted as ready-made.

If publics are assembled and made real through a range of consultation methods, then it is perhaps not surprising that debates over public preference and public concerns can take centre stage in socio-technical controversies. The practices and techniques that assemble publics and materialise participation can play an important role in socio-technical controversies because of their political and anti-political effects (Barry, 2002). Public consultation can have antipolitical effects in the sense that it can channel public debate, limit the space of contestation, and can be used to reach consensus (Barry, 2002, p. 270). However, assembling publics and making them real through a range of consultation methods can have political effects in the sense that it opens the possibility for actors to discuss issues surrounding public preference and common concerns. In the Kāpiti expressway project, controversies over public opinions and their concerns focused on their role in the decision-making process and the problem of generating 'accurate' knowledge about publics and their opinions. In the next section of this chapter I focus on the political effects of the public consultation process by examining the controversies surrounding the role of 'the people' in the decision making process.

\subsection{The 'Preferred Option' and the Rhetorical Construction of the Local Community}

While public consultation exercises help make publics real, they also function as sites and devices that allow actors to legitimise their particular demands by linking them to more universal demands for greater public involvement in political issues. In the case of the Kāpiti expressway project, I suggest the NZTA's production of an empty signifier - 'the preferred option' - that people could identify with provided disputants with an opportunity to pursue populist forms of political engagement by mobilising the popular collective discourse of what is best for the majority of Kāpiti residents. In particular, I examine the rhetorical appeals and populist forms of political engagement mobilised by anti-expressway groups when the NZTA 
consulted the public on the preferred route for the Kāpiti expressway in 2009. I argue that the production of preferred option signifier allowed opponents of the expressway to mobilise populist and institutionalist rhetoric that created a political frontier or division between local residents and the central government and highlighted the degree of public opposition to the project.

\subsubsection{The preferred option as an empty signifier}

When the NZTA consulted the public on possible routes for the Kāpiti expressway in 2009 they produced an empty signifier - 'the preferred option' or 'preferred route' - which people could identify with and express an opinion on. The production of the preferred option signifier allowed opponents of the expressway to organise a populist mode of protest that created a political frontier or division between local residents and the central government and highlighted the degree of public opposition to the project.

The preferred option functioned as an empty signifier in the sense that a number of different meanings were attached to it. Coding 50 news articles, letters to the editor, and government press releases on the Kāpiti expressway project from 2009, I identified a number of different meanings that were attached to the preferred option signifier. While the opinions expressed about the preferred option were diverse, they reflected a concern with the role that the public and experts play in decision-making processes. The opinions suggested that the preferred option was to be selected by the community or majority of Kāpiti residents. This sentiment was expressed by the Transport Minister Steven Joyce, representatives of the NZTA, and residents.

Specifically, the opinions on the role of the people in selecting the preferred route for the expressway suggested that it was the community's preferred option. Initially, popular appeals to the community were made by the Transport Minister and representatives of the NZTA. The Transport Minister Steven Joyce (2009) announced that, because there are "limited options for roading corridors on the [Kāpiti] coast", he "just want[s] the community to make a conscious decision about what their long-term preference is". After the community were consulted on the NZTA's two expressway routes on the $26^{\text {th }}$ of August 2009, Joyce stated that "there was a strong body of opinion coming out of the meetings that the highway should be shifted and that should be considered" (as cited in Blundell, 2009b). In response an NZTA spokesperson suggested that a 'third option' would be considered based on the community's response to the 
two initial options. These comments from Joyce and the NZTA suggest that the preferred option would be selected by the community.

However, a number of people had different opinions on which route should be selected as the people's preferred option. One concerned citizen suggested that "the majority of citizens want the Western link Road four-laned" (as cited in Blundell, 2009c) and when the NZTA selected this option it was described as a "victory for the people" (as cited in Calman, 2009). In contrast, some commentators, such as the Kāpiti mayor, claimed that there was "a lot of community pressure to go back to the current SH1 route" (as cited in Blundell, 2009c). When the NZTA announced that they had selected an expressway on the WLR route, one local resident suggested that locals "will be up in arms" and "chaining themselves to diggers" (as cited in Calman, 2009). These comments suggest that selecting the preferred option was a contested issue, with supporters for each option claiming to have support from a majority figure.

Once the NZTA selected the preferred option in December 2009, they emphasised that the selected route was the Board's preferred option, which, I suggest, helped unstitch the empty signifier of the preferred option from the particular idea of the 'local community'. A spokesperson for the NZTA suggested that this option was chosen because it balances local and national needs and is the least expensive. Whereas Joyce's earlier comments suggested that he wanted the community to decide on their preferred route, the NZTA suggested that the selection of the preferred route was based on a number of factors (such as cost, benefits etc.) and not the community's preference per se (New Zealand Transport Agency, 2009c). The 4,500 submissions, according to the NZTA (2009c), ensured "that the Board were well informed of their views on the options". In other words, the Board considers "all three options and the feedback from the community" and then chooses the preferred option (New Zealand Transport Agency, 2009c). The NZTA (2009c) acknowledged that the decision was not based entirely on public preference when they suggested that "we do appreciate our decision differs from the preference of the many". Commenting on the day of the NZTA's decision, Joyce seemed to agree with the NZTA's more technocratic interpretation of the consultation process by saying that the NZTA chose an "option that will benefit not only the Kāpiti Coast but also areas north and south of the Kāpiti Coast" (as cited in "Questions and Answers - 15 Dec 2009,” 2009). If a majority figure was initially stitched to the preferred option signifier, the NZTA's comments attempted to attach a different figure to it: the figure of an expert who selects the preferred option based on a number of factors. 


\subsubsection{The preferred option and political engagement}

While the NZTA disagreed with the idea of the local community selecting the preferred option, the conflict over whether the local community or NZTA's experts should select the route for the expressway seemed to spark interest in the expressway project and allowed disputants to connect their particular demands to the more universal demand for meaningful public participation in political issues. As I discuss below, the NZTA's selection of the unpopular WLR expressway route as the preferred option served as a rallying point for opponents of the expressway. While the opponents of the expressway had different reasons for opposing the project, the preferred option played, what Howarth and Griggs (2006, p. 40) call, a universal function that linked "together different demands against a 'common enemy' . . . [and represented] the entire chain of demands". Specifically, the public meetings and protests organised by anti-expressway groups in 2010 to 2011 reveal that populist and institutionalist rhetoric were used to engage with the project and challenge the idea that the NZTA selected the preferred option. The popular ideas mobilised by anti-expressway groups created a political frontier between 'the people of Kāpiti' and the 'central government' and highlighted the unpopularity of the NZTA's preferred option.

Although public criticism of the NZTA's selection of the WLR route as the preferred option first surfaced in 2009, greater public opposition to the decision formed in late 2010 when antiexpressway groups organised public meetings and protests. In August 2010, the Alliance for Sustainable Kāpiti (ASK) organised a public meeting to allow political representatives and transport experts to question the expressway project. This meeting, and its associated press release, which I have described in Chapter Five, helped politicise the preferred option as a contentious issue by framing it as not only an institutionalist issue to do with the decisionmaking and planning process, but also as a populist issue of 'the community' vs. 'the government'.

In contrast to the populist appeals that surfaced in 2009, which focused on the issue of public preference in liberal-democratic terms, the opponents of the expressway defined the relationship between the community and the NZTA in antagonistic terms. Rather than simply defining the community as a collective who express their preferences and provide feedback, the speakers at an anti-expressway meeting framed the community as a political actor that had not only been treated shoddily by the government, but had also been betrayed by them (Alliance for Sustainable Kāpiti, 2010). For example, one speaker said that the expressway 
project "does not have us in mind" and that "it has created a real sense of the government betraying the community" (Alliance for Sustainable Kāpiti, 2010). Furthermore, another speaker claimed that the proposal is "demonstrably not in the local interest" (Alliance for Sustainable Kāpiti, 2010). These appeals to the community as a political actor can be understood as a populist form of political engagement because they create a political frontier that symbolically divides society into two opposed camps: 'the community' (or underdog) and 'the government' ('the other') that has betrayed them and treated them shoddily (Panizza, 2005 , p. 5). This process of naming the enemy is an important aspect of populist politics as it creates a mode of identification that is based on antagonism (Panizza, 2005). Of course, the mobilisation of populist rhetoric does not mean that opponents of the expressway are 'populists': it means that populism is mobilised as a flexible mode of persuasion that can support the claims made by actors who oppose the Kāpiti expressway project (Panizza, 2005, p. 8).

Almost one year after the public meetings, an anti-expressway rally and petition re-publicised the preferred option as a contentious issue by using a mix of populist and institutionalist rhetoric. The purpose of the rally, which was organised by Save Kāpiti and ASK, was to protest against the NZTA's decision by presenting a 4,000+ signature petition to the Prime Minister and the Minister of Transport. The web-based version of ASK's petition encouraged people to sign their petition by appealing to the popular ideas of meaningful community consultation and environmentally sustainable transportation. The petition appealed to the popular idea of the government betraying the community by arguing that:

[The] decision process has been divisive, manipulative, and lacking information. Instead of consulting the community about possible solutions to the problems, we were only offered a choice between three equally unacceptable expressway routes. (Alliance for Sustainable Kāpiti, n.d.)

Moreover, the petition connected the issue of community consultation with the environmental issues of preserving the Kāpiti Coast's semi-urban character and supporting "sustainable transport solutions which ... lower our reliance on fossil fuels and to reduce greenhouse emissions at a local and national level" (Alliance for Sustainable Kāpiti, n.d.). ASK connected the issues of community consultation and environmental protection by suggesting that the local communities in Kāpiti would not support a road that would change the character of Kāpiti and that was environmentally unsustainable. 
However, while ASK used populist appeals to mobilise support, they did not connect them with broader struggles against automobility and road building in general. ASK (n.d.) did not argue that all expressways are problematic, but argued that an expressway through Kāpiti was 'unacceptable' and not a 'solution'. By focusing on the Kāpiti Coast, they connected their populist appeals with the local issue of selecting a "sustainable transport solution" for the Kāpiti district and addressing local traffic problems. ASK, therefore, appeared to engage with, what Griggs and Howarth (2008, p. 135) call, a "restricted form of populist politics" that related their broader political and environmental appeals to the local communities and environment of Kāpiti.

The anti-expressway rally and associated press releases mobilised the institutionalist and popular demands from ASK's petition to protest the NZTA's decision to build an expressway. While I did not attend the protest, the press releases and publicly available photos of the protest reveal that protesters mobilised a mix of institutionalist appeals that urged the National Party to change its decision and popular appeals to environmental protection and public participation. In one sense, the protest followed an institutionalist form of politics by targeting politicians and asking them to reconsider their decision to build an expressway through Kāpiti. For instance, a press release by Save Kāpiti (2011) challenged the NZTA's economic analysis. A spokesperson for Save Kāpiti claimed that the project will not "deliver the economic growth the government claims" and that alternative transport options would solve Kāpiti’s traffic problems, but without the "\$550 million price tag” (Save Kāpiti, 2011). Moreover, several protesters held placards that outlined what transport options were suitable for Kāpiti. For example, one protester held a placard that read: "THE ANSWERS! Community Link Road, Upgrade SH1, and finally RAIL!”

When examined in isolation, the focus on influencing political leaders to change the decision to build an expressway through Kāpiti reveals, what Griggs and Howarth (2008, p. 135) call, "a classically institutionalist form of mobilization and protest" that seems distant from popular forms of political engagement that focus on broader political or environmental issues. However, the protest aligns with popular forms of political engagement by articulating the particular demands of the people who signed the petition with the more universal demands for meaningful public participation and environmental protection. ASK's petition website reveals that a large number (approximately 550) of people who signed the 1,262 signature web-based petition provided various reasons for opposing the project. While many of the comments on the petition web-site were institutionalist appeals that requested politicians to change the 
decision, ASK and Save Kāpiti linked them to a populist discourse that appealed to a majority figure that opposes the project and created a political frontier between local residents and the government.

The press releases by ASK and Save Kāpiti linked the particular demands from the people who supported their petition to a more general appeal to majority rule and public participation. The use of a petition and surveys to highlight the unpopularity of the NZTA's preferred option is populist in the sense that it highlights, what Griggs and Howarth (2008, p. 129) call, "the degree of division and contestation brought about by a political mobilization or practice". Using petitions and surveys helps link the dispersed range of isolated opinions on transport options for Kāpiti to the more universal demand for greater public involvement in issues that affect them. For example, According to Jonathan Gradwell, a spokesperson for Save Kāpiti, "the 4,000 signatures represent three times the number who chose the expressway to go on the Western Link route during the poorly handled 2009 NZTA consultation” (Save Kāpiti, 2011).

While the appeals to a majority figure that opposes the project was an important element of ASK and Save Kāpiti's populist discourse, their main focus was on the government's antagonistic relationship with the local communities of Kāpiti. The protest and press releases mobilised a populist discourse that created a political frontier between the "Kāpiti Coasters", who are "fight[ing] to protect their seaside community", and the government that is "bullying" and "not listening" to the community (Begovich, 2011). In a press release by ASK, a spokesperson for Save Kāpiti stated that "the people of Kāpiti are refusing to be bullied into accepting a destructive, expensive, and unnecessary motorway through our community" (Pomare as cited in Alliance for Sustainable Kāpiti, 2011). She claimed that "the NZTA's consultation has been a sham - and has ended with a route significantly different from the one ‘consulted' on” (Pomare as cited in Alliance for Sustainable Kāpiti, 2011).

Publicly available images of the protest revealed that many of the protesters used placards to highlight a division between the government and the local community. Like the press releases, the populist rhetoric on the placards created a political frontier by appealing to the idea that the government is 'bullying' and 'not listening to' the local community. One protester (and possibly several others) appealed to the idea that the government was bullying the local communities of Kāpiti by holding up a placard with the word 'bullydozer' next to an image of the Transport Minister (Owen, 2011). And, another protestor referred to the idea of the 
government 'not listening' to the community by pointing to the anti-democratic aspects of the NZTA's decision. One protester's placard stated: "this is an anti-democratic decision that does nothing to enhance the lives of people living in Kāpiti” (Owen, 2011). Comments like these expose the antagonistic relationship between the government and the local communities in Kāpiti. The placards name the government as the enemy, rather than protector, of New Zealand citizens. This process of naming the enemy is an important aspect of populist forms of political engagement as it creates a mode of identification that is based on antagonism (Panizza, 2005).

Similarly, other protesters pointed to the division between the government and local communities by claiming that the expressway was for the trucking industry rather than for the benefit of the local community. A protester held a placard that read: "This GOVT has just BULLDOZED through what it has promised [to] the TRUCKING industry" (Owen, 2011). Other placards highlighted the government's relationship to the trucking industry by displaying images of the Transport Minister and a local politician next to the statements: "We can smell the diesel on your breath from here!" and "Me and My Mates $\vee$ [love] Expressways" (Owen, 2011). The idea of 'smelling diesel' on the Transport Minister's breath provides a clever way of referencing David Lange's well-known speech on nuclear weapons and New Zealand's nuclear free policy ${ }^{5}$. Using Lange's speech helps highlight the idea that the Transport Minister cannot disguise (signified by the word 'smell') the fact that the expressway project will primarily benefit the trucking industry, which is signified by the word 'diesel'. The placard helps reinforce the idea that the government listens to the powerful lobby groups, but not the local communities of Kāpiti.

Analysing ASK and Save Kāpiti's petition and protest reveals that public-making practices can function as rhetorical devices that allow actors to engage with socio-technical controversies and to make legitimate and persuasive claims. The anti-expressway groups engaged with the controversy over the preferred option by connecting the particular demands from local residents to the more universal demands of public participation in political decision-making and environmental protection. The creation of a division between local residents and the government helped construct a populist discourse that challenged the NZTA's decision. However, focusing on the rhetorical construction of the people overlooks

\footnotetext{
${ }^{5}$ David Lange was the Prime Minister of New Zealand from 1984 to 1989 . In his speech on why nuclear weapons are morally indefensible, Lange made the, now famous, comment that he could "smell the uranium" on the breath of the speaker for the opposition side (Ministry for Culture and Heritage, 2015).
} 
how knowledge of the public's preference is generated and debated. That is, persuasive appeals to 'the people' often involve questioning the devices that are used to assemble publics and measure their opinions. While I have briefly commented on Save Kāpiti's critique of the NZTA's use of numbers, the problem of accurately measuring public opinion was an important issue during the Board of Inquiry. In the next section I discuss how the technical and material issues of assembling publics and measuring their opinions allowed actors to enact populist forms of political engagement.

\subsection{Populism as a Technical Practice}

The antagonisms that were highlighted by the protestors reveal the importance of rhetoric in planning and socio-technical controversies, but a focus on the rhetorical devices that produce 'the people' can overlook the material and technological aspects of populist politics. Focusing on the material and technological aspects of politics highlights that a range of material devices and technologies are not incidental to politics, but make it possible for people to act as political agents (Barry, 2002, p. 269). In this case, a range of measurement techniques (such as petitions, surveys, feedback forms) functioned as public-making practices that made it possible for actors to enact populist forms of political engagement.

\subsubsection{Measuring public preference}

The NZTA's measurement of public preference with feedback forms and surveys helped spark interest in the importance of public opinion in the preferred option controversy. As discussed above, the NZTA posted 26,500 feedback forms to Kāpiti residents that asked them to either support one of the proposed expressway options or to provide comments and suggestions. By asking people to support one of the expressway options and to leave comments, the NZTA's feedback form suggested that the public's input and opinions played an important role in the selection process and in helping the NZTA "find the best option for the SH1 Expressway through the Kāpiti Coast” (New Zealand Transport Agency, 2009b). Similarly, the Colmar Brunton (2009) survey was commissioned by the NZTA "due to the tremendous response received by NZTA [who] felt that to better serve the Kāpiti community, another consultation was needed to allow for further feedback from residents on this important matter" (Colmar Brunton, 2009, p. 2). Like the feedback form, Colmar Brunton's research and findings informed the NZTA's deliberations. The feedback forms and survey, 
therefore, suggested to Kāpiti residents that the measurement of public opinion was to play an important role in the selection of the preferred option.

The NZTA's use of feedback forms to generate and quantify public opinions and preference made it possible for supporters and opponents of the expressway to make persuasive appeals to a majority figure and to question the accuracy of the NZTA's findings. The NZTA's empirical knowledge of the public's opinions and preferences enabled disputants to use measurement devices and techniques to make convincing appeals by highlighting the degree of support for, or opposition against, the expressway project. In other words, the use of numbers and the techniques that generated them enabled disputants to bring the majority into, what Barry (2002) calls, the frame of scientific calculation. By focusing on the techniques that were used to measure the public's concerns, the popular appeals used to engage with the preferred option controversy were reframed as technical and scientific matters of producing accurate measurements and using suitable scientific methods.

The NZTA used their findings from the feedback forms, the Colmar Brunton survey, and a petition as evidence of public support for an expressway on the Western Link Road (WLR) route. The NZTA's analysis of the feedback forms revealed that the 'WLR Expressway Option' received the largest number of supporters $-1,609$ people preferred this option compared to 1,171 votes for 'alternative transportation options', 1,041 votes for the 'Eastern Option', and 619 votes for the 'Western Option' (New Zealand Transport Agency, 2009a, p. 3). Similarly, the Colmar Brunton survey reinforced the NZTA's analysis of the feedback forms by finding that the Western Link Road option received the largest number of supporters - 527 people preferred this option compared to 183 votes for the 'Eastern Option', 112 votes for the 'Western Option', and 81 votes for the '2-lane Western Link Road' (Colmar Brunton, 2009, p. 5). Interestingly, a 2,141 signature petition supporting a "four-lane Western Link Road (Option 3)" was used by the NZTA as further evidence of support for an expressway. However, it is important to note that, while the petition does not explicitly mention the 'WLR Expressway Option', the NZTA used it as evidence of further support for this option (this is important because opponents of the expressway raised this as an issue at the BOI, which I discuss below). The use of feedback forms, a survey, and a petition, therefore, reveals that a number of measurement devices made it possible for the NZTA to make persuasive appeals to a majority figure that prefers the WLR Expressway Option. 
While a range of measurement devices made it possible for the NZTA and supporters of the expressway to generate empirical knowledge of the public's preferences, they also allowed opponents of the project to make their own appeals to 'the people' by questioning the NZTA's findings and generating their own empirical knowledge of publics. The dispute over who has public opinion on their side was not simply rhetorical, but also involved challenging the NZTA's interpretation of their survey findings. At the public rally in 2011, Save Kāpiti (2011) challenged the NZTA's finding that Kāpiti residents preferred the WLR Expressway Option, by pointing out that the 'vast majority' of submitters (66 percent or 2,837 submissions) preferred other options and that the 1,609 people who preferred the WLR Expressway Option counts for only 34 percent of the 4,446 submissions received by the NZTA. By providing an alternative interpretation of the NZTA's findings, Save Kāpiti was able to claim that the majority of Kāpiti residents did not prefer the WLR Expressway Option.

While the NZTA's survey findings helped disputants enact populist forms of political engagement by critiquing their knowledge claims, the petition developed by anti-expressway groups also helped opponents of the project make persuasive appeals to 'the people'. By generating their own empirical knowledge of the public's preference with a petition, ASK and Save Kāpiti were able to make a persuasive claim that the majority of Kāpiti residents did not support the expressway project. As Save Kāpiti’s spokesperson suggested, the 4,072 signatures represent three times as many people who support the WLR Expressway Option (Save Kāpiti, 2011). Indeed, the generation of empirical knowledge of the public's preference was used to request "that the Government rescind its decision to build an expressway through the Kāpiti community, and work with the whole community in a consultative manner to develop a sustainable transport solution" (Transport and Industrial Relations Committee, 2012). By generating empirical knowledge of the public's preference, the petition made it possible for anti-expressway groups to enact populist forms of political engagement. The antiexpressway groups, therefore, were not simply armed with rhetoric alone, but were equipped with a range of devices and technologies that made it possible to publicly critique the expressway project (Barry, 2002, p. 269).

Furthermore, at the Board of Inquiry in 2012, opponents of the expressway made persuasive appeals to the populist idea that the government was either 'misleading' or 'not listening to' the local community by critiquing the NZTA's measurement devices. Rather than simply reinterpreting the NZTA's survey findings to develop their claims, the opponents focused on the reliability and validity of their measurement devices and research methods. The issue of 
public input into the selection of a preferred option was framed by a number of submitters as a populist issue of the NZTA 'not listening' to local residents. There were many arguments surrounding the concern with the NZTA not listening to the public's views on selecting a route for the expressway. However, as the Board noted, this concern "can be summarised as a criticism of NZTA for misleading people" by referring to the four lane expressway project during the first consultation phase as the Western Link Road, which is often associated with the previous two lane road project (Board of Inquiry, 2013, p. 34). The issue of misleading the public seems to be important for many submitters as it suggested that the NZTA did not adequately consider the social impacts of the selected expressway option and/or the views of local residents, which could have implications for the justification of the preferred option. That is, if the majority of local residents did not support the project then this suggests that the project would have negative social impacts overall and should be abandoned (Board of Inquiry, 2013, p. 37).

While the NZTA's measurement devices might seem convincing due to the number of people surveyed, opponents of the expressway project argued that the NZTA's methodology and analysis failed to accurately measure the public's preference, which suggests they did not listen to the community and possibly misled the public and decision-makers. In total, approximately seven submitters provided relatively in-depth critiques of the NZTA's survey findings and methodology. Furthermore, many other opponents of the expressway briefly questioned the NZTA's consultation process while focusing on other issues that concerned them. Opponents pointed to what Barry (2002) calls the "fragility" of measurement devices by examining the reliability and validity of their research methods . Barry's (2002, p. 274) idea of fragility reveals that, while the measurement of a phenomenon can seem convincing, measurements are often unable "to capture the complexity of objects and practices in actuality". That is, different scientific methods, techniques, and other variables can expose the weaknesses of a measuring device.

To examine how disputants revealed the fragility of the NZTA's measurement devices, I focus on the evidence submitted by Rachel Mackay as she provided an extensive critique of their survey. Mackay (2013) argued that:

The lack of information provided to our community through the consultation process, and the potentially confusing consultation documents, surveys and petitions and 
timelines may have impacted on the final decision regarding the placement of the proposed Expressway route and the application. (p. 6)

In particular, she argued that "using the results of the Colmar Brunton survey to contribute towards gauging community support for the proposed Expressway" was problematic as its reliability and validity was questionable (Mackay, 2013, p. 9). Mackay revealed the fragility of the Colmar Brunton survey by claiming that that the wording of the questions "could derive ambiguous or inaccurate results, namely that respondents thought they were being asked for their preference of an Expressway on either the Eastern or Western routes, or a local arterial route - the 'Western Link Road Option'” (Mackay, 2013, p. 9). She also critiqued the NZTA's reference to the 'four-lane Western Link Road' petition as its wording was "ambiguous and potentially misleading". Mackay suggested that "anecdotal feedback from some Kāpiti residents was that they signed the petition thinking they were supporting the Western link arterial road, not an Expressway on the Western Link Road alignment" (Mackay, 2013, p. 9).

In their final report, the Board noted the fragility of the NZTA's measurement devices, but argued that "if anyone was misled, including those responding to the Colmar Bunton poll, it would be as a result of misreading, or not reading, the [October 2009 consultation] document" (Board of Inquiry, 2013, p. 37). The Board (2013, p. 37) noted that some people may have been misled by using the WLR project to refer to an expressway project, but they pointed out that "the October 2009 document makes it clear that it was an expressway that was being considered". The Board's comments suggest that, rather than the NZTA not listening to the local communities, the communities did not pay attention to their public consultation documents. Rather than pointing to the fragility of the NZTA's measurement devices and findings, the opponents of the project inadvertently pointed to the problems that can arise when the public are asked to read and form an opinion on technical matters.

\subsubsection{Assessing the preferred option's social impact}

While the NZTA's public consultation techniques were interrogated to make persuasive appeals to the people, Save Kāpiti also critiqued their social impact assessment tools in order to engage with the issue of greater public involvement in issues that affect them. Save Kāpiti's critique of the NZTA's social impact assessment highlights how populist appeals were supported by interrogating the measurement devices that assemble publics and gather their opinions. At the Board of Inquiry, Save Kāpiti translated the issue of public consultation 
on the preferred option as a legal issue of "whether adequate consideration has been given to alternative routes" (Save Kāpiti, 2012, p. 2). As decision-makers are required by the section 171 of the RMA to "pay particular regard" to alternative routes, Save Kāpiti argued that the NZTA's social impact, transport, and urban planning assessments failed to adequately consider alternatives. In particular, Save Kāpiti argued that the content and methodology of the NZTA's social impact assessment (SIA) was flawed, which "affect[ed] both the justification of the proposal and the consideration of alternatives” (Save Kāpiti, 2012, p. 3). That is, if a large number of residents would be negatively affected by the expressway then this would call into question the NZTA's justification for the preferred option.

Save Kāpiti's critique of the NZTA's social impact assessment reveals that the persuasiveness of appeals to 'the people' or majority depend not only on equivalential articulation, but also on the technical issues of assembling publics and measuring their opinions. Save Kāpiti's SIA expert, Buchan (2012, p. 11), highlighted these technical issues by arguing that "identify[ing] groups within a community that are particularly vulnerable, where they are located, their pattern of activity, what facilities and services they rely on ..." is important because it provides decision-makers with "a sound understanding of the communities affected - how it functions, what people value, current issues etc.". She concluded by claiming that the NZTA's social impact assessment failed to "identify and quantify the real social costs and benefits of the Expressway, the particular groups and sectors within each community who stand to lose or gain and why, and the development of more accurate judgements on the nature of the effects" (Buchan, 2012, p. 13).

Indeed, the Board (2013, p. 124) agreed that persuasive appeals to the social impacts of the project depended on an expert carrying out a social impact assessment so that decision-makers have "sufficient information" to understand the social effects and whether the proposed mitigation work would be "adequate". The Board (2013, p. 124) pointed out that, as they were presented with a "huge amount of material" on the range of social effects from technical experts, stakeholders, and members of the community, they had sufficient information to make a decision. They argued that:

What is important to us is that we have sufficient information to be able to assess the range of social effects, issues and concerns about the project, make determinations in relation to them and that [sic] be satisfied that proper and adequate mitigation is in place. (Board of Inquiry, 2013, p. 123) 
Based on this information presented to them, the Board (2013, p. 124) concluded that they were "satisfied that social effects, despite Ms Buchan's comments, were factored into the alternative route assessment process".

Moreover, the Board also argued that persuasive appeals to the people involved not only critiquing the technical assessments used by the NZTA, but also conducting alternative assessments that would reveal the weaknesses of the NZTA's evidence. The Board (2013) argued that Ms Buchan and other submitters criticised the NZTA's social impact assessment without undertaking their own assessment, which would have provided a more convincing critique of their assessment. In other words, the Board suggested that generating empirical knowledge of affected publics is important when debating the weaknesses of a social impact assessment and making persuasive appeals to an affected public.

The arguments surrounding the preferred option controversy at the BOI reveals that pursuing populist forms of political engagement can be a specialist activity that involves investments in the law, impact assessment, survey research, and a range of public-making devices and techniques. The arguments from the opponents of the expressway demonstrate that appealing to a majority figure that is negatively affected and has not been listened to is not simply rhetorical, but is also a technical matter of evaluating the methodology and techniques used to assemble publics, measure their opinions, and assess social impact.

\subsection{Conclusion}

Public consultation exercises that ask local communities for input into a project can provide an opportunity for them to enact populist forms of political engagement. In this case, by assembling 'potentially-affected' publics and seeking feedback on the preferred option, the NZTA's consultation exercises helped make them real and made it possible for concerned citizens to demand greater public involvement in political issues. The preferred option functioned as an empty signifier that allowed opponents of the expressway to mobilise populist demands that created a political frontier between residents of Kāpiti and the central government and called attention to the degree of opposition to the project. However, I argued that the enactment of populist forms of political engagement was not simply rhetorical, but also involved challenging the public-making techniques that assembled publics and measured their opinions. 
As I have argued, populist forms of political engagement can play an important role in planning and socio-technical controversies, which suggests that rhetorical and post-Marxist theories can be brought into dialog with object-oriented approaches to science, technology, and society. While Boltanski and Thévenot's (2006) orders of worth framework can be used to examine the preferred option controversy and populist rhetoric, their approach does not align well with populist modes of political engagement. In contrast, Laclau's (2005) focus on discourse and rhetoric has been useful for understanding how disputants engaged with the controversy over the preferred option. His approach highlights how disputants use publicmaking practices to rhetorically construct a collective agency and popular identity of the local community to engage with and challenge political and socio-technical issues. However, object-oriented theories are also important as they reveal that debates over the technical and material issues of assembling publics and measuring their opinions make it possible for actors to enact populist forms of political engagement. Using rhetorical and object-oriented theories, therefore, reveals that persuasive appeals to a majority figure involves engaging with the objects and techniques that support this form of political engagement.

More generally, the preferred option controversy reveals the opportunities and challenges anti-expressway groups faced when engaging with this issue. Asking the public to comment on the preferred route enabled people to discuss a range of problems that were otherwise absent from the NZTA's official documents. The preferred option controversy was seen by many opponents of the expressway project as part of an on-going debate over meaningful public participation in political issues and environmental protection. The use of populist rhetoric revealed an antagonistic relationship between the central government and the local community. However, sustaining this mode of engagement proved to be problematic at the Board of Inquiry. While a number of disputants translated populist appeals as an issue with the NZTA's technical assessments, the Board's comments suggest that opponents of the project needed to not only critique the NZTA's assessments, but also produce their own empirical knowledge of publics in order to reveal the weaknesses of the NZTA's evidence. The Board's decision, therefore, highlights the idea that enacting populist forms of politics can be a specialist activity that involves not only generating empirical knowledge of publics using appropriate public-making techniques, but also investments in the law, impact assessment, and survey research. 


\section{Chapter Eight: The Alliance}

\subsection{Introduction}

In the previous chapter I examined the preferred option as an empty signifier that sparked interest in populist modes of political engagement. I argued that making persuasive appeals to a majority figure involved challenging the public-making techniques that assembled publics and measured their opinions. However, the preferred option controversy involved not only assembling publics and mobilising populist rhetoric, but also enrolling allies that supported or opposed the proposed expressway alignment. Underpinning the popular idea of a preferred option was a large archive of documents that justified why this option was selected.

In this chapter, I focus on the importance of alliances in socio-technical controversies. During the early planning stages of the expressway project in 2009, the NZTA developed an alliancebuilding approach that gathered a team of experts who could not only plan and construct an expressway, but also align the numerous human and nonhuman actors that would challenge or be affected by the project. To develop a list of possible route options for the expressway, the NZTA's project team, who were conveniently called The Alliance, undertook extensive planning work that demonstrated how various route options would align the objectives of the National Government and NZTA with the interests of road users, residents, stakeholders, the environment, and a diverse number of affected human and nonhuman actors. Significantly, The Alliance did not simply consult interest groups and stakeholders to find out if the project would be suitable. They developed numerous environmental assessment reports and management plans that outlined a range of strategies and devices that could, in theory, align the human and nonhuman actors with the project.

The alliance-building approach to the Kāpiti expressway meant that opponents of the project were obliged to counter-enrol the actors that had been aligned by the NZTA with their significant organisational resources. In particular, I focus on one nonhuman actor that proved to be difficult for The Alliance to enrol in the project: Kāpiti’s wetlands. Although The Alliance had outlined an in-depth proposal for protecting the wetlands from the expressway, a number of residents and local groups challenged their evidence. However, the opponents faced the difficult task of not only understanding and evaluating their evidence, but also developing a counter-proposal that would re-align the wetlands as areas that would be threatened, not protected, by the expressway. 
It is important to note that nonhuman action is a controversial idea that raises a number of important philosophical and theoretical problems. It is beyond the scope of this thesis to discuss the agency of nonhumans ${ }^{6}$, but I suggest that the Kāpiti wetlands is an actor in the sense that it is a mediator ${ }^{7}$ that 'does something' or makes a difference to a state of affairs (Latour, 2005b, p. 52). As I will discuss in the next section, the idea that nonhuman actors play important roles in socio-technical controversies helps challenge the idea that road projects are about the clash between human actors and interest groups. Focusing on the wetlands as an actor highlights how nonhumans do not simply prop up human action, which is more 'real' and 'meaningful' (Sayes, 2014).

The alliances that were formed during the planning of the Kāpiti expressway reveal that key decisions in transport planning processes are not simply made by balancing competing social interests, but are the results of resource intensive "ordering work" that aligns human and nonhuman actors with a preferred project (Suchman, 2000). Drawing on ANT accounts of heterogeneous engineering and Callon's (1986) sociology of translation, I argue that the preferred option for the Kāpiti expressway was the outcome of significant ordering work that responded to the demands from human and nonhuman actors. The NZTA's alliance-building approach to the expressway project illuminates the idea that public consultation and democratic debate do not always provide a firm foundation for the public to challenge complex issues involving science and technology. Foregrounding the importance of alliances in socio-technical controversies reveals limitations with sociological theories of dispute that prioritise the importance of social interests and human-centred notions of democracy in controversies.

This chapter is divided into four sections. In section one, I review the literature on the organisational and sociological aspects of engineering and transportation projects. In sections two and three, I examine how the preferred option was informed by a large number of technical reports and an alliance-building approach to the project. In this case, the selection of the WLR route was an effect of the production of various reports and proposed mitigation devices that would be used to create stable associations or alliances between actors. Drawing on Callon's (1986) concepts of problematisation and interessement, I suggest that the reports

\footnotetext{
${ }^{6}$ There is an extensive literature on the issue of nonhuman agency (see Sayes, 2014).

${ }^{7}$ A mediator can be defined in relation to an intermediary, which refers to a human or nonhuman that simply relays or transports a force from A to B without modification; that is, it does not 'make a difference' or alter the course of an event (Latour, 2005b, p. 39). In contrast, a mediator does not transmit a force faithfully: it does not simply serve as a 'backdrop' because it can permit, encourage, or block human action (Latour, 2005b, p. 72).
} 
identified a set of problems that identified and linked key actors, while the proposed mitigation or interessement devices helped interest them in the project.

In section four, I discuss how the NZTA's reports and proposed interessement devices reveal the complex ordering and enrolment work that disputants face when challenging engineering projects. I suggest that the ordering work that informed the NZTA's selection of the preferred option points to the difficulties that the public encounter when they challenge these projects. To engage in the preferred option controversy, the public were faced with the difficult task of developing an argument that would not only challenge the NZTA's evidence, but also counter-enrol the actors that had been aligned with the project. Here, I examine the difficulties locally-based groups encountered when they prepared their evidence and the challenges their experts faced when they tried to counter-enrol the at-risk wetlands.

\subsection{STS and Democratic Theories of Road Projects}

As discussed in the previous chapter, the debate over the preferred option centred on whether the NZTA or the local community should select the route for the expressway. From, a Social Construction of Technology (SCOT) perspective, debates over a preferred technology project highlight how competing social groups attempt to impose their interpretation or meanings on the artifact (Pinch \& Bijker, 1989). That is, there are no essential meanings of a technological artifact; its meaning can only be found in relation to a social context of activities and amongst the social groups who interact with it and who share a common meaning with it (Jarzabkowski \& Pinch, 2013; Pinch, 2010, p. 79). By being open to interpretation or “interpretive flexibility", various groups socially construct technological artifacts by defining it as a problem (Pinch \& Bijker, 1989, pp. 29-30). For instance, residents associations might prefer a road that enhances pedestrian safety while automotive interest groups might argue that a road should improve transportation efficiency (Norton, 2008, p. 4). The selection of the WLR expressway route as the preferred option suggests that the NZTA and other supporters of the project were successful in closing the debate by selecting the project that was closely aligned with their objectives. From a SCOT perspective, the NZTA's resources, influence, and team of experts and supporters influenced the selection of this option.

While SCOT highlights the importance of social interests, the selection of the preferred option for the Kāpiti expressway involved the alignment of human and nonhuman interests. As I discussed in the previous chapter, the NZTA publicly stated that the preferred option was selected based on a number of different economic, environmental, social, and technical 
factors. After extensive research and deliberation, the preferred WLR expressway route was selected as the option that would best align these factors. SCOT does acknowledge that nonhumans can play a very visible role in socio-technical controversies, especially when experts disagree over the importance of their properties, but it tends to focus on the human actors who make choices and decisions regarding the design of an artifact (Pinch, 2010). For instance, Pinch (2010, p. 87) suggests that it is tempting to say that the decision to build a curved road is because of a hill that 'forces' the engineers to construct a bend in the road. However, this example of nonhuman 'forcing' is an outcome of a decision made by a team of human engineers. While it is beyond the scope of this chapter to discuss the issue of nonhuman agency, delegation, and intentionality, this example suggests that a SCOT approach to the preferred option controversy would focus on how the groups involved in this debate defined it as a problem.

However, when I investigated the work that went into researching the expressway options and the complexity of selecting a route that aligns human and nonhuman actors, focusing on the role played by the social groups in this debate seemed problematic. The decision to select the preferred option was made by the NZTA and their team of experts, but I observed that it did not appear to be a 'choice' that was made by social interests alone. Rather, the decision to select the preferred option was the result of the successful alignment of a diverse range of factors. Within ANT and ethnomethodological studies of science and technology, the complex decisions that are made by engineers and scientists are not seen as choices, but as 'effects' of the complex ordering work carried out by organisations (Suchman, 2000). In contrast to SCOT approaches, Suchman (2000) argues that the selection of preferred engineering projects are often based on years of extensive research that, not only assess its constructability, but also find ways to interest human and non-human allies in the project. Suchman's (2000) idea is closely aligned with Latour's (1987) and other ANT approaches to science and technology that examine how engineers transform their proposals into 'stable', material artifacts through the work of "translation" (Callon, 1986; Law, 1987; Sage et al., 2011). Translation is important to the stabilisation of an artifact because it is the process of interpreting the interests of actors so that they can be enrolled in a project. That is, it is the process that "transform[s] a claim into a matter of fact" by translating, or catering to, the interests of other actors (Latour, 1987, p. 108).

Although the concept of translation was used extensively by actor-network theorists in the 1980s and 1990s, the concepts outlined in Callon's (1986) sociology of translation continue to 
be used in contemporary studies on infrastructure projects and controversies (see Rydin, 2013; Sage et al., 2011). There are four aspects to Callon's (1986) sociology of translation: problematisation, interessement, enrolment, and mobilisation. Callon (1986, p. 196) constructed his "translation repertoire" to describe "a scientific and and economic controversy about the causes for the decline in the population of scallops in St. Brieuc Bay and the attempts by three marine biologists to develop a conservation strategy for that population". However, his research approach can be understood as vocabulary for studying how actors attempt to gain compliance from others (Callon, 1986).

Problematisation refers to how actors become indispensable to a project by identifying actors, outlining relationships between actors, and establishing an "obligatory passage point"; a series of questions, obstacles, and problems that confronts all of the actors and needs to be overcome or addressed (Callon, 1986, pp. 205-206). While a proposed motorway project appears to be different from the controversy that Callon (1986) describes, a similar process appears to be at work in technology projects. Law and Callon (1988, p. 290), for example, describe how a military aircraft project involved constructing a scenario ("an ideal social and technical world"), enrolling actors to realise this scenario, and creating an obligatory passage point the project's management.

An application of Callon's idea of problematisation to an infrastructure project can be seen in Sage, Dainty, and Brooke's (2011) case study of the Skye Bridge project. They argued that residents, stakeholders, and other diverse groups were aligned when the project sponsor provided a solution to the problem of funding: a Private Financing Initiative and a toll bridge. These two solutions to the funding problem created an obligatory passage point that:

... defined the identities of the stakeholders involved (residents, HIRC, shareholders, contractors), and their links (residents would benefit from the expertise of the contractors and the capital risk of investment banks, shareholders could make a profit from residents and tourists keen for a quicker route). (Sage et al., 2011, p. 282).

After the identities of the actors have been defined, the next moment of translation involves the difficult challenge of making the relevant actors interested in the problematisation. Interessement, which is the term Callon (1986, pp. 206-208) uses to describe the second moment of translation, is a device or series of actions that attempts to lock actors into place by imposing and stabilising "the identity of the other actors it defines through its 
problematizaton". Unlike problematisation, interessement can be understood as "a series of trials of strength whose outcome will determine the solidity of our researchers problematization" (Callon, 1986, p. 207). This moment of translation focuses on how actors or entities are integrated (or not) into the initial project: they can be aligned with the project or they can refuse by being defined in a different way (Callon, 1986, p. 207). Callon (1986, p. 208) suggests that to align other actors with a project, the process of interessement can be used to "build devices which can be placed between them and all other entities who want to define their identities otherwise". For instance, Sage, Dainty, and Brooke (2011) describe how the contractors of the Skye Bridge attempted to 'interest' the otters who would be affected by the project by:

... inserting a new series of actors to isolate them from old, now hazardous, habitats and paths. After consultation with the conservationists, the contractor constructed oneand-half miles of otter resistant road walls and otter tunnels to allow the animals to pass under the various access roads on the island and mainland (Ford et al., 1997, p. 58). In addition, new freshwater pools, essential to otter breeding, were built to replace those lost during construction (Ford et al., 1997, p. 58). (p. 283)

While interessement devices can succeed or fail, enrolment refers to the creation of alliances. That is, enrolment is achieved if the interessement devices have successfully locked the actors into place (Callon, 1986, p. 211). Enrolment, which is the third moment of translation, is "a device by which a set of interrelated roles is defined and attributed to actors who accept them" (Callon, 1986, p. 211). It involves "multilateral negotiations, trials of strength and tricks that accompany the interessements and enable them to succeed" (Callon, 1986, p. 211). For instance, Sage, Dainty, and Brooke (2011, p. 284) suggest that the various interessement devices (otter resistant walls and otter tunnels) successfully enrolled the otters and conservationists into the Skye Bridge project, but other interessement devices, such as making non-payment a criminal rather than civil offence, led to protest rather than enrolment.

Finally, mobilisation refers to how spokespeople for a project represent the allies and whether they will follow the spokesperson, without betraying him or her (Callon, 1986, p. 196). Mobilisation occurs when the various actors are aligned with, and are participating in, the project through representatives that speak for them. The representatives mobilise the actors in the sense that they assemble them around a problem and define what they are and what they want (Callon, 1986, p. 217). For instance, a conservationist might speak for the at-risk otter 
population by defining where they are, why they need protecting, and outlining a proposal that identifies appropriate devices that can be used to protect them (Sage et al., 2011).

ANT's focus on the alliance-building and organisational aspects of socio-technical controversies also reveals weaknesses with democratic or deliberative theories of public involvement. A number of democratic theories suggest that participation, open communication, representation, and transparency are some of the key issues that influence the public's ability to challenge infrastructure projects (Fischer, 2000; Flyvbjerg et al., 2003). Similarly, Habermasian planning theorists tend to emphasise the importance of reaching consensus or understanding through the creation of ideal speech situations that are not dominated by group interests or strategy (Fainstein, 2000; Healey, 1993).

In contrast to democratic theories of dispute, ANT tends to bypass issues of democratic representation and focuses, instead, on the work and resources that go into developing a persuasive re-presentation of an issue. For Latour (2005a), focusing on the democratic aspects of public involvement only tells half the story because it can overlook the collective and organisational aspects of socio-technical controversies. That is, ANT foregrounds the work involved in representing the object of concern to the actors that gather around it. Focusing on alliance-building and organisation reveals the significant obstacles that the public might encounter when challenging engineering projects. Instead of simply engaging in 'rational' argumentation as a way of objecting to an issue, ANT highlights the collective and organisational aspects of public dispute. It reveals that disagreeing with a decision to build a road or other artifact involves counter-enrolling allies that have been aligned by organisations that have significant resources (Callon \& Law, 1982). To counter-enrol an actor, a dissenter is obliged to organise their own evidence and to demonstrate how the actor's connections with the project or artifact can be severed.

Moreover, ANT suggests that focusing on consensus and 'rational' arguments can overlook the collective and material aspects of public involvement in socio-technical controversies. Democratic theories of consensus and representation can be problematic as they imply, as Latour (1987, p. 103) has suggested, that socio-technical controversies are like boxing matches, where, everything else being equal, the 'winner' has the most persuasive arguments and is able to generate knowledge claims using a range of appropriate scientific and technical practices. However, as Latour (1987, pp. 103-104) notes, this can be misleading because, "everything not being equal, it is possible to win with many other resources than articles and 
laboratories". Here Latour (1987, p. 104) is arguing that the construction of a 'fact' or persuasive argument depends not only on the actions of one disputant, but a chain of human and non-human actors who modify, strengthen, or weaken it. To clarify, ANT's focus on alliance-building and non-human actors does not simply overlook the democratic aspects of socio-technical controversies: it reconfigures it as the process of articulating techno-scientific issues (Marres, 2007, p. 764).

ANT's focus on objects of concern can be described as a "socio-ontological", rather than deliberative, approach to democratic processes. According to Marres (2007, p. 776), socioontological approaches to controversies problematize "the distinction between objectively existing issues and discursive definitions of these issues" by examining the "material, physical and technical associations that are at stake in controversies". Examining the associations between human and non-human actors is seen as a 'democratic' procedure in the sense that it adds non-human voices and associations to debates that have been limited to human interests and rights (Latour, 2004a, p. 69).

Because alliance-building and organisational problems were key issues in the preferred option controversy, this chapter utilises ANT's sociology of translation. As I will discuss, the dispute over the preferred option highlights how aligning human and non-human 'interests' and representing objects of concern were key aspects of this debate. To challenge the NZTA's preferred option, the public could reveal the social interests that influenced the decisionmaking process and they could argue that the NZTA's process was undemocratic. Indeed, as discussed in previous chapters, a number of submitters did focus on these issues. However, as I discuss in this chapter, a number of concerned citizens and locally-based groups challenged the expressway project by engaging with the NZTA's evidence and attempting to counterenrol their allies.

\subsection{The Preferred Option as an Alliance of Actors}

As discussed in the previous chapter, the idea that a preferred road project for Kāpiti would be developed by consulting local communities was a contentious matter, but this issue tends to overlook the significant research or scoping work that was conducted before the project was officially announced in August 2009. The NZTA had already conducted significant scoping work on possible road options for Kāpiti before local residents had a chance to consider what transport options would be appropriate for their communities. An engineering consultancy firm, Opus, was commissioned by the NZTA to study and identify possible routes for an 
expressway through Kāpiti. Opus's (2009) strategy study identified four possible routes or corridors and recommended that two of these expressway options should be investigated further and discussed with the public. Opus's reports indicate that a number of assessments and significant 'technical work' had been undertaken in order to reach its conclusions and recommendations. The production of these reports suggests that the NZTA had already demonstrated the technical feasibility of a Kāpiti expressway project before they consulted the public. Significantly, Opus's (2009) report recommended an expressway should be built as part of the Roads of National Significance programme.

Opus's reports revealed that an expressway was possible from an engineering perspective, but these preliminary studies had not yet examined which actors would oppose, resist, or support the project. Their preliminary reports had not yet examined the difficulties involved in finding allies to support the project and aligning the competing demands from human and nonhuman actors with the objectives of the project. These problems surfaced when the NZTA publicly announced the project in August 2009. In terms of finding allies to support the project, several key stakeholders, and potential allies, initially opposed the project. Significantly, Jenny Rowan, the mayor for the Kāpiti Coast District Council (KCDC), publicly announced that Steven Joyce "presented us [(the local community)] with two poorly conceived, destructive options, one is a dog and the other a lemon, and told us to make a decision on one of them in six weeks" (as cited in Kāpiti Coast District Council, 2009). Commenting on the NZTA's Option 3 proposal - an expressway on the WLR route - Rowan described it as a 'highway to hell' as it "has unacceptable economic, environmental and cultural impacts" (Kāpiti Coast District Council, 2009). The other twenty stakeholders identified in the NZTA's engagement report were divided in their opinions on the project, but requested that further evidence of its impacts were needed before they supported a particular option. Based on the opinions expressed in the NZTA's first engagement report it seems that there was no majority support for any of the options presented to the key stakeholders and the public.

The NZTA also faced the other difficult issue of demonstrating that the environmental and social impacts of the project could be adequately managed or mitigated. As discussed in previous chapters, the public were concerned about protecting local businesses, valued aspects of life and the environment. Many residents thought that an expressway on the WLR route would, literally, divide Kāpiti and destroy its character. In addition to these concerns, the NZTA's (2009a) engagement report revealed that people were concerned with their property values, the affordability of the project, and disruption to their lives during construction. 
In addition to opposition from human stakeholders and residents, the NZTA also had to identify and address the concerns from nonhuman actors. The NZTA had to recruit a number of experts to conduct engineering and environmental assessments for Notice of Requirement and resource consent applications. The 35 chapter assessment of environmental effects report examined topics that ranged from air quality, hydrology, and terrestrial ecology, to the cultural and social impacts of the project. While the experts identified positive and negative effects from the project, a key issue was whether they could be managed in a way that was 'adequate' "in the context of the purpose and principles of the RMA" (New Zealand Transport Agency, 2012, p. 16). That is, the NZTA had to demonstrate how a stable alignment of human and nonhuman actors would make the expressway project possible. For example, if it was not possible to mitigate or manage the impacts on ecology in a way that is not adequate within the RMA framework, then this could jeopardise the project.

The contrast between Opus's initial scoping work that greenlighted the project from an engineering perspective, and the human and nonhuman actors who would oppose or resist the project, illuminates the social aspects of the preferred option controversy. It helps bring into focus the idea that 'preferred' engineering projects are not simply an arrangement of materials, engineering principles and practices, but also an alliance of human and nonhuman actors. The objections to the expressway project illustrates Suchman's (2000, p. 322) idea that, while the process of selecting a preferred road project appears to be a 'rational' process, a closer inspection reveals that it involves the practical work of aligning competing demands and preferences. As I will discuss, the NZTA attempted to align human and nonhuman actors with the project by forming The Alliance.

\subsubsection{Forming The Alliance: Creating an alliance of human and nonhuman actors}

Given the difficulty of aligning these human and nonhuman actors and producing evidence that will withstand a legal test, how did the NZTA attempt this ordering work? The NZTA's first move was to gather a team of human actors that were interested in building the road. After the preferred option was selected in December 2009, the NZTA (2010a) selected a consortium or association of engineering companies, contractors, and other partners that would work together to "deliver" the expressway project and to "move much quicker into the investigation and design phases". An alliance helped the NZTA refine the design of the preferred option so that Notice of Requirement and resource consent applications could be lodged. More specifically, they helped the NZTA face the daunting task of enrolling other 
human and nonhuman actors that could potentially challenge or resist various facets of the project.

Being able to efficiently deliver the project with an alliance of actors highlights the importance of the social and organisational aspects of engineering work. It reveals that the work of building a material artifact according to engineering principles is tied up with the organisational problems of finding allies to support the project and organising the construction and maintenance of it (Suchman, 2000, p. 316). Moreover, the formation of an alliance suggests that the NZTA were not simply building an artifact, but were building a system that aligns environmental, economic, legal, scientific, social, and technical factors (Law, 1987, p. 112). As "system builders" (Law, 1987), the NZTA were faced with the challenge of addressing and resolving a vast number of problems associated with building a road. They had to simultaneously build a road that, not only improves transportation efficiency, but is also economically justifiable and meets various environmental, legal, and social requirements. For example, at an impact assessment conference that I attended in 2014, a legal team who were working on an expressway project north of Auckland described how having lawyers involved early in the project made the NZTA's application more robust because they were able to check everything against relevant legal tests (Brosnahan, 2014).

If an alliance-building approach highlights the importance of enrolling allies, then it suggested to opponents of the project that challenging it would involve contesting the relationships established by the NZTA and the identities attributed to them. The locally-based groups, Save Kāpiti and Alliance for a Sustainable Kāpiti (ASK), formed in early 2010 as a response to the Kāpiti Coast District Council (KCDC) joining the Mackays to Peka Peka (M2PP) Alliance. Indeed, in their legal appeal to the High Court, Save Kāpiti (2012) stated that they tried to fill a void that was created when KCDC became a member of the M2PP Alliance. Similarly, ASK formed in response to KCDC joining the M2PP Alliance and in case they decided to pursue legal action (Fisher, 2012). Locally-based alliances served the purpose of enrolling residents and human actors, but an important goal was to forge alliances with the nonhuman actors that the NZTA were trying to enrol as part of the environmental impact assessment.

\subsection{The Alliance's Enrolment Strategy}

To examine how the NZTA and locally-based groups attempted to enrol and counter-enrol human and nonhuman allies I discuss the work undertaken by the MacKays to Peka Peka (M2PP) Alliance to develop the WLR expressway as the preferred option. Similar to Callon's 
idea of problematisation, the first step taken by the Alliance (2010a) was to identify key actors and their interests in relation to a set of problems posed by the NZTA. The Alliance (2010a, p. 6) were asked to deliver an expressway project that aligns with the NZTA's wider RoNS design standards, is "responsive in terms of function and design to aspirations of the Kāpiti communities spanned by the expressway", and provides "long term solutions to transport and land use growth pressures in Kāpiti and the wider region". In relation to these objectives, the National Government wants to improve economic development by building 'essential' road projects, while the NZTA wants to improve transport efficiency and safety in a way that aligns with the legal framework that manages and funds land transport (MacKays to Peka Peka Alliance, 2010a, p. 59). Moreover, commercial and non-commercial road users will benefit from improved travel times and safer journeys, the health of residents will be protected through noise and environmental assessments, and environmental sustainability will be ensured through various specialist assessments (MacKays to Peka Peka Alliance, 2010a, pp. 60-61).

However, how can the Alliance align the interests and demands of these human and nonhuman actors with the objectives outlined above? To paraphrase Callon (1986, p. 205), how can the Alliance show that the interests of the human and nonhuman actors can be advanced by agreeing to the preferred expressway project? The Alliance illustrated how the interests of each actor could be ensured if they could, firstly, fulfil the project's objectives/statutory requirements while, second, demonstrating that the impacts of the project can be adequately managed. This problematisation constructed an obligatory passage point that hypothetically demonstrated how the NZTA's interest in improving transport could be aligned with the interests of the National Government, road users, residents, and the environment. Fulfilling the objectives and statutory requirements links the interests of the National Government, NZTA, and road users in a way that boosts economic development while improving transportation efficiency and safety. In contrast, the issue of managing impacts helps align the NZTA, residents, and the environment by demonstrating that they will not be adversely affected by the expressway project.

Based on this problematisation and inter-definition of actors, the Alliance were able to align the various interests and demands of these actors with the Western Link Road (WLR) expressway option. The Alliance stated that the WLR option was selected from a list of four route options because it was able to 'balance' the competing interests identified in their reports. Put simply, the WLR was selected as the preferred option "because it best balances 
the needs of the Kāpiti community with those of the Wellington region and the country as a whole" (MacKays to Peka Peka Alliance, 2010a, p. 8). The Alliance (2010a) described how the other three options were rejected because of higher costs associated with land purchases, transport engineering difficulties, and lower transport benefits. In contrast, the WLR option would not require as many properties to be acquired, minimise the effects on local residents, avoid impacts on the town centres, have a lower total cost, and allow "safer and more efficient traffic movements" by transforming the existing highway into a local arterial road (MacKays to Peka Peka Alliance, 2010a, p. 8). These reasons for choosing the WLR option illustrate how this particular expressway route could successfully respond to the interests and demands of the actors involved in the project. The lower cost and transport benefits align the National Government, the NZTA, and road users, while its lower impact aligns the NZTA and residents. Interestingly, environmental issues are not mentioned in this selection process summary, but the Alliance do note elsewhere in their reports that all expressway options would have significant environmental impacts.

The Alliance's problematisation reveals the alignment work that underpinned the decision to select the preferred option. The Alliance's reports reveal that the preferred option was not simply a decision based on cost, engineering, or legal factors, but was an effect of the ordering work that would be required to build an expressway. Out of the four projects identified, the Alliance predicted that the WLR option would align the actors and provide an answer to the problematisation outlined above. In a sense, the WLR expressway option would stabilise these relationships identified by the Alliance and, literally, concretise their problematisation.

\subsubsection{Environmental assessment and interessement}

The Alliance's problematisation reveals the ordering work that would be required to align and interest the actors identified in their reports. As the identified actors could accept, submit, or refuse the Alliance's preferred option, they developed a series of interessement devices that would help interest them in the project. In theory, the interessement devices would align the actors by severing the associations that were re-defining the interests of the actors in competitive ways (Callon, 1986). The Alliance's reports on the preferred option provide an outline of how their interessement devices would align the actors with the project. To interest the actors identified in the Alliance's reports, the NZTA relied on a multi-criteria assessment (MCA) of the four expressway options. The MCA process can be understood as series of 
interessement devices that were used by the Alliance. These interessement devices were: an 'Alliance procurement model'; stakeholder consultation; social and environmental assessments; and a 'value improvement process'. Here I focus on the environmental assessments that were used to enrol the wetlands in the project. I examine the work that was required to inter-esse, or place the Alliance in between their identified actors.

To interest residents and the environment - broadly defined as the natural and built environment - the Alliance conducted comprehensive social and environmental assessments. Their 35 chapter (761 pages) Assessment of Environmental Effects (AEE) report devoted 22 chapters (or 370 pages) to the assessment and management of the environmental impacts of the expressway project. Additionally, 36 technical reports (and supporting documents) were prepared to support the engineering and environmental assessment process and application for a Notice of Requirement and resource consent (Beca Carter Hollings and Ferner, Boffa Miskell, \& Incite, 2012, p. 21). The technical reports described the investigatory work undertaken by the Alliance's experts. In contrast, the AEE report presented the findings from their investigations while also describing other components of the project - such as the assessment of alternative options and the consultation process (Beca Carter Hollings and Ferner et al., 2012, p. 22). The reports identified the actors affected by the project and outlined possible strategies or interessement devices to manage or mitigate the impacts of the project.

In terms of the environmental assessments, a range of experts were employed to examine the environmental issues of ecology, hydrology and stormwater, landscape and visual effects, and climate change, to name just a few. These issues were important for meeting the statutory requirements and to help ensure that the expressway was integrated into Kāpiti's urban environment (MacKays to Peka Peka Alliance, 2010b, p. 7). Moreover, the environmental assessments were crucial for determining whether the non-human actors could be aligned with the expressway project. If the non-human actors could be enrolled without significant changes to the design of the expressway or if interessement devices could be used to protect them, then this would help support the feasibility of the project. In contrast, if the non-human actors refused to be enrolled, then the Alliance would assess whether this would stop the expressway project from proceeding or whether a suitable management plan could be formulated.

Overall, no serious threats to the feasibility of the project were identified. Instead, the AEE report identified a number of environmental constraints that could "influence decisions for the 
project both for construction and long term maintenance and operation" (MacKays to Peka Peka Alliance, 2012, p. 9). The Alliance identified approximately 45 environmental issues or factors that could influence the project and decision-making process. The issues identified were diverse, but some of the more challenging issues were related to the protection of wetlands, ecological areas, Kāpiti's dune landscape, and a regional park. Other key issues identified were related to the challenges of building a road on a floodplain and in an area with active fault lines and risk of liquefaction (MacKays to Peka Peka Alliance, 2012, pp. 13-15).

\subsubsection{Enrolling affected wetlands}

Although no project-threatening issues were identified, the work undertaken to enrol the nonhuman actors associated with these key environmental issues was substantial. I focus here on the impacts of the project on the wetlands (see Figure 26). A number of residents were concerned that the expressway project would destroy parts of the wetlands or affect wetland hydrology (Willams, 2012, p. 27). As the Wellington region has seen the loss of over 97.5 percent of its wetlands, they are valued by residents and "are generally considered to be ecologically sensitive" (Beca Carter Hollings and Ferner et al., 2012, p. 106). Moreover, the ecologists were concerned that changes in groundwater levels can lead to wetland loss and other detrimental impacts (Bennion, 2012, p. 4). The ecologists noted in their reports that "changes in hydrology [are] the leading causes of wetland degradation or destruction" (Park, 2012d, p. 33). 


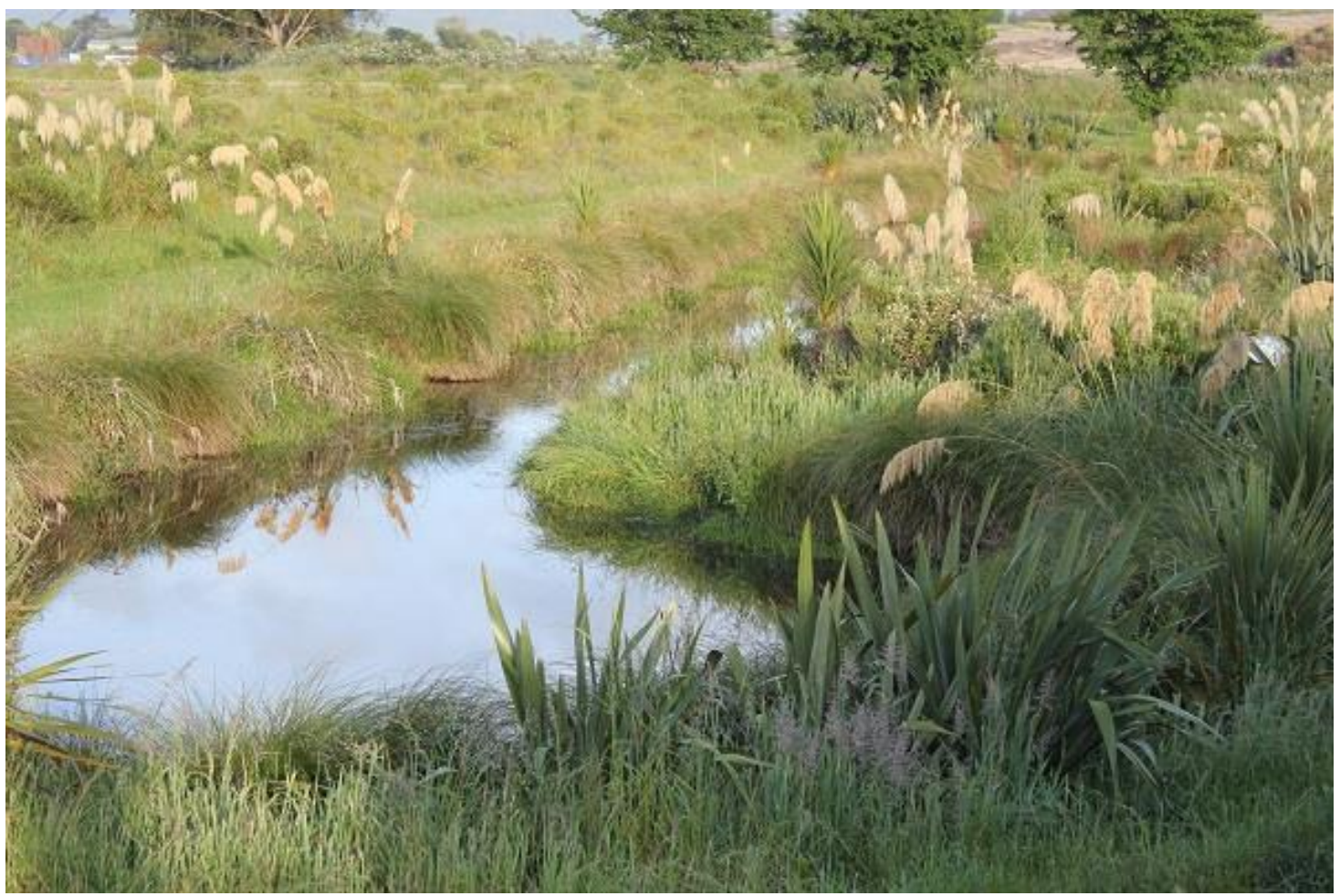

Figure 26. Wharemauku wetlands.

To enrol or protect the wetlands from the expressway, the Alliance's experts had to first describe or define the identities of these areas in relation to their ecological value. The researchers found that, while the expressway would be located on land with "limited or no ecologically significant vegetation", there would be "unavoidable ecological effects" and 5.6 hectares of native vegetation (including 1.8 hectares of wetland habitat) would be "permanently lost beneath the Project Footprint" (Park, 2012c, p. 169). This conclusion was based on an extensive study that involved a "desktop ecological assessment" (or review of documents on terrestrial flora), and botanical fieldwork that was undertaken over an eight month period during 2010 and 2011 (Park, 2012d, p. 13).

The desktop assessment reveals that significant preparatory work was conducted on the seemingly uncomplicated issue of describing the terrestrial vegetation on the proposed expressway route. The desktop assessment not only reviewed published documents on Kāpiti's terrestrial flora, but also unpublished information on the local and regional council's databases and national data sets produced by two Crown research institutes, the Department of Conservation, and the Ministry for the Environment (Park, 2012d, p. 13). The ecologists also had access to aerial photos of the proposed expressway route, GIS information, and earlier ecological assessments carried out in the Kāpiti region. The completed desktop study was 33 pages long. Its comprehensive description of the climate, wetlands, vegetation, 
geology, and other ecological issues allowed the ecologists to ascertain what wetlands, habitats, and vegetation were at risk from the expressway project and, importantly, to protect their assessment from scrutiny during the Board of Inquiry process.

In contrast to the description of the terrestrial vegetation, the assessment of ecological value illustrates the work that went into enrolling any at risk ecological areas. The botanical fieldwork allowed the researchers to identify the ecological value of the areas on or nearby the designated land for the project. The fieldwork involved researchers walking and driving along the proposed 16 kilometre expressway corridor in order to map vegetation patterns and conduct botanical surveys. The results of the fieldwork, combined with previous studies, were then used to determine the ecological impacts of the expressway and what enrolment devices or measures could be used to mitigate any adverse effects. The findings from the ecological assessment reveal that enrolling the environment was a research-intensive process that involved determining the value of the ecological areas and establishing what devices could be used to help mitigate the effects of the project.

\subsubsection{The devices used to enrol affected wetlands}

To interest the wetlands in the project, a range of strategies and devices were proposed by the ecologists and groundwater experts. I focus here on two devices that would be used to mitigate the effects on the wetlands and to manage groundwater related issues: 'restoration work' and an 'adaptive management' system. As there were 1.8 hectares of wetland that could not be protected from the project, the ecologists attempted to enrol the threatened wetland areas by recommending wetland restoration work (Park, 2012c, p. 136). The restoration work would not save the affected wetlands from the project, but it would help interest it in the project. The ecologists attempted to interest the affected wetlands by proposing a ' 3 to 1 ', mitigation ratio: for every hectare of habitat loss, the NZTA would recreate three hectares of wetland (Park, 2012c, p. 136). For example, to interest the affected Raumati Manuka Wetland, the ecologists "recommended approximately 1.4 ha of mass planting of wetland species within the proposed flood storage areas as well an additional 1.1 ha of wetland buffer planting between the proposed expressway, cycleway/walkway and the wetland" (Park, 2012c, p. 136).

As groundwater levels are important to the health of wetlands, the ecologists and groundwater experts also had to manage groundwater levels in order to interest the wetlands in the project. The experts outlined an adaptive management approach to manage the expressway's 
hydrological impact on the wetlands. This approach was recommended because any adverse effects on wetland hydrology cannot be "precisely defined" in advance (Park, 2012c, p. 145). Because of this uncertainty, an adaptive approach would allow the specialists to, firstly, monitor groundwater levels near the wetlands and, second, take remedial action if necessary.

To monitor the groundwater levels, the groundwater specialists recommended monitoring any changes in groundwater levels using piezometers, which would be installed in groundwater monitoring bores located between the expressway and the wetlands (Williams, 2013, p. 15). In total, 110 piezometers would be used to monitor water levels - 22 of which would be used specifically to monitor the wetlands (Williams, 2013, p. 15). A relatively large number of piezometers were required because small changes in water levels could have significant, deleterious effects on the wetlands (Williams, 2013, p. 16). If negative changes were detected, the ecologists and groundwater experts would review the health of the wetlands and take remedial action if appropriate (Park, 2012c, p. 146). Therefore, the piezometers would interest the wetlands in the expressway by helping the project team understand "the normal wetland water levels" and monitor the groundwater effects of the expressway (Williams, 2013, p. 16).

However, piezometers would not be able to interest the wetlands without some form of remedial action. As the monitoring devices would not protect the wetlands from the expressway, the ecologists had to outline which devices could be used to alter the groundwater levels and restore wetland function. A range of adaptive management devices were outlined in the ecological assessment, but the ecologists suggested that adjustable weirs or dams could be an important device. Weirs would be used to increase groundwater levels and manage water levels in the drains. For example, the ecologists suggested that an adjustable weir downstream from the Raumati Manuka Wetland would "increase groundwater levels with the wider peat complex" (Park, 2012c, p. 146). In this sense the weir would interest the wetlands in the expressway project by protecting its functionality and groundwater levels.

As interessement devices, the restoration work and groundwater devices would help insert the expressway between the wetlands and the actors that were defining them as areas that need protecting. The identity of the wetlands was defined by concerned residents that wanted to protect them, from laws that require formal protection of wetland areas (Park, 2012c, p. 68), from the groundwater levels that sustain them (Park, 2012a, p. 28), and from the vegetation and habitat that contribute to their biodiversity. The proposed interessement devices would 
respond to the challenges from residents and the law by ensuring that an expressway could be built through wetland areas without destroying them. The restoration work responded to the issue of biodiversity by ensuring that the expressway project would result in larger areas of wetland vegetation and no net loss of biodiversity. Finally, the groundwater devices would ensure that the project had "small or negligible" effects on groundwater level changes (Willams, 2012, p. 28) and that any adverse effects could be monitored and remedied (Park, 2012a, p. 28). In a sense the NZTA's interessement devices redefined the wetlands from areas that were threatened by the project to areas that could, in the long term, 'benefit' from it. In theory, the biodiversity of the wetlands would not be 'lost' and the groundwater levels would be regulated.

\subsection{Counter-enrolling the NZTA's allies}

While the Alliance argued that flooding issues and the impacts on the wetlands could be successfully managed or mitigated, a number of residents attempted to counter-enrol the wetlands by challenging the NZTA's findings and interessement devices. Because the NZTA had produced an in-depth environmental assessment and management plan, opponents were obliged to understand their findings, find faults, and offer alternative solutions. To do this, a number of locally-based groups familiarised themselves with the NZTA's reports, formulated a strategy, employed environmental experts, and challenged the NZTA's experts at the Board of Inquiry. As I will discuss, challenging the NZTA's experts and counter-enrolling actors was daunting in the sense that the submitters were working within a tight timeframe and with limited access to information and resources. Moreover, counter-enrolling actors that had been aligned with the project was daunting in the sense that they tried to re-translate or re-align the interests of the wetlands as areas that would be threatened by the expressway. In this case, the ecological expert for the Raumati South Residents Association (RSRA) conducted research that re-evaluated the ecological significance of the wetlands, the ecological effects of the project, and the mitigation/interessement devices.

\subsubsection{The challenges of counter-enrolling the NZTA's allies}

The Alliance spent 2009-2011 preparing their environmental assessments and legal documents for the Board of Inquiry in 2012. Because the NZTA were applying for a Notice of Requirement for the land and 29 Resource Consents that would allow them to build the 
expressway, their main goal was to prepare a robust application that would withstand scrutiny from the Board of Inquiry and submitters.

In contrast, local residents and other submitters were given only six weeks to prepare a submission and a further seven weeks if they were presenting expert evidence. This meant that the submitters had only several months to prepare evidence that would somehow challenge The Alliance's application. Of course, submitters, such as Save Kāpiti and other local groups, had been preparing their general responses to the project and all submitters could make a submission without reviewing the NZTA's application or hiring an expert or lawyer. To clarify, the Board of Inquiry called submissions that commented on personal opinions and how the project might affect the submitter, "representation". Submissions that relied on expert witnesses and appeals to factual statements were called "expert evidence" by the Board of Inquiry.

However, for residents and submitters who wanted to engage with the NZTA's application, they were only given six weeks to review the full (approximately 7000 pages) application and supporting information, which included the 35 chapter AEE document and 36 technical reports. To assist submitters, the Environmental Protection Authority held two public meetings to outline the Board of Inquiry process and offered free drop-in sessions with a lawyer that offered advice on the submission and hearing process (Environmental Protection Authority, 2012).

Not surprisingly, preparing a submission within a six week timeframe that engaged with the NZTA's full application was a daunting challenge for residents and locally-based groups. The submitters I interviewed commented that the six week timeframe was too short. A member of Save Kāpiti commented that, because of the short time frame, their submission was "not the full-blooded analysis of its views, so it was simply setting out basically what it thought about the expressway, what its position was and why, and which experts it was going to call" (Research Participant, personal communication, June 26, 2013). Similarly, another submitter described how her submission "was only like 36 pages and it was just headlines of 'I disagree with it on a general level, and a personal level'" (Research Participant, personal communication, August 22, 2013). Other submitters commented that they were working on their submission until the deadline in order to present a strong submission. For example, one interviewee commented that she did a "36 hour stint right through the night . . . to get mine in on time in the end" (Research Participant, personal communication, August 22, 2013). 
Because of the six week timeframe, many of the submitters I interviewed mentioned that the process was unfair and designed to 'put people off'. One submitter went as far to say that it was "a corrupt process setup for the people to shut up, go away, and not fight it" (Research Participant, personal communication, August 22, 2013). Other submitters suggested that the time frame was unfair because of the work that was required to make a persuasive submission. One submitter I talked to described it this way:

There was a constant feeling of 'how do we get anywhere', it was like two steps, no, no hell no. It was like an inch forward and two steps back, you know. You're constantly trying to come up with 'how do we combat this, how do we do this'. And of course people can be very effective, but maybe you need to be better organised." (Research Participant, personal communication, July 9, 2013)

The tight time frame meant that many submitters put in long hours so that they could submit their evidence before the deadline. After talking to my participants, my general impression was that the submission process for some participants took over their lives for several months. One participant, described her experience this way:

It took over my life. It was day and night. Some days I didn't even get dressed, I'd get up in the morning and I'd still be in my pyjamas at 7 o'clock at night so I was still going. I could hardly move, my shoulders and my back and my head. I hadn't eaten, you know and there was no point getting dressed I might as well go back to bed. You know, I'd have a couple of hours sleep and do it again. It was unbelievable the commitment to do that. (Research Participant, personal communication, August 22, 2013)

Another issue that added to the long hours was the recruitment of experts. Some participants did not encounter any problems when finding experts to help them, but for others it was a time consuming process. Submitters had to not only find suitable experts, but had to also find experts that were available and willing to help. For example, one submitter provided a descriptive account of the time she spent trying to find a hydrologist:

So we had all these names and phone numbers and bits of pieces that we had put together and we just went through ringing people up and quite often we'd hit people who were, that someone else had already got so they'd say 'oh sorry I can't because 
I'm working for the NZTA ...' And then sometimes . . . they'd try put us off. . . . They'd say, 'I don't think it's that bad' or 'no, no, we've got that covered' or 'you can be rest assured that, that would be alright', something like that. . . It was almost the last hour, the hydrologist that we almost got was going to catch the plane and yeah we lucked out on him, but he would have been good because he understood exactly what the issue was. (Research Participant, personal communication, October 16, 2014)

One reason why my participants spent so much time on their submissions and expert evidence was because they wanted to make sure that they could support their statements. For instance, a participant told me how her statement of evidence "was about 100 pages, qualifying every single point I'd made and giving information and proof to back up my statements and proved every single thing" (Research Participant, personal communication, August 22, 2013). Another participant suggested that the time and effort required to produce expert evidence was one reason why she submitted non-expert or personal evidence. Moreover, she was told, incorrectly, that the Board would give equal weighting to expert and personal evidence. She told me that:

The reason for going personal when I knew the weighting was the same was because it was a much easier process than trying to write a full length statement with all your references etc. etc. and when you're doing it off your own back and your own time it's hard (Research Participant, personal communication, November 9, 2014).

Once residents found a suitable expert they were faced with the issue of finding money and resources to prepare a robust statement of evidence. Some experts provided their services for free because they did not support the project, but, overall, the submitters used their own money or community funding. For example, Save Kāpiti spent over 80,000 dollars on their submission (Research Participant, personal communication, June 25, 2013). They received donations from the community and pro bono work from experts helped to keep their costs down. Other locally based groups reduced their costs by helping their lawyers and experts find gaps in the NZTA's evidence and by assisting them with the research process (Research Participant, personal communication, October 16, 2014). 
Beyond the issues of time and resources, another significant problem for the submitters I interviewed was accessing information from the NZTA that had not been made public. To develop an expert statement of evidence, a number of submitters had to make Official Information Act (OIA) requests so that they could understand how the NZTA supported their arguments. The reason why the NZTA withheld information seems to be related to legal requirements and to the pragmatic issue of keeping their application manageable. At an impact assessment conference I attended in 2014, a lawyer who worked on a RoNS project in Auckland, suggested that the reason why every piece of information was not included in the NZTA's application was because the law states that an assessment of the data, not the actual data itself, is what should be included in the application. That is, the data is there "if anyone questions it or doesn't agree with the expert's opinion" (Brosnahan, 2014). This meant that the NZTA did not need to "submit 1000s of pages of documents" (Brosnahan, 2014).

While some submitters understood that the NZTA could not include every piece of information in their application, making OIA requests was a frustrating experience for the people I interviewed because of the tight timeframe. For example, one expert for Save Kāpiti said that the NZTA provided:

... a fairly comprehensive amount of information, I mean, there is no limit to what you could ask for and they don't seem reluctant to give it. It's just that you have to wait up to 20 days and often it takes at least that to get it and they can extend it if . . . they are having difficulties getting all the stuff you want. (Research Participant, personal communication, June 26, 2013)

\subsubsection{Counter-enrolling the wetlands}

While the tight timeframe was frustrating for many submitters, many of them were able to gather evidence that could challenge the NZTA. One locally-based group that attempted to counter-enrol the wetlands was the Raumati South Residents Association (RSRA). They did not seek to oppose the project in general because some of their members supported it. Instead, their submission was based on their values and aspects of the project that threatened these values (Research Participant, personal communication, October 16, 2014). They argued that any road project in Kāpiti should "respect the existing Raumati South coastal land forms, the natural environment ... and allow residents the relaxed lifestyle and recreation that the natural landscape offers" (Bennion, 2012, p. 2). Specifically, because one of the RSRA's goals was to "identify, protect and enhance the unique character and heritage of Raumati 
South" they were concerned with the expressway's impact on the wetlands in their community (Bennion, 2012, p. 2). To develop and support their Board of Inquiry submission they decided to hire an ecologist who was able to help them submit expert evidence on the ecological impacts on the wetland.

To counter-enrol the wetlands as areas that would be threatened by the project, RSRA's ecology expert, Melanie Dixon (2012), prepared a report that critiqued the NZTA's assessment of ecological value and their proposed mitigation measures. In preparing her report, she reviewed six technical reports and management plans produced by the NZTA and their statement of evidence for ecology and ecological mitigation. That is, she read and reviewed over 1,000 pages of evidence produced by the NZTA. She also visited the wetlands to take notes and to talk to members of RSRA about the ecology of the area. While Dixon's fieldwork was limited to a one day site visit, her review of the NZTA's evidence revealed a number of weaknesses with their ecological assessment.

First, Dixon's re-evaluation of the wetlands' ecological value brought into question the ecological impacts of the expressway and the appropriateness of the mitigation measures. The NZTA claimed that the Raumati South wetlands were of "moderate ecological significance", but her assessment claimed that they were of "high ecological significance" (Dixon, 2012, p. 9). This finding was an important first step in counter-enrolling the wetlands because the NZTA argued that all areas of high ecological value were outside of the expressway designation (Park, 2012d, p. 70). Moreover, their mitigation calculations were seen as appropriate for wetlands of moderate, not high, ecological value (Park, 2012c, p. 136). If Dixon was correct, the mitigation measures would no longer be adequate and the wetlands would no longer be protected from the project. Indeed, during expert conferencing, the KCDC's ecologist, Shona Myers (2013), agreed that the ecological values and significance of the wetlands had been undervalued by the NZTA.

However, Dixon and Myers did not go one step further and claim that the NZTA's proposed mitigation would not adequately protect the wetlands. That is, Dixon's analysis did not assess whether the NZTA's proposed mitigation should be altered in light of the uncertainties surrounding ecological value. Interestingly, other ecologists did connect these two issues. A team of ecologists from the Greater Wellington Regional Council (GWRC) were not convinced that the NZTA's proposed mitigation would protect the wetlands. They claimed that several significant wetlands had been excluded from their assessment. 
Tim Porteous, from the GWRC, tried to counter-enrol the wetlands by identifying problems with the NZTA's assessment. He argued that the NZTA's assessment of value excluded a number of wetlands from the assessment of effects. According to Porteous (2012), the proposed mitigation measures were based on the finding that 1.8 hectares of moderate value wetland were directly under the project footprint and a further 14.22 hectares were within 200 metres of the project's footprint (Porteous, 2012, p. 7). However, Porteous's research team identified " 2.71 hectares of significant wetlands directly under the project footprint and 27.71 hectares within 200 metres of the project footprint" (Porteous, 2012, p. 8). He argued that the NZTA should have used "the figure of 30.42 hectares of regionally significant wetlands as the basis for designing the mitigation and offsetting” (Porteous, 2012, pp. 8-9).

Porteous (2012) offered a robust evaluation of the NZTA's ecological mitigation, but his reliance on a previous "desktop" study was not enough to challenge the NZTA's up-to-date assessment that used both desktop assessments and botanical fieldwork. Park (2012b, p. 8) argued that, in contrast to the 2011 study used by Porteous, his assessment was more detailed and 'accurate' in the sense that it used site visits/fieldwork, rather than aerial photography, to map the wetlands and confirm ecological value. In his rebuttal evidence, Park (2012b) pointed out that three of the ecological sites identified in the 2011 study as significant or indigenous were actually non-indigenous. Moreover, Park's fieldwork identified three significant/indigenous wetlands that were not identified in the 2011 desktop study.

While the issue of ecological values could have been a significant setback to the NZTA, the ecologists were unable to counter-enrol the wetlands with this line of argument. At the expert conferencing session, Porteous agreed with the ecological values that were recorded in Park's assessment (Board of Inquiry, 2012a, p. 4). Porteous accepted that Park's assessment was "based on a more rigorous approach" (Board of Inquiry, 2012d, p. 977). Moreover, the NZTA's assessment of ecological value was acceptable to the Board. They simply noted that the NZTA's ecologist and KCDC's ecologist agreed that the quantum or amount of mitigation was acceptable or "not outstanding" and that the other ecologists did not disagree with this (Board of Inquiry, 2013, p. 163). Furthermore, in his rebuttal evidence, Park argued that his assessment of ecological importance would not alter the mitigation requirements or the route selection process. Park argued that his assessment of value assumed that all indigenous habitats were significant and that its purpose was to guide the early stages of the design process so that the project would avoid "the areas of highest ecological value wherever possible" (Park, 2012b, p. 6). 
In relation to Dixon's and RSRA's concern with the Raumati Manuka Wetland, Park claimed that its status as a wetland of medium ecological significance did not influence the mitigation requirements because "the entire Project designation lies within 'Acutely Threatened Land Environments' ... where less than 10 percent of indigenous vegetation cover remains" (Park, 2012b, p. 31). Moreover, Park (2012b, p. 31) claimed that the proposed alignment for the expressway "has the least impact of the options considered - and importantly, the flood storage and mitigation proposed will enhance this area in the long-term".

As the disputants were unable to counter-enrol the wetlands with the argument of ecological significance, they shifted their focus to the proposed mitigation measures or interessement devices. Dixon (and other ecologists and residents) seemed to anticipate that the issue of ecological significance would not counter-enrol the wetlands because the main focus of their submissions was on the effects of the project and the mitigation measures. Like other submitters, Dixon (2012) focused on the removal of wetland vegetation, the spread of invasive weeds/plants, biodiversity planting, the monitoring of water levels, and wetland hydrology. To connect her evidence with the discussion on hydrology and groundwater above, I examine her argument on wetland hydrology.

Dixon's (2012, p. 12) central argument was that raised water levels from nearby flood storage areas could negatively affect the manuka trees; that is, it could "lead to the die back of the manuka canopy". To clarify, she argued that the stormwater management system should be designed based on an understanding of the wetland's hydrology rather than an adaptive approach that 'fixes problems' as they arise. In other words, Dixon was suggesting that without an understanding of the wetland's hydrological regime it was problematic to claim that wetlands could be enrolled with the flood storage areas and other stormwater management devices, such as weirs. Dixon (2012) recommended an investigation that would describe, among other things, how often the wetland floods and dries, the length of time between wet and dry periods, and seasonal variation of water levels. Because this investigation would be conducted over the course of at least one year (in order to assess seasonal variations in water levels), the project could have been delayed or redesigned to reflect the findings from the investigation.

In response, the NZTA agreed that further monitoring was needed to understand the wetland's hydrology, but they disagreed with her recommendation to investigate the Raumati Manuka Wetland's hydrological regime. The NZTA's hydrologist, Graham Levy (2012, p. 19), 
claimed that they did have information to assess the impact of the flood storage area on the Raumati Manuka Wetland. He stated that this wetland "is currently prone to flooding in large flood events" and that the "flood risk for the Wetland will not change as a result of the Project". In relation to the uncertainty surrounding the wetland's hydrology, Park (2012b, p. 32) stated that the proposed adaptive management programme was being used so that the NZTA could understand and monitor the Raumati Manuka Wetland. This would allow the NZTA to continue with the project and to 'fix' any problems that might arise. The arguments by Levy and Park suggest that the proposed stormwater management system was designed appropriately and that an adaptive management approach would help address any uncertainties (Park, 2012b, p. 32). In other words, the NZTA's experts argued that this wetland could be enrolled without current knowledge of its hydrological regime: the flood storage areas would not increase the flood risk and the adaptive management approach would monitor the health of the wetland.

Dixon and the RSRA were successful in the sense that some of their concerns were incorporated into the NZTA's management plans. When I interviewed a member of the RSRA she explained that they "won everything they asked for", which means that they hold several resource consents and Board of Inquiry requirements against the expressway (Research Participant, personal communication, October 16, 2014). In particular, she said that one of the most important victories for RSRA was related to wetland hydrology and groundwater levels. She explained that the NZTA cannot change the hydrology and water levels in the Raumati South wetlands. This meant that the NZTA would be required to restore the wetlands if they did not meet the base-line water level.

However, overall, the evidence from non-NZTA ecologists did not counter-enrol the wetlands. During the Board of Inquiry, Dixon's concerns with wetland hydrology and adaptive management were not mentioned in the Board of Inquiry's final report. This was because, during cross-examination, she agreed that adaptive management was an appropriate way to respond to the ecological effects (Board of Inquiry, 2012e, p. 994). During the expert conferencing, she agreed - subject to her comments/concerns - to the use of an adaptive management approach. Moreover, her concern with the monitoring of the wetland's hydrological regime was included as a condition in the Groundwater (Level) Management Plan (Board of Inquiry, 2012b, p. 8). The NZTA were required to provide "a summary of understanding of the hydrological regime in each high-value wetland" (Board of Inquiry, 2012b, p. 9). Because the NZTA were able to include Dixon's concern with hydrology into 
the management plan, they were able to keep the wetlands enrolled in the project. Dixon did not think the NZTA went far enough with their changes to the management plan, but the changes made to the project were enough to convince the Board of Inquiry.

\subsection{Conclusion}

The debates over the environmental effects of the expressway have revealed the importance of alliances in socio-technical controversies. I have argued that the NZTA's preferred expressway alignment was not only informed by public opinion or social interests, but was an outcome of their alliance-building approach to the project and the production of a large number of technical reports. Using this approach, The Alliance were able to identify and interest human and nonhuman actors in the project. In particular, they were able to enrol a significant nonhuman actor that would have been adversely affected by the expressway: Kāpiti's wetlands. By developing a small list of possible route options for the expressway, The Alliance were able to examine which option would align the objectives of the project with the stakeholders and nonhuman actors affected by the project. They selected the WLR option as it provided an answer to the problem of how an expressway could be built that advances the interests of the National Government and NZTA while also mitigating and managing its adverse impacts on affected stakeholders and the environment.

The NZTA's alliance-building approach to the expressway project suggests that an open, democratic debate would not be enough to stop the expressway project. Although The Alliance spent over two years developing a 761 page environmental assessment that outlined how the affected actors would be aligned with the project, opponents of the project were given only several months to prepare their evidence for the Board of Inquiry. To challenge the NZTA's ecology evidence, the public were obliged to not only develop convincing scientific and legal arguments, but also to unpick the NZTA's proposed alliance with the wetlands and other non-human actors. Challenging the NZTA's findings was a daunting task for locallybased submitters because of their limited resources. The submitters were working within a very short timeframe and they had limited access to information and expert knowledge. For the submitters that were able to employ experts, such as the RSRA, they had to determine why the wetlands would be threatened by the expressway project. A number of ecology experts, including RSRA's expert, re-evaluated the value or significance of the wetland areas, the possible impacts from the project, and the proposed devices that would interest the wetlands in the project. While the RSRA successfully challenged a number of aspects of the 
project, the ecologists were unable to counter-enrol the wetlands. The NZTA were able to respond to the concerns of the submitters and, therefore, keep the wetlands interested in the project. The NZTA outlined how they would address the concerns from the submitters and this convinced the Board that the wetlands would be protected from the expressway project.

The importance of enrolling allies to support an argument points to the limitations of humancentric theories of democratic deliberation. In contrast, the socio-ontological approach offered here suggests that theories of public dispute can be expanded to include, not only the subjects of democracy, but also the articulation of issues and material things as matters of concern (Marres \& Lezaun, 2011, p. 495). Socio-ontological approaches to dispute have revealed the importance of expanding the notion of democracy to include non-human voices. As I have discussed, human and non-human actors played central roles in the preferred option controversy. However, in practice, "extending democracy to things" did not make it easier for the public to challenge the NZTA's expressway project (Latour, 1993b, p. 12). This expanded notion of democracy reveals that there are many ways for the public to challenge an issue, but it involves the difficult and resource-intensive task of forming alliances with non-human actors and organising expert evidence. 


\section{Chapter Nine: The Final Decision}

\subsection{Introduction}

The previous chapter highlighted the work that went into aligning actors with the Kāpiti expressway project. During and after the Board of Inquiry it became clear to many people that challenging the NZTA's evidence would not be enough to halt the expressway project. Because the NZTA's application to build the project had been developed over several years and had aligned hundreds of actors, it was unlikely that locally based groups would be able to successfully counter-enrol the human and nonhuman allies that had been aligned by the NZTA.

The Board's decision to approve the project confirmed for many people that the inquiry 'rubber stamped' or uncritically approved the project. During the inquiry it emerged that opportunities for challenging the NZTA's decision to build an expressway rather than a smaller, local road were limited because the Board did "not have the powers to direct a specific road type" (Board of Inquiry, 2013, p. 62). The Board's final report revealed that they did not have the jurisdiction or "power to order NZTA to carry out further investigations into alternative sites or even require a different route" (Board of Inquiry, 2013, p. 259). In hindsight, some commentators believed that the limited opportunities available to challenge the project combined with the questionable public consultation, vested interests, and political weight behind the project meant that it was just waiting to be rubber stamped by the Board.

Disappointed by the Board's decision to approve the project, two locally based groups made an appeal to the High Court in the hope that they would provide a neutral assessment of the expressway project. Because submitters could only appeal on points of law, the hearing did not focus on the NZTA's evidence, but the legal deficiencies in the Board's process or decision. In this sense, the local groups could have their submission and the Board's decision tested based on legal merit alone. They hoped that the High Court's neutral stance would mean that their decision would not be influenced by the political weight behind the project. Ultimately, the legal appeals were lost and construction began on the expressway. The judges disagreed with the argument that the Board's decision contained legal errors.

In this chapter, I utilise Boltanski, Chiapello, and Thévenot's concepts of "criticism" and "trial" to examine the High Court appeal and the public critiques of the planning process. I 
argue that the public responses to the Board's decision were an important corrective criticism that challenged the legitimacy of the planning process.

This chapter is divided into four sections. First, I review the literature on rubber stamping and judicial decision-making and compare it to sociological theories of criticism. Second, I discuss how opponents of the project viewed the Board of Inquiry as a legal test that would reveal the weaknesses in the NZTA's evidence. Third, I examine the public criticisms of the Board's decision to approve the project. I suggest that the critique of the inquiry as a rubber stamp was not simply a knee-jerk reaction, but a type of corrective criticism that unveiled the outside or 'political' influences in the decision-making process. Finally, I focus on Save Kāpiti and ASK's High Court appeal as a corrective criticism that aimed to improve the fairness of the process and to halt the expressway project. They believed that the High Court would not simply rubber stamp the project because of the narrow focus on points of law. A key challenge for the appellants was to translate their frustration with rubber stamping as a legal issue that could be argued in court.

\subsection{Decision-Making, Rubber Stamping, and Critique}

The critique of the inquiry as a rubber stamping exercise raised questions about the decisionmaking process in transport planning and the role of public critique in challenging the legitimacy of trial systems. As this chapter examines rubber stamping in relation to public critique, I briefly survey the literature on decision-making in socio-technical controversies and then review sociological theories of criticism.

In New Zealand, transport planning decisions follow a legal-rational process. Land transport funding is prioritised by the central government and the consenting of individual road projects is guided by RMA law. The legal-rational character of transport planning aligns with rational choice theories of decision-making that suggest decisions are reached based on reason and established procedures (Drobak \& North, 2008). While the ideological and political preferences of a judge can influence their decisions, the judicial process is supposed to check, constrain, or filter any personal elements that might influence the decision (Gillman, 2001, p. 466). An impersonal, judicial process is one way decision-makers guard against accusations of rubber stamping and criticisms of fairness.

Despite the idea that transport planning is guided by legal-rational processes, the approval of projects with questionable economic, social, and technical justifications tends to reinforce the 
idea that decision-makers simply rubber stamp controversial road projects. The rubber stamp metaphor is often used in the transport planning literature as a general criticism of decisions that are either biased, influenced by powerful actors, or lack justification. In particular, critical planning theorists have argued that, in practice, transport planning is not a legal-rational process that is free from outside influences (Flyvbjerg, 1998; Flyvbjerg et al., 2003; Mees \& Dodson, 2007; Willson, 2001). For example, Flyvbjerg et al. (2003) argue that large, problematic infrastructure projects are often approved because promoters of the projects strategically misrepresent their costs and benefits.

The question of whether the planning process for the Kāpiti expressway project really was a rubber stamping exercise is beyond the scope of this research. To examine this issue I would need to examine the planning process from legal and transport planning perspectives. As my research focuses on public involvement in socio-technical controversies, I focus instead on rubberstamping as a public critique of the planning process; that is, how the public used this term to criticise the decision-making process.

There is an extensive literature on public criticism and critique in the sociological literature that ranges from the unveiling of power relations and domination in society to descriptions of criticism in everyday situations and disputes. Theories that focus on unveiling power relations in social life have been approached from a wide range of theoretical positions. For example, some of the well-known theories are the Marxist concepts of false consciousness and dominant ideologies; feminist theories of patriarchy and domination; Foucaultian theories of discipline and power/knowledge; and Bourdieu's concept of symbolic violence (a type of violence that is not directly experienced or perceived by the actor). The idea of critique as an unveiling operation that is conducted by academic researchers has been very influential in studies on planning processes and decision-making. For instance, critical and argumentative planning theorists have revealed how planning decisions that appear to be 'rational' and 'neutral' are actually embedded in socio-political processes (Yiftachel \& Huxley, 2000), power relations (Fischer \& Forester, 1993; Flyvbjerg, 1998), and structures of social control and oppression (Yiftachel, 1998).

While critical and argumentative theories are useful for revealing the operation of power in society and planning processes, these approaches tend to overlook how criticism is used by the actors involved in socio-technical controversies. By revealing relations of power and domination within decision-making processes, critique can be reduced to an explanatory tool 
or unveiling operation rather than a phenomenon that needs explaining (Boltanski, 2011; Latour, 2004b) or a practical accomplishment (Lynch \& Bogen, 1996). In this sense, critical theorists use critique to examine the social context or conditions that influence planning processes and decision-makers. While this approach can be useful and important, it can mean that the actors' own critical capacities and the accomplishment of critique in disputes are overshadowed by the sociologist's critique.

As I am examining public involvement in the Kāpiti expressway dispute, actor-centred approaches to criticism are used as they can help describe how the disputants produced justifiable critiques of the planning and decision-making process. As mentioned above, there are several different approaches that can be used to describe the criticisms of the Kāpiti expressway project. For instance, Lynch and Bogen's (1996) ethnomethodological approach could be used to "respecify" critique by describing how actors used it at the Board of Inquiry, High Court, and in other "routine courses of action". Similarly, Latour's (2005b) actornetwork approach could be used to examine how the issue of rubber stamping does not 'socially explain' the Board's decision to approve the project, but is a phenomenon that needs explaining. That is, how did the Board arrive at their 'final conclusion' in the face of uncertainty? And, how was the criticism of rubber stamping used to reengage with issues that had been black boxed or closed by the Board?

Boltanski and Thévenot's pragmatic sociology of critique shares a number of similarities with ethnomethodology and ANT, but there are also several important differences. Their interest in describing action in everyday life and disputes aligns with a number of actor-centred theories, including ethnomethodology and ANT (Boltanski, 2011). However, as Silber (2003, p. 429) notes, whereas ethnomethodologists study practical actions in everyday life, Boltanski and Thévenot's pragmatic sociology focuses on a specific type of practical reasoning: the principles of evaluation/equivalence that actors use to justify their actions, establish worth, and reach agreement. Moreover, ANT tends to focus on criticism within "trials of strength" or as one potential resource that actors can use to challenge an argument or enrol allies (Latour, 1993a). That is, justice and merit are just two resources that an actor can refer to when strengthening their position or enrolling allies (Boltanski \& Chiapello, 2005b, p. 258). In contrast, the sociology of critique tends to focus on "trials of greatness" or tests that are subject to justificatory constraints (Boltanski \& Chiapello, 2005a, p. 31). Boltanski and Chiapello (2005b) agree that any test reveals the strength or capabilities of the actors, but they 
suggest that trials of greatness are organised in a way that are supposed to test merit and "filter" any strengths that are not subjected to justificatory constraints.

As the Board of Inquiry process and High Court appeal was organised as a legitimate test of merit, I utilise Boltanski and Thévenot's pragmatic sociology of critique to examine how the disputants challenged the legitimacy of these tests. Their focus on justification, critique, and trial systems offers a useful theoretical toolkit for examining the critical capacities of the actors involved in the expressway project. Ethnomethodology, ANT and other actor-centric theories could be used to examine the critical capacities of actors, but, as discussed above, these approaches do not foreground the importance of justification and establishing equivalence in disagreements. As these argumentative resources were important aspects of the Kāpiti expressway dispute, the pragmatic sociology of critique is being used to investigate the issue of rubber stamping and how actors challenged the legitimacy of the planning and decision-making process.

\subsection{The Board of Inquiry as a Trial of Greatness}

For many opponents of the project, the Board of Inquiry was supposed to be a legitimate test or trial of greatness that would reveal insurmountable problems with the expressway project by testing the legal merits of the NZTA's application. The Board's final report revealed that over half of the 410 submissions that opposed the project claimed it would not be economically viable; would sever the communities; would have significant noise, vibration, health, and social effects; and would not be the best transport option for Kāpiti (Board of Inquiry, 2013, p. 18). A range of other views on the project's air quality, cultural, ecological, and visual/landscape effects were also raised during the inquiry. By raising these significant RMA-relevant issues at the inquiry, opponents of the project hoped that the Board would decline the NZTA's applications for the resource consents and Notice of Requirement.

In the lead up to the Board of Inquiry, Save Kāpiti suggested that the inquiry would be a trial of greatness in the sense that the decision would be based on the merit of the evidence presented to the Board. As a trial of greatness, the NZTA's application would be subject to a legal test that would be used to evaluate the submissions. As an equivalence convention, legal principles would make it possible for the Board to compare evidence and to reach a decision on the legal merit of the submissions. For example, Save Kāpiti's (n.d.a) website suggested that an important task for submitters was to relate their personal concern with the project to the requirements of the RMA: 
There are a huge range of matters under the RMA that NZTA have to comply with. You don't have to submit on all of them. Pick the one(s) that affect you most, or that you care about the most, read the relevant piece of the application and tell the Board why you don't think the measures proposed would satisfy your requirements under the RMA.

Save Kāpiti (n.d.a) believed that it was important for submitters to connect their concerns to the requirements of the RMA because the Board would be:

... listen[ing] to the evidence provided before granting or denying the consents required to proceed. They will hear experts provided by NZTA and they will hear experts provided by people and groups opposed to the application. They will hear lawyers from both sides argue that the application complies with or breaches the RMA. They will hear from the individuals and groups themselves why this application should be denied. And they will read all the submissions that are sent in, both for and against.

The idea that the inquiry would be a trial of greatness was confirmed by the Board and the government agency that provides administrative support for inquiries into nationally significant infrastructure projects - the Environmental Protection Authority (EPA). The EPA's information sheet for submitters reinforced the idea that the inquiry would be a trial of greatness that would test the legal merits of the NZTA's application. The information sheet described how:

The matters will be judged on their merits in accordance with the provisions of the RMA. The Board, not the Minister, will make the decision and this decision can only be appealed to the High Court on points of law. (Environmental Protection Authority, 2012)

Indeed, in their final report, the Board (2013, p. 25) noted that they "are appointed by the Minister for the Environment, pursuant to the RMA, as an independent Board . . . [and] conducted the hearing in judicial manner throughout". As the Board's decision making process was guided by the relevant sections of the RMA, opponents could only appeal to the High Court based on points of law (Environmental Protection Authority, 2012, p. 2).

During the inquiry, a number of opponents thought that the Board would decline the project due to the poor quality of evidence presented by the NZTA. As the inquiry was supposed to 
be a legitimate, legal test of the NZTA's application, opponents thought that they would need to produce robust evidence from independent experts. Opponents hoped that the Board's legal test would mean the political weight behind the project would not influence the decision making process. That is, to paraphrase Boltanski and Chiapello (2005b, p. 259), opponents hoped that any political forces would be "filtered" by the strictness of the legal test, and therefore would not undermine the fairness of the inquiry. For example, two members of Save Kāpiti questioned the independence of the NZTA's experts because they appeared to be advocates for the project. As part of the hearing procedure, a person who submitted expert evidence was required to not only have relevant qualifications, but also had "a duty to be independent and not advocate for the party who engages the witness" (Board of Inquiry, 2012c, p. 2). Independent expertise was an important issue for Mark and Julia Harris (2013, p. 3) because they believed that "the BOI process requires independent expertise to assess the proposal, using technical knowledge that the Board lacks, to inform the Board's decision". However, they suggested that:

Of the experts put forward, all bar one either work for NZTA or have worked on the project or work for organisations that have been contracted to the project. . . It appears to me that they have been defending the project they or their companies have been working on for 2-3 years, rather than advising the Board independently. Thus, their testimony should be taken as that of advocates, rather than independent experts, and weighted accordingly. (Harris \& Harris, 2013, p. 3)

The idea of NZTA's experts as advocates implies that the project lacks an independent and robust analysis of the benefits and problems associated with the project. This quote provides a glimpse into the wider issues of the fairness of the test and the idea that the Board of Inquiry was a rubber stamping exercise that did not critically evaluate the merits of the NZTA's application.

\subsection{Board of Inquiry as a Rubber Stamping Exercise}

Due to the problems that Save Kāpiti and other opponents identified during the inquiry, they were surprised by the Board's decision to approve the project. The Board's decision shattered any hope that the inquiry was a trial of greatness that would produce a decision based on the legal merit of the NZTA's application. In media reports and in my interviews, opponents of the project criticised the inquiry as a rubber stamping exercise that used cherry picked evidence to approve a road that was being built for political reasons. As I will discuss, the 
decision to build the Kāpiti expressway and not a smaller two-lane local road was political in the sense that it was seen as a decision that was made by the National Party without robust economic and traffic justifications. A number of people were concerned that the public consultation exercises and Board of Inquiry were established for the purpose of fast tracking and rubber stamping the National Party's preferred projects and that the RoNS projects were designed for the trucking industry.

While the public criticisms from opponents is not surprising, I suggest that their concerns were not simply knee-jerk reactions, but corrective criticisms of society's trial systems. The idea that the inquiry was a rubber stamping exercise points to the importance of criticism in planning and socio-technical controversies. As Boltanski and Chiapello (2005b, p. 260) point out, criticism plays an important role in “continually keeping an eye on a society's main trials, ensuring that ... [they] are run according to the agreed format (and that deviance is denounced)". In this case, the criticism of the inquiry as a rubber stamping exercise functioned as an unveiling operation that revealed 'outside' influences within the Board's decision. By unveiling the political influences behind the decision, opponents accused the Board of letting an inappropriate domestic worth influence what was supposed to be a legal test that evaluated the project based on civic, industrial, green, and market orders of worth. The accusation of rubber stamping, I suggest, revealed the hidden "domestic" or political influences within the Board's decision by pointing out that the project lacked robust economic/market and traffic/industrial justifications. Opponents argued that the Board reached their decision by cherry picking or over weighting the NZTA's evidence. Moreover, they suggested that the political weight and vested interests behind the project could have influenced the decision making process. These criticisms were corrective, rather than radical, in the sense that the opponents focused on improving the fairness of the trial. As Boltanski and Thévenot (1999, p. 373) suggest, corrective criticisms focus on "unveiling the worth belonging to another world that persons are accused of having introduced into the test situation. The reparation process would then consist in carrying out a new and purer test".

To analyse the media reports on the Board of Inquiry and their final decision, 127 news items from 2012-2013 were selected using the key words "Kāpiti expressway" and compared with the interview transcripts. I used open coding to find opinions on the justification of the project, the inquiry's process, and the final decision. I coded 56 references to these three thematic issues with descriptive labels and compared them to the interview transcripts. By analysing and coding the media reports and interview transcripts I developed one category, 
which is named Rubber Stamping, and three sub-categories that are labelled Lack of Justification, Cherry Picking, and Vested Interests. These three sub-categories are used to examine the idea that the Board of Inquiry was a rubber stamping exercise. Specifically, Boltanski and Thévenot's sociology of critique is used to understand the issue of rubber stamping as an unveiling operation that reveals the outside forces that influenced the decisionmaking process.

\subsubsection{Rubber stamping as a lack of justification}

While the inquiry was supposed to be a trial of greatness that focused on the legal merits of the evidence, a number of people publicly stated that the Board did not adequately consider two fundamental issues with the project: traffic decline and the economic benefits of the road. In 17 media reports $(n=127)$ and interview transcripts, the public thought that the justification of the project was politically influenced because of declining traffic on the Kāpiti Coast and its low economic benefits. These two criticisms pointed out that the Board's decision did not adequately test the project from within industrial and market orders of worth. To provide a fair test of the NZTA's application, opponents believed that traffic decline on the Kāpiti Coast and the low benefit-cost ratio of the project would be taken as proof of why the project should be declined.

The issue of traffic decline emerged in two letters to the editor that highlighted how the NZTA's own traffic data did not support the need for an expressway project. Both opinion pieces argued that the Board of Inquiry should not have approved the project because "car numbers on our roads haven't grown since 2007 . . . [and] total vehicle kilometres per annum are falling, with daily commuter car numbers at MacKays Crossing being much the same today as they were 10 years ago" (Harding, 2013). This critique of the NZTA's traffic analysis points to the idea that without this relevant proof the Board should not have approved the project. The opinion pieces suggest that a lack of robust industrial/traffic justifications was a fundamental weakness of the project and that this oversight by the Board meant that it was "a complete waste of everybody's time" (Harding, 2013).

The issue of traffic decline was also connected to the proposed economic benefits of the project in order to highlight how an issue that is relevant within the "industrial world" is also important within the "market world". This industrial-market compromise was an attempt to strengthen the importance of traffic decline by connecting it to what many opponents thought was a fundamental weakness of the project: its economic cost. The Green Party's transport 
spokesperson, Julie Anne Genter, claimed that declining traffic in the Kāpiti region meant that the government should invest money in transport projects that "make economic sense" (as cited in Forbes, 2013). Genter claimed that "we can get much better value for our transport dollar with projects like light rail for Wellington and the City Rail Link in Auckland that fix transport choke-points, not big, empty motorways" (as cited in Forbes, 2013). Market and industrial qualifications are not always compatible in the sense that market evaluations tend to focus on monetary, as opposed to planning or technical, considerations (Thévenot et al., 2000). However, by connecting these two orders of worth, opponents of the project were able to criticise the Board's decision from within two testing devices that are relevant to the RMA law.

The questionable market justification of the project was also extended to the issue of the low (0.2) benefit/cost ratio of the project. In a press release from the Labour Party, Iain LeesGalloway (2013) stated that the decision to approve a low-value project was "a blow to anyone who supports sensible, sustainable transport infrastructure". A key issue that surfaced in the media was that the National Party were committed to spend " $\$ 630$ million on an uneconomic motorway" rather than supporting "a much more cost-effective alternative" - the smaller, two-lane Western Link Road (Green as cited in Carlisle, 2013). The decision to build an uneconomic expressway meant that taxpayers were funding a 'lemon' (Gradwell, 2013) or 'unnecessary' expressway (Generation Zero, 2013a). Moreover, a spokesperson for the environmental group, Generation Zero (2013b), claimed that one "justification for wasting the remaining $\$ 508$ million is that it will create 1,000 jobs, but at $\$ 508,000$ per job, that's a hefty price for New Zealand to pay".

Moreover, as many of the issues raised by local residents and experts were not resolved during the inquiry, some people thought that the Board preferred the NZTA's evidence without an adequate civic justification: a justification based on the needs and concerns of local residents (Thévenot et al., 2000). In the Final Report, the Board summarised the evidence that was submitted on the effects of the project and then explained what evidence they accepted or preferred. The Board's report tended to focus on expert or sworn evidence as it was given greater weight compared to "unsworn representations and submissions" (Board of Inquiry, 2013, p. 27). The Board (2013, p. 19) noted that all submissions "formed part of . . . [their] considerations", but because the report focused on expert evidence and what they thought were key issues, many people believed that they rubber stamped or uncritically accepted the NZTA's evidence. In media reports, this issue was framed in terms of the Board 
not listening to the views of concerned residents. For instance, in a letter to the editor, a concerned Kāpiti resident commented that:

The outcome was never in doubt, even in any submitter's wildest dreams. But for the board not to have the grace to acknowledge, in the 300-page draft, that perhaps one point made in all those submissions might be valid is an arrogant disgrace. (S. Smith, 2013)

Similarly, almost all $(n=8)$ of my research participants that submitted expert evidence were disappointed that the Board either ignored certain viewpoints or favoured the NZTA's evidence by 'writing off' the evidence submitted by local residents and their experts. One expert for one of the locally based groups was frustrated with the Board's report because:

They didn't really analyse anything in any great detail, they just picked out a few points and wonder and meander through the field and then come to this sort of allembracing conclusion at the end. So it was very, very disappointing. (Research Participant, personal communication, June 26, 2013)

For many of my research participants, the perceived weakness of the NZTA's evidence and the Board's inadequate response to local residents confirmed that the project lacked a civic justification. The Board's decision confirmed what they had suspected all along: that the expressway project was a political decision that had been 'finalised' in 2009 by the National Party and Transport Minister Steven Joyce. The controversial public consultation and decision making process indicated to my participants that the expressway project was not for local residents. First, asking the public to comment on two problematic route options suggested that WLR expressway route had been the preferred option all along. For example, one participant labelled the expressway as the 'Barabbas motorway' because of:

... the dishonesty and the duplicity that's been shown right throughout the process. I mean, they came along with two options ... and they were both crap. And everyone said, 'ugh'. The Eastern option and the Western option were the only two presented. . . The Sandhills option [(the 'preferred' route)] wasn't there, but they had it there in the background. So they got everyone pissed off. And they said 'oh, well maybe this' and they said 'yeah, yeah that one', you know, it's like Barabbas .... Yeah, so this is the 
Barabbas motorway I reckon. (Research Participant, personal communication, June 19, 2013).

Another interviewee who had talked to Steven Joyce suggested that he chose the WLR expressway option because the government had already invested a significant amount of money in the project:

I asked him why he hadn't compared the Western Link Road to the expressway, you know, because there was so many benefits in the Western Link Road and he said 'oh I don't know, NZTA made that decision'. When I asked NZTA, they said 'no, it was a political decision and you made that decision' and he said, 'oh well, this is what we've decided to do'. I said 'will you now compare the two' and he said 'no, um, because we've thrown too much money at it. ... And I said 'surely you should investigate all alternatives and if you found a better one and a cheaper one, isn't it a no brainer?' And he said, 'oh we're too far down the track'. (Research Participant, personal communication, August 22, 2013)

Second, the NZTA's public consultation was described by my participants as a 'box ticking' exercise, which suggested to them that project had been finalised in 2009. One participant described how the staff at the expos could not adequately answer the questions from concerned residents. She speculated that the staff were reluctant to provide 'real information' because Steven Joyce had 'told them, 'build this thing no matter what', and you could actually see it in their faces that they knew it was wrong ..." (Research Participant, personal communication, August 22, 2013). For one interviewee, the consultation was a 'jack up' because they tried to:

... engage people in mitigation discussion. As soon as you do that you've lost [because] they're making out it's going to happen. . . . The whole strategy has been it's a done deal. You go to Coastlands [mall] and they got that thing [(the visual flythrough)] going on all the time. (Research Participant, personal communication, June $19,2013)$

Finally, as the project was being fast tracked as a nationally significant road, this suggested to my participants that the entire decision making process was politically driven. Several $(n=4)$ 
of my participants speculated that the expressway project was made by the Transport Minister Steven Joyce. One participant described it as a:

Ministerial directive. He's [Joyce] got support within caucus, he's got the support behind him, he's probably checked with various business interests [to get] . . their support. . . . He's probably checked with NZTA beforehand roughly 'is this achievable, hmm, no details needed'. There you go. And then a powerful presentation to Council, basically brooking no refusal. There you go, forces at work. (Research Participant, personal communication, July 9, 2013)

\subsubsection{Rubber stamping as cherry picking}

The questionable justification of the project tended to reinforce the belief shared by many people that the main purpose of the Board of Inquiry was to 'fast track' or rubberstamp the expressway project. When the Board announced their decision to approve the project, the issue of 'cherry picking' surfaced in 15 media articles and in almost all (nine) of my interviews $(\mathrm{n}=10)$. In these media items and interviews, people suggested that the Board had rubberstamped the project because their decision favoured the NZTA's evidence despite the fact that over half of the submitters (410 submitters or 56.3 percent) opposed the project. People were left wondering how the Board could approve the project when there were problems with the NZTA's evidence and unresolved issues that were not adequately addressed in the Final Report. The overall conclusion reached in the media and interviews was that the Board approved the project by over weighting the NZTA's evidence and dismissing and, in some cases, 'ignoring' counter-evidence.

Some people claimed that the Board had given too much weight to the NZTA's evidence because there were significant problems with their evidence. According to some of my participants, the NZTA lacked evidence to support crucial aspects of the application so the Board 'sent them away' to find missing evidence or to improve on what they had presented (Research Participant, personal communication, August 22, 2013). Based on the publicly available transcripts of the hearing, the NZTA's evidence was scrutinised under crossexamination and there were instances where the NZTA's experts were asked to rephrase their responses by the Board. However, the key point here is that some people took this to mean that the NZTA did not have a strong case. For example, in a press release from the Green Party, Julie-Anne Genter (2013) stated that: 
The economics and traffic evidence presented by NZTA at the hearings was of very poor quality and leaves no doubt that this highway will create, rather than solve, traffic problems in the region. It is disappointing, but predictable, that the EPA has rubberstamped the Government's spin on the Kāpiti Expressway.

Similarly, a concerned Kāpiti resident suggested that:

To me, this hearing was a rubber stamping process which unfairly weighted weak, suppositional, and even, as I perceive it, incorrect NZTA evidence against cogently argued counter evidence to press through an unnecessarily expensive and harmful solution to traffic flow through the district (O'Sullivan, 2013, p. 10)

\subsubsection{Rubber stamping as vested interests}

While Steven Joyce's role in the project can be questioned, a key concern for my participants was that the political weight behind the project influenced the Board's decision to approve it. The idea of political forces influencing the decision making process indicates that a domestic order of worth based on "esteem", "reputation", or "personal ties", influenced the Board's decision and undermined the idea that the inquiry was a legal test (Thévenot et al., 2000). Three of my participants believed that the Board were 'handpicked' by their 'political masters' - the National Party - and so "they just went along with it" (Research Participant, personal communication, June 19, 2013). My participants were aware that, 'officially', the Board had to disclose any conflicts of interest and were 'independent' from the Environmental Protection Authority and the Minister for the Environment. However, they suspected that the Board were 'politically appointed'. As one participant suggested:

... although ultimately the Minister of the Environment, I think, appoints the members of the Board, the proposed members actually go through a number of vetting processes that goes to ... a Cabinet Caucus committee. I think it goes through the entire government caucus and there's another one as well so it's a highly political process. I mean the people who end up sitting on the Board must be aware that they're there because the politicians want them to be there. And they also know in the case of the proposal like this that it's the politicians who want this blimmin' proposal put through, so it seems to me that this kind of biases the whole approach. They claim to be independent and transparent and all the rest of it, but how can you be sure in this 
kind of way the thing's set up. (Research Participant, personal communication, June $26,2013)$

The 'political weight' behind the project was problematic for my participants because it could have meant that the Board would need 'strong grounds' to decline the project. Looking back on the Board's decision, one interviewee described how during the inquiry he was:

.. 95 percent sure they would just rubberstamp it. Everyone else is saying 'oh no, it's due process', you know, it's like, you've got no idea because they're just driven by a higher level agenda, they're just being told what to do really. And the way the thing is setup, it's setup so they virtually can't say no to it. I just thought it was an expensive joke, it's really annoying. (Research Participant, personal communication, June 19, 2013)

The questionable justification of the project suggested that the decision to approve the project was problematic because it is being built for 'vested interests' - the National Party's supporters. When I asked my participants who would benefit from the project, almost all of them suggested that it was for National's 'mates' - the trucking and construction industries that support their election campaigns and that have vested interests in road building projects. The following quote from one of my interviews summarises the idea that the expressway project was for vested interest groups and not the public:

Steven Joyce ran a huge media campaign at the last [2008] election and he owes them all, they're his mates and he owes them all pay back because they supported the campaign financially, which is public knowledge. You can go and look at the donations and all of those people donated hugely. . . 'You scratch my back, I'll scratch yours'. It's the only reason it's being built. (Research Participant, personal communication, August 22, 2013).

Similarly, nine media reports from 2009-2013 referred to the Kāpiti expressway as a 'pork barrel' project that caters to the trucking industry. For example, Save Kāpiti publicly stated that the project is "a bad idea and is of so little benefit to the majority of taxpaying New Zealanders. It only benefits a select few in the trucking, infrastructure and banking industries.” (Begovich as cited in Radio New Zealand, 2013). 


\subsection{High Court as a Corrective Criticism}

The criticisms of the inquiry that surfaced in the media focused on the outside, political influences on the Board's decision making process. By criticising the Board as rubber stampers, opponents of the project engaged in a corrective critique that suggested the Board strayed from the RMA law when making their decision. Their criticisms implied that the NZTA's evidence should have been revaluated according to a strict legal test that was 'purified' from outside influences. According to Boltanski and Chiapello (2005b, p. 261), the aim of corrective criticism is to "admit only those strengths that are deemed to be consistent with that particular type of trial". As opponents of the project could only appeal to the High Court on points of law, disputing the Board's decision in a legal setting was seen as an opportunity to not only stop the project from proceeding, but to also improve the fairness of the decision making process.

In this section, I discuss how local residents and appellants to the High Court - Save Kāpiti and ASK - engaged in a corrective criticism of the inquiry by publicly denouncing it and claiming that the Board's decision should be overturned because of several errors of law. Based on my interviews and observations at an expressway hui, Save Kāpiti and other opponents believed that the High Court would not simply rubber stamp the project as they would be examining the legal errors in the Board's decision. However, because of the narrow focus on points of law, appellants were obliged to translate their concern with rubber stamping as a legal error in the Board's decision. This meant that the appellants focused on very specific aspects of the RMA law: the "permitted baseline" test, the effects of the project on the environment, and the Minister's reasons for directing the project to a Board of Inquiry. While the appellants did not explicitly raise the issue of rubber stamping, I suggest that their criticisms of the Board's decision reinforced the idea that the inquiry did not adequately filter the outside or political influences. The claims that the Board did not acknowledge certain issues, and made inconsistent and wrong decisions, reveals that appellants engaged in a corrective critique with the aim of improving the fairness of the inquiry, which would hopefully lead to the NZTA's application being declined.

\subsubsection{Expressway hui as a public critique}

A hui (community gathering) that I attended in June 2013 publicly unmasked the inquiry as a rubber stamping exercise. The hui revealed that opponents were continuing to fight the project because of its questionable justification. The gathering, which was called 'Expressway hui: 
The battle is not over', was held at Whakarongotai Marae in Waikanae. It was an all-day event that gathered over 90 people to hear the concerns from residents, thank them, and to discuss what could be done to stop the project. Officially, the hui was organised to encourage people to continue supporting the local groups that were appealing the decision in the High Court (Tristram, 2013). However, I suggest that the hui was also a public critique of the Board's decision. Like the media reports on the Board's final decision, the attendees believed that the Board rubber stamped the project because of the problems with the NZTA's application and the way they evaluated the evidence. That is, many of the attendees talked about how the NZTA and the Board ignored the concerns of the community and the evidence they submitted.

The public critique of the inquiry began during the mihimihi (a round of introductions). As all huis begin with a mihimihi, everyone in attendance could hear the concerns from local residents before the speeches began. The mihimihi was almost two hours long and no one had anything positive to say about their experiences or the process. Indeed, one attendee suggested that it made no difference submitting to the inquiry as "they will do what they are going to do". This comment connects to the idea that the Board were simply rubber stamping the expressway project in the sense that the planning process has been organised in a way that uncritically allows the NZTA to implement ('do') their Roads of National Significance programme ('what they are doing'). Similarly, another attendee described the process as a "battle against cynicism". The concern with the project and the inquiry was also explored by the speakers. One of the speakers suggested that it was naïve to think that the Board would be neutral as they only rubber stamped it.

The hui was a public critique of the inquiry in the sense that it was an open event that was covered by several journalists. The hui was advertised in local media outlets, community news letters, and received media coverage due to the controversy surrounding the project and the high profile speakers - politicians, councillors, and activists. The concerns that were discussed during the hui were noted by journalists and activists and published in Scoop.co.nz by the activist group Save the Basin and the local news outlet Kāpiti Independent. For instance, Save the Basin publicised the critique of the inquiry by describing how:

The Government sent the Kāpiti Expressway proposal to an EPA Board of Inquiry hearing which, true to the EPA's role as a rubber-stamping mechanism, ignored the 
evidence presented to it by anyone other than NZTA, and decided in favour of the Expressway. (Jones, 2013)

While the attendees publicly denounced the inquiry as a rubber stamping exercise, they also engaged in a corrective critique of the project and the inquiry. Based on my observations of the event, I noted that local residents were pursuing further action because they believed that the planning process and inquiry were unfair. If opponents could unveil the political forces behind the inquiry's decision, then this could open the possibility of a new, impartial evaluation of the project and evidence. For instance, the workshop organiser suggested that the process was unfair because you can have a "clear voice", but then "you are faced with big money" and the dynamics of politics. Comments like this suggested that the evidence from local residents (the 'clear voice') was not evaluated with the appropriate criteria or orders of worth. That is, rather than evaluating the project from a civic mode of evaluation, which is based on rules and regulations, the attendees suggested that inappropriate relationships from the domestic world connected the Board to the NZTA, trucking lobbies ('big money') and politicians (the 'dynamics of politics'). While the domestic order of worth implies relationships based on kinship and tradition, in this case it refers to hidden friendship links that are inappropriate within the civic world, which is based on impersonal or juridical relationships (Boltanski \& Thévenot, 1999, p. 374).

The idea that the inquiry could be purified from outside influences indicated that the purpose of the hui was to not only unveil the problems with the inquiry, but also to announce that Save Kāpiti would be pursuing a corrective critique through the High Court. Save Kāpiti believed that the High Court would provide a fairer, or at least neutral, test of the evidence. Save Kāpiti were appealing to the High Court because of the rubber stamping issue and problems with the Board's decision - specifically how the smaller two-lane WLR project was assessed. A spokesperson for Save Kāpiti described how the inquiry was a "box ticking exercise" and was not based on "the rule of law". He was disappointed that the Board's final report did not resemble what was said during the inquiry, which suggests that the Board either dismissed or ignored the concerns from local residents. He speculated that, in contrast to the Board of inquiry, the High Court judge would be 'neutral'. In other words, Save Kāpiti hoped that their appeal to the High Court would be a strict legal test that was free from any outside influences. 


\subsubsection{High Court as a strict legal test}

The High Court appeal was a strict legal test in the sense that appellants could only appeal on points of law. This meant that they were obliged to translate their concerns with rubber stamping as a legal error in the Board's decision. To clarify, during the hearing, which I attended, Save Kāpiti and ASK did not unveil the problems with the Board's decision by referring to the issue of rubber stamping. Instead, they focused on several legal issues with the Board's decision in order to argue that the inquiry was unfair and should be corrected with the appointment of a new Board. In simple terms, both appellants focused on why the Board did not consider the smaller two-lane road project to be a viable alternative to the expressway. Save Kāpiti argued that the Board made a legal error when they excluded the two-lane WLR project from the environment. Save Kāpiti claimed that if the smaller two-lane road project was included as part of Kāpiti's environment the "positive effects" of the proposed expressway would have been neutralised (Gendall, 2013, p. 13). In contrast, ASK argued that the Board made an error when they excluded the WLR from the "permitted baseline" test, which is a test of whether an adverse effect can be disregarded. Additionally, ASK claimed that the Board "did not have regard to the Minister's reasons for directing the matter to the Board" (Gendall, 2013, p. 12). A key issue for ASK was that, while the project was labelled as "nationally significant" by the Minister, the Board "did not consider that the Expressway would represent a significant change in the use of land from its current state, a state that supports a number of different activities and land uses" (Gendall, 2013, p. 12).

The appellant's did not explicitly mention the issue of rubber stamping, but their legal arguments suggest that they engaged in a corrective critique that tried to demonstrate that the Board's decision strayed from the RMA law. That is, their legal arguments translated the issue of rubber stamping so that the inquiry could be critiqued. Save Kāpiti's claim that the Board placed too much emphasis on the positive environmental effects of the expressway connects with the issue of cherry picking. Their claim that the Board over weighted the positive effects of the expressway by not adequately considering alternative options suggests that the project was not subjected to an appropriate industrial-environmental test that weighs the positive and negative effects of alternative options. Save Kāpiti’s legal argument pointed out that the inquiry over weighted the environmental worth of the expressway (its positive environmental effects) by excluding alternative options (a test of industrial worth) from the decision-making process. An evaluation of alternative options can be seen as a test of industrial worth in the sense that roads are usually considered long-term investments that 
should be well-planned (Thévenot et al., 2000). Therefore, Save Kāpiti's appeal suggested that including the two-lane WLR project in the decision-making process would help correct or improve the fairness of the inquiry by providing a balanced industrial-environmental test of the expressway.

Similar to the issue of cherry picking, ASK's claim that the Board did not consider the significant change in the use of land was a civic-industrial critique of their decision. As the planning process for roads takes into consideration its impacts on local residents, ASK argued the Board only addressed these issues in broad terms (Gendall, 2013). By only addressing the effects on amenity values - in terms of housing, food production, and equestrian activities in general terms, the negative impacts of the expressway project would not be adequately taken into account. The impacts on local residents connects with the civic and industrial orders of worth in the sense that roads are designed to benefit the public. As civic-industrial justifications are important for determining the worth of the project, ASK's critique highlighted how the Board reached its decision by downplaying the negative impacts of the project.

Finally, ASK's argument that the two-lane WLR project should have been part of the permitted baseline test suggests that the Board's decision was not a strict legal test of the evidence. Put simply, ASK argued that the Board misinterpreted and misapplied relevant case laws when it decided to exclude the WLR project from the baseline test. By focusing on potential legal errors in the decision, ASK were implying the NZTA received an unfair advantage. By correcting the legal errors in the Board's decision, the NZTA's advantage would vanish and a stricter test could be used to reconsider the evidence. In this sense, the expressway project did not meet the crucial "planning" or "technical competency" test from within the industrial order of worth. Without meeting this test, it would be unclear whether the expressway project could be qualified as an "industrial entity" or an entity of questionable worth that was being rubber stamped without adequate proof (Thévenot, 2002).

During the hearing, I thought that the appeals from Save Kāpiti and ASK were very persuasive compared to the NZTA's response. The representatives for Save Kāpiti and ASK spoke confidently when outlining the problems with the Board's decision. Surrounded by their supporters in the public gallery, the appellants presented well-reasoned arguments that would appear to be difficult to challenge. As discussed above, both appellants referred to the relevant sections of the RMA to identify the legal errors in the Board's decision. This was 
reinforced when the NZTA's lawyer responded to the appellants. He spoke quickly, and hesitated when responding to the appellant's evidence. He also seemed to have difficulty finding evidence and notes when responding to questions. The issues with his presentation were seen by supporters in the public gallery as a positive sign, with one gallery member gleefully pointing this out for me.

The NZTA's legal representative disagreed that the inquiry was not a strict legal test by claiming that the appellant's critique was mistaken. The NZTA's response reinforced the idea that the inquiry was a legitimate test that did not need correcting. The crux of their argument was that the appeal was based on matters of fact and not legal errors with the decision. This type of response can be seen as an operation that disarms critique by denying its basis (Boltanski \& Chiapello, 2005b, p. 262). First, the NZTA's lawyer claimed that the issues with the Board's decision to exclude the WLR project from the environment was a factual, rather than legal, argument. Moreover, he argued that if "the Board was required to discount the positive effects of the expressway project on the environment ... [this would be] contrary to what the RMA directs" (Gendall, 2013, p. 14). That is, if the Board followed Save Kāpiti's reasoning it would be contrary to the RMA law. Second, the NZTA's lawyer argued that the ASK's concern with changes in land use and the effects on amenity values and environment was also a factual argument in the sense that it focuses on the findings of the evidence (Gendall, 2013, p. 15). Finally, the NZTA's lawyer admitted that the permitted baseline argument was a legal issue, but argued that the Board did not make an error of law by excluding the WLR from the baseline test. This is because the Board were 'entitled' to do so and because, contrary to ASK's appeal, the effect of the baseline test is not to diminish the positive effects of the expressway project - it is used to diminish the adverse effects (Gendall, 2013, p. 15).

The High Court's decision to dismiss the appeal on all grounds meant that the appellant's corrective critique was unable to improve the fairness of the inquiry by having a new Board appointed. The judge agreed with the NZTA that the Board were entitled to exclude the WLR from the permitted baseline test and that ASK's concern with changes in land use was not a matter of law (Gendall, 2013). The judge did not mention whether the Board's decision to exclude the WLR project from the environment was a matter of fact, but concluded that they were "entitled to find the WLR was unlikely to be put into effect, so was entitled to exclude it from its environment" (Gendall, 2013, p. 21). In other words, as the two-lane WLR project 
was not seen as an alternative to the expressway project, they were entitled to exclude it from this test.

However, the High Court did not make the final decision on Save Kāpiti's argument as they appealed to the Supreme Court in a final-ditch effort. For the NZTA, the Supreme Court was the final barrier that prevented construction from beginning. Whereas, for Save Kāpiti, it was a way to keep the battle going and to have a second evaluation of their appeal (Blundell, 2013a). Ultimately, the Supreme Court dismissed their application to appeal the decision. They were "not persuaded that a further appeal is justified either in the Court of Appeal or this court" (Blundell, 2013c). When the decision was announced, an NZTA spokesperson stated that they would begin construction, and Save Kāpiti did not pursue further legal action (Blundell, 2013c).

While the appellant's critique was unable to convince the judges or lead to direct changes to the Board of Inquiry process, it reveals the important role that criticism plays in ensuring that society's important trial systems are run fairly. The appellants were unable to improve the strictness of the inquiry, but they made sure that it operated within the RMA law. In this sense, the criticism of the Board of Inquiry as a rubber stamping exercise surfaced because opposition groups suspected that outside or political influences had undermined the fairness of the planning process. While trial systems, as Boltanski and Chiapello (2005b, p. 259) note, are never completely purified from outside strengths, criticism helps ensure that trials "are clarified, organized and regulated so as to approximate to the ideal of the trial of greatness" a trial that is as close as possible to meritocratic ideals.

Moreover, the appellant's corrective critique publicly challenged the aspects of the inquiry that they believed were illegitimate. This type of operation, as Boltanski (2011, p. 107) suggests, aims "to get others to recognize the validity of their claims and the factual character of the injustice they have suffered". The High Court case was publicised in the media and it raised awareness of their concerns with the inquiry and the project. In The Dominion Post, a number of commentators "welcomed the decision", but Save Kāpiti suggested that the decision does not mean that an expressway is the right option for Kāpiti (Blundell, 2013a). That is, while the High Court did not validate their legal appeal, they maintained the view that it would "divide Kāpiti, hurt the people that have to live near it and change the nature of the coast from a community to a dormitory" (Harris as cited in Blundell, 2013a). 


\subsection{Conclusion}

Public involvement in large expressway projects implies that the decision to build or not build a road is open for debate. If evidence emerges that raises serious questions about the feasibility of a road project then it would seem reasonable that the project would be halted and an alternative transportation project would be developed. As I have discussed, this assumption underpinned the public's criticism of the Board of Inquiry as a rubber stamping process. Before the Board's final decision was released, many opponents of the project were hoping that the large four-lane expressway project would be scrapped for the smaller two-lane WLR project. By revealing numerous RMA-relevant issues with the project, the opponents were hoping that the Board would agree with them and decline the NZTA's application for resource consent and the Notice of Requirement. Indeed, in the lead up to the inquiry, the idea that the Inquiry would be a strict legal test or trial of greatness was confirmed by the Board and the EPA. They stated that the application and evidence would be judged on merit in relation to the RMA. This meant that any outside forces would not influence the Board's decision-making process or the fairness of the inquiry.

However, when the Board approved the expressway project, the inquiry was criticised as a rubber stamping exercise. The Board commented that they did not have the jurisdiction to approve the two-lane WLR project or to require the NZTA to find an alternative route for the expressway, but this was overshadowed by the potential flaws in their decision-making process. Opponents argued that the Board cherry picked favourable evidence from the NZTA to approve a project that lacked robust economic and traffic justifications. By approving a project that seemed to have significant issues, the inquiry was labelled as a rubber stamping exercise designed to fast track projects that benefitted the trucking industry. While the idea of rubber stamping seems like a knee-jerk reaction, I suggested that it was an important corrective criticism that revealed the outside, political forces within the Board's decision. It suggests that an inappropriate "domestic" or political influence was not filtered by the Board, which affected the fairness of the inquiry and challenged the idea that it was a strict legal test.

The corrective intent of the rubber stamping critique helped opponents re-engage with the project by appealing to the High Court for a legal test that was free from any outside influences. Save Kāpiti and ASK's appeal provided an opportunity to not only improve the fairness of the decision-making process, but also stop the expressway from proceeding. Because the appellants could only appeal on points of law, they faced the difficult challenge 
of translating the issue of rubber stamping as a legal error in the Board's decision-making process. Their appeal did not explicitly refer to the issue of rubber stamping, but it did provide a corrective critique that highlighted why the Board's decision was not a fair legal test that did not evaluate the two-lane WLR project as a viable alternative to the expressway. However, the judge disagreed with the appeal by arguing that the Board were entitled to not evaluate the two-lane road.

While the appellants did not win their legal challenge, their critique helped them keep the issues associated with the project visible to the general public and open for debate. The appellants made sure that the inquiry was a fair test while also re-publicising their concern that the project would divide Kāpiti and negatively impact on its quiet, peri-urban feel. While the issue of rubber stamping seems like a simplification of the decision-making process, as a type of critique, it has revealed how the public create meaningful evaluations of complex issues that appear to be dominated by expert-driven politics and a top-down style of decisionmaking. It helped the public re-open an issue that had been closed by the Board's 'final decision' to approve the project. 


\section{Chapter Ten: Conclusion}

\subsection{Introduction}

In 2015, the Roads of National Significance projects are in the final stages. Nationally, thousands of citizens have been involved in the planning of large roads projects that have been celebrated by some and fiercely opposed by others. Big questions remain over whether the public's concerns have been adequately represented in the planning process: why did the NZTA plough ahead with the controversial projects that faced significant public opposition? Was the public consultation genuine or was it simply a rubber stamping exercise? While public or political representation is important, in this thesis I have focused on how the representation of the Kāpiti expressway as an object of concern was a key issue throughout the planning stages of the project.

All six empirical chapters of this thesis have been underpinned by the question of how citizens and the general public engage with and evaluate expert-dominated issues that involve science and technology. To explore this question I developed a theoretical approach that is situated within science and technology studies and the broader material turn in the human sciences. By bridging object-oriented and socio-cultural theories of dispute, I have been able to discuss how a range of devices, materials and technologies help engage concerned citizens and to examine how the public create persuasive evaluations of an issue by enrolling allies, finding relevant evidence, and producing justifiable critiques.

My central argument, developed in the empirical chapters, is that concerned residents and local groups were obliged to re-present the Kāpiti expressway as an object of concern by demonstrating how their personal objections were relevant to the legal and technical aspects of the project. The first three empirical chapters examined the issue of representation from an object-oriented perspective by focusing on how residents and local groups evaluated and publicised the Kāpiti expressway project as an object of public concern. In the final three empirical chapters, I discussed the challenges residents and local groups encountered when they presented their concerns and arguments to decision-makers in the legal settings of the Board of Inquiry and the High Court.

\subsection{Driving Through the Empirical Chapters}

I started my analysis (Chapter Four) by examining how the public's initial concerns with the expressway project in 2009 were translated as legal and technical issues during the Board of 
Inquiry in 2012-2013. I focused on the contrast between the public's initial gut reactions to the expressway project and the legal and technical arguments that were put forward during the inquiry to understand how the public sustained their engagement with the project as it became focused on technicalities. Drawing on object-oriented theories of dispute and Boltanski and Thévenot's orders of worth framework, I suggested that the local residents and opposition groups initially engaged with the project in 2009 by qualifying it within civic, domestic, and green orders of worth. However, as the planning phase became focused on technical issues with the design of the road and its legal aspects, the disputants had to identify legal and technical faults with the NZTA's evidence and then connect them to the environmental, political, and social issues they were concerned with. Specifically, I examined two issues debated by Save Kāpiti during the Board of Inquiry: an urban design controversy and a debate over the NZTA's social impact assessment. I discussed how Save Kāpiti translated their concern with community division as an issue with the number of planned intersections/connections along the expressway. And, in relation to the NZTA's social impact assessment, I examined how Save Kāpiti connected their initial concern with public consultation and the selection of the route for the expressway with the impact assessment's methodology and whether this affected the legal requirement to consider alternative routes for the expressway. Overall, the findings in this chapter suggest that public participation in the Kāpiti expressway project involved not only representing the voices of concerned local residents and stakeholder groups in the planning process, but also engaging with the technical and legal aspects of the project to represent it as a matter of concern.

Having discussed public involvement in the Kāpiti expressway project as a problem of representing it as an object of concern, Chapter Five examined how residents and opposition groups publicised it as an important public issue. Drawing on Barry's object-oriented theory of demonstration, I argued that representing the expressway as an object of concern or matter of fact was not simply achieved by making public claims, but was accomplished through a range of socio-technical arrangements that made the expressway visible to an audience. For the NZTA, their public consultation exercises did not simply allow concerned residents and stakeholders to express their opinions: they also made the expressway appear fact-like by selectively pointing to what could be commented on and by regulating public disagreement through consulting them at a distance by the use of feedback forms that were subsequently categorised and interpreted by NZTA staff. However, passive forms of public consultation were not able to contain public opposition to the project. From the end of 2009 to 2013, a number of open days, public meetings, and community organised protests helped opponents 
voice their concerns in a public forum and in the media. Due to the difficulties of debating the problems with a road that only existed in a plan, opponents of the project shifted their protest strategy by organising site-specific demonstrations that pointed to areas in Kāpiti that would be directly affected or damaged by the expressway. The site-specific protests had difficulty publicising the expressway as a national problem, however, the practice of pointing directly to the impacts of the expressway allowed protestors to make the expressway visible as a public issue.

In Chapter Six I continued to examine how the expressway was publicised as an object of concern by focusing on how its potential impacts were visualised, and publicly debated. Like the previous chapters, I claimed that opponents of the project did not simply speak on behalf of directly affected residents, communities, and environments, but also visualised the impacts of the expressway using, what Girard and Stark (2007) call, the tools of representation. Drawing on Thévenot's (2007) concept of engagement regimes, I examined the use of visual imagery in the expressway controversy to highlight the wider problem of how the public learn about and engage with important issues that involve science and technology. Both the NZTA and opponents of the project relied on demo-models of the expressway to demonstrate its benefits and problems. Operating from within a professional regime of engagement, the NZTA focused on the functionality of the expressway by visualising what it would look like in-use. The NZTA's visuals enacted a professional vision of reality that purified vision from feeling. As the NZTA had purified the lived aspects of the project from its visuals, a key challenge for the opponents of the project was to demonstrate what it would be like to live with a large concrete structure in a residential area. In this case, the documentary produced by opponents of the project functioned as a cognitive tool that created competing interpretations of the project by visualising the familiar attachments to Kāpiti that would be threatened by the expressway project. In addition to its function as a cognitive tool, the documentary also acted as a rhetorical device that persuaded concerned citizens to take action against the project. It did this by connecting familiar attachments to Kāpiti with three justifiable modes of evaluation: domestic, civic, and green orders of worth.

Chapters Seven, Eight, and Nine shifted focus from the issues of publicity and demonstration by examining how residents and local groups translated their initial concerns with the expressway in a legal setting. Specifically, these three chapters investigated how the public engaged with the preferred option controversy at the Board of Inquiry and in the High Court. In Chapter Seven I examined the populist rhetoric that was mobilised to challenge the route 
selection process. I argued that persuasive appeals to a majority figure were not simply rhetorical, but also involved challenging the public-making devices and techniques that assembled affected publics and materialised their participation. I departed from Boltanski and Thévenot's orders of worth framework by utilising Laclau's (2005) notion of populism. As Boltanski and Thévenot's framework aligns populist forms of engagement with their civic and renoun orders of worth, it was unable to capture the distinctive style of political engagement associated with populist politics: the linking of singular demands into equivalential chains and the creation of a political frontier that divides society into two hostile groups. The production of the preferred option signifier sparked interest in populist modes of political engagement that allowed concerned residents to connect their particular demands to a more universal demand for meaningful public participation in political issues. However, to support the idea that the government misled and did not listen to the concerns of residents, opponents used a petition to quantify the level of opposition to the project and critiqued the surveys and social impact assessments conducted by the NZTA. My discussion of the preferred option controversy highlighted that the public's populist mode of engagement involved investments in the law, impact assessment, and the various devices and techniques that assemble publics and materialise participation.

In Chapter Eight I continued to focus on the preferred option controversy by examining the ordering work that underpinned the selection and justification of the route for the Kāpiti expressway. To challenge the preferred option decision, the public were faced with the daunting challenge of counter-enrolling the actors that had been aligned by the NZTA. Drawing on ANT theories of heterogeneous engineering and translation, I argued that public engagement with the route selection process went beyond the important issue of democratic deliberation. To challenge the preferred option, the public were obliged to not only develop convincing scientific and legal arguments, but also unravel the human and nonhuman alliances that supported it. Before the public were consulted on the routes for the expressway, the NZTA had already conducted extensive research and technical work that identified an expressway project as being feasible from an engineering perspective. As an expressway project was possible, the NZTA faced the difficult work of aligning hundreds of human and nonhuman actors with the project. Because of the challenges involved in protecting wetlands from large road projects, I focused on how the NZTA used various assessments, devices, and strategies to interest the wetlands in the preferred expressway alignment. By outlining a proposal that would mitigate the expressway's impact on the wetlands, opposition groups were obliged to demonstrate why the wetlands would be damaged from the NZTA's preferred 
option. I examined how the Raumati South Residents Association (RSRA) attempted to counter-enrol the at-risk wetlands by re-evaluating the ecological significance of the wetlands, the ecological effects of the project, and the NZTA's proposed mitigation devices. While the RSRA successfully challenged aspects of the NZTA's ecological evidence, the NZTA were able to respond to their concerns, which helped them keep the wetlands aligned to their preferred expressway option.

As opponents of the project were unable to persuade the BOI decision-makers to halt the expressway project they launched a legal appeal to the High Court. In the final empirical chapter (Chapter Nine), I focused on how two opposition groups attempted to translate their concern with the Inquiry's decision to rubber stamp the project as a legal issue that could be debated in the High Court. Drawing on Boltanski, Chiapello, and Thévenot's concepts of "criticism" and "trial", I argued that the public's concern with rubber stamping was not simply a knee-jerk reaction, but was a way of engaging with the legitimacy of the project. The issue of rubber stamping, in other words, was an important corrective criticism of the planning process. By revealing the significant problems with the project, opponents believed that the Board of Inquiry would reject the NZTA's proposal. They believed that the inquiry would be a legal test that would reveal the weaknesses in the NZTA's evidence. However, the Board's decision to approve the project shattered the idea that the inquiry would test the legal merit of the NZTA's application. The Board's decision reinforced the idea that, as the expressway was being built for political reasons, the inquiry's role was to simply rubber stamp the project. As a form of critique, the issue of rubber stamping helped opponents reveal the political influences in a process that should be based on a strict legal test. By taking the NZTA to the High Court, the opponents engaged in a corrective critique that was purified from any outside influences. The High Court, opponents believed, would be a fair trial that would reveal legal errors in the Board's decision. To translate the issue of rubber stamping as an argument that could be debated in court, the appellants focused on why the Board rejected the smaller two-lane WLR project as a viable alternative to the preferred expressway project. While the High Court did not agree with the appellants' argument, their actions reveal the importance of criticism and legitimacy as forms of public engagement in issues involving science and technology. 


\subsection{Key Findings and Implications}

Having discussed the importance of object-oriented representation in public participation in issues that involve science and technology, I have identified two important implications of my findings and theoretical approach. First, representing the expressway project as an object of concern involved significant work, resources, and time. While it is difficult enough for the public to have a voice in the planning process, I have suggested that, in the case of the Kāpiti expressway project, they also faced the challenge of engaging with the technical and legal documents in order to publicise the project as a significant public issue. Having utilised object-oriented approaches to dispute, I was able to bring into focus the work that was required to make the expressway project visible as an important political and public issue. The work of publicising the expressway as an object of concern was not simply a barrier that discourages public participation, but is "the stuff of politics", to use Braun and Whatmore's (2010) phrase. By zooming in on the stuff of politics, my research revealed that the objects of politics were central issues in the Kāpiti expressway project. My finding, therefore, aligns with other object-oriented studies that highlight how socio-technical controversies involve not only struggles between interest groups, but also disagreements over the objects of politics (Barry, 2013; Braun \& Whatmore, 2010; Latour, 2005a; Marres \& Lezaun, 2011).

My focus on the objects of politics has also revealed the important role that nonhumans play in representing objects of concern to an audience. My research has brought into focus the equipment and investments that make public engagement with expert-dominated issues possible. Focusing on the devices, materials, and technologies that materialise participation foregrounds the idea that having non-expert voices included in socio-technical controversies is not simply a procedural issue that allows all voices to be heard, but involves a close examination of how investments in, for example, law, expertise, impact assessments, and a range of technologies allow persuasive arguments to be made and publicised. My findings illuminate the idea that representation cannot be separated from the range of devices, sites, and technologies that equip actors and make it possible for them to voice their concerns (Barry, 2002).

Similarly, by foregrounding the objects of politics, my research revealed the importance of including nonhuman actors in human-centric theories of democratic deliberation. My analysis of the alliance building aspects of the expressway project reveals how disputants act as spokespersons for human and nonhuman actors. Expanding democracy to include subjects and things challenges human-centric theories of democracy that frame human subjects as 
active and nonhumans as passive (J. Bennett, 2005). However, my research revealed that expanding democracy to include nonhumans did not simply provide another avenue for the public to challenge the expressway project, but involved the difficult and resource-intensive task of enrolling experts and counter-enrolling the nonhuman actors that had been aligned by the NZTA.

The second implication of my findings and theoretical approach is that culturally specific meanings of the Kāpiti expressway project underpinned the public's engagement with it. Drawing on cultural sociological theories of dispute has helped me bring into focus the important problem of how the public engage with issues that are associated with expert-driven politics. The idea that the expressway would threaten and, in some cases, destroy residents' familiar attachments to Kāpiti helped engage concerned residents and motivate them to take action against it. By linking their particular concerns to justifiable modes of evaluation, the public were able to create meaningful evaluations of the project and mobilise action. My findings highlight the idea that culture coordinates action and underpins how people assess the worth or value of people and things. In the Kāpiti expressway controversy, culture did not simply underpin the dispute, nor was it simply used as a resource. The opponents were obliged to 'test' their claims by qualifying the expressway within relevant orders of worth and offering various forms of proof that they thought were relevant to the situation.

Finally, by creating a dialogue between object-oriented and socio-cultural approaches to dispute, I have been able to argue that opponents of the expressway project represented the expressway project as an object of concern by demonstrating how their personal objections to the project were relevant to issues involving science and technology. By utilising these two theoretical approaches, I have been able to find a balance between object- and discoursecentric approaches to socio-technical controversies. Specifically, focusing on the cultural and material aspects of the controversy helped reveal that evaluations of the expressway project were achieved through a range of devices, materials, and technologies.

\subsection{Limitations}

Although my research contributes to sociological studies of dispute and socio-technical controversies, there are several limitations to my approach and methodology. First, because I have limited my research focus to the Kāpiti expressway controversy, I am unable to comment on whether the actions of the opponents are typical of public engagement in the RoNS projects or whether their actions are exceptional. Researching the other RoNS projects 
and comparing them to the Kāpiti expressway would be ideal, but because of time and word limit constraints it was not feasible to undertake a comparative project. However, one advantage of a single case study was that I was able to focus my attention on the unexpected aspects of the controversy and the creative aspects of public participation. If I had compared cases I could have lost sight of the unique aspects of each case.

Second, as I started my research near the end of the planning phase of the project I was unable to provide rich, ethnographic descriptions of the early stages of the controversy. While publicly available documents and reports on the controversy have been invaluable, following the actors from the beginning of a controversy would help provide a first-hand perspective on how the public engaged with the expressway project. However, because documents play a key role in large, complex engineering projects, I would not focus exclusively on publicly observable actions. Indeed, throughout this thesis I have used semi-structured interviews and qualitative observations to crosscheck and reveal any issues that did not surface in publicly available documents.

Finally, while object-oriented theories of representation have been helpful for understanding public involvement in socio-technical controversies, my thesis has, to some extent, downplayed the importance (or lack thereof) of social diversity in public disputes. In terms of the Kāpiti expressway controversy, the residents and concerned citizens that engaged with the project were mainly older, property-owning adults who had previous experience working in the public sector and in professions that equipped them with the ability to engage with, and challenge, complex legal and technological issues. Moreover, Māori play a key role in issues that involve the management of resources. In particular, the negative impact on wahi tapu, urupa, and other culturally relevant areas of land were important issues in the Kāpiti expressway controversy. As I focused on how issues are re-presented to an audience, I bracketed the important issue of political representation in socio-technical controversies. Moreover, the epistemological and ontological assumptions that underpin my research have steered me away from the idea that pre-existing social groups and publics assemble around issues; as Marres (2005) claims, “issues spark a public into being”. However, on reflection, I could have examined the connections between object-oriented representation and political representation without reducing the Kāpiti expressway controversy to a clash of social interests. Examining the issue of political representation in more depth would help me reveal what voices are present and absent in socio-technical controversies. 


\subsection{Future Research}

On a more positive note, the limitations of my research and my key findings also reveal possibilities for future research. First, a comparative analysis of the RoNS projects that examines the issue of political representation and the objects of concern would help understand the distinctive forms of public engagement in each project while also providing insight into the wider issue of public involvement in socio-technical controversies in New Zealand. As public participation in science and technology is becoming increasingly important both nationally and internationally, mapping the public's involvement in a range of issues would help contribute to this important area of study while also identifying problems with existing engagement practices and suggestions for improving public participation in projects that are associated with top-down decision making and expert-driven politics. With changes to the RMA that have restricted opportunities for meaningful engagement in large infrastructure projects, comparative research into the RoNS projects would help illuminate the changing dynamics of public involvement in science and technology.

Second, my research has focused on public involvement in the planning stages of the Kāpiti expressway project, but public engagement did not simply stop when construction began. Examining the dynamics of public engagement before, during, and after construction would help reveal how public interest in the road projects are sustained and the strategies that are used to keep the general public interested in the project. I have examined the planning stages of the project because of the high-level of public interest, but important questions remain: how do citizens engage with large infrastructure projects during and after construction? Why do some citizens continue to actively oppose road projects while others do not? Are there opportunities to challenge completed infrastructure projects? My research provides insight into the planning stages of the project, but future studies could help illuminate what happens after the road projects are complete. In particular, if a bridge collapses, or environmental damage occurs, how would the public re-engage with the project?

Finally, an object-oriented approach to the Kāpiti expressway has helped reveal the importance of nonhumans in socio-technical controversies, but further research could also discuss why certain groups do not engage with important issues involving science and technology. As the residents and concerned citizens that engaged with the Kāpiti expressway project were not representative of New Zealand's culturally and socio-economically diverse population, researching the lack of social diversity in important public disputes would help 
provide insights into what can be done to engage groups and populations that do not actively participate or engage with public issues. Researching the groups who are not active in sociotechnical controversies would help reveal insights into the barriers and opportunities that regulate the public's involvement and what motivates people to engage with issues involving science and technology. I am interested in researching these problems in future research on road projects and other matters that appear, at first sight, to be closed to meaningful public deliberation. Moreover, I think it is important to acknowledge the actions of concerned citizens on the Kāpiti Coast who helped make an infra-structural problem visible as a socialstructural problem that is relevant to all areas of life and is open for public debate. 


\section{Appendices}

\section{Appendix A: Ethics approval}

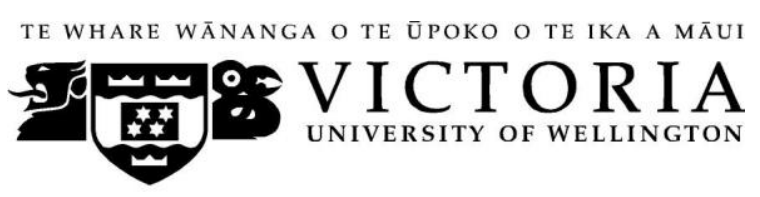

\section{MEMORANDUM}

\begin{tabular}{l|l}
\hline TO & Morgan Hamlin \\
\hline COPY TO & \\
\hline FROM & Dr Rhonda Shaw \\
\hline
\end{tabular}

\begin{tabular}{l|l}
\hline DATE & 5 May 2013 \\
\hline PAGES & 1 \\
\hline
\end{tabular}

\begin{tabular}{l|l}
\hline SUBJECT & $\begin{array}{l}\text { Ethics Approval: No. } 19736 \\
\text { Title: 'What is a motorway? A sociological examination' }\end{array}$ \\
\hline
\end{tabular}

Thank you for your request for ethical approval, which has been considered by the Social and Cultural Studies Human Ethics Sub-Committee. Your ethics application has been approved. The approval period is May 2013 to December 2015. If your data collection has not been completed by this date please contact the Ethics Committee.

Best wishes,

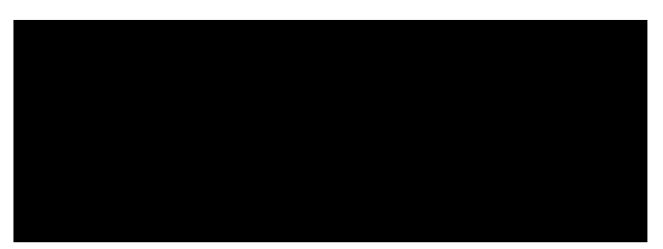

Dr Rhonda Shaw 


\section{Appendix B: Information sheet for confidential interview}

\section{Participant information sheet for a study of proposed motorway projects}

Researcher: Morgan Hamlin, School of Social and Cultural Studies, Victoria University of Wellington.

I am a PhD student in sociology at Victoria University of Wellington. I am interviewing people involved with the Mackays to Peka Peka Expressway and Western Link Road projects to explore the justifications and evaluations people use to support or oppose these projects. The research is examining how motorway projects are shaped by the dynamics of public dispute, decision making processes, and enrolment strategies.

If you agree to participate, I will ask you to share with me your opinions about these projects, your personal interest in the projects, and your reasons for supporting or opposing them. The interview will be at a time and place that is suitable for you and will be approximately 40 minutes in duration. The interview will be audio-taped so that it can be transcribed and used in the research at a later date.

Every question in the interview is voluntary, which means you can choose not to answer any question and you can stop participation at any time. The information you give me will be treated as confidential. The audio recordings, transcript, and final research report will not contain any identifying characteristics of the participants. Furthermore, you can withdraw yourself (or any information you have provided) from the research project (up to two months after the interview), without having to give reasons, by emailing or phoning the researcher.

I will be the only person that has access to the audio recordings. My academic supervisors will be the only other people who will have access to the transcripts. The transcripts will be stored in a locked file, and the audio recordings will be stored in a password protected file, which will be deleted after the transcription is complete. You will be able to obtain a summary of the results of this research when it is completed. The data will be used in the final research report and for any research articles/conference reports.

If you have any questions, you can contact me via email phone My supervisors Chamsy el Ojeili or Mike Lloyd can also be contacted the School of Social and Cultural Studies at Victoria University, PO Box 600, Wellington 6140, or phone
or by phone
or by phone

This research has been reviewed and approved by the Victoria University of Wellington Human Ethics Committee (reference number \#19736, $5^{\text {th }}$ May 2013).

Morgan Hamlin

Signed: 


\section{Appendix C: Consent form for confidential interviews}

\section{Consent to participation in research}

\section{Title of project: 'What is a motorway? A sociological examination'}

I have been given and have understood an explanation of this research project. I have had an opportunity to ask questions and have them answered to my satisfaction. I understand that the interviews will be audio-taped. Furthermore, I understand that I may withdraw myself (or any information I have provided) from this project (up to two months after the interview), without having to give reasons, by emailing or phoning the researcher.

I understand that any information I provide will be kept confidential to the researcher and his supervisors. The published results will not use my name, and that no opinions will be attributed to me in any way that will identify me. I understand that the audio-taped interviews will be electronically wiped at the end of the project unless I indicate that I would like them returned to me.

$\square$ I understand that the data I provide will not be used for any other purpose or released to others without my written consent.

$\square$ I understand that the interviews will be audio-taped.

$\square$ I would like to receive a summary of the results of this research when it is completed.

$\square \mathrm{I}$ agree to take part in this research

I would like to be sent a summary of the results of this research when it is completed to the following email or postal address:

Signed:

Name of participant

(please print clearly)

Date: 
Appendix D: Information sheet for named interviews

\section{Participant information sheet for a study of proposed motorway projects}

Researcher: Morgan Hamlin, School of Social and Cultural Studies, Victoria University of Wellington.

I am a PhD student in sociology at Victoria University of Wellington. I am interviewing people involved with the Mackays to Peka Peka Expressway and Western Link Road projects to explore the justifications and evaluations people use to support or oppose these projects. The research is examining how motorway projects are shaped by the dynamics of public dispute, decision making processes, and enrolment strategies.

If you agree to participate, I will ask you to share with me your opinions about these projects, your personal interest in the projects, and your reasons for supporting or opposing them. The interview will be at a time and place that is suitable for you and will be approximately 40 minutes in duration. The interview will be audio-taped so that it can be transcribed and used in the research at a later date.

Every question in the interview is voluntary, which means you can choose not to answer any question and you can stop participation at any time. Furthermore, you can withdraw yourself (or any information you have provided) from the research project (up to two months after the interview), without having to give reasons, by emailing or phoning the researcher.

I will be the only person that has access to the audio recordings. My academic supervisors will be the only other people who will have access to the transcripts. The transcripts will be stored in a locked file, and the audio recordings will be stored in a password protected file, which will be deleted after the transcription is complete. You will be able to obtain a summary of the results of this research when it is completed. The data will be used in the final research report and for any research articles/conference reports.

If you have any questions, you can contact me via email phone My supervisors Chamsy el.Ojeili or Mike Lloyd can also be contacted at the School of Social and Cultural Studies at Victoria University, PO Box 600, Wellington 6140, or phone Chamsy el.Ojeili can be contacted via email or by phone
or by phone

This research has been reviewed and approved by the Victoria University of Wellington Human Ethics Committee (reference number \#19736, $5^{\text {th }}$ May 2013).

Morgan Hamlin

Signed: 


\section{Appendix E: Consent form for named interviews}

\section{Consent to participation in research}

\section{Title of project: 'What is a motorway? A sociological examination'}

I have been given and have understood an explanation of this research project. I have had an opportunity to ask questions and have them answered to my satisfaction. I understand that the interviews will be audio-taped. Furthermore, I understand that I may withdraw myself (or any information I have provided) from this project (up to two months after the interview), without having to give reasons, by emailing or phoning the researcher.

The published results will use my name, and my professional opinion might be attributed to me in a way that will identify me. However, no personally sensitive information will be attributed to me in any way that will identify me. I understand that the audio-taped interviews will be electronically wiped at the end of the project unless I indicate that I would like them returned to me.

$\square$ I agree to allow my name to be published and my professional opinions to be attributed to me.

$\square$ I understand that the interviews will be audio-taped.

$\square$ I understand that the data I provide will not be used for any other purpose or released to others without my written consent.

$\square$ I would like to receive a summary of the results of this research when it is completed.

$\square$ I agree to take part in this research

I would like to be sent a summary of the results of this research when it is completed to the following email or postal address:

Signed:

Name of participant

(please print clearly) 


\section{Appendix F: Interview guide}

1. What do you like most about Kāpiti?

2. What do you think about the expressway?

3. What are your reasons for supporting or opposing the proposed expressway?

4. What do you think Kāpiti will be like if the expressway is completed?

5. What do you think Kāpiti is like with the existing state highway?

6. What is your personal interest in the Kāpiti expressway project?

7. What does the term "Roads of National Significance" mean to you?

8. What do you think about public consultation and participation in this project?

9. What do you think about the Board of Inquiry's decision to allow the project?

10. Why do you think the NZTA decided to choose an expressway over the Western Link Road?

11. What do you think about the Resource Management (Simplifying and Streamlining) Amendment Act?

12. What do you think about the Public Works Act? 


\section{References}

About - 100\% Possible. (n.d.). Retrieved March 26, 2015, from http://www.100percentpossible.org.nz/about/

Alexander, J. C. (2003). The meanings of social life: A cultural sociology. New York: Oxford University Press.

Alexander, J. C. (2006). The civil sphere. New York: Oxford University Press.

Alexander, J. C. (2010). Iconic Consciousness: The Material Feeling of Meaning. Thesis Eleven, 103(1), 10-25. http://doi.org/10.1177/0725513610381369

Alexander, J. C., \& Smith, P. (1993). The Discourse of American Civil Society: A New Proposal for Cultural Studies. Theory and Society, 22(2), 151-207. http://doi.org/10.2307/657770

Alliance for Sustainable Kāpiti. (n.d.). Petition: Choose the sustainable option. Retrieved March 4, 2015, from http://www.thepetitionsite.com/1/kapiti-coast/

Alliance for Sustainable Kāpiti. (2010, August 20). Public meeting in Kapiti questions expressway [Press release]. Retrieved from http://www.scoop.co.nz/stories/AK1008/S00322/public-meeting-in-kapiti-questionsexpressway.htm

Alliance for Sustainable Kāpiti. (2011, June 15). Rally for sensible transport In Kapiti.

Retrieved February 2, 2015, from

http://www.scoop.co.nz/stories/AK1106/S00367/rally-for-sensible-transport-inkapiti.htm

Alonso, W., \& Starr, P. (Eds.). (1987). The politics of numbers (First Edition). New York: Russell Sage Foundation.

Arnstein, S. R. (1969). A ladder of citizen participation. Journal of the American Institute of Planners, 35(4), 216-224. http://doi.org/10.1080/01944366908977225 
Asdal, K. (2012). Contexts in action-And the future of the past in STS. Science, Technology \& Human Values, 37(4), 379-403. http://doi.org/10.1177/0162243912438271

Barry, A. (1999). Demonstrations: Sites and sights of direct action. Economy and Society, 28(1), 75-94. http://doi.org/10.1080/03085149900000025

Barry, A. (2001). Political machines: Governing a technological society. London, England: The Athlone Press.

Barry, A. (2002). The anti-political economy. Economy and Society, 31(2), 268-284. http://doi.org/10.1080/03085140220123162

Barry, A. (2013). Material politics: Disputes along the pipeline. Oxford, United Kingdom: Wiley-Blackwell.

Beca Carter Hollings and Ferner, Boffa Miskell, \& Incite. (2012). Mackays to Peka Peka expressway project: Assessment of environmental effects report. Retrieved from http://www.nzta.govt.nz/projects/mackays-to-peka-peka-application/docs/aee-fullreport.pdf

Beck, U. (1992). Risk society: Towards a new modernity (1st ed.). London, England: Sage Publications.

Begovich, B. (2011, July 5). Angry Kapiti Coast residents at parliament tomorrow. Retrieved February 2, 2015, from http://www.scoop.co.nz/stories/AK1107/S00110/angry-kapiticoast-residents-at-parliament-tomorrow.htm

Bénatouïl, T. (1999). A tale of two sociologies: The critical and the pragmatic stance in contemporary French sociology. European Journal of Social Theory, 2(3), 379-396. http://doi.org/10.1177/136843199002003011

Bennett, J. (2005). In parliament with things. In L. Tønder \& L. Thomassen (Eds.), Radical democracy: Politics between abundance and lack (pp. 133-148). Manchester, United Kingdom; New York, NY: Manchester University Press. 
Bennett, J. (2010). Vibrant matter: A political ecology of things. Durham: Duke University Press Books.

Bennett, T., \& Joyce, P. (2010). Material powers: Cultural studies, history and the material turn (1 edition). London; New York: Routledge.

Ben Ngaia - Takamore Trust. (2011). Retrieved from http://www.youtube.com/watch?v=4NQcmd40uOk\&feature=youtube_gdata_player

Bennion, T. H. Raumati South Residents Association opening submissions (2012). Retrieved from http://www.epa.govt.nz/Publications/RSRA\%200pening\%20submissions.pdf

Blok, A. (2013). Pragmatic sociology as political ecology: On the many worths of nature(s). European Journal of Social Theory. http://doi.org/10.1177/1368431013479688

Blok, A., \& Meilvang, M. L. (2014). Picturing urban green attachments: Civic activists moving between familiar and public engagements in the city. Sociology, 0038038514532038. http://doi.org/10.1177/0038038514532038

Bloor, D. (1976). Knowledge and social imagery. London, United Kingdom; Boston, MA: Routledge \& Kegan Paul.

Blundell, K. (2009a, August 27). Residents seek third road option. Stuff.co.nz. Retrieved from http://www.stuff.co.nz/dominion-post/news/2805150/Residents-seek-third-road-option

Blundell, K. (2009b, September 11). Kapiti link road gets a new chance. Stuff.co.nz. Retrieved from http://www.stuff.co.nz/dominion-post/news/2853335/Kapiti-link-road-gets-anew-chance

Blundell, K. (2009c, September 16). Council throws new road plan into mix. The Dominion Post, p. 4.

Blundell, K. (2009d, October 16). Kapiti endorses four-lane SH1. The Dominion Post, p. 2.

Blundell, K. (2011, February 21). Protesters in force as rail opens. Stuff.co.nz. Retrieved from http://www.stuff.co.nz/dominion-post/news/4681246/Protesters-in-force-as-rail-opens 
Blundell, K. (2013a, August 20). Kapiti expressway appeals lost. Stuff.co.nz. Retrieved from http://www.stuff.co.nz/dominion-post/news/kapiti/9063459/Kapiti-expresswayappeals-lost

Blundell, K. (2013b, October 31). Expressway protesters brave weather. Stuff.co.nz. Retrieved from http://www.stuff.co.nz/dominion-post/news/kapiti/9346866/Expresswayprotesters-brave-weather

Blundell, K. (2013c, November 14). Kapiti Expressway gets final nod. Stuff.co.nz. New Zealand. Retrieved from http://www.stuff.co.nz/national/9400725/Kapiti-Expresswaygets-final-nod

Board of Inquiry. (2012a). Expert conferencing joint witness statement to the Board of Inquiry - ecology. Retrieved from http://www.epa.govt.nz/Publications/Expert\%20Conferencing\%20Joint\%20Witness\% 20Statement\%20-\%20Terrestrial\%20Ecology.pdf

Board of Inquiry. (2012b). Expert conferencing third joint witness statement to the Board of Inquiry - ecology. Retrieved from http://www.epa.govt.nz/Publications/Third\%20Conferencing\%20Statement\%20$\% 20$ Ecology.pdf

Board of Inquiry. (2012c). Hearing procedures: MacKays to Peka Peka expressway proposal. Retrieved from http://www.epa.govt.nz/Publications/Hearing\%20Procedures\%20\%20updated\%2013\%20Dec\%2012.pdf

Board of Inquiry. Transcript of proceedings: Board of Inquiry MacKays to Peka Peka expressway proposal: Hearing at Kapiti Coast on 27 November 2012 (2012). Retrieved from http://www.epa.govt.nz/Publications/Hearing\%20Transcript\%20Day\%209.pdf Board of Inquiry. Transcript of proceedings: Board of Inquiry MacKays to Peka Peka expressway proposal: Hearing at Kapiti Coast on 28 November 2012 (2012). 
Retrieved from

http://www.epa.govt.nz/Publications/Hearing\%20Transcript\%20Day\%2010.pdf

Board of Inquiry. Final report and decision of Board of Inquiry under section 149R of the Act (2013). Retrieved from http://www.epa.govt.nz/Publications/Final_Report_-_Vol_1__Final_Decision_and_Report.pdf

Boffa Miskell. (2012). Assessment of landscape and visual effects - Visual effects: MacKays to Peka Peka expressway: Appendix B figures VS1-VS16. Boffa Miskell. Retrieved from http://nzta.govt.nz/projects/mackays-to-peka-peka-application/docs/plan-settechnical-report-7-part-4.pdf

Böhm, S., Jones, C., Land, C., \& Paterson, M. (2006). Introduction: Impossibilities of automobility. The Sociological Review, 54, 1-16. http://doi.org/10.1111/j.1467954X.2006.00634.x

Boltanski, L. (2011). On critique: A sociology of emancipation. (G. Elliott, Trans.). Cambridge, United Kingdom; Malden, MA: Polity Press.

Boltanski, L., \& Chiapello, E. (2005a). The New Spirit of Capitalism. London; New York: Verso.

Boltanski, L., \& Chiapello, E. (2005b). The role criticism in the dynamics of capitalism: Social criticism versus artistic criticism. In M. Miller (Ed.), Worlds of capitalism: Institutions, governance and economic change in the era of globalization (pp. 237267). New York, NY.

Boltanski, L., \& Thévenot, L. (1999). The sociology of critical capacity. European Journal of Social Theory, 2(3), 359-377. http://doi.org/10.1177/136843199002003010

Boltanski, L., \& Thévenot, L. (2006). On justification: Economies of worth. Princeton: Princeton University Press. 
Bond, S., \& Thompson-Fawcett, M. (2007). Public participation and New Urbanism: A conflicting agenda? Planning Theory \& Practice, 8(4), 449-472. http://doi.org/10.1080/14649350701664689

Boudet, H. S. (2011). From NIMBY to NIABY: Regional mobilization against liquefied natural gas in the United States. Environmental Politics, 20(6), 786-806. http://doi.org/10.1080/09644016.2011.617166

Braun, B., \& Disch, L. (2002). Guest Editorial: Radical democracy's “modern constitution.” Environment and Planning D: Society and Space, 20(5), 505 - 511. http://doi.org/10.1068/d2005ed

Braun, B., \& Whatmore, S. J. (Eds.). (2010). Political matter: Technoscience, democracy, and public life. Minneapolis, MN: University Of Minnesota Press.

Brosnahan, P. (2014). Contrasting approaches: Transmission Gully and Puhoi to Warkworth. Presented at the 2014 New Zealand Association for Impact Assessment conference, Auckland, New Zealand.

Bucchi, M., \& Neresini, F. (2008). Science and public participation. In E. J. Hackett, O. Amsterdamska, M. Lynch, \& J. Wajcman (Eds.), The handbook of science and technology studies (Third edition, pp. 449-472). Cambridge, Massachusetts; London, England: MIT Press.

Buchan, D. Statement of evidence of Dianne Buchan (social impact assessment) (2012). Retrieved from http://www.epa.govt.nz/Publications/Save-Kapiti-Inc-EvidenceEvidence-Dianne-Buchan-505-7.pdf

Burawoy, M. (1991). The extended case method. In M. Burawoy, A. Burton, A. A. Ferguson, K. J. Fox, J. Gamson, N. Gartrell, ... S. Ui (Eds.), Ethnography unbound: Power and resistance in the modern metropolis (pp. 271-287). Berkeley, CA; Los Angeles, CA; Oxford, England: University of California Press. 
Burawoy, M. (1998). The extended case method. Sociological Theory, 16(1), 4-33. http://doi.org/10.2307/202212

Burningham, K. (2000). Using the language of NIMBY: A topic for research, not an activity for researchers. Local Environment, 5(1), 55-67. http://doi.org/10.1080/135498300113264

Büscher, M. (2006). Vision in motion. Environment and Planning A, 38(2), 281 - 299. http://doi.org/10.1068/a37277

Callon, M. (1986). Some elements of a sociology of translation: Domestication of the scallops and the fishermen of St Brieuc Bay. In J. Law (Ed.), Power, action and belief: A new sociology of knowledge? (pp. 196-233). London, England: Routledge \& Kegan Paul.

Callon, M. (2004). Europe wrestling with technology. Economy and Society, 33(1), 121-134. http://doi.org/10.1080/0308514042000176766

Callon, M., Lascoumes, P., \& Barthe, Y. (2011). Acting in an uncertain world: An essay on technical democracy. Cambridge, Massachusetts; London, England: MIT Press.

Callon, M., \& Latour, B. (1981). Unscrewing the big leviathan: How actors macro-structure reality and how sociologists help them to do so. In K. Knorr-Cetina \& A. V. Cicourel (Eds.), Advances in social theory and methodology: Toward an integration of microand macro-sociologies. Boston, MA: Routledge \& Kegan Paul.

Callon, M., \& Law, J. (1982). On interests and their transformation: enrolment and counterenrolment. Social Studies of Science, 12(4), 615-625. http://doi.org/10.2307/284830

Calman, M. (2009, December 16). Expressway verdict splits Kapiti. Stuff.co.nz. New Zealand. Retrieved from http://www.stuff.co.nz/national/3164552/Expressway-verdict-splitsKapiti

Carlisle, T. (2013, May 16). Most want expressway: Key. Stuff.co.nz. Retrieved from http://www.stuff.co.nz/dominion-post/news/local-papers/horowhenuamail/8678174/Most-want-expressway-Key 
Cheyne, C. (2015). Changing urban governance in New Zealand: Public participation and democratic legitimacy in local authority planning and decision-making 1989-2014. Urban Policy and Research, O(0), 1-17.

http://doi.org/10.1080/08111146.2014.994740

Collins, H. M. (1988). Public experiments and displays of virtuosity: The core-set revisited. Social Studies of Science, 18(4), 725-748. http://doi.org/10.1177/030631288018004006

Colmar Brunton. (2009). NZ Transport Agency Kapiti Coast survey: A Colmar Brunton report - December 2009. Retrieved from http://www.nzta.govt.nz/projects/mackaysto-peka-peka/docs/colmar-brunton-phone-report-dec09.pdf

Commission of the European Communities. (2001). European governance: A White Paper. Retrieved October 31, 2015, from http://eur-lex.europa.eu/legalcontent/EN/TXT/?uri=URISERV:110109

Connor, D. M. (1988). A new ladder of citizen participation. National Civic Review, 77(3), 249-257. http://doi.org/10.1002/ncr.4100770309

Coole, D. H., \& Frost, S. (2010). New materialisms: Ontology, agency, and politics. Durham, NC: Duke University Press.

Crotty, M. (1998). The foundations of social research: Meaning and perspective in the research process. Sydney, Australia: Allen \& Unwin.

D’Angelo, P., \& Kuypers, J. A. (2010). Doing news framing analysis: Empirical and theoretical perspectives. New York, NY; Oxon, England: Routledge.

Debs, M. (2012). The suffering of symbols: Giotto Frescoes and the cultural trauma of objects. Cultural Sociology. http://doi.org/10.1177/1749975512454086

de Vries, G. (2007). What is Political in Sub-politics? How Aristotle Might Help STS. Social Studies of Science, 37(5), 781-809. http://doi.org/10.1177/0306312706070749 
Dixon, M. Statement of evidence of Melanie Robyn Dixon for the Raumati Sourth Residents Association Inc. (RSRA), submitter nbumber 0707 (2012). Retrieved from http://www.epa.govt.nz/Publications/RSRA-Evidence-Melanie-Dixon-0707-2.pdf

Doerr, N., \& Milman, N. (2014). Working with images. In D. della Porta (Ed.), Methodological practices in social movement research (pp. 418-445). Oxford, United Kingdom: Oxford University Press.

Doherty, B. (1999). Paving the way: The rise of direct action against road-building and the changing character of British environmentalism. Political Studies, 47(2), 275-291. http://doi.org/10.1111/1467-9248.00200

Drobak, J. N., \& North, D. C. (2008). Understanding judicial decision-making: The importance of constraints on non-rational deliberations. Washington University Journal of Law and Policy, 26, 131.

Dyble, L. N. (2007). Revolt against sprawl: Transportation and the origins of the Marin County growth-control regime. Journal of Urban History, 34(1), 38-66. http://doi.org/10.1177/0096144207308049

Editorial: Bring on the expressway. (2011, May 10). Stuff.co.nz. Retrieved from http://www.stuff.co.nz/dominion-post/comment/4980972/Editorial-Bring-on-theexpressway

Environmental Protection Authority. (2012). Information sheet: MacKays to Peka Peka expressway proposal. Retrieved from http://www.epa.govt.nz/Publications/m2ppInformation-Sheet.pdf

Fainstein, S. S. (2000). New directions in planning theory. Urban Affairs Review, 35(4), 451478. http://doi.org/10.1177/107808740003500401

Fischer, F. (2000). Citizens, experts, and the environment: The politics of local knowledge. Durham, NC: Duke University Press Books. 
Fischer, F., \& Forester, J. (Eds.). (1993). The argumentative turn in policy analysis and planning. Durham, England: Duke University Press.

Fisher, N. Alliance for a sustainable Kapiti inc. 572: Notes for hearing (2012). Retrieved from http://www.epa.govt.nz/Publications/Mr\%20Nick\%20Fisher\%20$\% 20$ Alliance\%20for\%20a\%20Sustainable\%20Kapiti\%20-\%20Representation.pdf

Fiskaa, H. (2005). Past and future for public participation in Norwegian physical planning. European Planning Studies, 13(1), 157-174. http://doi.org/10.1080/0965431042000312451

Flyvbjerg, B. (1998). Rationality and power: Democracy in practice. (S. Sampson, Trans.). Chicago, IL: University Of Chicago Press.

Flyvbjerg, B. (2006). Five misunderstandings about case-study research. Qualitative Inquiry, 12(2), 219-245. http://doi.org/10.1177/1077800405284363

Flyvbjerg, B., Bruzelius, N., \& Rothengatter, W. (2003). Megaprojects and risk: An anatomy of ambition. Cambridge, United Kingdom: Cambridge University Press.

Forbes, M. (2013, March 20). Time savings justify road projects says Brownlee. Stuff.co.nz. New Zealand. Retrieved from http://www.stuff.co.nz/national/politics/8446469/Timesavings-justify-road-projects-says-Brownlee

foxpine. (2011, October 1). Why we need an Expressway on the Kapiti coast [Video file]. Retrieved December 15, 2014, from https://www.youtube.com/watch?v=R_E3WiBex8o\&feature=youtube_gdata_player Fyfe, G., \& Law, J. (1988). Picturing power: Visual depiction and social relations. London, Great Britain: Routledge.

Gamson, W. A. (1992). Talking politics. Cambridge, England: Cambridge University Press.

Gendall, D. In the High Court of New Zealand Wellington registry: Save Kapiti Incorporated v New Zealand Transport Agency (2013). Retrieved from https://forms.justice.govt.nz/search/Documents/pdf/jdo/f2/alfresco/service/api/node/co 
ntent/workspace/SpacesStore/4c5707af-a503-4942-9b31-206cbfeabf6a/4c5707afa503-4942-9b31-206cbfeabf6a.pdf

Generation Zero. (2013a, February 25). Poll shows Govt's dinosaur transport plans behind the times. Scoop.co.nz. Retrieved from http://www.scoop.co.nz/stories/PO1302/S00250/poll-shows-govts-dinosaur-transportplans-behind-the-times.htm

Generation Zero. (2013b, May 10). Job Creation Scheme to Cost Taxpayer \$500,000 Per Job | Scoop News. Retrieved from http://www.scoop.co.nz/stories/PO1305/S00127/jobcreation-scheme-to-cost-taxpayer-500000-per-job.htm

Genter, J. A. (2013). Kapiti Expressway a waste of taxpayers' money. Retrieved July 17, 2015, from https://home.greens.org.nz/press-releases/kapiti-expressway-wastetaxpayers-money

Gillman, H. (2001). What's law got to do with it? Judicial behavioralists test the "legal model" of judicial decision making. Law \& Social Inquiry, 26(2), 465-504. http://doi.org/10.1111/j.1747-4469.2001.tb00185.x

Girard, M., \& Stark, D. (2007). Socio-technologies of assembly: Sense making and demonstration in rebuilding lower Manhattan. In V. Mayer-Schönberger \& D. Lazer (Eds.), Governance and information technology: From electronic government to information government (pp. 145-176). Cambridge, Massachusetts; London, England: The MIT Press.

Goodwin, C. (1994). Professional vision. American Anthropologist, 96(3), 606-633. http://doi.org/10.1525/aa.1994.96.3.02a00100

Gotham, K. F. (1999). Political opportunity, community identity, and the emergence of a local anti-expressway movement. Social Problems, 46(3), 332-354. http://doi.org/10.2307/3097104 
Gradwell, J. (2013, November 23). Taxpayers left with a lemon. The Dominion Post.

Retrieved from http://www.knowledge-

basket.co.nz.helicon.vuw.ac.nz/databases/newztext-

uni/view/?sid=1361295\&d4=fairfax/text/2013/11/23/C004177409298-EK.html

Griggs, S., \& Howarth, D. (2007). Protest movements, environmental activism and environmentalism in the United Kingdom. In J. Pretty, A. S. Ball, T. Benton, J. S. Guivant, D. R. Lee, D. Orr, ... H. Ward (Eds.), The SAGE handbook of environment and society. London, United Kingdom; Thousand Oaks, CA: SAGE Publications.

Griggs, S., \& Howarth, D. (2008). Populism, localism and environmental politics: The logic and rhetoric of the Stop Stansted Expansion campaign. Planning Theory, 7(2), 123144. http://doi.org/10.1177/1473095208090431

Guest, G., Namey, E. E., \& Mitchell, M. L. (2013). Collecting Qualitative Data: A Field Manual for Applied Research. Thousand Oaks, CA; London, United Kingdom: SAGE Publications.

Guggenheim, M., \& Potthast, J. (2012). Symmetrical twins: On the relationship between Actor-Network theory and the sociology of critical capacities. European Journal of Social Theory, 15(2), 157-178. http://doi.org/10.1177/1368431011423601

Guy, S., \& Karvonen, A. (2011). Using sociotechnical methods: Researching humantechnological dynamics in the city. In J. Mason \& A. Dale (Eds.), Understanding social research: Thinking creatively about method (pp. 120-133). London, England; Thousand Oaks, California: SAGE Publications.

Hall, S. (1997). The work of representation. In S. Hall (Ed.), Representation: Cultural representations and signifying practices (pp. 13-74). London, England; Thousand Oaks, CA: SAGE Publications in association with The Open University. 
Harding, J. (2013, May 2). Letter: Board reminiscent of three monkeys. Stuff.co.nz. Retrieved from http://www.stuff.co.nz/dominion-post/comment/letters-to-theeditor/8622271/Letter-Board-reminiscent-of-three-monkeys

Harris, M., \& Harris, J. (2013). Representation to the Board of Inquiry Mackays to Peka Peka Expressway proposal. Retrieved from http://www.epa.govt.nz/Publications/J\%20and\%20M\%20Harris\%20\%20Representation.pdf

Harvey, P., \& Knox, H. (2012). The enchantments of infrastructure. Mobilities, 7(4), 521536. http://doi.org/10.1080/17450101.2012.718935

Hawkins, G. (2010). Plastic materialities. In Political matter: Technoscience, democracy, and public life (pp. 119-138). Minneapolis, MN: University of Minnesota Press.

Healey, P. (1993). Planning through debate: The communicative turn in planning theory. In F. Fischer \& J. Forester (Eds.), The argumentative turn in policy analysis and planning (pp. 233-253). Durham, England: Duke University Press.

Hindmarsh, R., \& Du Plessis, R. (2008). GMO regulation and civic participation at the "edge of the world": The case of Australia and New Zealand. New Genetics and Society, 27(3), 181-199. http://doi.org/10.1080/14636770802326869

Hird, M. J., Lougheed, S., Rowe, R. K., \& Kuyvenhoven, C. (2014). Making waste management public (or falling back to sleep). Social Studies of Science, 44(3), 441465. http://doi.org/10.1177/0306312713518835

Hommels, A. (2010). Changing obdurate urban objects: The attempts to reconstruct the highway through Maastricht. In I. Farías \& T. Bender (Eds.), Urban assemblages: How actor-network theory changes urban studies (pp. 139-160). London, England: New York, NY: Routledge. 
House of Lords Select Committee on Science and Technology. (2000). Science and society: Third report. United Kingdom: UK House of Lords. Retrieved from http://www.publications.parliament.uk/pa/ld199900/ldselect/ldsctech/38/3802.htm Howarth, D., \& Griggs, S. (2006). Metaphor, catachresis and equivalence: The rhetoric of Freedom to Fly in the struggle over aviation policy in the United Kingdom. Policy and Society, 25(2), 23-46. http://doi.org/10.1016/S1449-4035(06)70073-X

Irwin, A. (2001). Constructing the scientific citizen: Science and democracy in the biosciences. Public Understanding of Science, 10(1), 1-18. http://doi.org/10.1088/0963-6625/10/1/301

Irwin, A., Jensen, T. E., \& Jones, K. E. (2013). The good, the bad and the perfect: Criticizing engagement practice. Social Studies of Science, 43(1), 118-135. http://doi.org/10.1177/0306312712462461

Irwin, A., \& Michael, M. (2003). Science, social theory and public knowledge. Maidenhead, England: Open University Press.

Issel, W. (1999). “Land values, human values, and the preservation of the city's treasured appearance": Environmentalism, politics, and the San Francisco freeway revolt. Pacific Historical Review, 68(4), 611-646. http://doi.org/10.2307/4492372

Jansson, A., \& Lagerkvist, A. (2009). The future gaze: City panoramas as politico-emotive geographies. Journal of Visual Culture, 8(1), 25-53. http://doi.org/10.1177/1470412908100902

Jarzabkowski, P., \& Pinch, T. (2013). Sociomateriality is "the New Black": Accomplishing repurposing, reinscripting and repairing in context. M@n@gement, 16(5), 579-592.

Jasanoff, S. (2003). Technologies of humility: Citizen participation in governing science. Minerva, 41(3), 223-244. http://doi.org/10.1023/A:1025557512320

Jasper, J. M. (1992). The Politics of abstractions: Instrumental and moralist rhetorics in public debate. Social Research, 59(2), 315-344. 
Jasper, J. M. (2014). Protest: A cultural introduction to social movements. Cambridge, United Kingdom; Malden, MA: Polity Press.

Jones, T. (2013, June 12). At a Kapiti hui, advice about fighting a flyover at the Basin Reserve. Scoop.co.nz. Retrieved from http://wellington.scoop.co.nz/?p=56171

Joyce, S. (2009, August 20). Govt wants strategic plan for Kapiti highway. Scoop.co.nz. Retrieved from http://www.scoop.co.nz/stories/PA0908/S00286/govt-wants-strategicplan-for-kapiti-highway.htm

Kapiti Coast District Council. (2009). Kapiti mayor criticises "shock tactics" on roading plans. Retrieved from http://wellington.scoop.co.nz/?p=11752

Kemp, R. (1985). Planning, public hearings, and the politics of discourse. In J. Forester (Ed.), Critical theory and public life. Massachusetts, MA: MIT Press.

Kirkpatrick, G. (2008). Technology and social power. Palgrave Macmillan.

Laclau, E. (2005). On populist reason. London, United Kingdom; New York, NY: Verso.

Laclau, E., \& Mouffe, C. (2001). Hegemony and socialist strategy: Towards a radical democratic politics (2nd edition). London, United Kingdom; New York, NY: Verso.

Lamont, M., \& Thévenot, L. (2000). Introduction: Toward a renewed comparative cultural sociology. In M. Lamont \& L. Thévenot (Eds.), Rethinking comparative cultural sociology: Repertoires of evaluation in France and the United States (pp. 1-22). Cambridge, United Kingdom: Cambridge University Press.

Latour, B. (1986). The powers of association. In J. Law (Ed.), Power, action and belief: A new sociology of knowledge? (pp. 264-280). London, England: Routledge \& Kegan Paul.

Latour, B. (1987). Science in action: How to follow scientists and engineers through society. Cambridge, MA: Harvard University Press. 
Latour, B. (1990). Drawing things together. In M. Lynch \& S. Woolgar (Eds.), Representation in scientific practice (pp. 19-68). Cambridge, MA; London, England: The MIT Press.

Latour, B. (1992). Where are the missing masses? The sociology of a few mundance artifacts. In W. E. Bijker \& J. Law (Eds.), Shaping technology/building society: Studies in sociotechnical change (pp. 225-258). Cambridge, MA: MIT Press.

Latour, B. (1993a). The pasteurization of France. (A. Sheridan \& J. Law, Trans.) (First Harvard University Press paperback edition). Cambridge, MA; London, England: Harvard University Press.

Latour, B. (1993b). We have never been modern. Cambridge, MA: Harvard University Press.

Latour, B. (1996). Aramis, or the love of technology. Cambridge, MA; London, England: Harvard University Press.

Latour, B. (2004a). Politics of nature: How to bring the sciences into democracy. (C. Porter, Trans.). Cambridge, MA; London, England: Harvard University Press.

Latour, B. (2004b). Why has critique run out of steam? From matters of fact to matters of concern. Critical Inquiry, 30(2), 225-248. http://doi.org/10.1086/421123

Latour, B. (2005a). From realpolitik to dingpolitik or how to make things public. In B. Latour \& P. Weibel (Eds.), Making things public: Atmospheres of democracy (pp. 14-41). Cambridge, MA; London, England: MIT Press.

Latour, B. (2005b). Reassembling the social: An introduction to actor-network-theory. New York, NY: Oxford University Press.

Latour, B., \& Weibel, P. (Eds.). (2005). Making things public: Atmospheres of democracy. Cambridge, MA; London, England: The MIT Press.

Latour, B., \& Woolgar, S. (1986). Laboratory life: The construction of scientific facts (Reprint edition). Princeton, NJ: Princeton University Press. 
Law, J. (1987). Technology and heterogeneous engineering: The case of Portuguese expansion. In B. E. Wiebe, T. P. Hughes, \& T. J. Pinch (Eds.), The social construction of technological systems: New directions in the sociology and history of technology (pp. 111-134). London, England: MIT Press.

Law, J. (2009). Actor network theory and material semiotics. In B. S. Turner (Ed.), The new Blackwell companion to social theory (pp. 141-158). Wiley-Blackwell. Retrieved from http://onlinelibrary.wiley.com/doi/10.1002/9781444304992.ch7/summary

Law, J., \& Callon, M. (1988). Engineering and sociology in a military aircraft project: A network analysis of technological change. Social Problems, 35(3), 284-297. http://doi.org/10.2307/800623

Law, J., \& Mol, A. (1995). Notes on materiality and sociality. The Sociological Review, 43(2), 274-294. http://doi.org/10.1111/j.1467-954X.1995.tb00604.x

Lees-Galloway, I. (2013, March 4). Another community ignored as road gets sign-off | Scoop News. Scoop.co.nz. Retrieved from http://www.scoop.co.nz/stories/PA1303/S00050/another-community-ignored-as-roadgets-sign-off.htm

Lemke, T. (2015). New materialisms: Foucault and the "government of things." Theory, Culture \& Society, 32(4), 3-25. http://doi.org/10.1177/0263276413519340

Levy, G. Statement of rebuttal evidence of Graham Levy (hydrology) for the NZ Transport Agency (2012). Retrieved from http://www.epa.govt.nz/Publications/21.\%20Graham\%20Levy\%20rebuttal\%20(Hydro $\log y) \cdot p d f$

Lewis, J. L. (2012). More art than science: The sources and effects of stylistic variation in visualization for planning and design. Environment and Planning B: Planning and Design, 39(3), 551 - 565. http://doi.org/10.1068/b37148 
Lezaun, J., \& Soneryd, L. (2007). Consulting citizens: Technologies of elicitation and the mobility of publics. Public Understanding of Science, 16(3), 279-297. http://doi.org/10.1177/0963662507079371

Lindholm, G. (2012). "Visible gestures": On urban landscape perspectives in planning. Planning Theory, 11(1), 5-19. http://doi.org/10.1177/1473095211400151

Lynch, M. (1985). Art and artifact in laboratory science: A study of shop work and shop talk in a research laboratory. London, England: New York, NY: Routledge \& Kegan Paul.

Lynch, M., \& Bogen, D. (1996). The spectacle of history: Speech, text, and memory at the Iran-contra hearings. Durham: Duke University Press.

Lynch, M., Hilgartner, S., \& Berkowitz, C. (2005). Public proofs in the 2000 US presidential election. In B. Latour \& P. Weibel (Eds.), Making things public: Atmospheres of democracy (pp. 814-827). Cambridge, MA; London, England: The MIT Press.

Lynch, M., \& Woolgar, S. (Eds.). (1990). Representation in scientific practice. Cambridge, MA; London, England: The MIT Press.

Mackay, R. Representation of Rachel Mackay (2013). Retrieved from http://www.epa.govt.nz/Publications/Ms\%20R\%20MacKay\%20Representation.pdf MacKays to Peka Peka Alliance. (2010a). Mackays to Peka Peka scoping report: Prepared for the NZ Transport Agency. Retrieved February 5, 2013, from http://www.nzta.govt.nz/projects/mackays-to-peka-peka/scoping-report.html

MacKays to Peka Peka Alliance. (2010b). Statutory approvals management plan. Retrieved from http://www.nzta.govt.nz/projects/mackays-to-peka-peka/docs/statutoryapprovals-management-plan.pdf

MacKays to Peka Peka Alliance. (2012). M2PP-SAR-RPT-DL-GE-271: Scheme assessment report. Retrieved from http://www.nzta.govt.nz/projects/mackays-to-pekapeka/docs/scheme-assessment-report/scheme-assessment-report.pdf 
Magaudda, P. (2013). The broken boundaries between science and technology studies and cultural sociology: Introduction to an interview with Trevor Pinch. Cultural Sociology. http://doi.org/10.1177/1749975513484604

Marres, N. (2005). Issues spark a public into being. A key but often forgotten point of the Lippmann-Dewey debate. In B. Latour \& P. Weibel (Eds.), Making things public: Atmospheres of democracy (pp. 208-217). Cambridge, MA; London, England: MIT Press.

Marres, N. (2007). The issues deserve more credit pragmatist contributions to the study of public involvement in controversy. Social Studies of Science, 37(5), 759-780. http://doi.org/10.1177/0306312706077367

Marres, N. (2011). The costs of public involvement: Everyday devices of carbon accounting and the materialization of participation. Economy and Society, 40(4), 510-533. http://doi.org/10.1080/03085147.2011.602294

Marres, N. (2012). Material participation: Technology, the environment and everyday publics. Basingstoke, England; New York, NY: Palgrave Macmillan.

Marres, N., \& Lezaun, J. (2011). Materials and devices of the public: An introduction. Economy and Society, 40(4), 489-509. http://doi.org/10.1080/03085147.2011.602293

Matthewman, S. (2011). Technology and social theory. Hampshire, NY: Palgrave Macmillan. Maxwell, J. (2011, October 17). Kapiti film fights expressway. Stuff.co.nz. Retrieved from http://www.stuff.co.nz/dominion-post/news/local-papers/kapitiobserver/5795036/Kapiti-film-fights-expressway

McIndoe, G. Statement of evidence of Graeme McIndoe (urban design) (2012). Retrieved from http://www.epa.govt.nz/Publications/Save-Kapiti-Evidence-Graeme-McIndoe0505-4.pdf

McIndoe, G. Statement of evidence of Graeme McIndoe (Urban Design): Speaking notes (2012). Retrieved from 
http://www.epa.govt.nz/Publications/Mr\%20Graeme\%20McIndoe\%20Speaking\%20N otes.pdf

McLennan, G. (2005). The "new American cultural sociology" An appraisal. Theory, Culture \& Society, 22(6), 1-18. http://doi.org/10.1177/0263276405059411

Mees, P., \& Dodson, J. (2007). Backtracking Auckland?: Technical and communicative reason in metropolitan transport planning. International Planning Studies, 12(1), 3553. http://doi.org/10.1080/13563470701346568

Mikami, N. (2015). Public participation in decision-making on energy policy: The case of the "national discussion" after the Fukushima accident. In Y. Fujigaki (Ed.), Lessons from Fukushima: Japanese case studies on science, technology and society (pp. 87-122). Springer.

Ministry for Culture and Heritage. (2015). Sound: Oxford Union debate on nuclear weapons. Retrieved from http://www.nzhistory.net.nz/media/sound/oxford-union-debate

Mohl, R. A. (2004). Stop the road: Freeway revolts in American cities. Journal of Urban History, 30(5), 674-706. http://doi.org/10.1177/0096144204265180

Mohl, R. A. (2008). The interstates and the cities: The U.S. Department of Transportation and the freeway revolt, 1966-1973. Journal of Policy History, 20(02), 193-226. http://doi.org/10.1353/jph.0.0014

Moody, M., \& Thévenot, L. (2000). Comparing models of strategy, interests, and the public good in French and American environmental disputes. In M. Lamont \& L. Thévenot (Eds.), Rethinking comparative cultural sociology: Repertoires of evaluation in France and the United States (pp. 273-306). Cambridge, United Kingdom: Cambridge University Press.

Mukerji, C. (2015). The material turn. In R. A. Scott \& S. M. Kosslyn (Eds.), Emerging trends in the social and behavioral sciences (pp. 1-13). New York, NY: John Wiley \& 
Sons. Retrieved from

http://onlinelibrary.wiley.com/doi/10.1002/9781118900772.etrds0109/abstract

Myers, S. C. Statement of evidence of Shona Claire Myers on behalf of the Kāpiti Coast District Council (2013). Retrieved from http://www.epa.govt.nz/Publications/KCDC_6_Myers.pdf

Nash, K. (2010). Contemporary political sociology: Globalization, politics and power (2nd edition). Chichester, United Kingdom; Malden, MA: Wiley-Blackwell.

New Zealand Transport Agency. (2009a). MacKays Crossing to Peka Peka community engagement report. Retrieved from http://www.nzta.govt.nz/projects/mackays-topeka-peka/docs/mackays-pekapeka-engagement-report.pdf

New Zealand Transport Agency. (2009b). MacKays Crossing to Peka Peka community engagement report - Appendix 1. Retrieved from http://www.nzta.govt.nz/projects/mackays-to-peka-peka/docs/appendix1-aug09consultation-brochure.pdf

New Zealand Transport Agency. (2009c, December 15). "Milestone” decision: A 4-lane expressway from Levin to Wellington airport. Retrieved from http://wellington.scoop.co.nz/?p=17993

New Zealand Transport Agency. (2010a). MacKays to Peka Peka Expressway Alliance partners announced. Retrieved March 17, 2015, from http://www.nzta.govt.nz/about/media/releases/685/news.html

New Zealand Transport Agency. (2010b). MacKays to Peka Peka expressway expo: Southern end - The details of what we are proposing [Information panel 9]. Retrieved from http://www.nzta.govt.nz/projects/mackays-to-peka-peka/docs/infopanel9.pdf

New Zealand Transport Agency. (2010c). We welcome your comments on the proposals for the expressway. Retrieved from http://www.nzta.govt.nz/projects/mackays-to-pekapeka/docs/infopanel14.pdf 
New Zealand Transport Agency. (2011a). MacKays to Peka Peka expressway expo 2: North of Waikanae River [Information panel 7]. Retrieved from http://www.nzta.govt.nz/projects/mackays-to-peka-peka/docs/expo-2/7-north-ofwaikanae-river.pdf

New Zealand Transport Agency. (2011b). MacKays to Peka Peka expressway expo 2:

Raumati Road and Wharemauku Stream crossing [Information panel 4]. Retrieved from http://www.nzta.govt.nz/projects/mackays-to-peka-peka/docs/expo-2/4-raumatiroad-and-wharemauku-stream-crossing.pdf

New Zealand Transport Agency. (2011c). Technical report 3: Consultation summary report. Retrieved from http://www.nzta.govt.nz/projects/mackays-to-peka-pekaapplication/docs/technical-report-3.pdf

New Zealand Transport Agency. (2012). Assessment of environmental effects: Non-technical summary. Retrieved from http://www.epa.govt.nz/Publications/M2PP-Non-TechnicalSummary.pdf

New Zealand Transport Agency. (2013). Roads of national significance. Retrieved October 1, 2013, from http://www.nzta.govt.nz/network/rons/

New Zealand Transport Agency. (n.d.-a). MacKays to Peka Peka project: Assessment of environmental effects report. Retrieved from http://www.nzta.govt.nz/projects/mackays-to-peka-peka-application/docs/aee-section10.pdf

New Zealand Transport Agency. (n.d.-b). MacKays to Peka Peka visual fly-through [Web video]. Retrieved December 15, 2014, from https://www.youtube.com/watch?v=J7OIjXVMAWs

Nimmo, R. (2011, December 20). Actor-network theory and methodology: Social research in a more-than-human world. Retrieved August 13, 2014, from https://www.escholar.manchester.ac.uk/uk-ac-man-scw:134378 
North, P. (1998). "Save our Solsbury!”: The anatomy of an anti-roads protest. Environmental Politics, 7(3), 1-25. http://doi.org/10.1080/09644019808414406

Norton, P. D. (2008). Fighting traffic: The dawn of the motor age in the American city. Cambridge, MA; London, England: MIT Press.

Opus International Consultants. (2009). Kapiti SH1 strategy study: Technical report.

Retrieved February 5, 2013, from http://www.nzta.govt.nz/projects/mackays-to-pekapeka/technical-report.html

Osborne, T., \& Rose, N. (1999). Do the social sciences create phenomena? The example of public opinion research. The British Journal of Sociology, 50(3), 367-396. http://doi.org/10.1111/j.1468-4446.1999.00367.x

O’Sullivan, B. (2013, November 29). What we should call the expressway. The Dominion Post. Retrieved from http://www.knowledge-basket.co.nz/databases/newztextuni/view/

Owen, D. (2011, January 1). Kapiti expressway protest at parliament, Wellington. Retrieved March 2, 2015, from http://ndhadeliver.natlib.govt.nz/delivery/DeliveryManagerServlet?dps_pid=IE154810 45

Panizza, F. (2005). Introduction: Populism and the mirror of democracy. In F. Panizza (Ed.), Populism and the mirror of democracy (pp. 1-31). London, United Kingdom; New York, NY: Verso.

Park, M. Statement of evidence of Matiu Park (terrestrial ecology and herpetofauna) for the NZ Transport Agency (2012). Retrieved from http://www.epa.govt.nz/Publications/Matiu\%20Park\%20\%20Terrestrial\%20Ecology\%20and\%20Herpetofauna\%20Evidence.pdf

Park, M. Statement of rebuttal evidence of Matiu Park (terrestrial ecology and herpetofauna) for the NZ Transport Agency (2012). Retrieved from 
http://www.epa.govt.nz/Publications/25.\%20Matiu\%20Park\%20rebuttal\%20(Terrestri al\%20Ecology\%20and\%20Herpetofauna).pdf

Park, M. (2012c). Technical report 26: Ecological impact assessment. Retrieved from http://www.nzta.govt.nz/projects/mackays-to-peka-peka-application/docs/technicalreport-26.pdf

Park, M. (2012d). Technical report 27: Ecological technical report 1: Terrestrial vegetation and habitats (including wetlands). Retrieved from http://www.nzta.govt.nz/projects/mackays-to-peka-peka-application/docs/technicalreport-27.pdf

Parliamentary Commissioner for the Environment. (1996). Public participation under the Resource Management Act 1991: The management of conflict. Wellington: Parliamentary Commission for the Environment. Retrieved from http://pce.parliament.nz/assets/Uploads/Reports/pdf/Pre97-reports/PublicParticipation-under-the-Resource-Management-Act-1991-The-Management-ofConflict-Dec-1996.pdf

Pickering, A. (Ed.). (1992). Science as practice and culture. Chicago, IL; London, United Kingdom: University of Chicago Press.

Pinch, T. J. (2010). On making infrastructure visible: Putting the non-humans to rights. Cambridge Journal of Economics, 34(1), 77-89. http://doi.org/10.1093/cje/bep044

Pinch, T. J., \& Bijker, W. E. (1989). The social construction of facts and artifacts: Or how the sociology of science and the sociology technology might benefit each other. In W. E. Bijker, T. P. Hughes, \& T. J. Pinch (Eds.), The social construction of technological systems: New directions in the sociology and history of technology (pp. 17-50). Cambridge, MA; London, England: MIT Press.

Porteous, T. R. Brief evidence of Timoth Ronald Porteous (2012). Retrieved from http://www.epa.govt.nz/Publications/WRC-Evidence-Tim-Porteous-0684-6.pdf 
Prewitt, K. (1987). Public statistics and democratic politics. In W. Alonso \& P. Starr (Eds.), The politics of numbers (pp. 261-274). New York, NY: Russell Sage Foundation.

Prior, L. (2008). Repositioning documents in social research. Sociology, 42(5), 821-836. http://doi.org/10.1177/0038038508094564

Questions and Answers - 15 Dec 2009. (2009, December 17). Retrieved November 15, 2015, from http://www.scoop.co.nz/stories/PA0912/S00305/questions-and-answers-15-dec2009.htm

Radio New Zealand. (2013). Kapiti residents and iwi vow to block expressway. Retrieved July 14, 2015, from http://www.radionz.co.nz/news/regional/132640/kapiti-residentsand-iwi-vow-to-block-expressway

Resource Management Act, No. 69 (1991). Retrieved from http://www.legislation.govt.nz/act/public/1991/0069/latest/whole.html\#DLM236241

Rose, G. (2001). Visual methodologies: An introduction to the interpretation of visual materials. London, England; Thousand Oaks, CA: SAGE Publications.

Rose, N. (1999). Powers of freedom: Reframing political thought. Cambridge, United Kingdom; New York, NY: Cambridge University Press.

Rosental, C. (2013). Toward a Sociology of Public Demonstrations. Sociological Theory, 31(4), 343-365. http://doi.org/10.1177/0735275113513454

Rydin, Y. (2013). Using Actor-Network Theory to understand planning practice: Exploring relationships between actants in regulating low-carbon commercial development. Planning Theory, 12(1), 23-45. http://doi.org/10.1177/1473095212455494

Sage, D., Dainty, A., \& Brookes, N. (2011). How actor-network theories can help in understanding project complexities. International Journal of Managing Projects in Business, 4(2), 274-293. http://doi.org/10.1108/17538371111120243

Saldana, J. (2009). The coding manual for qualitative researchers. London, England; Thousand Oaks, CA: SAGE Publicatons. 
Salmon, R. A., \& Priestley, R. K. (2015). A future for public engagement with science in New Zealand. Journal of the Royal Society of New Zealand, 45(2), 101-107. http://doi.org/10.1080/03036758.2015.1023320

Save Kāpiti. (n.d.a). Why you should make a submission. Retrieved June 4, 2013, from http://savekapiti.co.nz/board-of-inquiry/why-you-should-make-a-submission/

Save Kāpiti. (2010, October 23). Save Kapiti: What do we want? [Web log post]. Retrieved from http://savekapiti.co.nz/page/2/

Save Kāpiti. (2011). 4000+ People Hate the "Highway from Hell” [Press release]. Retrieved July 21, 2014, from http://business.scoop.co.nz/2011/06/30/4000-people-hate-thehighway-from-hell/

Save Kāpiti. Synopsis of opening submissions for Save Kapiti Inc (SK) (2012). Retrieved from http://www.epa.govt.nz/Publications/Save\%20Kapiti\%20Opening\%20Submissions.pd f

Save Kāpiti. (2013, July 1). Octogenarians lead blockade to stop Kapiti motorway [Press release]. Retrieved from http://www.scoop.co.nz/stories/AK1307/S00001/octogenarians-lead-blockade-to-stopkapiti-motorway.htm

Save Kāpiti. (n.d.-b). Presentations. Retrieved December 15, 2014, from http://savekapiti.co.nz/facts/presentations/

Sayes, E. (2014). Actor-Network Theory and methodology: Just what does it mean to say that nonhumans have agency? Social Studies of Science, 44(1), 134-149. http://doi.org/10.1177/0306312713511867

Scott, J. C. (1998). Seeing like a state: How certain schemes to improve the human condition have failed. Durham, NC: Yale University Press. 
Senjmito. (2011, June 13). March on Parliament 6 July: Rail against the expressway [Web log comment]. Retrieved from http://wellingtontransport.wordpress.com/2011/06/13/march-on-parliament-6-july/

Shapin, S., \& Schaffer, S. (1985). Leviathan and the air-pump: Hobbes, Boyle, and the experimental life. Princeton, NJ: Princeton University Press.

Sheppard, S. R. J. (2001). Guidance for crystal ball gazers: Developing a code of ethics for landscape visualization. Landscape and Urban Planning, 54(1-4), 183-199. http://doi.org/10.1016/S0169-2046(01)00135-9

Shipman, C. (2011, February 19). Kapiti expressway protesters vent at Steven Joyce. 3news.co.nz. Retrieved from http://www.3news.co.nz/Kapiti-expressway-protestersvent-at-Steven-Joyce/tabid/423/articleID/199012/Default.aspx

Silber, I. F. (2003). Pragmatic sociology as cultural sociology Beyond repertoire theory? European Journal of Social Theory, 6(4), 427-449. http://doi.org/10.1177/13684310030064004

Smith, P. (2001). Cultural theory: An introduction. Malden, MA; Oxford, United Kingdom: Blackwell Publishers.

Smith, P. (2003). Narrating the guillotine: Punishment technology as myth and symbol. Theory, Culture \& Society, 20(5), 27-51. http://doi.org/10.1177/02632764030205002 Smith, S. (2013, March 12). Letter: Expressway inquiry was a pretence. The Dominion Post. Retrieved from http://www.stuff.co.nz/dominion-post/comment/letters-to-theeditor/8411911/Letter-Expressway-inquiry-was-a-pretence

Snow, D. A., \& Benford, R. D. (1988). Ideology, frame resonance, and participant mobilization. In B. Klandermans, H. Kriesi, \& S. G. Tarrow (Eds.), From structure to action: Comparing social movement research across cultures (pp. 197-218).

Greenwich, CT: JAI Press. 
Stark, D., \& Paravel, V. (2008). PowerPoint in Public: Digital technologies and the new morphology of demonstration. Theory, Culture \& Society, 25(5), 30-55. http://doi.org/10.1177/0263276408095215

Stone, D. A. (1988). Policy Paradox and Political Reason. Glenview, IL: Scott Foresman.

Suchman, L. (2000). Organizing Alignment: A case of bridge-building. Organization, 7(2), 311-327. http://doi.org/10.1177/135050840072007

Sun Harvest Media, [Creator]. (2012). Through the heart [Video File]. Retrieved from https://www.youtube.com/watch?v=n7SSAIXz0i0

Takamore Urupa V Western Link Road. (2009). Retrieved from http://www.youtube.com/watch?v=BUEPlfMvMWQ\&feature=youtube_gdata_player

The Sustainable Option. (n.d.). Home: What will the proposed expressway look like? Retrieved December 15, 2014, from http://web.archive.org/web/20101112192251/http://www.thesustainableoption.co.nz/

Thévenot, L. (2001). Pragmatic regimes governing the engagement with the world. In T. R. Schatzki, K. K. Cetina, \& E. von Savigny (Eds.), The practice turn in contemporary theory (pp. 64-82). London; New York: Routledge.

Thévenot, L. (2002). Which road to follow? The moral complexity of an "equipped" humanity. In J. Law \& A. Mol (Eds.), Complexities: Social studies of knowledge practices (pp. 53-87). Durham, England: Duke University Press.

Thévenot, L. (2007). The plurality of cognitive formats and engagements moving between the familiar and the public. European Journal of Social Theory, 10(3), 409-423. http://doi.org/10.1177/1368431007080703

Thévenot, L., Moody, M., \& Lafaye, C. (2000). Forms of valuing nature: Arguments and modes of justification in French and American environmental disputes. In M. Lamont \& L. Thévenot (Eds.), Rethinking comparative cultural sociology: Repertoires of 
evaluation in France and the United States (pp. 229-272). Cambridge, United Kingdom: Cambridge University Press.

Thomas, G. (2011). A typology for the case study in social science following a review of definition, discourse, and structure. Qualitative Inquiry, 17(6), 511-521. http://doi.org/10.1177/1077800411409884

Throgmorton, J. A. (1992). Planning as persuasive storytelling about the future: Negotiating an electric power rate settlement in Illinois. Journal of Planning Education and Research, 12(1), 17-31. http://doi.org/10.1177/0739456X9201200103

Throgmorton, J. A. (1993). Planning as a rhetorical activity: Survey research as a trope in arguments about electric power planning in Chicago. Journal of the American Planning Association, 59(3), 334-346. http://doi.org/10.1080/01944369308975884

Tilly, C., \& Tarrow, S. (2007). Contentious politics. Boulder, Colorado: Paradigm Publishers.

Tolich, M., \& Davidson, C. (1998). Starting fieldwork: An introduction to qualitative research in New Zealand. Auckland, New Zealand: Oxford University Press.

Transport and Industrial Relations Committee. (2012, February 17). Petition 2008/151 of Loretia Pomare on behalf of Save Kapiti and the Alliance for Sustainable Kapiti. Retrieved February 5, 2015, from http://www.parliament.nz/ennz/pb/sc/documents/reports/50DBSCH_SCR5347_1/petition-2008151-of-loretiapomare-on-behalf-of-save-kapiti

Tristram, A. (2013, June 13). Kapiti motorway fight. Kapiti Independent News. Retrieved from http://kapitiindependentnews.net.nz/kapiti-motorway-fight/

Turner, G. (2003). British cultural studies: An introduction (3rd ed.). London, England: New York, NY: Routledge.

Urry, J. (2007). Mobilities. Cambridge, United Kingdom; Malden, MA: Polity. 
van Dijk, T. (2011). Imagining future places: How designs co-constitute what is, and thus influence what will be. Planning Theory, 10(2), 124-143. http://doi.org/10.1177/1473095210386656

Warner, M. (2002). Publics and counterpublics (abbreviated version). Quarterly Journal of Speech, 88(4), 413-425. http://doi.org/10.1080/00335630209384388

Waterton, E. (2009). Sights of sites: Picturing heritage, power and exclusion. Journal of Heritage Tourism, 4(1), 37-56. http://doi.org/10.1080/17438730802221117

Whatmore, S. J., \& Landström, C. (2011). Flood apprentices: An exercise in making things public. Economy and Society, 40(4), 582-610. http://doi.org/10.1080/03085147.2011.602540

Wheeler, B. (2011, January 26). Letter: Sooner Kapiti road gets under way the better. Stuff.co.nz. Retrieved from http://www.stuff.co.nz/dominion-post/comment/letters-tothe-editor/4581192/Letter-Sooner-Kapiti-road-gets-under-way-the-better

Willams, A. Statement of evidence of Ann Williams (Groundwater) for the NZ Transport Agency (2012). Retrieved from http://www.nzta.govt.nz/projects/mackays-to-pekapeka-application/docs/evidence-ann-williams.pdf

Williams, A. (2013). Groundwater (level) management plan (GMP). Retrieved from http://www.nzta.govt.nz/projects/mackays-to-peka-pekaapplication/docs/management-plan-approved-groundwater-part-1.pdf

Willson, R. (2001). Assessing communicative rationality as a transportation planning paradigm. Transportation, 28(1), 1-31. http://doi.org/10.1023/A:1005247430522

Winner, L. (1980). Do artifacts have politics? Daedalus, 109(1), 121-136. http://doi.org/10.2307/20024652

Woolgar, S., \& Cooper, G. (1999). Do artefacts have ambivalence? Moses' bridges, Winner's bridges and other urban legends in S\&TS. Social Studies of Science, 29(3), 433-449. http://doi.org/10.2307/285412 
Woolgar, S., \& Lezaun, J. (2013). The wrong bin bag: A turn to ontology in science and technology studies? Social Studies of Science, 43(3), 321-340. http://doi.org/10.1177/0306312713488820

Wynne, B. (1992). Misunderstood misunderstanding: Social identities and public uptake of science. Public Understanding of Science, 1(3), 281-304. http://doi.org/10.1088/0963$6625 / 1 / 3 / 004$

Wynne, B. (2007). Public participation in science and technology: Performing and obscuring a political-conceptual category mistake. East Asian Science, Technology and Society: An International Journal, 1(1), 99-110. http://doi.org/10.1007/s12280-007-9004-7

Yiftachel, O. (1998). Planning and social control: Exploring the dark side. Journal of Planning Literature, 12(4), 395-406. http://doi.org/10.1177/088541229801200401

Yiftachel, O., \& Huxley, M. (2000). Debating dominance and relevance: Notes on the "communicative turn" in planning theory. International Journal of Urban and Regional Research, 24(4), 907-913. http://doi.org/10.1111/1468-2427.00286 
